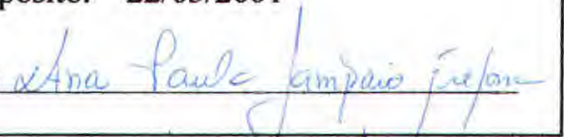

\title{
Um Método para Análise e Projeto de Sistemas de Workflow Administrativo com Interface para a Web
}

\section{Ludimila Monjardim Casagrande}

Orientador: Prof. Dr. Paulo Cesar Masiero

Dissertação apresentada ao Instituto de Ciências Matemáticas e de Computação - ICMC-USP, como parte dos requisitos para obtenção do título de Mestre em Ciências de Computação e Matemática Computacional.

USP - São Carlos

Maio/2001 


\section{A Comissão Julgadora:}

Prof. Dr. Paulo Cesar Masiero

Profa. Dra. Maria da Graça Campos Pimentel

Prof. Dr. Antonio Carlos dos Santos
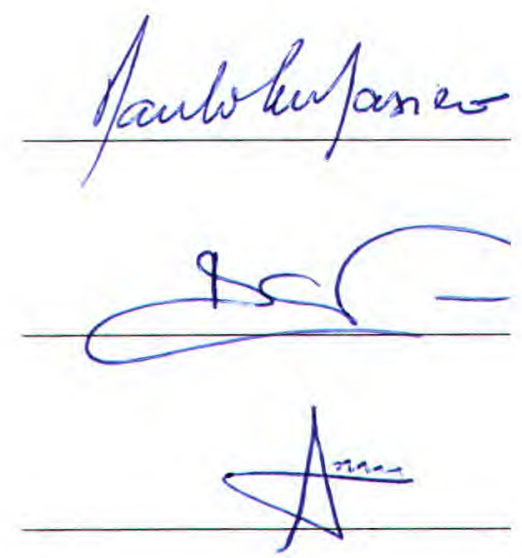
À minha mãe, Angela, ao meu pai, João, e ao meu irmão, Ludo. 


\section{Agradecimentos}

Em primeiro lugar, a Deus, que me deu a vida, a sabedoria, a saúde e a força necessárias para que eu pudesse atingir os meus objetivos e realizar os meus maiores sonhos, sempre agindo como companheiro e guia.

Aos meus pais, Angela e João, que me ofereceram todas as oportunidades, me estimularam a crescer, me apoiaram nos momentos difíceis, vibraram com as minhas vitórias e sempre serviram como modelos de integridade, justiça e amor à vida e ao trabalho.

Ao meu irmão, Ludovico, que acreditou no meu potencial e disse: "Filha! Vai fazer Informática!". Ludo, obrigada pela escolha certa e por todos os outros conselhos que contribuíram para o meu amadurecimento e para a minha formação.

Ao meu orientador, Prof. Dr. Paulo Cesar Masiero, pela paciência, profissionalismo e competência, durante toda a realização deste trabalho.

Às professoras, Profa. Dra. Maria Cristina Ferreira de Oliveira e Prof. Dra. Maria da Graça Campos Pimentel, que participaram da banca do meu Exame de Qualificação e colaboraram para o aperfeiçoamento desta dissertação.

Ao meu professor e amigo, Prof. Dr. José Luís Braga, que me incentivou a fazer o Mestrado e contribuiu para a construção da base de conhecimentos indispensável para a realização deste projeto.

Aos meus amigos, Léo, Dani, Líllian, Rachel, Ana Paula, Baiano, Rodolfo, Gisele, Andromeda, Jorge, Marcelo, Roberto, Matite e Tavinho que, próximos ou distantes, me ajudaram muito e estiveram presentes durante todo o meu Mestrado.

A todos que confiaram em mim e me apoiaram.

A todos os professores e funcionários do ICMC.

Ao CNPq, pelo apoio financeiro. 


\section{Resumo}

O propósito principal desta dissertação de Mestrado é a apresentação de um método para análise e projeto de sistemas de workflow administrativo com interface na Web. O processo de desenvolvimento proposto baseia-se na integração de métodos e técnicas preexistentes, específicas para modelar sistemas de workflow e aplicações hipermídia em geral. As técnicas integradas são: a UML, que é a notação padrão para a modelagem de sistemas orientados a objetos, amplamente aceita pela comunidade de Engenharia de Software, o BPI, que consiste em um processo direcionado especificamente para o desenvolvimento de sistemas de workflow; o RMM, que consiste na primeira metodologia estendida com o intuito de modelar aplicações hipermídia para a Web, e o W2000, que consiste em um framework para o projeto de aplicações para a Web baseado no HDM - o antecessor de uma família formada por vários métodos que apóiam o projeto de aplicações hipermídia. Para testar o método proposto, foi desenvolvido um sistema para administração de cursos pela Web. Esse sistema, denominado Atena, tem características de administração de workflows e foi usado inicialmente como base para o desenvolvimento do método e, em um momento posterior, como base para testar a abrangência e adequação do método ao domínio proposto. 


\section{Abstract}

The main purpose of this Master's thesis is the proposition of a method for analysis and design of Web-based business workflow systems. The suggested development process is based on the integration of preexisting methods and specific techniques for modeling workflow systems and hypermedia applications in general. The integrated techniques are: UML, the standard notation for modeling object-oriented systems, widely accepted by the Software Engineering community; BPI, a specific process for developing workflow systems; RMM, the first extended methodology for designing Web-based hypermedia applications; and W2000, a framework for designing Web applications based on HDM, the ancestor of a family of several methods that support the design of hypermedia applications. In order to test the proposed method, a system for administration of Web courses was developed. This system, called Atena, has caracteristics of workflow administration, and it was inicially used as a basis for the development of the method and, in a second moment, as a basis to test its scope and adequacy to the proposed domain. 


\section{Sumário}

1 Introdução 1

1.1 Considerações Iniciais . . . . . . . . . . . . . . . . . . . . . 1

1.2 Objetivo do Trabalho . . . . . . . . . . . . . . . . . . 4

1.3 Organização do Trabalho . . . . . . . . . . . . . . . 5

2 Modelos e Métodos para Especificação de Aplicações Hipermídia 7

2.1 Considerações Iniciais . . . . . . . . . . . . . . . . 7

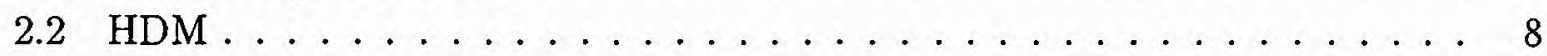

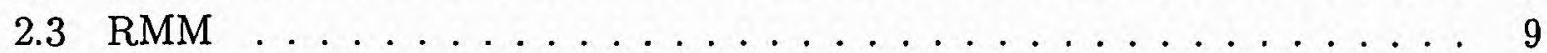

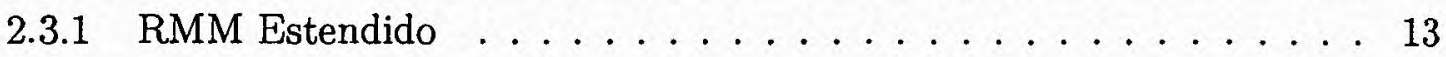

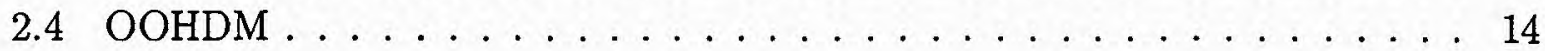

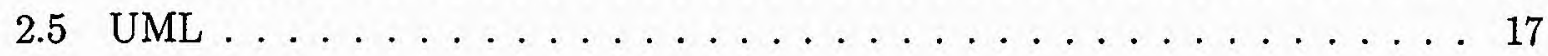

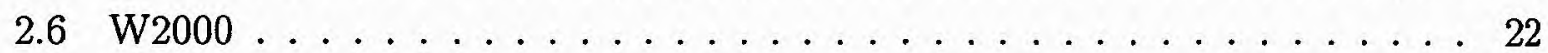

2.7 Considerações Finais . . . . . . . . . . . . . . . . . 27

3 Sistemas Baseados em Fluxo de Trabalho 29

3.1 Considerações Iniciais . . . . . . . . . . . . . . . . . . . 29

3.2 Processos de Workflow . . . . . . . . . . . . . . . . . . 29

3.3 Métodos para Especificação de Workflow . . . . . . . . . . . . . 32

3.3.1 Business Process Implementation . . . . . . . . . . . . . . 32

3.3.2 Padronizações da WfMC . . . . . . . . . . . . . . . 39

3.3.3 Modelo de um Sistema de Workflow para Gestão de Documentos . 44

3.4 Considerações Finais . . . . . . . . . . . . . . . . . 48

4 Sistemas de Informação Baseados na Web 49

4.1 Considerações Iniciais . . . . . . . . . . . . . . . . . . . . . 49

4.2 Características dos Sistemas de Informação Baseados na Web . . . . . . . . 49

4.3 Sistemas Voltados para o Ensino via WWW ; . . . . . . . . . . . . 51

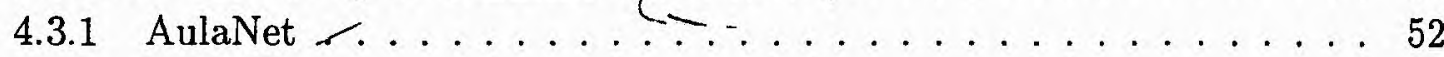

4.3 .2 WebCT $\therefore \ldots \ldots \ldots \ldots \ldots \ldots$

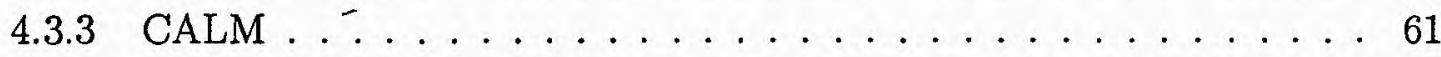

4.3.4 Outros Exemplos de Ambientes para o Ensino a Distância . . . . . 63

4.4 Considerações Finais . . . . . . . . . . . . . . . . . . 64 
5 Um Método para Análise e Projeto de Sistemas de Workflow Administrativo com Interface para a Web $\quad 67$

5.1 Considerações Iniciais . . . . . . . . . . . . . . . . . 67

5.2 Estudo de Caso: Sistema Atena - Administração de Cursos de Extensão na Web . . . . . . . . . . . . . . . . . 67 67

5.3 O Processo de Desenvolvimento . . . . . . . . . . . . . . . . 70

5.4 Fases do Processo de Desenvolvimento . . . . . . . . . . . . . . . 72

5.4 .1 Análise e Modelagem de Requisitos . . . . . . . . . . . 72

5.4 .2 Modelagem Estática . . . . . . . . . . . . . . . . 79

5.4 .3 Modelagem Dinâmica . . . . . . . . . . . . . . . . 86

5.4 .4 Implementação . . . . . . . . . . . . . . . . 103

5.5 Considerações Finais . . . . . . . . . . . . . . . 106

6 Implementação e Uso do Sistema Atena . 109

6.1 Considerações Iniciais . . . . . . . . . . . . . . . . . . . 109

6.2 Decisões de Implementação . . . . . . . . . . . . . . . . . . . . . . 109

6.3 Interface do Sistema . . . . . . . . . . . . . . . . 112

6.4 Exemplo de Uso . . . . . . . . . . . . . . . . . . . . . . . 117

6.5 Avaliação de Resultados . . . . . . . . . . . . . . . . 125

6.6 Considerações Finais . . . . . . . . . . . . . . . . 127

7 Conclusões 129

7.1 Considerações Gerais . . . . . . . . . . . . . . . . . . . . 129

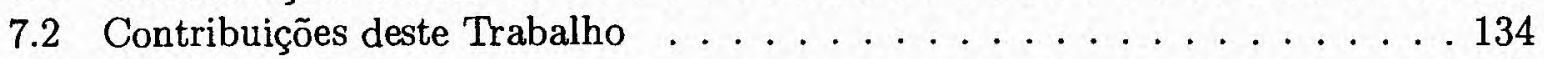

7.3 Trabalhos Futuros . . . . . . . . . . . . . . . . 135 


\section{Lista de Figuras}

1.1 Contexto atual dos sistemas de workflow administrativos . . . . . . . . 4

1.2 Novo contexto que integra os sistemas de workflow à Web . . . . . . . . 4

2.1 Primitivas do modelo RMM . . . . . . . . . . . . . . . . 11

2.2 Exemplos de primitivas de navegação do RMDM . . . . . . . . . . . 12

2.3 Exemplo de uso de $m$-slices . . . . . . . . . . . . . . . 15

2.4 Sumário das fases do método OOHDM . . . . . . . . . . . . . . 16

2.5 Notação para a especificação de casos de uso . . . . . . . . . . . . . . 18

2.6 Exemplo de uma associação em um diagrama de classes . . . . . . . . . . 19

2.7 Exemplo de diagrama de seqüência . . . . . . . . . . . . . . . 20

2.8 Exemplo da aplicação das extensões feitas à UML . . . . . . . . . . . . . . . . . . . . . .

2.9 Atividades do framework W2000 . . . . . . . . . . . . . 22

2.10 Projeto estrutural da hiperbase . . . . . . . . . . . . . . . . . . . . . . . . . . . . . .

2.11 Projeto de navegação da hiperbase . . . . . . . . . . . . . . . . . . . . . . . . . . . .

2.12 Uso de estruturas de navegação . . . . . . . . . . . . . . . . . . . . . . . . . . . . . . . . . .

2.13 Projeto da estrutura da camada de acesso . . . . . . . . . . . 26

3.1 Exemplo de entidade de ligação e atributos associativos . . . . . . . . . . 33

3.2 Exemplo de diferentes entidades que assumem um mesmo papel . . . . . . 34

3.3 Atividade externa iniciando um ciclo de vida . . . . . . . . . . . . 35

3.4 Dependência entre ciclos de vida (muitos dependem de um) . . . . . . . . 35

3.5 Grupos de seleção - relação de exclusividade mútua . . . . . . . . . . . . 36

3.6 Conjunto de dados para orçamento de um pedido . . . . . . . . . . 37

3.7 Modelo simplificado de tarefas . . . . . . . . . . . . . . . . . . . . . . . . . . .

3.8 Associações entre tarefas, usuários e habilidades . . . . . . . . . . . . . 39

3.9 Características de um sistema de workflow . . . . . . . . . . . . . . . 40

3.10 Relacionamentos entre os componentes da terminologia básica . . . . . . 41

3.11 Meta-modelo para a definição de um processo básico . . . . . . . . . . . . 42

3.12 Construtores gráficos da WfMC . . . . . . . . . . . . . . . . . . . . . . . 43

3.13 Representação dos roteamentos OR-Join e OR-Split . . . . . . . . . . . . 46

3.14 Terminadores indicando os pontos inicial e final da execução . . . . . . . . 46

3.15 Representação de iteração da WFMC e da LiRA . . . . . . . . . . . . . . 46

3.16 Representação gráfica de uma atividade atômica e de um subprocesso . . . 47

3.17 Exemplo simplificado de um workflow para cálculo de imposto de renda . . 47

4.1 Tela para seleção dos mecanismos de comunicação . . . . . . . . . . . . . 53

4.2 Controle remoto contendo o menu com os serviços específicos do curso . . . 54 
4.3 Tela inicial para identificação ou para solicitação de registro no ambiente . 55

4.4 Interface inicial do docente . . . . . . . . . . . . . 56

4.5 Tela de trabalho do designer . . . . . . . . . . . . . . 58

4.6 Interface do My WebCT . . . . . . . . . . . . . . . . . . . . . . . . . . .

4.7 Planilha de notas dos alunos . . . . . . . . . . . . . . 60

4.8 Comparação de ferramentas de ensino a distância . . . . . . . . . . . 64

5.1 Fases do processo de desenvolvimento . . . . . . . . . . . 70

5.2 Modelo de casos de uso funcionais . . . . . . . . . . . . . 76

5.3 Modelo de casos de uso navegacionais . . . . . . . . . . . . . . . 78

5.4 Exemplo de classes com operações . . . . . . . . . . . . . . . . . 82

5.5 Modelo de classes do Sistema Atena . . . . . . . . . . . . . . . 83

5.6 Exemplo de interface que agrupa atributos de diferentes classes . . . . . . 85

5.7 Exemplo de um m-slice do Sistema Atena . . . . . . . . . . . . . 86

5.8 Diagrama de atividades do Sistema Atena . . . . . . . . . . . . . . 92

5.9 Diagrama de atividades representando tarefas . . . . . . . . . . . . 93

5.10 Exemplo de uma coleção e de um centro . . . . . . . . . . . . . . 98

5.11 Exemplo de uma interface representada por um agrupamento . . . . . . 98

5.12 Modelo navegacional parcial do Sistema Atena . . . . . . . . . . . . . 99

5.13 Expansão do agrupamento "Ambiente do Assistente Acadêmico" . . . . . . 100

5.14 Diagrama de estados para o objeto curso do Sistema Atena . . . . . . . . 103

5.15 Arquitetura de três camadas . . . . . . . . . . . . . 105

6.1 Arquitetura utilizada para a execução do Sistema Atena . . . . . . . . . 111

6.2 Tela principal do Sistema Atena - exemplo de agrupamento . . . . . . . . 112

6.3 Exemplo de um índice . . . . . . . . . . . . . . . . . . . . . . . . . . . . . . . . . . . . .

6.4 Exemplo de uma página de conteúdo . . . . . . . . . . . . . . . . 114

6.5 Exemplo de um m-slice . . . . . . . . . . . . . . . . 115

6.6 Tela de Entrada no Sistema . . . . . . . . . . . . . . . . 115

6.7 Ambiente do Assistente Acadêmico - exemplo de visão . . . . . . . . . . 116

6.8 Interface para a criação de usuários - exemplo de formulário . . . . . . . 117

6.9 Lista de cursos cuja abertura de processo encontra-se pendente . . . . . . 118

6.10 Formulário para abertura de processo . . . . . . . . . . . . . . 119

6.11 Aprovação da proposta de curso pelo Conselho Departamental . . . . . . 120

6.12 Aprovação da proposta de curso pela CCEx . . . . . . . . . . . . . 120

6.13 Fomulário de inscrição . . . . . . . . . . . . . . . . . . 121

6.14 Informações para aprovação de candidatos . . . . . . . . . . . . . . . . . . . . . . . . . . . . . . . .

6.15 Interface para a edição do calendário de aulas . . . . . . . . . . . . 122

6.16 Interface para o controle de freqüência . . . . . . . . . . . . 123

6.17 Interface para o controle de notas . . . . . . . . . . . . 123

6.18 Encaminhamento da Diretoria à Pró-Reitoria . . . . . . . . . . . . . . 124

6.19 Autorização para emissão de certificados . . . . . . . . . . . . . . . . . . . . . . . . . . . . . .

6.20 Arquivamento de processos . . . . . . . . . . . . . 125 


\section{Lista de Tabelas}

5.1 Descrição do caso de uso . . . . . . . . . . . . . . 73

5.2 Progresso típico de eventos . . . . . . . . . . . . . 73

5.3 Progressos alternativos . . . . . . . . . . . . . 73

5.4 Exemplo de descrição de um caso de uso funcional . . . . . . . . . . . 75

5.5 Exemplo do progresso típico de eventos ide um caso de uso funcional . . . . 75

5.6 Exemplo dos progressos alternativos de eventos de um caso de'uso funcional 75

5.7 Exemplo de descrição de um caso de uso navegacional . . . . . . . . . . 77

5.8 Exemplo do progresso típico de eventos de um caso de uso navegacional . . 77

5.9 Descrição do caso de uso "Inscreve-se em Curso" . . . . . . . . . . . . 81

5.10 Progresso típico de eventos do caso de uso "Inscreve-se em Curso" . . . . . 81

5.11 Exemplo de classificação de tarefas . . . . . . . . . . . . 95 


\section{Capítulo 1}

\section{Introdução}

\subsection{Considerações Iniciais}

O uso da Web como plataforma para sistemas de gerenciamento de informação ou para sistemas baseados em fluxo de trabalho ainda é muito recente, porém tem despertado grande interesse e, portanto, precisa e deve ser explorado pela Engenharia de Software. Do ponto de vista tecnológico, pesquisadores afirmam que cada vez mais desenvolver um software é sinônimo de desenvolver uma solução baseada na tecnologia Web (Web-based solution), o que torna essencial a pesquisa na área de Engenharia de Software voltada para a criação de métodos, modelos, linguagens e ferramentas que apóiem a análise, a especificação e o projeto de softwares baseados na Web.

De fato, a cada dia aumenta a utilização da Web como plataforma para a implantação de sistemas de gerenciamento de informação ou para sistemas baseados em fluxo de trabalho que implementam processos administrativos. A própria navegação em um sistema para a Web pode sugerir ou mesmo restringir as seqüências de operações válidas prescritas pelas regras de negócio. Além disso, a Web permite que os participantes do processo de workflow interajam diretamente com o sistema, sem a necessidade de agentes intermediários. Dessa forma, os conceitos de sistemas de informação para a Web e sistemas baseados em fluxo de trabalho, estão cada vez mais próximos e de certa forma integrados, e são exatamente esses os aspectos que devem ser investigados neste trabalho.

Do ponto de vista empresarial, o investimento em sistemas de informação baseados na Web ou Web Information Systems (WISs) tem-se mostrado bastante vantajoso, o que tem contribuído para o desenvolvimento de tecnologias de suporte relacionadas. Por estarem disponíveis na Web, esses sistemas atingem um público mais extenso e heterogêneo, ampliando o mercado consumidor das empresas; são boas estratégias de marketing, pois oferecem facilidades e benefícios para o consumidor; agregam com isso valor às empresas, além de reduzirem custos, pois não exigem a instalação de software adicional nas 
máquinas dos usuários finais, minimizarem gastos com manutenção e suporte técnico e permitirem treinamento em larga escala a baixo custo.

Além disso, os serviços oferecidos pelos WISs transpõem limites temporais e espaciais, permitindo que operações e atualizações sejam realizadas a partir de qualquer lugar do mundo, suportando assim bases de dados institucionais integradas e consistentes. Os WISs são ainda excelentes meios de difusão de informação, permitem o trabalho cooperativo e contribuem para a construção de comunidades de conhecimento.

O presente trabalho propõe a investigação de forma integrada dos conceitos envolvidos pelos sistemas baseados em fluxo de trabalho ou sistemas workflow e pelos sistemas de informação baseados na Web, por meio do desenvolvimento de um sistema para administração de cursos de extensão para a Web, com o objetivo de obter como resultado final a proposta de um método para análise e projeto de sistemas de workflow administrativo com interface para a Web.

Os sistemas de informação, por serem voltados para o gerenciamento de um conjunto amplo de informações, são aplicáveis a organizações de diversas naturezas, dentre as quais destacam-se as instituições de ensino e, em particular, as Universidades.

Um dos papéis da administração geral de uma Instituição Universitária é manter controle constante de suas atividades, o que normalmente é feito por meio de processos administrativos. Tais processos gerenciam recursos e informações, e contribuem para a manutenção efetiva e atualizada dos registros referentes às atividades realizadas no âmbito interno da Instituição, o que é de fundamental importância. O fator "eficiência" na gestão é crítico no contexto atual em que as Universidades, particularmente as públicas, estão constantemente sujeitas a processos de avaliação por órgãos superiores e financiadores.

A avaliação de uma Universidade é medida, sobretudo, pela qualidade do trabalho de seu corpo docente, que executa fundamentalmente atividades de ensino, pesquisa e extensão. No contexto de extensão enquadra-se uma variedade de atividades, dentre as quais destacam-se os cursos de especialização, atualização, aperfeiçoamento e difusão cultural. Tais atividades podem ser desenvolvidas tanto no âmbito interno da instituição, em complemento às atividades específicas do ensino e da pesquisa, ou podem atender a demandas especiais da comunidade externa à Instituição. O objetivo primordial da atividade de extensão é disseminar o conhecimento armazenado na Universidade para a comunidade. Sob esse ponto de vista, a utilização da WWW como meio de disseminação é bastante apropriada.

Nesse sentido, constata-se que o contexto envolvido pela administração de cursos de extensão é apropriado para a aplicação e para a investigação das chamadas tecnologias de informação, que envolvem tanto sistemas voltados para a Web quanto sistemas para gerenciamento e tratamento de informações. 
Vários fatores motivam e justificam a escolha do sistema para administração de cursos de extensão na Web como base para o trabalho. O primeiro deles é devido ao fato do sistema proposto caracterizar-se como um sistema baseado em um fluxo de trabalho administrativo, uma vez que a execução e a seqüência de realização de suas tarefas são regidas por regras bem definidas internamente ao escopo de um processo administrativo. $\mathrm{O}$ segundo fator está associado à possibilidade de implementação desse sistema na Web. E o terceiro e mais importante fator, refere-se à possibilidade de investigar as correspondências ou relações existentes entre essas duas tecnologias, por meio do desenvolvimento desse sistema.

Devido ao fato de ser implementado para a Web, o sistema proposto também permite a verificação da adequação de modelos e métodos para a especificação de aplicações hipermídia quanto à especificação de aplicações para a WWW, ou seja, possibilita a avaliação da habilidade em expressar a execução da lógica de negócios do sistema em termos de elementos e tecnologias específicos para essa plataforma.

Outros fatores de motivação referem-se à necessidade de aumentar a eficiência e otimizar o processo de administração de cursos de extensão e à possibilidade de utilização do sistema proposto como um módulo administrativo de apoio a servidores de cursos a distância.

Com a integração dos sistemas de informação para a Web e dos sistemas baseados em fluxo de trabalho, o contexto dos sistemas de apoio à administração sofre alteração, como ilustrado nas Figuras 1.1 e 1.2. De acordo com o contexto descrito por Jackson \& Twaddle (1997), existe um setor administrativo composto por funcionários que trabalham para uma empresa ou organização que conduz negócios por meio de interações com o ambiente externo. Existe também uma máquina onde é executado o sistema workflow que é responsável por implementar o processo administrativo e por apoiar o trabalho dos funcionários. Todas as interações com o ambiente externo ocorrem por intermédio do setor administrativo ou via sites na WWW integrados ao sistema, ou seja, participantes externos não interagem diretamente com o sistema de workflow e, portanto, não são considerados usuários do mesmo. A máquina de workflow pode interagir diretamente com outros sistemas de apoio como sistemas legados, que na maioria das vezes fornecem informações necessárias para a condução do negócio, e sistemas bancários, que apoiam transações financeiras.

No novo contexto, o workflow passa a ser executado na própria WWW, onde também passam a ser realizadas as interações com os usuários e com os sistemas de apoio. Sob esse ponto de vista, todos os participantes do processo atuam como usuários e interagem diretamente com o sistema sem a necessidade de intermediários. Além disso, o sistema está acessível e seus serviços estão disponíveis a partir de qualquer lugar e a qualquer 
momento, o que supostamente otimiza a execução do processo administrativo.

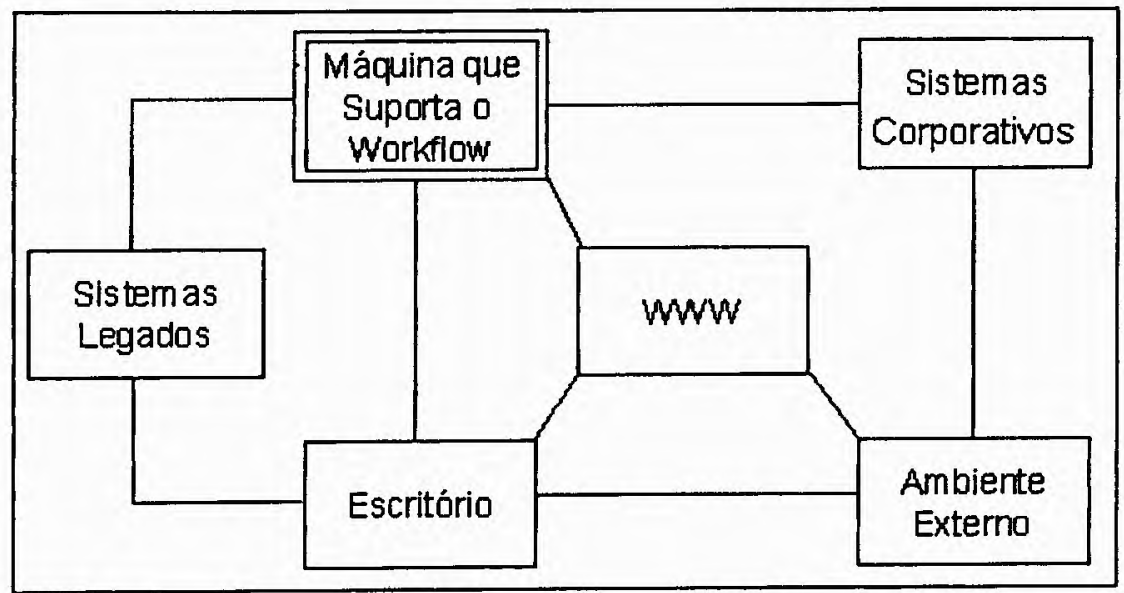

Figura 1.1: Contexto atual dos sistemas de workflow administrativos (Jackson \& Twaddle, 1997)

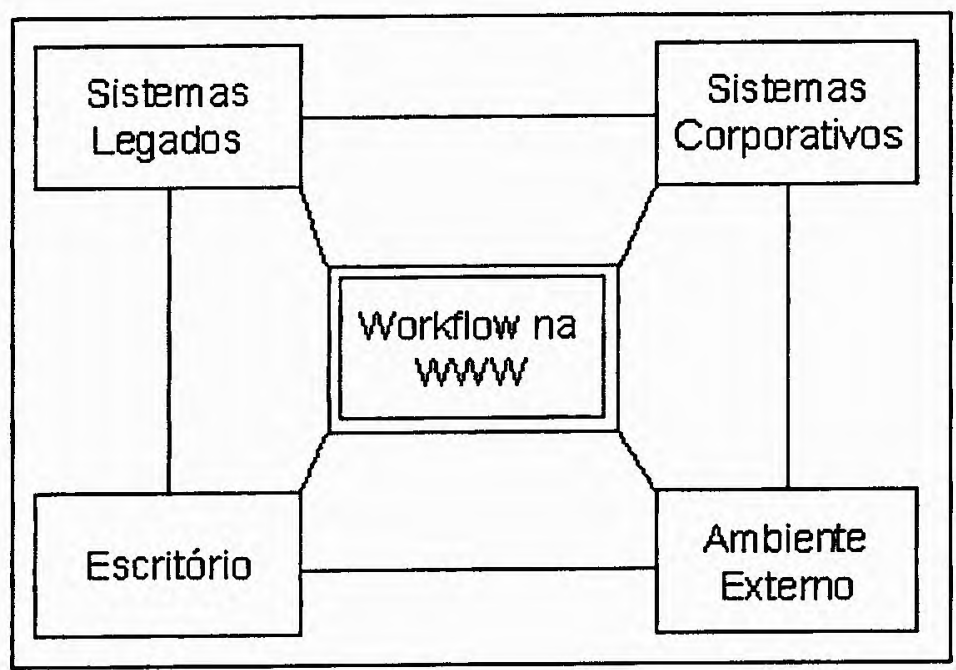

Figura 1.2: Novo contexto que integra os sistemas de workflow à Web

\subsection{Objetivo do Trabalho}

O objetivo deste trabalho é explorar os aspectos associados às tecnologias de sistemas de informação baseados na Web e aos sistemas baseados em fluxo de trabalho ou sistemas workflow, identificando as relações existentes por meio da construção de um sistema para administração de cursos de extensão via Web. A partir da análise dos resultados obtidos pretende-se propor um método para a análise e o projeto de sistemas de informação administrativos com interface para a Web. 
O sistema a ser desenvolvido deve apoiar o gerenciamento de processos administrativos relacionados ao oferecimento de cursos de extensão, aos quais estão associados dois aspectos principais:

- O aspecto burocrático, uma vez que existe a necessidade de gerenciamento do processo de criação, aprovação e oferta dos cursos pela Universidade. Depois de oferecidos os cursos, essa atividade deve ser registrada, notas e conceitos processados, certificados emitidos, etc.

- O próprio oferecimento dos cursos. Como forma de disseminar a oferta em um meio acessível a um público externo amplo, os cursos devem estar disponíveis na Web.

Além de integrar os processos administrativos relacionados ao oferecimento do curso, o sistema deve estabelecer uma interface com o servidor de cursos que está sendo desenvolvido no próprio ICMC como trabalho de Doutorado, para dar apoio à tarefa de disponibilizar material para acesso remoto pelos alunos de cursos a distância. O que se espera, portanto, é que o sistema de informação para administração de cursos de extensão atue de forma integrada ao servidor de cursos a distância, o que satisfaria os dois aspectos acima citados.

\subsection{Organização do Trabalho}

Esta dissertação está organizada da seguinte forma: neste capítulo foi apresentada uma visão geral do problema a ser investigado, dos objetivos a serem atingidos e das características do sistema proposto. Foram também descritos o contexto do problema, as motivações e as justificativas para a escolha do tema.

O Capítulo 2 contém uma revisão de literatura que versa sobre os modelos e métodos para a especificação de aplicações hipermídia. Descreve também extensões realizadas com o propósito de tornar a UML mais adequada para a modelagem de aplicações para a Web.

No Capítulo 3 são apresentadas inicialmente algumas das definições mais aceitas para sistemas baseados em fluxo de trabalho ou sistemas workflow e as classificações nas quais subdividem-se. São também revisados os métodos e as notações utilizados para a modelagem dessa categoria de sistema, além de propostas de padronização dos termos e conceitos envolvidos.

No Capítulo 4 são descritas as principais características dos sistemas de informação para a Web e são apresentados alguns exemplos de sistemas de informação voltados para o ensino a distância via WWW, com o intuito de identificar os principais recursos oferecidos pelos mesmos. São enfatizados os aspectos administrativos envolvidos por essa classe de sistemas. 
No Capítulo 5 é descrito o método para análise e projeto de sistemas de workflow administrativo com interface para a Web, que consiste na principal contribuição deste trabalho. Esse capítulo subdivide-se em seções nas quais são apresentadas, de forma detalhada, as fases que integram o processo de desenvolvimento proposto, enfatizando, em cada uma delas, as atividades que devem ser realizadas, a notação sugerida para a modelagem e a documentação dessas atividades, os resultados obtidos e a exemplificação da aplicação do método ao Sistema Atena - estudo de caso utilizado para apoiar a construção do método, testá-lo e validá-lo - que também é descrito nesse capítulo.

No Cápítulo 6 são apresentadas as decisões de implementação, incluindo a arquitetura utilizada, algumas das interfaces e exemplos de uso do Sistema Atena. Também é realizada uma avaliação preliminar dos resultados obtidos e da adequação do método proposto à modelagem de outros domínios de informação.

Finalmente, o Capítulo 7 contém as conclusões, a síntese das contribuições desta dissertação de Mestrado e as sugestões de trabalhos futuros relacionados. 


\section{Capítulo 2}

\section{Modelos e Métodos para Especificação de Aplicações Hipermídia}

\subsection{Considerações Iniciais}

A qualidade de uma aplicação hipermídia está diretamente relacionada à maneira pela qual foi projetada e à habilidade do desenvolvedor em capturar e organizar um complexo conjunto de informações, disponibilizando-as de modo claro e acessível a um público amplo e variado. Bons projetos devem beneficiar-se de um desenvolvimento sistemático e estruturado, especialmente quando se trata de um domínio complexo e extenso.

A tecnologia hipermídia, por sua vez, tem evoluído de modo a apoiar a criação de aplicações cada vez mais abrangentes em termos da apresentação do conteúdo, por intermédio de diferentes mídias e das estruturas organizacional e navegacional (Turine, 1998). O problema consiste em combinar essa flexibilidade com mecanismos de organização de forma a evitar que, durante a navegação, o leitor se perca no hiperespaço. Paralelamente ao rápido avanço tecnológico, modelos e métodos destinados a fornecer mecanismos de organização para apoiar a especificação e o projeto de aplicações hipermídia foram propostos. Neste capítulo são apresentados alguns dos mais difundidos. Nas Seções 2.2 a 2.4, são apresentados o modelo HDM e seus sucessores, os métodos RMM e OOHDM originais e estendidos, e na Seção 2.5 são apresentadas a linguagem UML e suas extensões. 


\subsection{HDM}

HDM (Hypertext Design Model) foi o primeiro modelo amplamente conhecido para a especificação e projeto de aplicações hipermídia, voltado especialmente para a modelagem do domínio da aplicação (Garzotto, Paolini \& Schwabe, 1991). Seu projeto compreende três fases:

(a) Especificação de um esquema HDM - descreve os objetos conceituais que compõem uma classe de aplicação em termos de características semânticas e estruturais comuns.

(b) Instanciação do esquema para uma aplicação em particular, obedecendo às definições estabelecidas no esquema global. Tạl instância apresenta somente os aspectos estáticos da aplicação.

(c) Definição da semântica de navegação que determina como os objetos são apresentados ao leitor (propriedades de visualização) e qual é o comportamento dinâmico da aplicação.

Um esquema HDM é, portanto, uma coleção de tipos de entidades que descrevem uma classe de aplicação em um nível global, enquanto uma instância de um esquema consiste em uma coleção de entidades, componentes, unidades e ligações de uma aplicação específica (Garzotto, Paolini \& Schwabe, 1993a). A vantagem no uso de tais conceitos está na possibilidade de reutilização de um mesmo esquema para aplicações diferentes que pertençam a um mesmo domínio e que compartilhem a mesma estrutura global, diferenciando-se apenas nas instâncias.

Além dos tipos de entidades, os esquemas também são compostos por um conjunto de tipos de ligações que interconectam as entidades. As entidades, que são representantes dos objetos do domínio, correspondem aos elementos básicos do modelo e sendo formadas por componentes hierarquicamente estruturados que, por sua vez, são constituídos por unidades. As unidades (que correspondem ao conceito de nó nos hipertextos) são as menores porções de informação que podem ser visualizadas em uma aplicação HDM. Cada unidade apresenta o conteúdo de um componente de acordo com uma determinada perspectiva, ou seja, a perspectiva estabelece a aparência da porção de informação na unidade. Os componentes são mecanismos lógicos de organização da informação (Garzotto, Mainetti \& Paolini, 1995)

As ligações podem ser utilizadas para relacionar entidades, componentes ou unidades, além de exercerem sua função tradicional de conectar informaçōes de tipos diferentes. Em HDM, as ligações podem ser classificadas como: estruturais, de perspectiva ou de 
aplicação. Ligações estruturais conectam os diferentes componentes pertencentes a uma mesma entidade. Ligações de perspectiva são usadas para relacionar diferentes unidades de um mesmo componente. Já as ligações de aplicação especificam a semântica dos relacionamentos no domínio da aplicação, isto é, representam as relações de dependência entre as entidades e podem conectar componentes e entidades do mesmo tipo ou de tipos diferentes.

Em HDM, existem ainda estruturas de acesso que definem pontos de entrada usados para orientar o leitor no processo de navegação e para tornar mais rápido e direto o acesso às informações. Tais estruturas podem ser os chamados outlines, que são estruturas tipo índice, ou os roteiros guiados.

O HDM define uma semântica de navegação default que, por um processo de compilação, permite transformar a especificação da instância do esquema HDM em um modelo intermediário baseado em grafos (modelo de nós e ligações). Em seguida, os nós e as ligações devem ser mapeados diretamente para os objetos do sistema hiperdocumento destino, o qual é responsável por especificar o comportamento dinâmico e as propriedades de visualização das informações. Assim, para uma mesma especificação estática HDM, podem-se definir diferentes semânticas de navegação, permitindo que o mesmo hiperdocumento tenha comportamentos dinâmicos diferentes ou que seja implementado em diferentes sistemas hiperdocumento (Turine, 1998).

Extensões subseqüientes feitas ao modelo HDM, como o HDM2 (Garzotto, Paolini \& Schwabe, 1993b), acrescentaram novas primitivas de modelagem, como os slots, que permitem que as entidades sejam estruturadas na forma de frames. Também foi proposto por Garzotto, Mainetti \& Paolini (1994) o uso de coleções multimídia como uma forma de melhor organizar a estrutura navegacional da aplicação, diminuindo a desorientação do leitor.

O modelo HDM ainda tem sido a base de pesquisas atuais direcionadas para as fases de avaliação e análise de hiperdocumentos. Apesar de bastante difundido, o modelo restringe-se às aplicações hipertexto, não sendo apropriado para a especificação de aplicações hipermídia dinâmicas, pois não trata os aspectos temporais relacionados à multimidia. Por outro lado, possui vantagens com relação a outros modelos devido à ênfase dada aos requisitos relativos à obtenção e organização da informação, aspecto fundamental em qualquer bom projeto.

\subsection{RMM}

O RMM (Relationship Management Methodology) é um método para o projeto estruturado e construção de aplicações hipermídia que compreende sete etapas (Isakowitz, Stohr \& 
Balasubramanian, 1995):

- Projeto de entidades e relacionamentos (E-R)

- Projeto de fatias

- Projeto navegacional

- Projeto de interface com o usuário

- Projeto de protocolos de conversão

- Projeto de comportamento em tempo de execução

- Construção e teste

Embora baseado em um modelo em cascata, o método é flexível e apóia processos iterativos. Durante a primeira fase do projeto, é construído um modelo de entidades e relacionamentos (ME-R) com o intuito de representar as informações relevantes do domínio da aplicação. Tais entidades e relacionamentos formam a base da aplicação hipermídia e poderão apresentar-se como nodos e ligações no produto resultante.

O projeto de fatias determina como as informações de cada entidade devem ser apresentadas aos usuários e como devem ser acessadas. Para isso, as entidades são divididas em fatias significativas de informação que são organizadas na forma de uma rede hipertexto. Cada fatia agrupa um ou mais atributos da entidade. Tal subdivisão produz um diagrama E-R estendido (DE- $R+$ ), que compreende o DE-R construído na fase anterior e o diagrama de fatias gerado para cada entidade.

No projeto de navegação, o esquema E-R é enriquecido com as estruturas de acessos que especificam como os leitores podem navegar pelas informações, ou seja, são definidos caminhos navegacionais. Já no projeto de interface com o usuário, é especificado como as informações serão apresentadas ao leitor.

Durante o projeto de protocolos de conversão, é produzido um conjunto de regras para a tradução dos componentes do diagrama RMDM, explicado em seguida, em objetos físicos de um sistema hiperdocumento resultante. O projeto de comportamento em tempo de execução determina como as informações do hiperdocumento são recuperadas e como é realizada a interação do leitor com o sistema. Finalmente, a fase de construção e teste é responsável por implementar o projeto obtido nas fases anteriores, por criar uma base de dados com as informações do domínio e por realizar testes para verificar se os requisitos funcionais, navegacionais e de usabilidade foram satisfeitos.

O núcleo do método RMM é o modelo de dados RMDM (Relationship Management Data Model), baseado no ME-R e nos modelos de dados HDM e HDM2. O RMDM 
fornece uma linguagem gráfica para especificar a semântica do domínio (primitivas do domínio) e os mecanismos de navegação apoiados pela aplicação hipermídia (primitivas de acesso). Tal modelo é obtido como resultado final das três primeiras etapas do processo de desenvolvimento. Vale ressaltar que, diferentemente do diagrama de entidades e relacionamentos, que representa o projeto do banco de dados, o diagrama RMDM descreve a maneira pela qual os usuários deverão navegar sobre a aplicação, ou seja, o modelo também incorpora aspectos dinâmicos. Na Figura 2.1, são ilustradas as primitivas que compõem o modelo RMDM.

\begin{tabular}{|c|c|c|}
\hline \multirow{4}{*}{ Primitivas do dominio E-R } & Entidade & 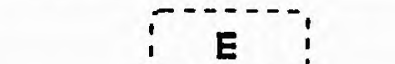 \\
\hline & Atributo & $\cdot$ \\
\hline & Relacionamento associativo (1-1) & $\ldots$ \\
\hline & Relacionamento associativo (1-n) & \\
\hline Primitivas do domínio RMD & Fatia & \\
\hline \multirow{6}{*}{ Primitlvas de acesso } & Ligaçẩo unidirecional & \\
\hline & Ligaçāo bidirecional & $\therefore$ \\
\hline & Agrupamento & $\stackrel{\longrightarrow \longrightarrow}{\longrightarrow}$ \\
\hline & Índice & $\equiv$ \\
\hline & Roteiro guiado & $\longrightarrow$ \\
\hline & Roteiro guiado indexado & $\equiv$ \\
\hline
\end{tabular}

Figura 2.1: Primitivas do modelo RMM (Isakowitz et al., 1995)

As primitivas do domínio modelam as informações referentes ao domínio da aplicação e dividem-se em primitivas do domínio $E-R$, que incluem as entidades, atributos e relacionamentos associativos; e primitivas do domínio RMD, que são as fatias ou slices. As 
entidades e seus atributos representam objetos físicos ou abstratos que se constituem nos elementos básicos do domínio. Os relacionamentos associativos, que podem ter a cardinalidade de "um para um" (1-1) ou de "um para muitos" (1-n), descrevem associações entre diferentes tipos de entidades.

Devido ao fato de as entidades serem formadas por atributos de natureza distinta, pode ser desejável apresentar esses atributos separadamente. Por isso, em RMM, os atributos de uma entidade podem ser agrupados em fatias que correspondem a porções significativas de informação. Tais fatias são organizadas de modo a modelar como a informação será apresentada ao leitor.

As primitivas de acesso permitem modelar como será o processo de navegação no hiperdocumento. A navegação é apoiada no RMM por seis primitivas de acesso: ligações uni e bidirecionais, índices, roteiros guiados, roteiros guiados indexados e agrupamentos, sendo algumas ilustradas na Figura 2.2.

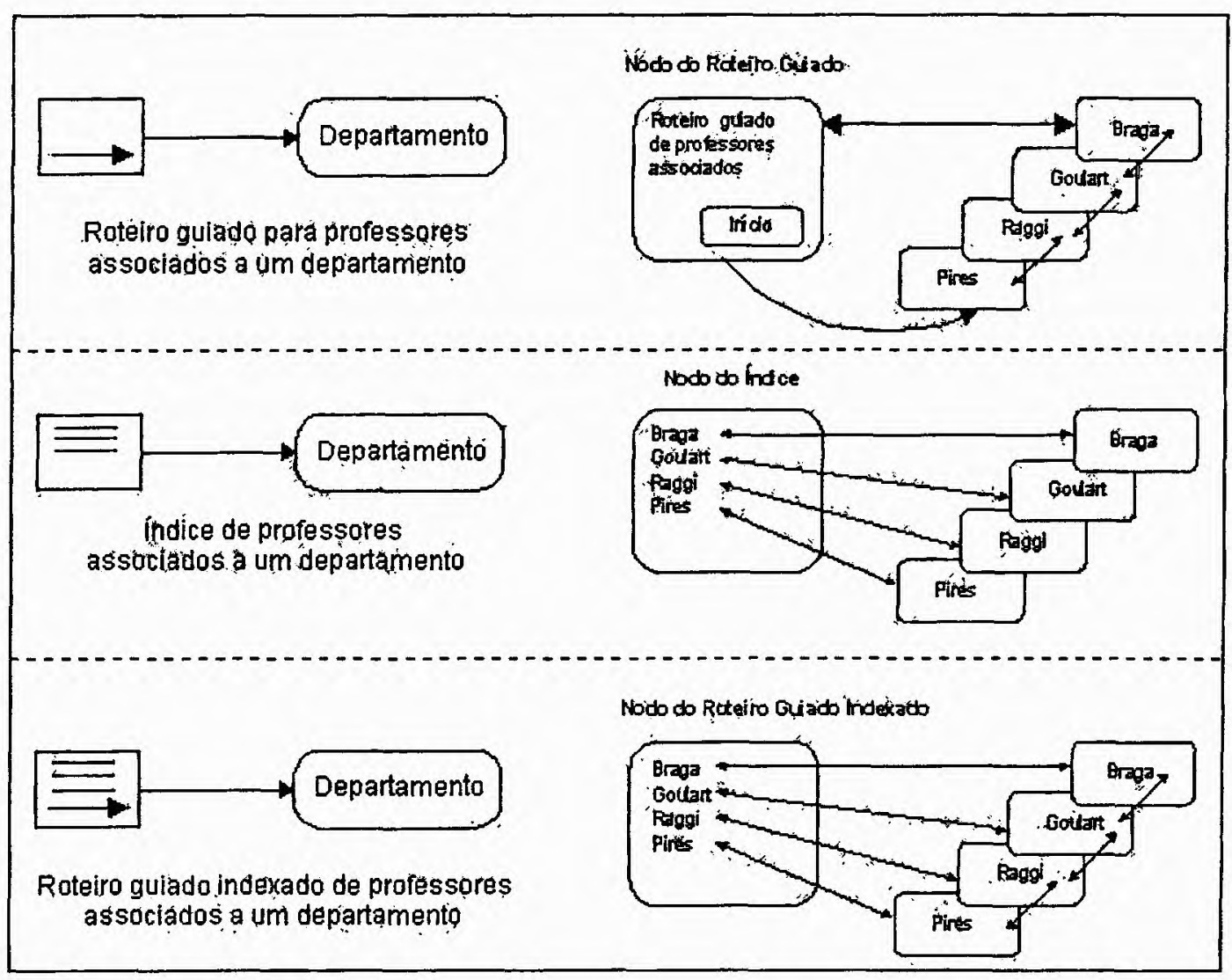

Figura 2.2: Exemplos de primitivas de navegação do RMDM (Isakowitz et al., 1995)

As ligações uni e bidirecionais são usadas para especificar o acesso entre fatias de uma mesma entidade. É importante frisar que tais ligações somente podem ser usadas internamente às entidades. A navegação entre diferentes entidades é realizada pelas demais primitivas de acesso, isto é, por meio dos índices, roteiros guiados e agrupamentos. 
De acordo com Isakowitz et al. (1995), o RMM original é mais apropriado para o projeto e construção de aplicações que possuem uma estrutura regular e que necessitam, especialmente, de freqüentes atualizações das informações (alta volatilidade) para a manutenção do sistema. Esses são os critérios que configuram a necessidade de meios para sistematizar e automatizar o desenvolvimento e os subseqüentes processos de atualização do hiperdocumento.

\subsubsection{RMM Estendido}

Com base na experiência adquirida e em resultados obtidos com a aplicação do RMM original, proposto em 1995 (Isakowitz et al., 1995), a projetos de sistemas hipermídia para a Web, verificou-se que esse método apresentava restrições que limitavam a implementação e que exigiam que os sistemas se adaptassem ao método. Com o intuito de suprir essas limitações, tornando o RMM um método mais flexível e apropriado para o projeto e para a modelagem de um número mais amplo de aplicações, extensões foram propostas inicialmente em 1997 (Isakowitz, Kamis \& Koufaris, 1997) e, em seguida, complementadas em 1998 (Isakowitz, Kamis \& Koufaris, 1998b). Essas foram as primeiras extensões realizadas a um método desenvolvido originalmente com o objetivo de projetar aplicações hipermídia em geral, para adequá-lo ao projeto de sistemas de informação para a Web.

As principais limitações do RMM original são:

Restrições quanto ao conteúdo das fatias (slices): No RMM original as fatias somente podem conter atributos de uma única entidade e não podem ser aninhadas. Cada fatia corresponde a uma página de conteúdo que pode conter uma estrutura de acesso, que a interconecta a outras páginas. Um projeto elaborado dessa maneira, resulta em uma série de páginas cujo conteúdo, embora relacionado semanticamente, apresenta-se de forma isolada. A inabilidade de agregação do método exigia que o título de um artigo e os nomes dos seus autores, por exemplo, fossem apresentados em páginas distintas. Os dados completos de uma referência bibliográfica também não poderiam ser inclúdos em uma única página, a menos que existisse no modelo de entidades e relacionamentos uma entidade, denominada "referência bibliográfica", que incluísse informações sobre autores, livros, artigos, revistas, congressos, etc., o que não seria apropriado.

Falta de contexto na navegação: Como conseqüência da primeira limitação apresentada, há uma perda do contexto de navegação uma vez que conteúdos associados são apresentados separadamente. Essa é uma implicação séria pois viola um dos principais requisitos de um bom projeto de hipertexto que é a redução da desorientação do usuário. $\mathrm{O}$ aumento do número de nodos da hiperbase e das estruturas de acesso, dificultam a navegação e o acesso à informação desejada, além de reduzir a compreensão do conteúdo 
pelo leitor.

A solução encontrada para suprir essas limitações foi estender o projeto de fatias. Para isso, foi criado o construtor denominado $m$-slice. A característica mais importante dos $m$-slices é a possibilidade de agrupar elementos (atributos) provenientes de diversas entidades, o que elimina a primeira limitação, e de prover conteúdos de navegação contextualizados, o que exclui a segunda limitação. Os $m$-slices podem conter ainda informações que não são armazenadas na base de dados ou que não pertencem a nenhuma entidade, mas que auxiliam a compreensão do conteúdo e a navegação. Diversos $m$-slices também podem ser aninhados; com isso a informação é melhor estruturada, porções de conteúdo podem ser reutilizadas e os projetos tornam-se mais flexíveis. Um exemplo de uso de $m$-slices aninhados para modelar informações que compõem a referência bibliográfica de um artigo é apresentado na Figura 2.3

Web Information Systems.

T. Isakowitz, A. Kamis and M Koufaris.

Communications of the Assaciation of Computer Machinery

$1998-41(7): 78-80$.

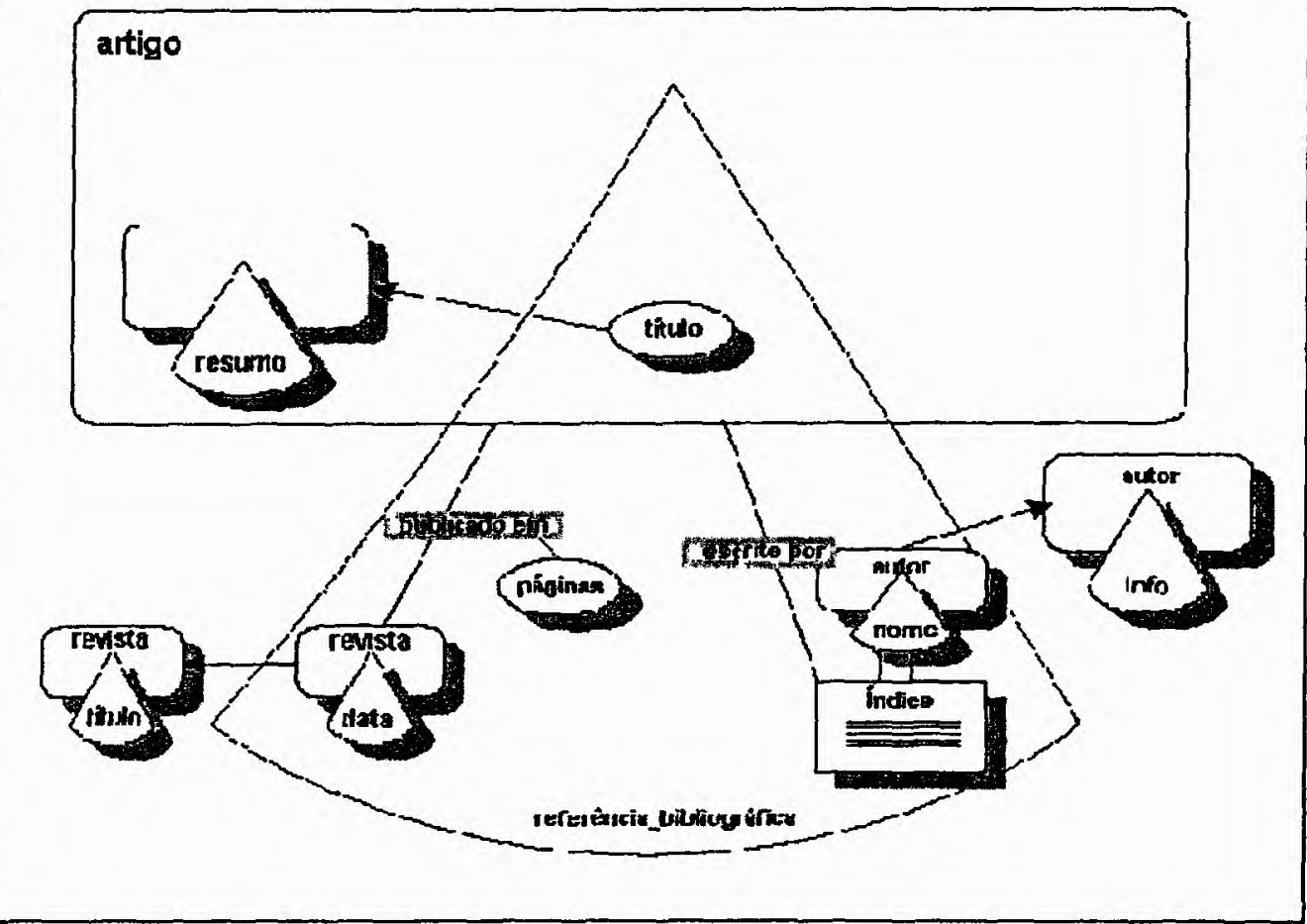

Figura 2.3: Exemplo de uso de m-slices (Isakowitz et al., 1998b) 


\subsection{OOHDM}

O OOHDM (Object-Oriented Hypermedia Desing Method) é um método voltado para a construção de aplicações hipermídia orientadas a objetos e de larga escala. Compreende quatro fases de desenvolvimento: projeto conceitual, projeto navegacional, projeto de interface abstrata e implementação (Rossi, 1996; Schwabe \& Rossi, 1995; Schwabe \& Rossi, 1998b). As atividades de cada fase são executadas ao longo de um ciclo de desenvolvimento que permite processos iterativos, incrementais e de prototipação. A Figura 2.4 apresenta resumidamente as fases, os produtos, os mecanismos e os interesses do projeto abordados pelo método OOHDM.

\begin{tabular}{|c|c|c|c|}
\hline Fases & Produtos & Mecanismos & Interesses do Projeto \\
\hline Projeto Conceitual & $\begin{array}{c}\text { Classes, subsistemas, } \\
\text { relacionamentos, } \\
\text { perspectivas de atributos. }\end{array}$ & $\begin{array}{c}\text { Classificação, composiçã̃o, } \\
\text { generalização e } \\
\text { especialização. }\end{array}$ & $\begin{array}{l}\text { Modela a semântica do } \\
\text { domínio de aplicação. }\end{array}$ \\
\hline Projeto de Navegação & $\begin{array}{c}\text { Nós, ligações, estruturas de } \\
\text { acesso, contextos de } \\
\text { navegação, transformações } \\
\text { navegacionais. }\end{array}$ & $\begin{array}{c}\text { Mapeamento entre objetos } \\
\text { conceituais e de } \\
\text { navegação. Padrôes de } \\
\text { navegação para a } \\
\text { descrição da estrutura geral } \\
\text { da aplicação. }\end{array}$ & $\begin{array}{l}\text { Considera o perfil do } \\
\text { usuário e as tarefas: } \\
\text { enfatiza os aspectos } \\
\text { cognitivos e arquiteturais. }\end{array}$ \\
\hline $\begin{array}{l}\text { Projeto de Interface } \\
\text { Abstrata }\end{array}$ & $\begin{array}{c}\text { Objetos de interface } \\
\text { abstrata, reações a eventos } \\
\text { externos, transformaçőes } \\
\text { de interface. }\end{array}$ & $\begin{array}{c}\text { Mapeamento entre objetos } \\
\text { de navegação e objet os de } \\
\text { interface. }\end{array}$ & $\begin{array}{c}\text { Modela objetos } \\
\text { perceptiveis, implementa } \\
\text { metáforas escolhidas, } \\
\text { descreve a interface para } \\
\text { objetos navegacionais. }\end{array}$ \\
\hline Implementação & Aplicação executável. & $\begin{array}{c}\text { Recursos fornecidos pela } \\
\text { plataforma de destino. }\end{array}$ & $\begin{array}{l}\text { Promove o desempenho e } \\
\text { a completitude. }\end{array}$ \\
\hline
\end{tabular}

Figura 2.4: Sumário das fases do método OOHDM (Rossi, 1996)

Durante o projeto conceítual, um modelo do domínio da aplicação é construído de acordo com os princípios da orientação a objetos, acrescidos de algumas primitivas, tais como, perspectivas de atributos e subsistemas, usando-se uma notação semelhante à UML. O resultado dessa fase é um esquema composto por subsistemas, classes e relacionamentos. Os mecanismos de agregação e generalização/especialização podem ser usados para especificar as classes conceituais. O principal objetivo dessa etapa é capturar a semântica do domínio da aplicação, sem qualquer preocupação com os tipos de usuários ou tarefas do produto final. 
Uma aplicação é vista no OOHDM como uma visão navegacional do modelo conceitual. Essa visão é construída durante o projeto de navegação, considerando-se agora os tipos de usuários aos quais a aplicação se destina e o conjunto de tarefas que deverão ser desempenhadas pela mesma. Diferentes modelos navegacionais podem ser construídos para o mesmo esquema conceitual, expressando, dessa forma, visões (aplicações) diferenciadas do mesmo domínio.

A estrutura navegacional da aplicação é definida em termos de contextos de navegação, que são induzidos a partir de classes navegacionais, tais como, nós, ligações, âncoras e estruturas de acesso, refletindo a visão escolhida. Os contextos navegacionais expressam a estrutura navegacional da aplicação, enquanto as classes especificam os objetos que serão visualizados pelo usuário. Os contextos navegacionais possuem função similar às coleções propostas por Garzotto et al. (1994), sendo definidos como um conjunto de nós, ligações e outros contextos navegacionais (aninhados) que auxiliam na organização dos objetos navegacionais.

As classes e os contextos navegacionais definem a estrutura estática da aplicação hipermídia. O comportamento dinâmico, isto é, a maneira pela qual a navegação irá proceder, é especificado por diagramas que descrevem as transformações no espaço navegacional, isto é, no conjunto de objetos navegacionais acessíveis em cada instante de tempo.

Durante o projeto de interface abstrata, um modelo de interface é construído. Tal modelo especifica os objetos de interface que serão visualizados pelo usuário, a forma pela qual esses objetos serão apresentados, quais objetos ativarão a navegação, o modo como os objetos multimídia serão sincronizados e quais transformações ocorrerão na interface. A separação entre interface abstrata e modelo de navegação permite a construção de diferentes interfaces para o mesmo modelo navegacional, o que torna o projeto mais flexível quanto às necessidades ou preferências dos usuários e quanto à tecnologia utilizada para a construção da interface.

Para a especificação de interfaces em OOHDM, são usadas "Visões de Dados Abstratas" ou ADVs (Abstract Data Views). As ADVs são modelos formais que têm como objetivo separar o projeto de interface da implementação, proporcionando maior reusabilidade. As ADVs definem os aspectos estáticos dos objetos de interface, o modo como esses objetos estão relacionados aos objetos navegacionais e como reagem a eventos externos.

Finalmente, na última fase, os modelos navegacionais e de interface gerados devem ser traduzidos para um ambiente de implementação, produzindo o sistema hipermídia a ser executado. Os modelos gerados podem ser implementados de forma direta sobre plataformas hipermídia disponíveis, tais como, Hypercard, Toolbook e HTML. Embora o OOHDM tenha sido construído com base nos modelos orientados a objetos (OO), o 
método não exige um ambiente de implementação 00 .

A independência entre os projetos conceitual, navegacional e de interface garante ao método uma de suas principais vantagens: a construção de projetos modulares e reutilizáveis. Publicações mais recentes sobre o OOHDM enfątizam a necessidade de padrões de projeto no processo de desenvolvimento de aplicações|hipermídia, promovendo a reusabilidade de estilos de navegação e interface. Além do reuso de componentes de software e de informação no contexto de projeto, propõe-se a reutilização da experiência de projeto ou das estruturas de projeto (Rossi, Schwabe \& Garrido, 1997).

Desde 1998 os autores do OOHDM também vêm desenvolvendo extensões, que enfatizam o uso de padrões de projeto (design patterns), entre os quais existem padrões arquiteturais, navegacionais e de interface, próprios para as aplicações Web, com o objetivo de adequar o método a essa plataforma (Schwabe \& Rossi, 1998a). A proposta dessas extensões também foi baseada na experiência obtida com o uso do método em projetos de sistemas para a Web. As adequações realizadas abordam, principalmente, aspectos associados à contextualização da informação e ao uso de estruturas de acesso padronizadas para a navegação.

\subsection{UML}

A UML (Unified Modeling Language) é uma linguagem usada para a especificação, visualização, construção e documentação de sistemas de software, assim como para a modelagem de negócios (OMG, 2000). A UML surgiu com o objetivo de suprir a necessidade de criação de uma notação padrão que pudesse ser seguida pelas empresas para o desenvolvimento de sistemas orientados a objetos e que servisse de base para a elaboração de ferramentas. Diante dessa necessidade, as propostas apresentadas inicialmente pelos metodologistas James Rumbaugh, Grady Booch e Ivar Jacobson foram sofrendo um processo de convergência, objetivando a obtenção de uma notação única e comum a todos os processos de desenvolvimento. Assim, os conceitos existentes nos métodos OMT (Object Modeling Technique), Booch e OOSE (Object-Oriented Software Engineering) fundiram-se, gerando uma linguagem de modelagem unificada - a UML - e que pode ser utilizada por esses e outros métodos. Sua criação foi apoiada pela indústria de ferramentas CASE de segunda geração e pelo OMG (Object Management Group), cuja função, dentre outras, é estabelecer padrões de objetos (Barbieri, 1997).

A UML é uma notação gráfica cujo principal objetivo é padronizar os produtos elaborados ao longo dos processos de desenvolvimento, a saber: a modelagem, a notação sintática e os diagramas. Os modelos resultantes, por adotarem uma notação orientada a objetos, permitem a captura dos processos e das entidades manipuladas por estes com 
maior precisão. Os resultados desse tipo de decomposição são sistemas mais flexíveis a mudanças. O segundo objetivo da UML é estabelecer uma linguagem de modelagem utilizável por muitos métodos, ao longo de todo o ciclo de vida, em diferentes tecnologias de implementação. Esse padrão é a base para a reutilização em larga escala e a industrialização do saftware. O terceiro objetivo da UML é estabelecer um mapeamento explícito entre os modelos conceituais e os artefatos executáveis. Sem essa característica, os ganhos de produtividade seriam poucos (Sette, 1998).

A UML é composta por uma série de conceitos e recursos que estimulam a identificação de objetos e classes no problema sob análise, que permitem associar esses objetos e classes aos requisitos do sistema e oferecem um meio para planejar e gerenciar projetos baseados nesses requisitos. O primeiro desses conceitos é o de casos de uso.

Pära a modelagem dos casos de uso, a UML sugere o diagrama de casos de uso, que tem o objetivo de registrar as interações entre os atores (entidades externas) e o sistema. A notação utilizada para representar os atores e os casos de uso é apresentada na Figura 2.5. Um ator é um estereótipo de uma classe e pode representar um usuário ou um outro sistema capaz de interagir com o sistema modelado. Um caso de uso é uma seqüência de transações realizadas pelo sistema em resposta ao disparo de um evento, do ator para o sistema. Os casos de uso podem ter relacionamentos de associação ou de generalização explicitados entre si no diagrama que os modela.

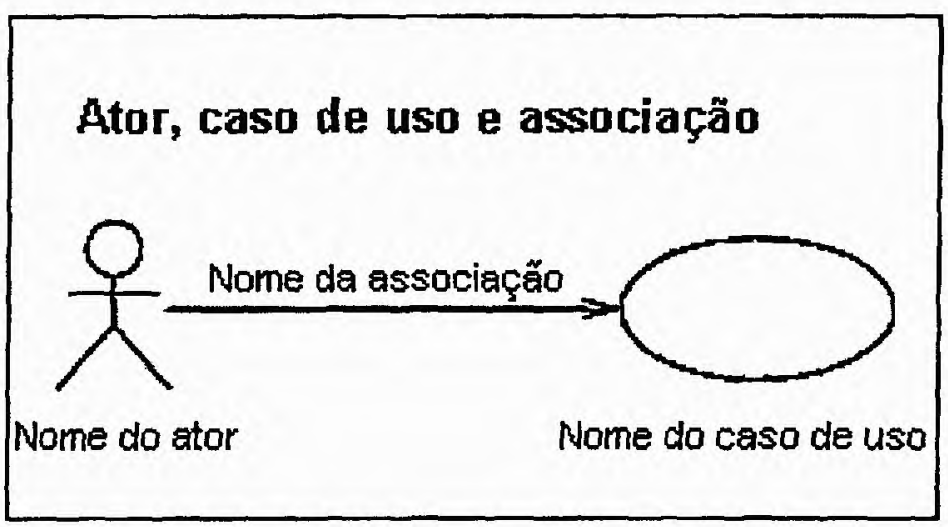

Figura 2.5: Notação para a especificação de casos de uso

Além do diagrama de casos de uso, a UML é composta por mais oito diagramas que apóiam a modelagem da estrutura estática e do comportamento dinâmico e funcional do sistema. A modelagem estática apóia-se nos diagramas de classes e de objetos. A modelagem dinâmica apóia-se nos diagramas de estados, de seqüência, de colaboração e de atividades. Já a modelagem funcional baseia-se nos diagramas de componentes e de execução (Barros, 1998).

Os diagramas de classes e diagramas de objetos têm o objetivo de mostrar as clas- 
ses/objetos em modo estático, sem nenhuma correlação com o tempo. Os diagramas de classes mostram as classes e seus relacionamentos (Figura 2.6). Os relacionamentos interconectam classes, criando relações lógicas entre as mesmas e podem ser dos seguintes tipos: generalização, dependência, associação e agregação. Cada classe possui propriedades (atributos) e métodos (comportamentos). Nos diagramas de objetos, são mostrados os objetos (ocorrências de classes) num determinado instante de tempo. Esses diagramas são semelhantes aos de classes, porém com ênfase nos objetos num momento particular.

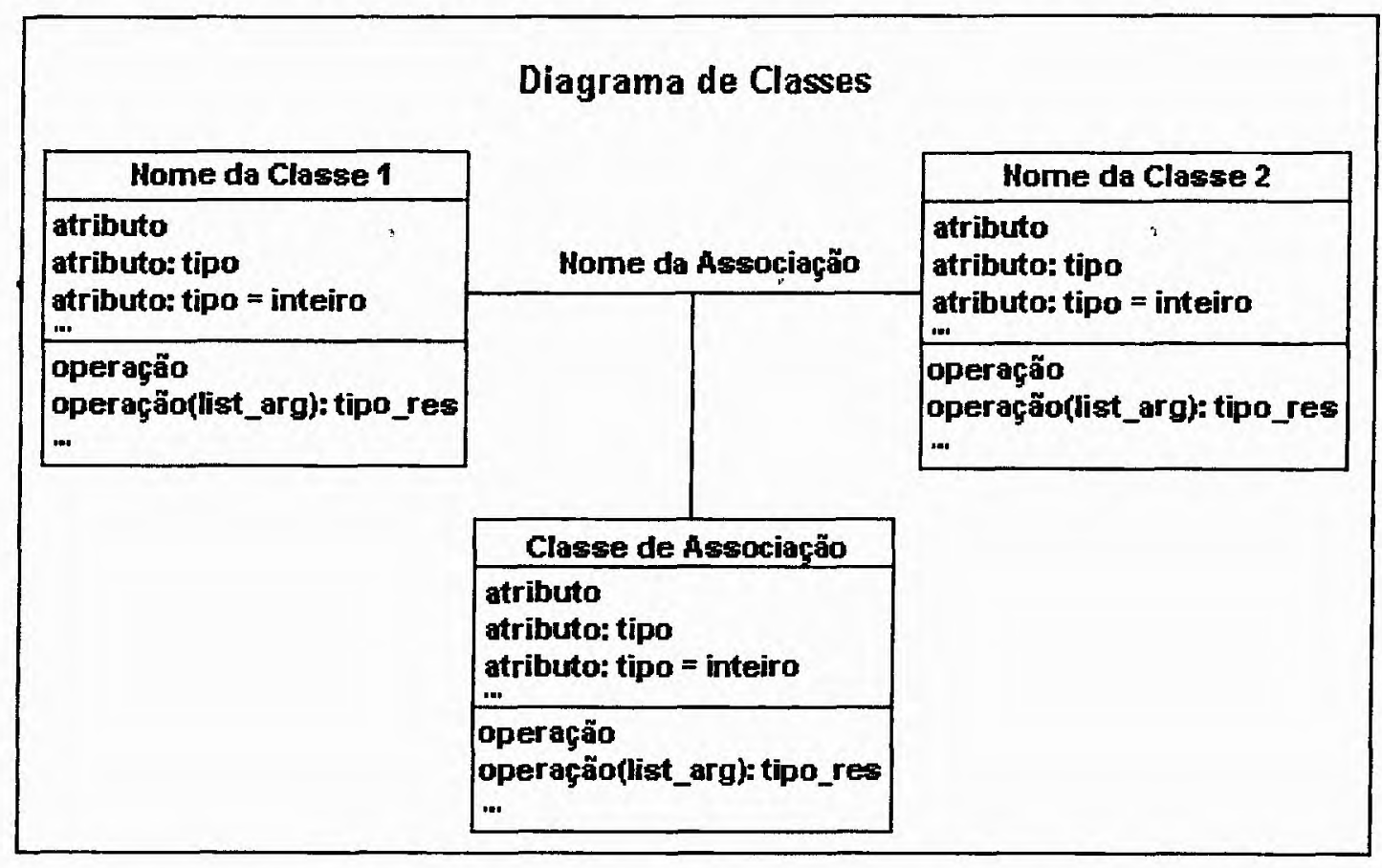

Figura 2.6: Exemplo de uma associação em um diagrama de classes (Rumbaugh et al., 1999)

Com o objetivo de permitir a modelagem dinâmica do sistema, a UML é composta por uma série ampla de diagramas. O diagrama de seqüência, ilustrado na Figura 2.7, mostra as interações (por meio da troca de mensagens) entre os objetos em um período de tempo. Os diagramas de colaboração possuem o mesmo objetivo, porém sem especificação temporal e, além disso, mostram também as associações entre objetos. Já o diagrama de estados permite especificar o ciclo de vida dos objetos e os subsistemas e possui a finalidade de representar todos os estados possíveis que objetos de uma certa classe podem assumir, como reação aos estímulos recebidos. Esse diagrama é um grafo direcionado, composto por estados, eventos e transições.

Os diagramas de atividades são casos especiais de diagramas de estados, em que as transições são disparadas quando se encerra a atividade associada ao estado ativo. A finalidade desse diagrama é focalizar fluxos dirigidos por processamento interno, ao invés de eventos externos. 
Para representar o estado de implementação do sistema, a UML oferece os diagramas de componentes e de execução. O primeiro evidencia as classes, agora sob o ponto de vista de componentes de software, mostrando as dependências existentes entre esses componentes (código fonte, código binário, componente executável). O diagrama de execução é baseado no diagrama de processos do método Booch e mostra a distribuição dos processadores e respectivos componentes de software neles localizados, além de dispositivos de entrada e saída. Esse diagrama mostra a organização do hardware e a ligação do software com os dispositivos físicos.

Apesar da UML ter sido aceita pelo OMG como a linguagem oficial para a modelagem de sistemas baseados em objetos e de seus conceitos e recursos serem capazes de modelar uma grande variedade de sistemas, estudos recentes revelam algumas deficiências da linguagem com relação à modelagem de aplicações para a Web, considerando-se que tais, aplicações incluem muitos mecanismos tecnológicos que não são adequadamente tratados pela notação (Conallen, 1999b).

Por exemplo, uma mesma página de uma aplicação Web pode possuir comportamentos diferenciados no servidor e no cliente, isto é, existem operações que são executadas no lado do servidor, como preparação do conteúdo dinâmico, que não são executadas no lado do cliente e vice-versa. As diferenças presentes no comportamento dinâmico de um objeto não podem ser ignoradas pelos modelos, caso contrário o sistema não estará sendo representado apropriadamente. A UML tradicional, porém, não apóia esse tipo de representação, pois não é capaz de distinguir o comportamento de uma mesma página no

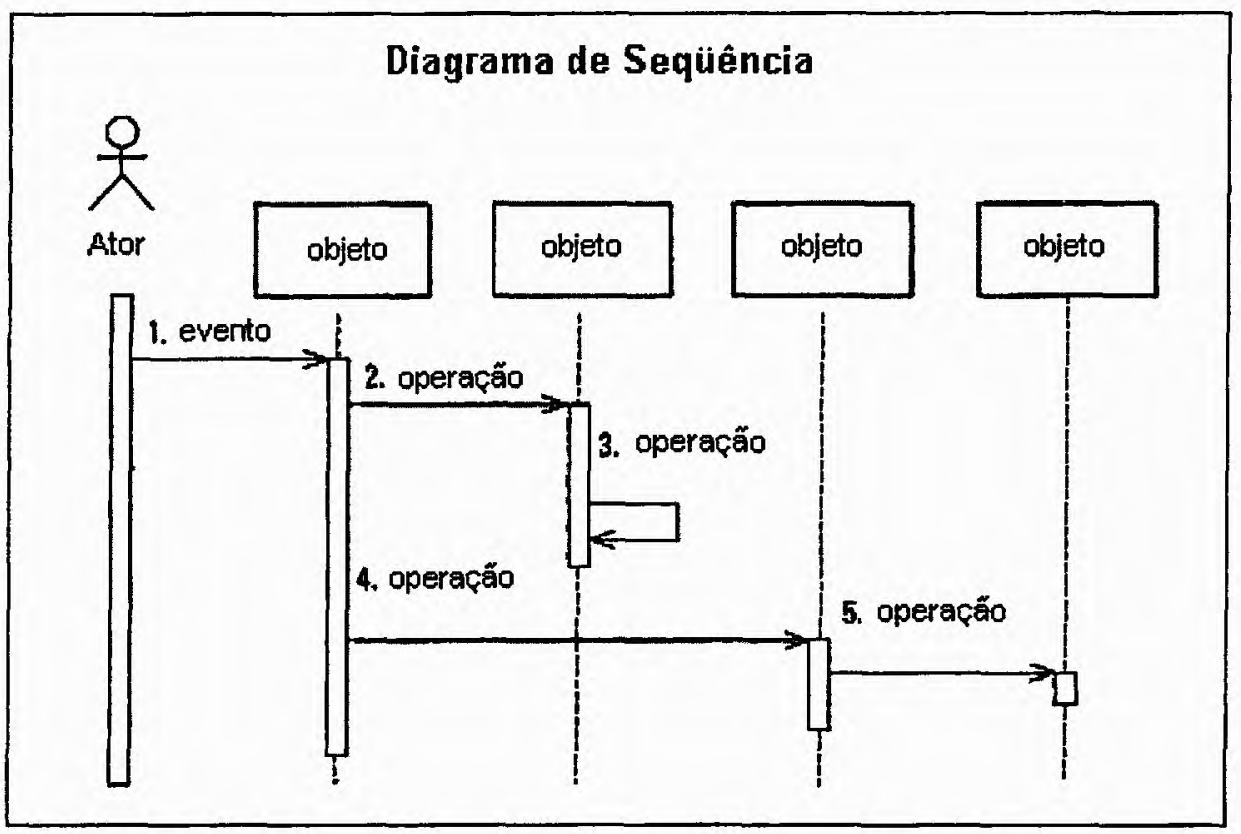

Figura 2.7: Exemplo de diagrama de seqüência (Rumbaugh et al., 1999) 
servidor e no cliente.

Com o objetivo de suprir essas deficiências, mecanismos foram definidos para estender a semântica da UML. Tais mecanismos permitem a definição de novos estereótipos, valores rotulados e restrições. Os estereótipos permitem a definição de novas características semânticas para os elementos modelados. Os valores rotulados são usados para definir os parâmetros passados juntamente com a ativação de uma ligação, que equivale a uma requisição de página. Esses valores normalmente são usados para identificar a página requisitada. As restrições são regras que definem possíveis limitações dos elementos do modelo.

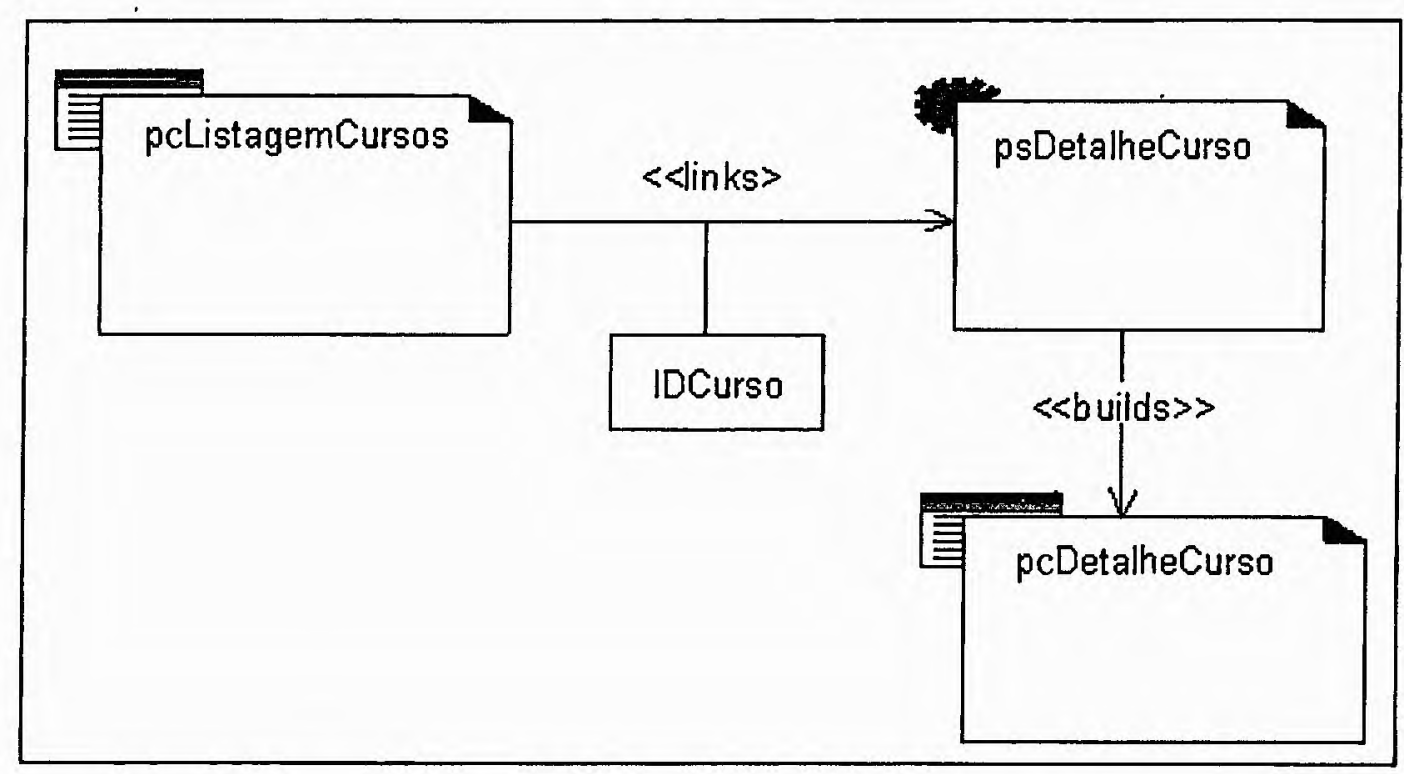

Figura 2.8: Exemplo da aplicação das extensões feitas à UML (Conallen, 1999c)

Com as extensões, o comportamento de uma página no servidor pode ser modelado por uma classe e o comportamento no cliente, por outra, diferenciando-as pela utilização do mecanismo de extensão da UML que define os estereótipos "cliente" e "servidor", ilustrados na Figura 2.8. A principal vantagem de separar os dois aspectos de uma página em diferentes classes é a facilidade de representar os relacionamentos entre as páginas e as demais classes do sistema. Relacionamentos também podem ser estereotipados representando ligações, representando a relação entre páginas do cliente e do servidor e a relação entre formulários e páginas do servidor (Conallen, 1999b).

As extensões feitas à UML oferecem aos projetistas uma solução comum para a modelagem de características e elementos específicos das aplicações Web, permitindo a abstração completa de todo o domínio em questão e ampliando a utilização da notação. 


\section{$2.6 \quad W 2000$}

O W2000 é um framework para o projeto de aplicações baseadas na Web, proposto por Baresi, Garzotto \& Paolini (2001), que integra duas técnicas preexistentes: a linguagem UML e o modelo HDM. Na Figura 2.9, são apresentadas as atividades de projeto que compõem o framework. A figura ilustra as relações de interdependência entre as tarefas e indica quais são as atividades que podem ocorrer em paralelo.

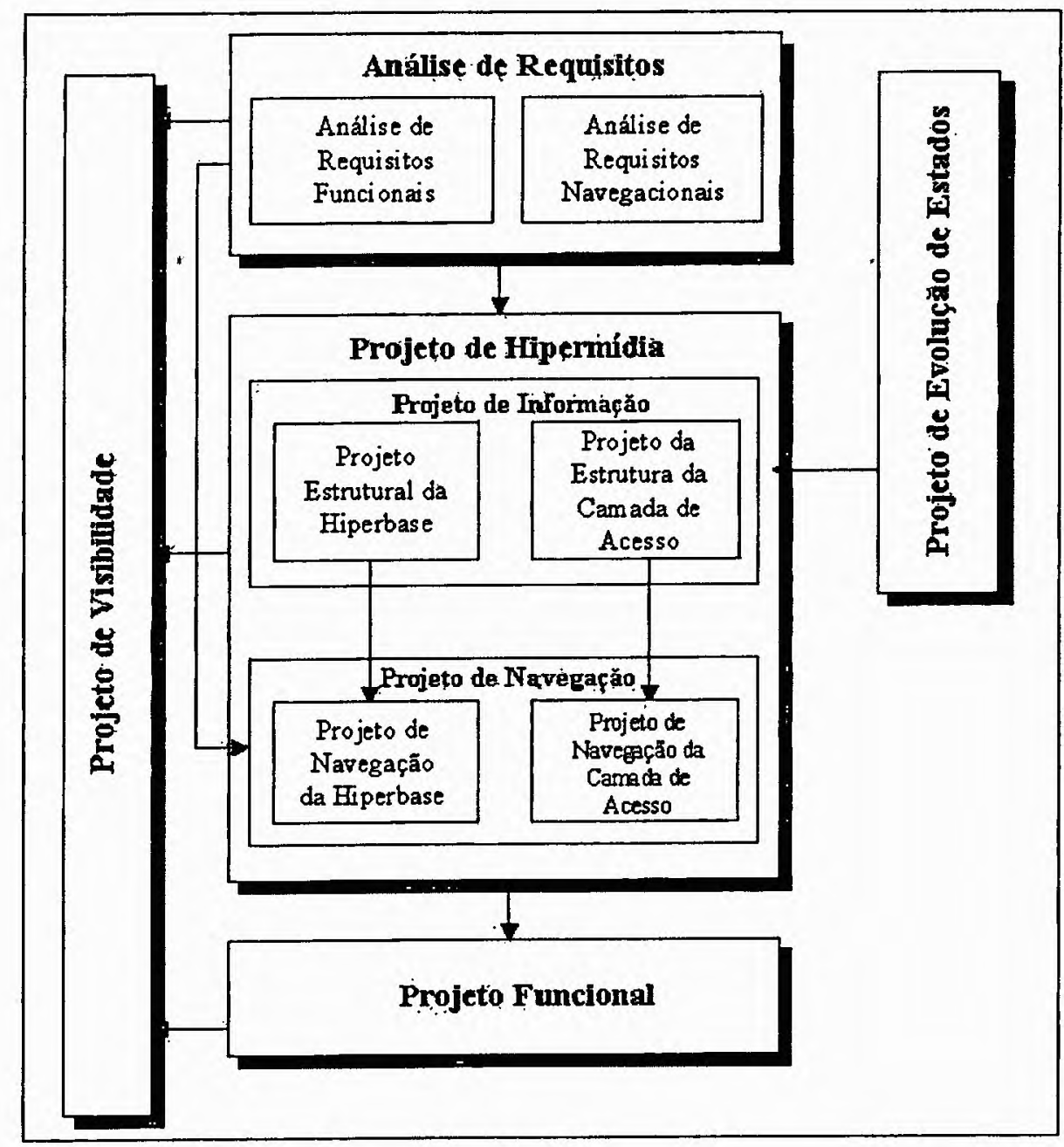

Figura 2.9: Atividades do framework W2000 (Baresi et al., 2001)

A primeira atividade, que corresponde à análise de requisitos, divide-se em duas partes: a análise de requisitos funcionais e a análise de requisitos navegacionais. A primeira delas identifica as operações do sistema, ou seja, as funcionalidades que transpõem os limites da aplicação e que são ativadas externamente. A segunda define as possibilidades de visão e de acesso às informações, para cada classe de ator, durante a navegação. Para a modelagem de ambas são utilizados os diagramas de casos de uso da UML. Desse modo, o conceito de caso de uso é estendido para apoiar também a análise de requisitos 
navegacionais.

$O$ projeto de hipermídia também subdivide-se em dois blocos principais correspondentes ao projeto de informação e ao projeto de navegação. No primeiro, o domínio e o conteúdo da aplicação é especificado e organizado. Durante essa atividade é realizado o projeto estrutural da hiperbase, no qual as informações armazenadas pelo sistema são estruturadas para serem disponibilizadas aos usuários, e o projeto da estrutura da camada de acesso, que organiza o conteúdo em estruturas de mais alto nível, tais como as coleções do HDM, que agrupam, ordenam ou restringem as informações apresentadas, contextualizando-as ou agregando aspectos semânticos às suas estruturas. No segundo bloco de atividades são definidas as estruturas de acesso e a forma como os usuários navegam pelos elementos de informação. Todos os modelos resultantes dessa etapa de projeto baseiam-se na integração dos conceitos do HDM aos modelos de, classes da UML, nos quais são utilizados estereótipos apropriados para a caracterização dos seus elementos. Esta etapa é melhor detalhada posteriormente.

O projeto de evolução de estados complementa a análise de requisitos e define como o conteúdo da aplicação evolui. Essa não é uma atividade obrigatória para todas as aplicações, mas deve ser realizada para aquelas que são formadas por objetos cuja mudança de estado afeta significativamente o comportamento do sistema. Para a representação dos possíveis estados assumidos por um objeto da aplicação e das condições que determinam essa evolução, são utilizados os diagramas de estados da UML.

No projeto funcional são especificadas as principais atividades ou operações do sistema. No framework W2000, a tradicional modelagem funcional é estendida para abordar também funcionalidades específicas das aplicações hipermídia. Para isso são construídos cenários, contendo todas as atividades identificadas no diagrama de casos de uso funcionais, nos quais são explicitados os objetos relevantes do sistema e as cooperações existentes entre eles para a completa execução de uma atividade. O projeto funcional pode ser expresso por extensões feitas a qualquer um dos diagramas de interação da UML, ou seja, por diagramas de seqüência ou diagramas de colaboração estendidos.

No projeto de visibilidade são definidas as diferentes visões ou perspectivas do sistema, sob o ponto de vista dos diferentes atores. As visões têm como objetivo agrupar porções de informação, operações e estruturas de acesso e navegação e determinar quais desses elementos devem estar disponíveis para quais perfis de usuário.

A etapa do framework na qual ocorre, de fato, a integração entre a UML e o HDM é o projeto de hipermídia. De acordo com o HDM, o projeto de hipermídia é organizado em duas camadas distintas: a camada da hiperbase, que define os objetos básicos de informação, as associações entre eles e os caminhos navegacionais necessários para percorrê-los; e a camada de acesso, que introduz alternativas para o agrupamento e para a 
organização dos elementos de informação e define como os usuários iniciam a navegação pelo hiperespaço. Essas duas camadas, por sua vez, apresentam aspectos associados à informação e à navegação.

No projeto estrutural da hiperbase, a informação é organizada em tipos de entidades, tipos de componentes e tipos de associações semânticas, como ocorre no HDM. Esses elementos, no entanto, são representados usando os diagramas de classes da UML e são identificados pelo uso de estereótipos específicos (Figura 2.10). O uso do diagrama de classes possibilita a modelagem de relações de herança, de dependência e de agregação entre as entidades e seus componentes.

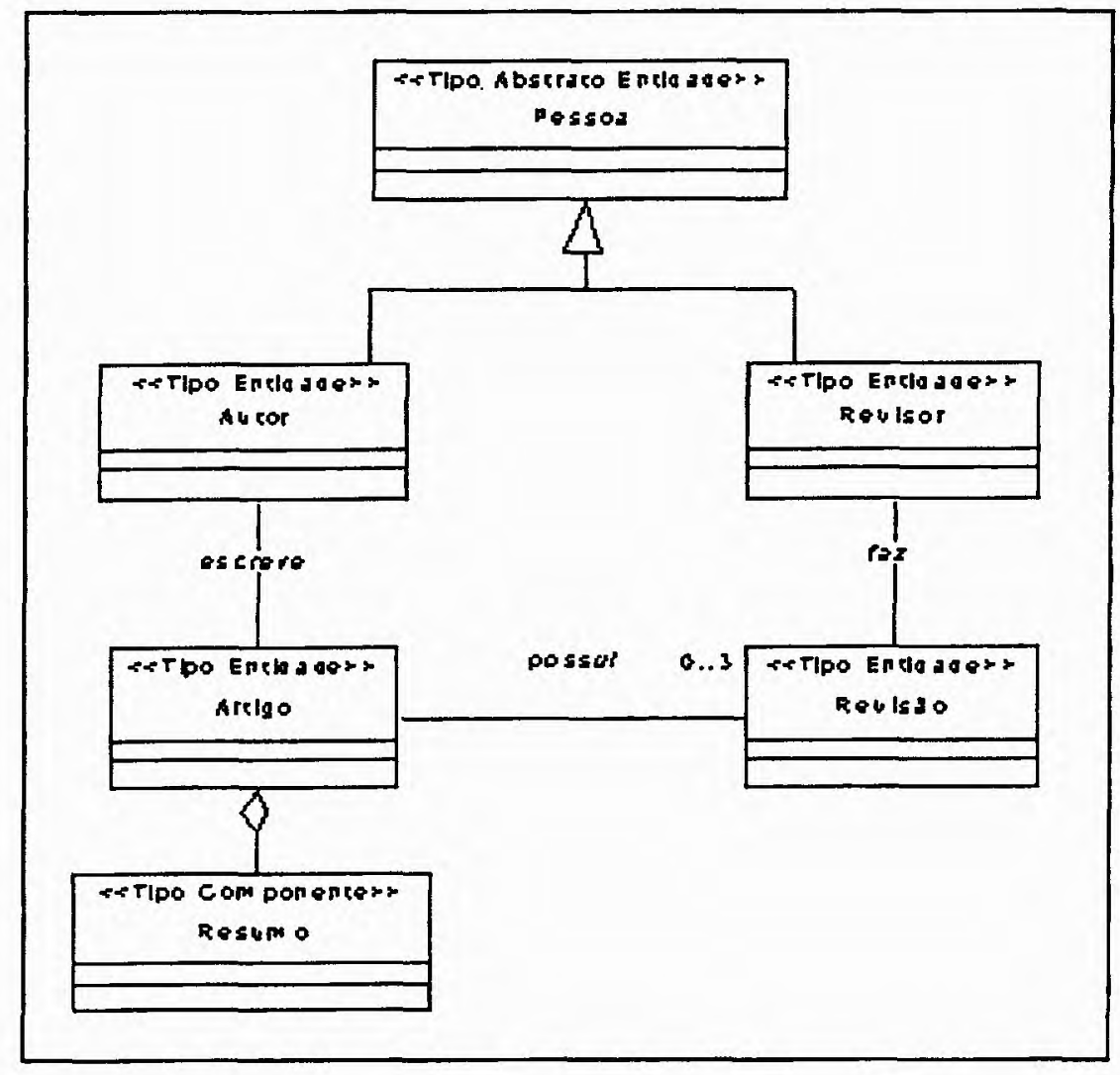

Figura 2.10: Projeto estrutural da hiperbase

Os atributos ou slots, de acordo com o jargão do HDM, pertencentes a uma associação semântica, são definidos como elementos de um centro (center). O centro de uma associação semântica é a estrutura de informação utilizada pelos usuários para navegar por essa associação. Um centro pode conter, por exemplo, atributos que descrevem os objetos conectados, auxiliando os usuários a identificar e selecionar os objetos de seu interesse antes mesmo de efetivar a navegação.

O projeto de navegação da hiperbase define os nodos e as ligações (links) navegacionais da aplicação. Os nodos, que são derivados dos elementos do projeto estrutural, são unida- 
des de informação perceptíveis e navegáveis pelos usuários. Normalmente, correspondem a páginas da Web ou a porções bem definidas de informação existentes em um página. Os nodos também são identificados por estereótipos e são representados por classes de interface, usando a notação da UML. Uma ligação é um caminho que interconecta dois nodos e que corresponde a uma associação entre as classes de interface. As ligações podem ser semânticas ou estruturais. A topologia de navegação é hierárquica, como mostra a Figura 2.11. Ao nodo raiz é atribuído o símbolo "@”, que indica que esse é o nodo default, ou seja, é a partir dele que todos os usuários iniciam a navegação.

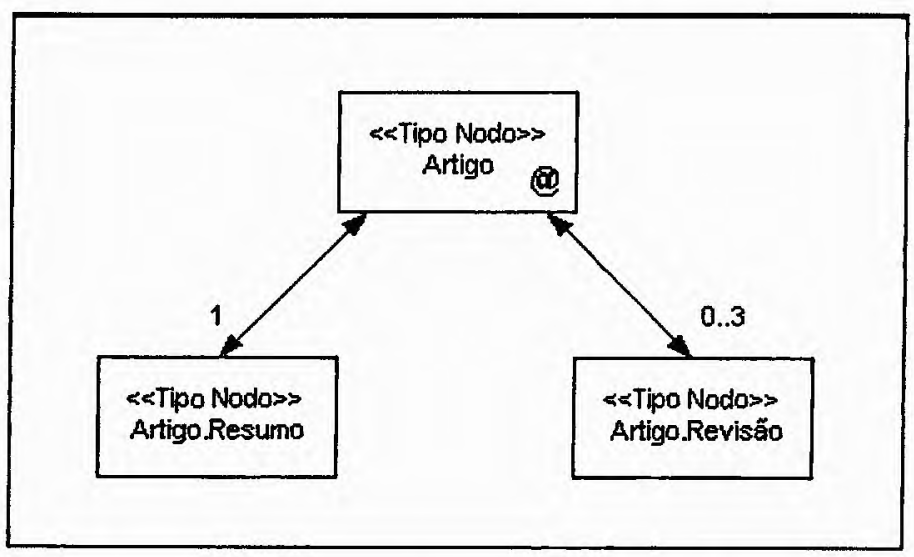

Figura 2.11: Projeto de navegação da hiperbase

O projeto de navegação não pode ser automaticamente gerado a partir do projeto estrutural da informação, mas deve ser consistente com ele. Para a sua construção, algumas decisões de projeto são tomadas e o modelo obtido como resultado incorpora estruturas de navegação baseadas em padrões de projeto, que correspondem a soluções predefinidas para problemas bem conhecidos, associados à navegação em aplicações hipermídia (Rossi, Schwabe \& Lyardet, 1999a). Os exemplos de padrões de navegação mais comumente utilizados são os índices, os roteiros guiados e os roteiros guiados indexados. Na Figura 2.12, é ilustrado o uso de um índice, que permite o acesso às revisões de um artigo por intermédio de um centro.

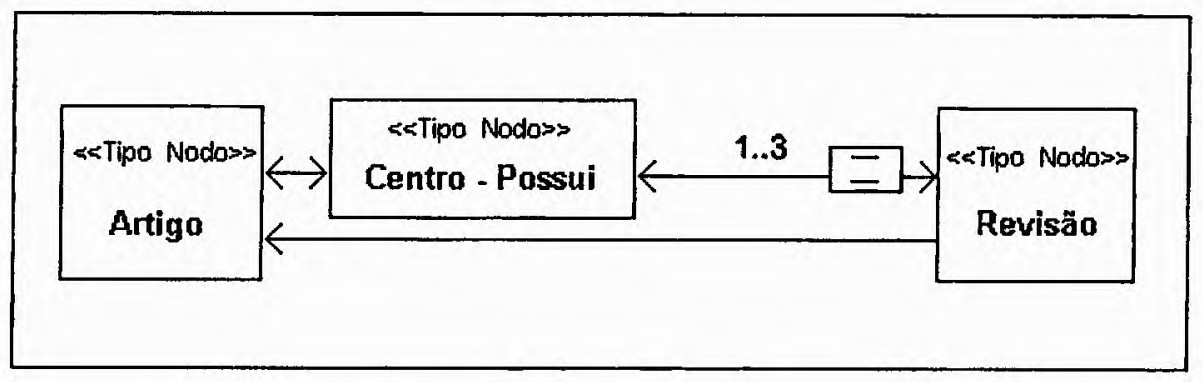

Figura 2.12: Uso de padrões de navegação (Baresi et al., 2001) 
Durante o projeto da estrutura da camada de acesso é realizada a definição de estruturas sobrepostas à hiperbase, que descrevem modos alternativos de organização do conteúdo da aplicação, de forma a facilitar o seu entendimento pelos usuários. O modelo que representa esse projeto, portanto, é composto por coleções, que definem critérios de seleção ou organização dos seus elementos, os quais podem ser instâncias de uma entidade, de um componente, de uma associação ou de outra coleção. Comumente, as coleções estão associadas a um centro, cujo principal objetivo é fornecer informações suficientes para que os usuários possam identificar quais são os membros que compõem a coleção. Os elementos que definem um centro, normalmente, são atributos pertencentes a membros da coleção e que servem como âncoras ou pontos de origem de uma navegação. Um exemplo da notação utilizada para a representação de coleções e centros é apresentado na Figura 2.13 .

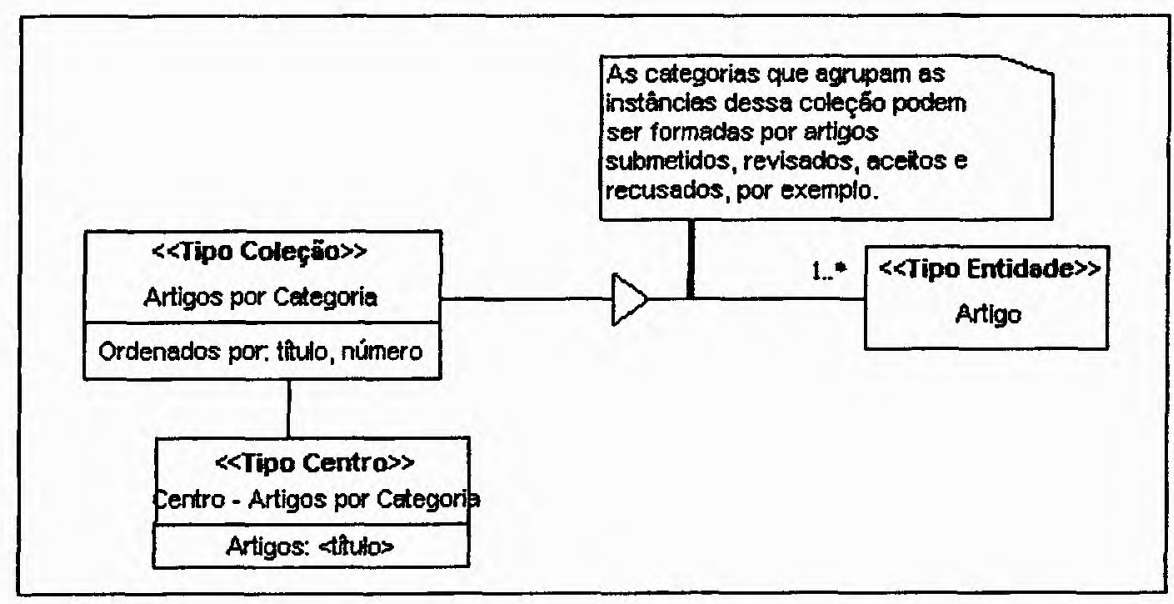

Figura 2.13: Projeto da estrutura da camada de acesso (Baresi et al., 2001)

Finalmente, o projeto de navegação da camada de acesso consiste na definição das ligações que compõem cada coleção. Esses conjuntos de ligações definem como os usuários podem navegar entre um centro e os membros de uma coleção e entre as suas várias instâncias. O que de fato ocorre nessa etapa é a associação de coleções, isto é, de critérios de seleção e de organização, a estruturas de navegação. Essas associações possibilitam a modelagem de estruturas de acesso dinâmicas, que são muito comuns nas aplicações para a Web.

\subsection{Considerações Finais}

Um dos objetivos deste trabalho é verificar a adequação dos modelos e métodos pesquisados quanto à especificação de aplicações para a Web. Segundo Conallen (1999b), existem alguns requisitos fundamentais que devem ser satisfeitos pelos métodos para a realização 
dessa tarefa como, por exemplo, a capacidade de modelar os mecanismos tecnológicos usados na implementação da lógica de negócios presente nas atuais aplicações para a Web. Alguns desses mecanismos referem-se às visões, às estruturas de acesso e de navegação e às estruturas de informação, por exemplo, que necessitam ser modeladas uma vez que contribuem significativamente para a execução das regras de negócios. Outra característica importante é a modelagem do comportamento dinâmico do sistema. As aplicações para a Web, comumente, são compostas por páginas cujos conteúdos são criados dinamicamente ou cujo comportamento no lado do cliente difere do comportamento no lado do servidor e isso deve ser especificado no momento de representar o sistema.

Um método apropriado para a especificação de aplicações para a Web deve ser capaz de modelar páginas, ligações e relacionamentos entre as páginas, o conteúdo estático $\mathrm{e}$ dinâmico de cada página, a seqüência de navegação, a çriação de conteúdo dinâmico, os controles, os diferentes comportamentos apresentados e demais mecanismos que afetam a execução do sistema. Deve ser avaliada, portanto, a habilidade dos métodos revisados em expressar a execução da lógica de negócios do sistema, em termos de elementos e tecnologias específicos para a Web.

Dentre os modelos pesquisados, os diagramas e a notação utilizada pela UML parecem ser os mais apropriados para a modelagem da categoria de sistemas em foco, excetuando-se algumas limitações identificadas mas que já estão sendo tratadas por extensões propostas para a linguagem. Devido à ausência de recursos para a modelagem de alguns elementos específicos das aplicações Web, deve ser considerada a integração da UML a outras notações ulizadas por modelos próprios para a reprsentação de aplicações hipermídia. Desse modo, alguns símbolos devem ser incorporados aos modelos da UML para que esses também possam ser utilizados para modelar o projeto estrutural de informação e o projeto de navegação, por exemplo.

Analisando brevemente as técnicas apresentadas neste capítulo, verifica-se que a solução proposta pelos autores do framework W2000 é a que mais aproxima-se do objetivo deste trabalho. Isso porque além de enfatizar e representar com detalhes os aspectos associados aos sistemas de informação para a Web, o framework ainda define atividades relacionadas ao projeto funcional do sistema, o que corresponde a uma introdução para a modelagem de workflows. No entanto, no projeto funcional sugerido somente são identificadas as operações do sistema, isto é, ações iniciadas externamente por usuários ou sistemas integrados. Os métodos, as tarefas automatizadas e as respostas do sistema às interações com os atores externos não são consideradas e, desse modo, não é possível representar completamente um fluxo de trabalho ou processo de negócio, utilizando o W2000. 


\section{Capítulo 3}

\section{Sistemas Baseados em Fluxo de Trabalho (Workflow)}

\subsection{Considerações Iniciais}

Este capítulo contém um levantamento de métodos e notações utilizados para a especificação de sistemas baseados em fluxo de trabalho ou sistemas workflow que implementam processos genéricos ou, em particular, processos administrativos.

Na Seção 3.2 são apresentadas algumas das definições mais aceitas para sistemas workflow, embora ainda não exista um consenso a esse respeito. Também são descritas algumas das possivieis classificações que caracterizam esses sistemas. A Seção 3.3 contém uma descrição das fases que compõem o método Business Process Implementation, voltado para a modelagem $\mathrm{e} o$ desenvolvimento de sistemas baseados em fluxo de trabalho administrativo, e das propostas de padronização da terminologia e dos conceitos envolvidos pelos processos de workflow criadas pela WfMC. Na Seção 3.3 também é descrito um modelo baseado nos padrões da WfMC para a especificação de um sistema de workflow voltado para a gestão de documentos.

\subsection{Processos de Workflow}

Não existe uma definição única para fluxo de trabalho ou workflow. Entretanto, podese dizer que esse conceito baseia-se na noção de processos administrativos, os quais se concentram nos aspectos que determinam rotinas de trabalho. Tais processos agrupam atividades de trabalho em tarefas bem definidas, papéis, regras e procedimentos que regem o trabalho. Desse modo, os workflows têm como objetivo descrever os fatores de um processo de trabalho relevantes para controlar e coordenar a execução de suas tarefas e 
possivelmente as habilidades de indivíduos requeridas para executar cada tarefa.

Os processos, portanto, definem regras de negócios que regulamentam o workflow. As regras de negócio determinam não só as atividades que devem ser executadas, mas a seqüência na qual a execução deve ocorrer e quais são as condições necessárias para a realização de cada atividade. Sendo assim, as regras impõem restrições ao fluxo de trabalho e delegam responsabilidades.

Os sistemas baseados em fluxo de trabalho ou sistemas workflow, por sua vez, têm como objetivo automatizar completa ou parcialmente as atividades do processo de trabalho, obedecendo às regras de negócio. No caso da automatização parcial, o sistema dá apoio à coordenação e colaboração de pessoas que implementam o processo. A automatização é válida, pois aumenta a eficiência do trabalho e o mantém consistente.

Quanto aos tipos de workflow existentes, as publicações comerciais normalmente fazem distinção entre três categorias de workflow: ad hoc, administrativo e de produção. Normalmente essas categorias de workflow são descritas com base em características que envolvem repetitividade e previsibilidade de tarefas e fluxos de trabalho; a maneira como o workflow é iniciado e controlado (controle humano ou automatizado) e requisitos para a funcionalidade do sistema gerenciador de workflow (Georgakopoulos, Hornick \& Sheth, 1995).

Os workflows ad hoc executam processos de escritório, tais como propostas de vendas, nos quais não existe um padrão para a movimentação e transferência de informação entre os participantes. As tarefas de um workflow ad hoc tipicamente envolvem coordenação, colaboração ou co-decisão humana. Desse modo, a ordenação e coordenação de tarefas nessa categoria de workflow não são automatizadas, mas controladas por serem humanos, e as decisões são tomadas enquanto o workflow é executado. Workflows ad hoc normalmente envolvem pequenos grupos de profissionais e têm como objetivo apoiar atividades de curta duração que requerem uma solução rápida.

Os sistemas gerenciadores que apóiam workflows ad hoc devem oferecer funcionalidades que facilitem a coordenação, colaboração e co-decisão humana. O controle de atividades manuais e da ordenação de tarefas, no entanto, são funcionalidades que geralmente não são tratadas pelos sistemas gerenciadores de workflow. Sendo assim, os usuários devem acessar o sistema gerenciador para notificar a finalização de um determinado trabalho e dar prosseguimento ao processo. Como as atividades são essencialmente manuais, os gerenciadores ad hoc não realizam funções críticas, o que significa que eventuais falhas do sistema não interferem significativamente no progresso do fluxo de trabalho. As tecnologias atualmente utilizadas pelos sistemas gerenciadores englobam desde o correio eletrônico até sistemas de conferência e agendas em grupo. Esses sistemas normalmente utilizam uma base de dados proprietária para armazenar informações compartilhadas. Os sistemas 
gerenciadores de workflow ad hoc também são chamados de groupware.

Um workflow administrativo envolve processos repetitivos e previsíveis com regras simples de coordenação de tarefas, tais como o roteamento de um relatório de despesas ou uma solicitação de viagem por intermédio de um processo de autorização. A ordenação e coordenação de tarefas em um workflow administrativo podem ser automatizadas. Os sistemas gerenciadores que apóiam workflows administrativos tratam do roteamento de informações e funções de aprovação de documentos. Workflow administrativos não abrangem um processo de informação complexo e não requerem acesso a múltiplos sistemas de informação usados para apoiar a produção e/ou serviços a clientes. Os sistemas gerenciadores administrativos geralmente não são críticos para o negócio. A infra-estrutra tecnológica utilizada por essa categoria de sistemas baseia-se tipicamente em correio eletrônico.

Os workflows de produção envolvem processos repetitivos e previsíveis, como aplicações de empréstimo ou solicitações de seguro. Diferentemente dos administrativos, os workflows de produção tipicamente englobam um complexo processo de informação que envolve acesso a múltiplos sistemas de informação. A ordenação e coordenação de tarefas nesses workflows também podem ser automatizadas. Entretanto, a automação de workflows de produção é complicada devido à complexidade do processo de informação e à necessidade de acesso a múltiplos sistemas de informação para a execução do trabalho e para a recuperação de dados para as tomadas de decisão. Um sistema gerenciador que apóia essa categoria de workflows deve fornecer facilidades para a definição de dependências de tarefas e para o controle de execução de tarefas com pouca ou nenhuma intervenção humana. Sistemas gerenciadores de produção normalmente desempenham funções críticas para o negócio e devem lidar com a integração e interoperabilidade de sistemas de informação heterogêneos, autônomos e distribuídos (sistemas HAD).

Uma segunda classificação, proposta por Georgakopoulos et al. (1995), categoriza os workflows de acordo com o modo como são implementados e possíveis graus de automatização, que se estendem de orientados a humanos a orientados a sistemas. Em um dos extremos, encontram-se os workflows orientados a humanos, que envolvem colaboração humana na execução e coordenação de tarefas. Nesse contexto, o requisito de um sistema gerenciador é apoiar a colaboração e coordenação entre os participantes do processo, aumentando sua produtividade. Os participantes, no entanto, devem assegurar a consistência de documentos e resultados do workflow.

No extremo oposto, estão os workflows orientados a sistemas, os quais envolvem sistemas baseados em computador que executam operações intensivas de computação e tarefas de software especializadas. Além de serem altamente automatizados, também acessam sistemas de informação HAD. Desse modo, workflows orientados a sistemas controlam 
e coordenam tarefas de software, portanto suas implementações devem incluir softwares para controle de concorrência e técnicas de recuperação para assegurar a consistência e a confiabilidade das informações. No caso dos sistemas automatizados, a consistência dos dados pode e deve ser garantida pelos sistemas gerenciadores, pois esses possuem conhecimento de informações semânticas embutido em suas atividades. Isso, no entanto, não é requerido e não pode ser provido pelos sistemas que gerenciam workflows orientados a humanos, uma vez que tais sistemas não possuem conhecimento real da semântica das informações processadas. A responsabilidade, portanto, pela consistência dos dados é atribuída aos participantes do processo que somente são assistidos pelo sistema gerenciador.

Com relação aos workflows orientados a humanos, as principais questões envolvidas são:

- interação homem-computador;

- casamento das habilidades humanas com os requisitos das tarefas;

- mudança da cultura do escritório, isto é, como as pessoas necessitam ou preferem trabalhar.

Quanto aos workflows orientados a sistemas, as questões tratadas incluem:

- casamento dos requisitos do processo de negócio com as funcionalidades e dados providos pelos sistemas de informação e/ou suas aplicações;

- interoperabilidade entre sistemas HAD;

- identificação de tarefas de software apropriadas para executar tarefas do workflow;

- determinação de novos softwares requeridos para automatizar o processo de negócio;

- garantia da corretitude e confiabilidade na execução do sistema.

\subsection{Métodos para Especificação de Workflow}

\subsubsection{Business Process Implementation}

O Business Process Implementation (BPI) é um método para a especificação de sistemas workflow proposto por Jackson \& Twaddle (1997). Segundo esses autores, um sistema workflow é definido pelas seguintes características: as relações de negócios e as obrigações são de longo prazo, isto é, o sistema é composto por atividades que possuem uma certa 
duração; as interações entre os usuários e o sistema são restritas a seqüências de operações válidas e devem satisfazer aos requisitos especificados; o propósito do sistema deve ser apoiar o trabalho dos usuários, o que significa fornecer-lhes as informações de que necessitam, assegurar que somente seqüências de operações válidas sejam executadas e garantir que a ordem de execução de tarefas previamente estabelecida seja seguida.

De acordo com o método BPI, o workflow divide-se em atividades que correspondem às interações de negócios e estas subdividem-se em tarefas. As atividades duram um certo período de tempo, durante o qual elas passam por diversos estágios e assumem diferentes estados. Desse modo, torna-se necessário o armazenamento de um conjunto de informações sobre a história das atividades, que deve ser mantido durante os períodos de inatividade e recuperado quando a execução da atividade tiver prosseguimento. A ordem de execução dessas atividades é regida pelas regras de negócios que impõem restrições à execução. O sistema deve automatizar as atividades que não dependem de entradas de usuários ou de tomadas de decisão e deve garantir que o trabalho esteja sendo desenvolvido de acordo com as regras de negócios.

O método BPI define quatro fases de desenvolvimento, que são: elaboração do modelo de entidades; elaboração do modelo de interações de negócios; definição das tarefas de negócios e definição do fluxo de trabalho (workflow). Essas quatro fases são descritas mais detalhadamente a seguir.

\subsubsection{Elaboração do Modelo de Entidades}

Durante a primeira fase, é realizada a modelagem estática, ou seja, é construído um modelo de dados em termos de entidades, relacionamentos e atributos, que contém informações relevantes para a condução do negócio. As associações entre as entidades são representadas por atributos associativos, que são ponteiros para a entidade relacionada, ou por entidades de ligação. Uma entidade de ligação pode representar uma associação entre duas ou mais entidades e, normalmente, corresponde ao conceito de relacionamento

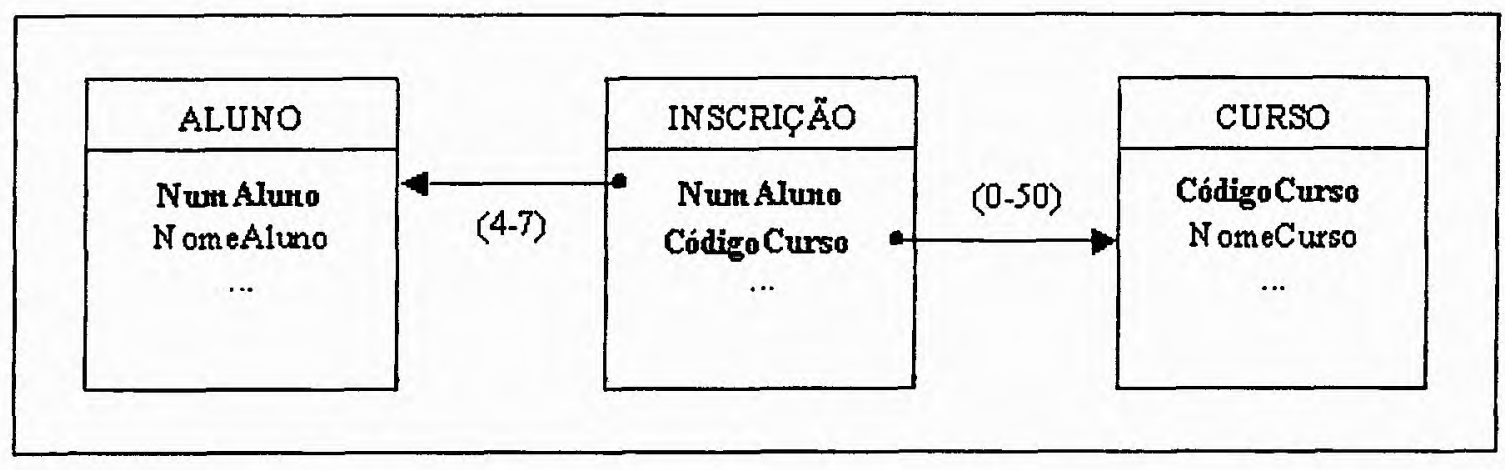

Figura 3.1: Exemplo de entidade de ligação e atributos associativos 
do modelo de entidades e relacionamentos tradicional. As entidades de ligação também possuem ponteiros representados por atributos que contêm o identificador das entidades relacionadas.

Durante a modelagem estática, também ocorre a definição de papéis. Diferentes instâncias de entidades de uma mesma classe podem assumir diferentes papéis. Os atributos pertencentes a cada papel são formados por um subconjunto dos atributos da classe da entidade, sendo que o papel define qual deve ser esse subconjunto. Um mesmo papel também pode ser assumido por entidades de diferentes classes, como apresentado na Figura 3.2.

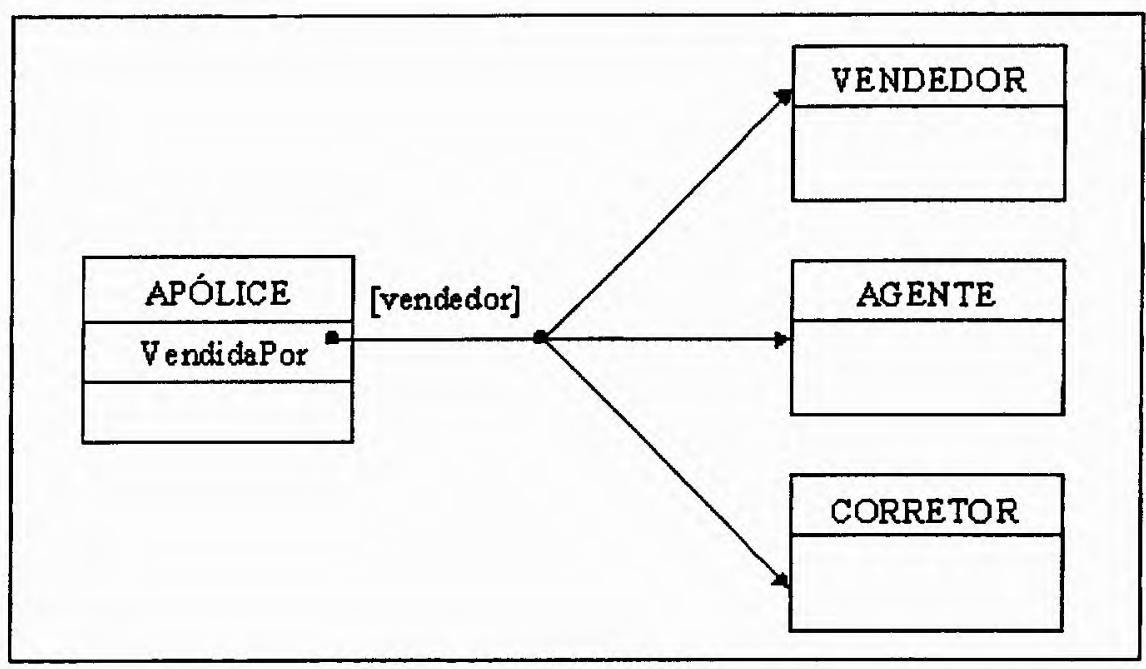

Figura 3.2: Exemplo de diferentes entidades que assumem um mesmo papel

\subsubsection{Elaboração do Modelo de Interações de Negócios}

Na segunda fase, é construído o modelo dinâmico ou modelo de processos. Nessa etapa, são identificadas as restrições relativas às seqüências de operações válidas, isto é, interações de negócios permitidas, e são definidos os ciclos de vida das entidades, suas fases e suas tarefas.

Os ciclos de vida, definidos durante a modelagem dinâmica, são sequiências de fases, relativas ao período de atividade de uma entidade, que progridem em uma ordem definida. Os ciclos de vida são divididos em fases que, por sua vez, são compostas por tarefas e subtarefas. As tarefas correspondem a blocos de atividades fundamentais que constituem as interações de negócio. Existem ainda tarefas independentes e externas aos ciclos de vida que, normalmente, são responsáveis pelo início dos mesmos, como representado na Figura 3.3. Cada ciclo de vida pode assumir diferentes estados que indicam a posição de um objeto em relação às fases do ciclo de vida. Existem quatro estados possíveis: na fase $\mathrm{N}$, falha na fase $\mathrm{N}$, aguardando a fase $\mathrm{N}$ e parado na fase $\mathrm{N}$. 


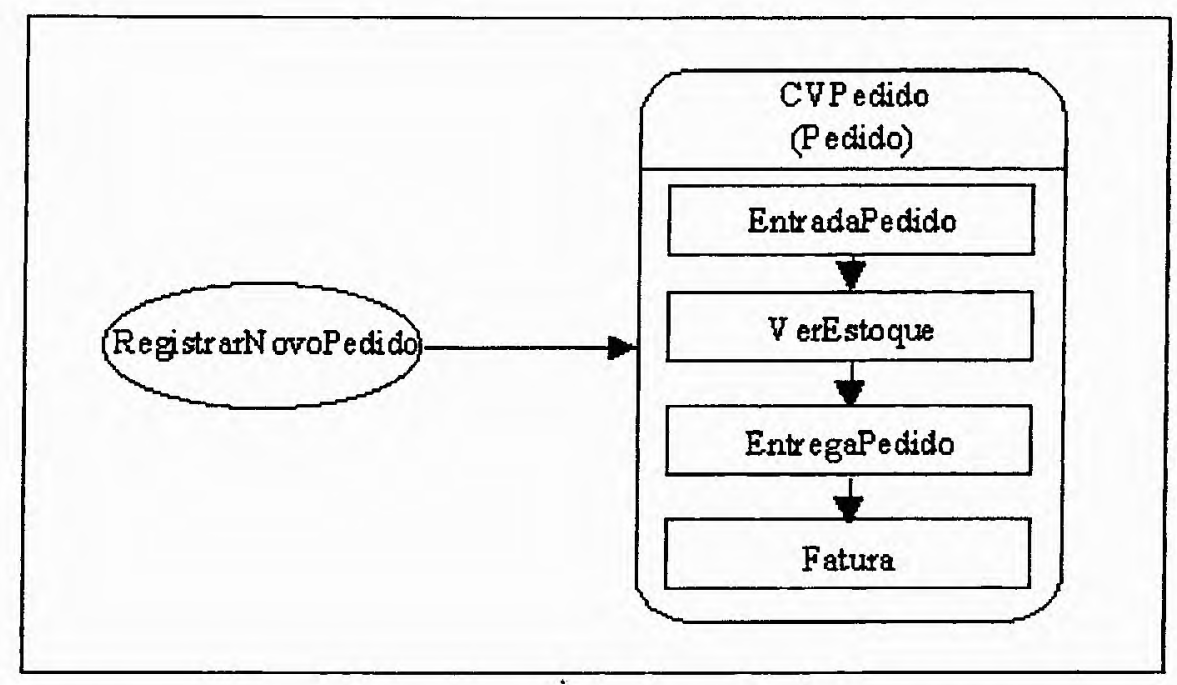

Figura 3.3: Atividade externa iniciando um ciclo de vida

Relações de dependência entre ciclos de vida podem ser definidas, uma vez que os ciclos de vida de entidades associadas podem não ser totalmente independentes e podem interagir uns com os outros. Uma das formas de dependência ocorre quando uma fase de um ciclo de vida não pode ser iniciada antes que uma determinada fase do ciclo de vida associado tenha sido atingida. Outra forma de dependência é identificada quando uma certa tarefa de um ciclo de vida deve interromper o outro ciclo ou deve tomar uma decisão baseada no estado do outro ciclo.

$\mathrm{Na}$ Figura 3.4, é apresentado um exemplo de dependência entre ciclos de vida, no qual o pedido não pode ser entregue até que a avaliação de crédito do cliente tenha sido totalmente efetivada $e$ a fase de atividade tenha sido atingida.

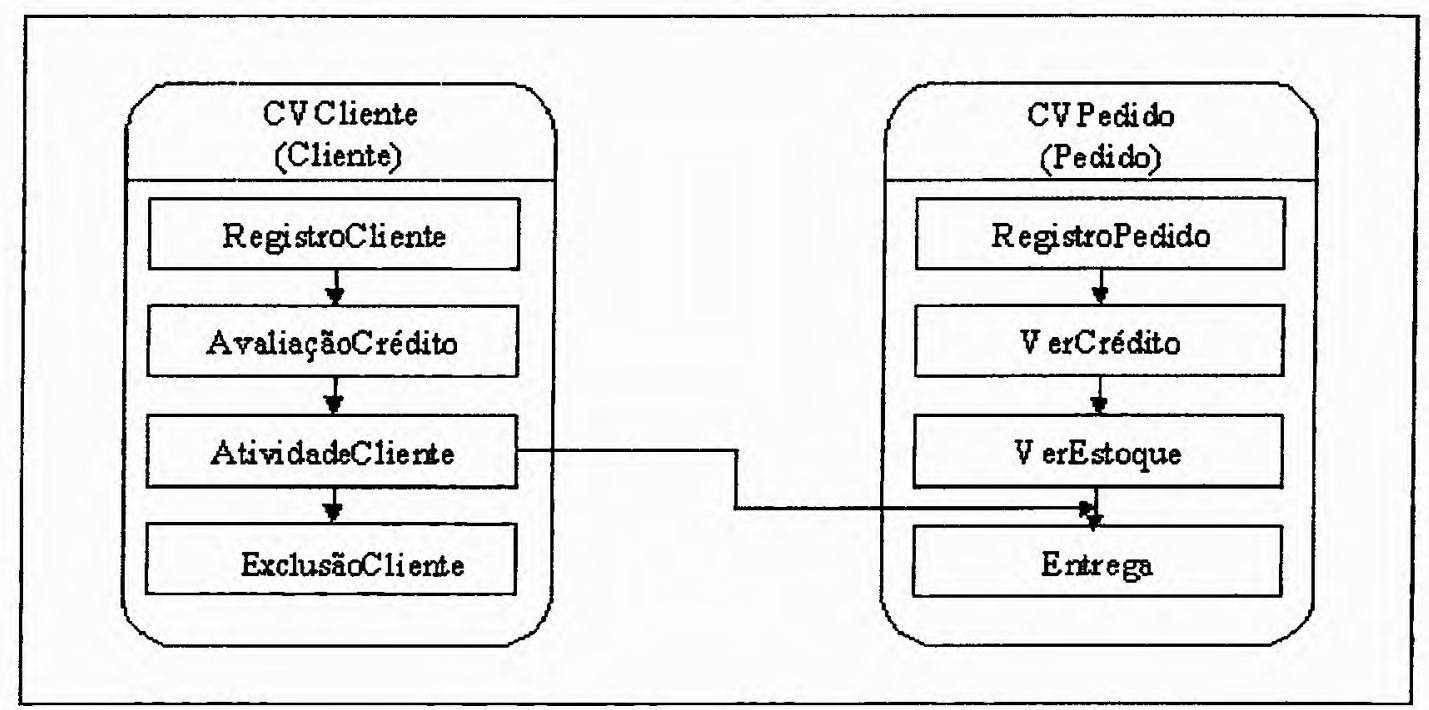

Figura 3.4: Dependência entre ciclos de vida (muitos dependem de um) 
As tarefas podem ser executadas em paralelo internamente a uma fase do ciclo de vida, o que significa que não existem restrições de negócio que exijam que uma tarefa seja executada após a outra em uma mesma fase; caso essa restrição exista, as tarefas devem estar contidas em fases distintas. Uma tarefa é dividida em subtarefas, quando se torna incapaz de completar seu trabalho e deve delegar que isso seja feito. Cada tarefa pode dividir-se em duas ou mais subtarefas independentes que podem ser executadas simultaneamente ou que se excluem, como ocorre nos grupos de seleção (Figura 3.5). As tarefas também podem assumir diferentes estados, tais como: o estado nulo, que indica que a tarefa ainda não foi iniciada; o estado inicial, que indica que a tarefa está pronta para ser executada; o estado passado, que indica que a tarefa foi executada com sucesso; e o estado executado, que indica que uma tarefa foi executada, mas não atingiu seu objetivo e deve solicitar que uma subtarefa o faça.

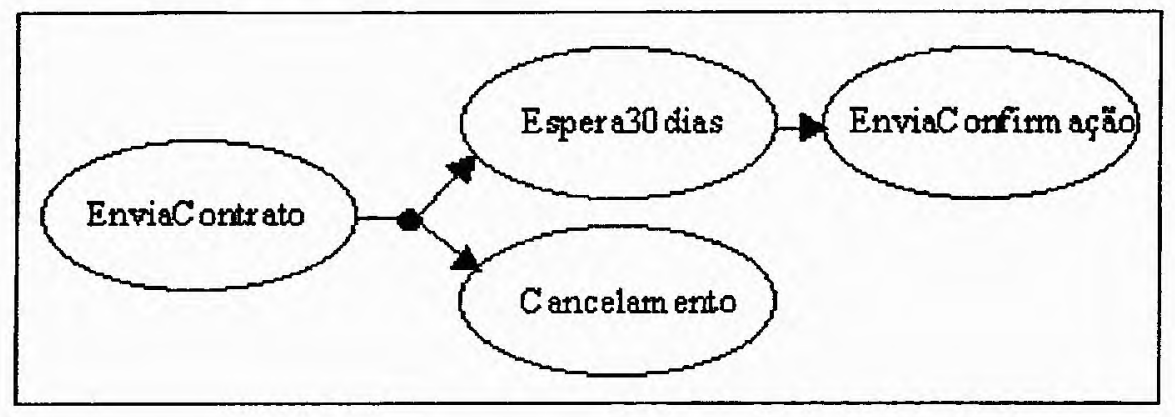

Figura 3.5: Grupos de seleção - relação de exclusividade mútua (Jackson \& Twaddle, 1997)

\subsubsection{Definição das Tarefas de Negócios}

O detalhamento das tarefas válidas é realizado na fase de definição das tarefas para cada ciclo de vida e são definidas as regras para a execução de cada uma delas. Na terceira fase do desenvolvimento, também é feita a classificação das tarefas que podem ser classificadas de acordo com:

- o modo como são iniciadas: (a) tarefas X: iniciadas externamente, normalmente pelo recebimento de alguma entrada do ambiente externo ao sistema; (b) tarefas T: iniciadas pela ocorrência de um tempo predeterminado; (c) tarefas P: iniciadas imediatamente após a ocorrência de uma determinada tarefa; e (d) tarefas I: iniciadas internamente;

- o modo como são executadas: (a) tarefas A: executadas automaticamente; e (b) tarefas M: executadas manualmente, isto é, necessitam da interferência de um usuário ou de uma tomada de decisão; 
- o seu conteúdo: (a) tarefas E: tarefas de entradas de dados ou criação de novos registros; (b) tarefas K: checagem da consistência ou completitude das informações ou conformidade às regras do negócio; (c) tarefas U: atualização das informações do banco de dados; (d) tarefas D: tomadas de decisão; e (e) tarefas O: produzem dados de saída.

Nessa fase, as entidades associadas a cada tarefa são agrupadas e formam conjuntos de dados relacionados, também chamados de conjuntos de dados de tarefas (exemplificados na Figura 3.6). Os elementos dos conjuntos de dados são, então, estruturados hierarquicamente. Diferentes hierarquias definem diferentes contextos e diferentes opções de acessibilidade.

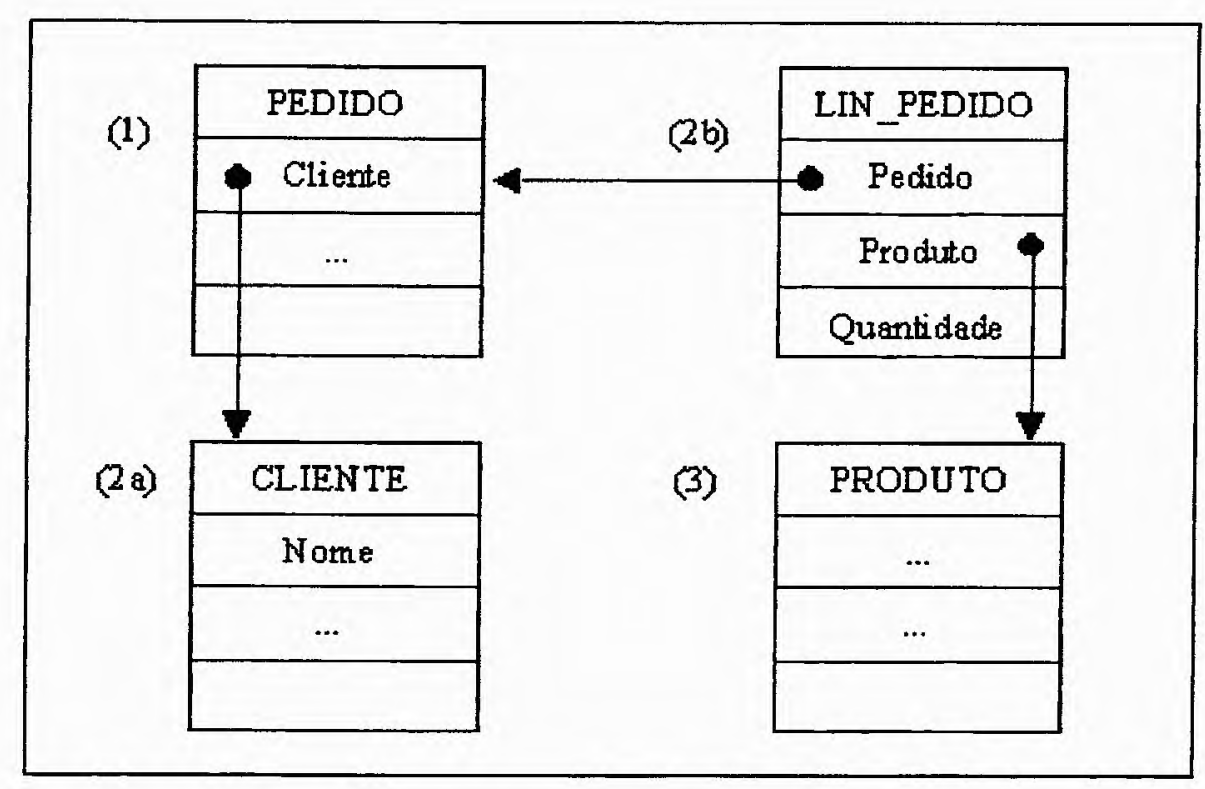

Figura 3.6: Conjunto de dados para orçamento de um pedido (Jackson \& Twaddle, 1997)

Para a melhor compreensão do contexto no qual as tarefas são executadas é útil a criação de um modelo de dados. Um modelo simplificado em termos tarefas e fases do ciclo de vida é apresentado na Figura 3.7.

\subsubsection{Definição do Fluxo de Trabalho (Workflow)}

O fluxo de trabalho é, então, especificado por completo na quarta e última fase por meio da coordenação das tarefas. São especificadas quais tarefas devem ser executadas automaticamente e quais tarefas devem ser executadas manualmente. $O$ fluxo de trabalho define o escalonamento e gerenciamento do trabalho realizado pelos usuários. Sua definição é uma conseqüência natural das regras de negócios e de como as ações progridem no mundo real. Na realidade, o fluxo de trabalho determina o que deve ser feito, enquanto 


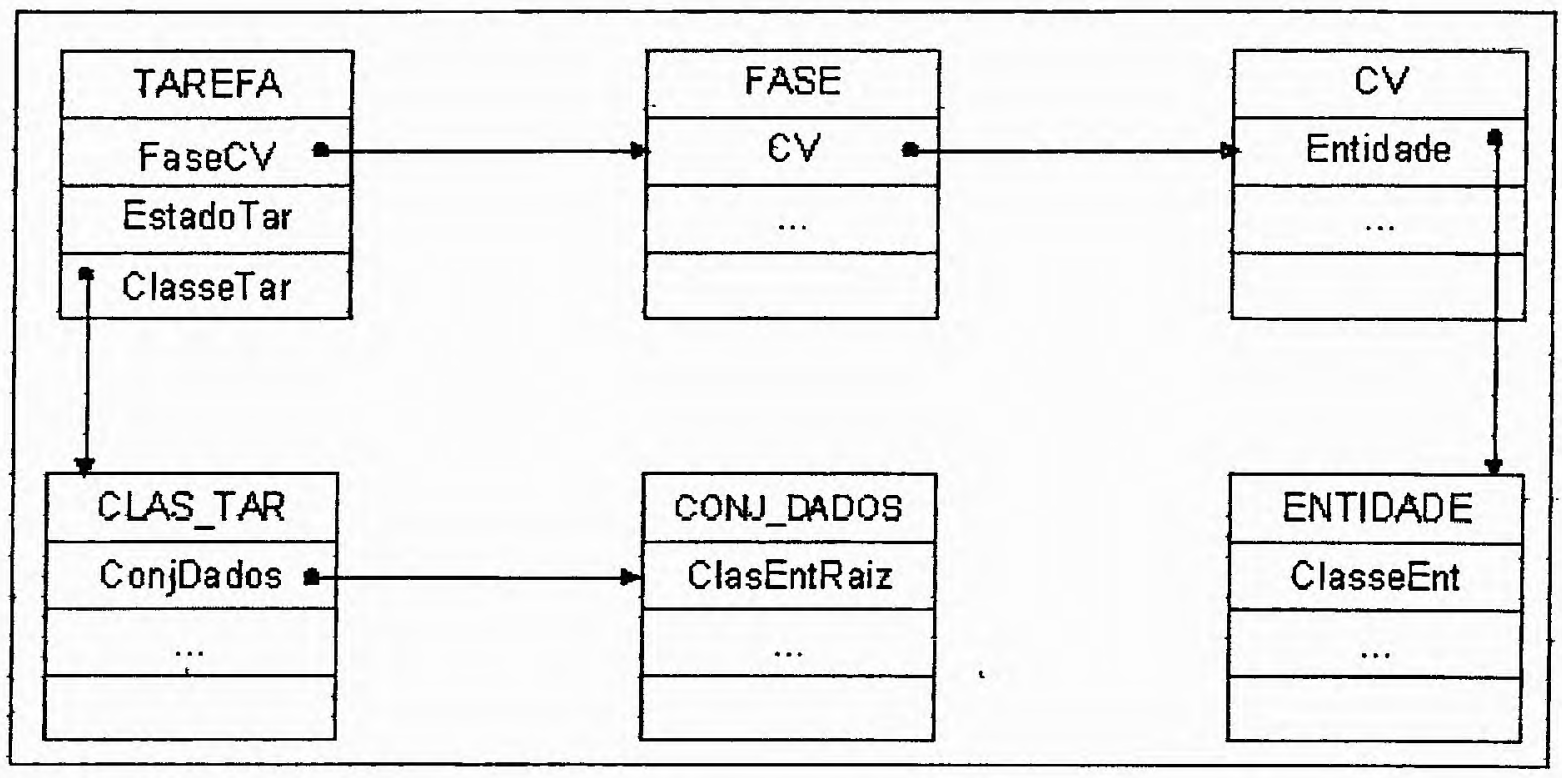

Figura 3.7: Modelo simplificado de tarefas (Jackson \& Twaddle, 1997)

as regras de negócios especificam o que não deve ocorrer em cada interação ou operação ao longo do desenvolvimento do trabalho.

A implementação do fluxo de trabalho deve garantir que as seqüências dos ciclos de vida sejam respeitadas. O fluxo de trabalho deve ainda coordenar as tarefas, atribuindoas às pessoas responsáveis e habilitadas, tornando o trabalho eficiente e otimizando a utilização de recursos, além de selecionar quais tarefas devem ter prioridade quando existirem várias tarefas prontas para serem executadas. Por fim, tarefas relacionadas devem ser agrupadas, formando serviços significativos para os usuários. Configurações de serviços diferentes geram diferentes estruturas de menu. Tais configurações definem relações de dependência entre seus elementos e são especificadas de acordo com regras de negócios. A ordenação e a combinação desses serviços dá origem ao fluxo de trabalho.

Com relação à coordenação de tarefas, o método sugere a organização do workflow em estruturas de grupos de trabalho considerando-se que classes particulares de tarefas envolvem grupos particulares de usuários em um setor administrativo. De forma mais precisa, normalmente, fases individuais do ciclo de vida de uma entidade em organizações tradicionais são associadas a departamentos específicos nos quais existem usuários especializados cuja habilidade, conhecimento ou mesmo grau de autoridade são apropriados para a realização de tarefas particulares internas a um ciclo de vida. As estruturas propostas correspondem aos grupos de trabalho existentes nas empresas atuais que são responsáveis por um aspecto coerente e significativo do negócio.

Tais considerações sugerem, portanto, que a execução de certas tarefas sejam agrupadas e mesmo restritas a determinados locais de trabalho e aos usuários aptos e res- 
ponsáveis, como representado na Figura 3.8.

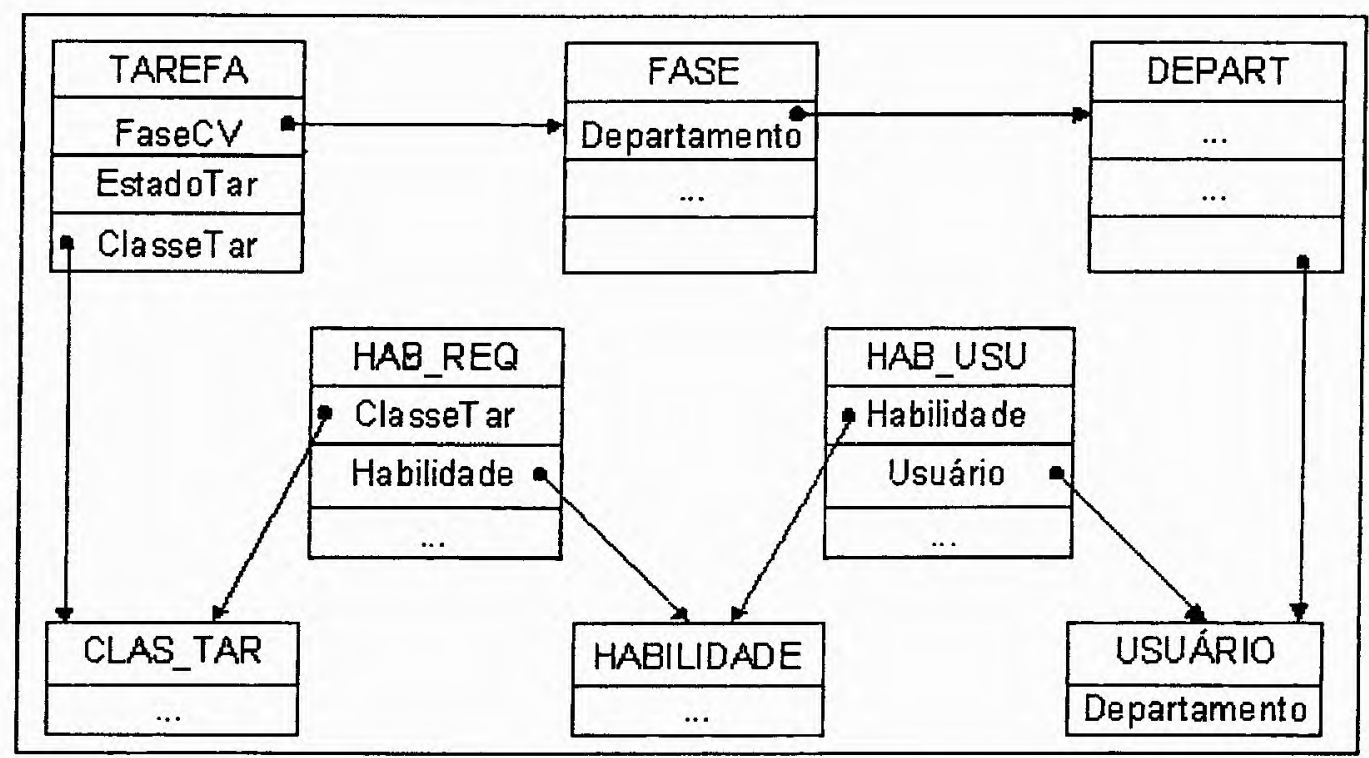

Figura 3.8: Associações entre tarefas, usuários e habilidades (Jackson \& Twaddle, 1997)

\subsubsection{Padronizações da WfMC}

A Workflow Management Coalition (WfMC) é uma organização internacional cujo objetivo é promover o uso de workflow e a exploração de tecnologias associadas, pelo estabelecimento de uma terminologia comum e de padrões para interoperabilidade e conectividade entre os produtos de workflow (WfMC, 1995).

A WfMC define workflow como a automatizaçãa completa ou parcial de um processo de negócio, durante o qual documentos, informações ou tarefas são passadas de urn participante para outro visando à realização de uma ação de acordo com um conjunto de regras procedimentais pré-definidas. A automatização do processo baseia-se em parte na definição de seus componentes, isto é, na identificação das atividades, das regras procedimentais e dos dados de controle que compõem o processo e que são usados para o gerenciamento do workflow durante a sua execução. A fase na qual essa identificação ocorre é chamada de definição do processo (WfMC, 1999b).

Diversas instâncias de um processo podem estar operacionais durante a sua execução, sendo que cada qual é associada a um conjunto específico de dados relevantes para aquela instância individual. Os dados relevantes para o workflow são aqueles usados pelo sisterna gerenciador para determinar as transições de estados de uma instância do processo. As instâncias são criadas pelo sisterna gerenciador de workflow, que armazena e interpreta definições de processos, gerencia as instâncias enquanto estão sendo executadas, controla as interações com os participantes do processo e invoca o uso de ferramentas ou aplicações 
externas. Um sistema gerenciador de workflow também realiza funções administrativas e de supervisão, tais como, distribuição e escalonamento de trabalho e validação e gerenciamento de informações. A Figura 3.9 ilustra as características dos sistemas workflow descritas.

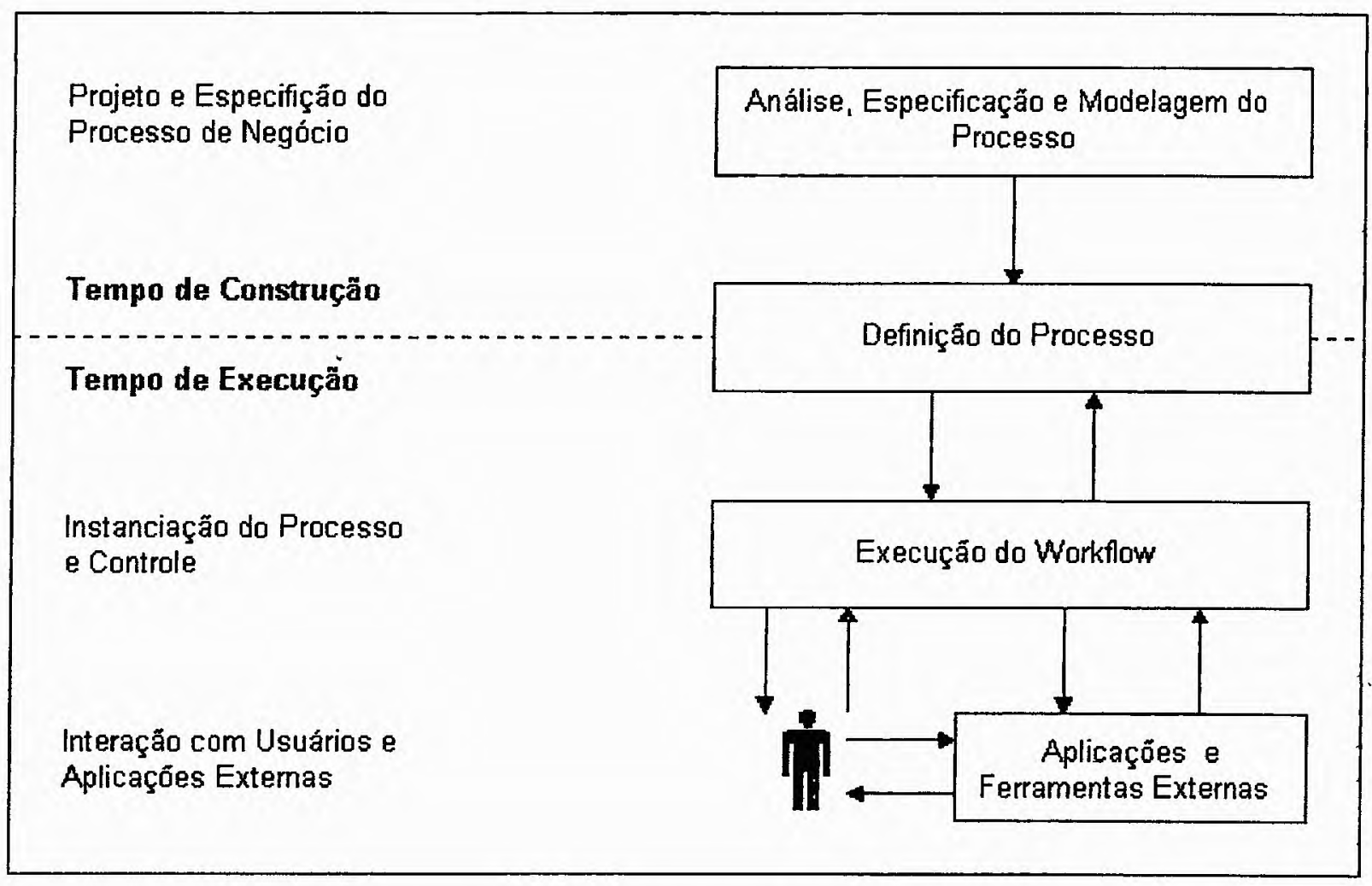

Figura 3.9: Características de um sistema de workflow (WfMC, 1995)

Segundo a WfMC, um processo de negócio é composto por um conjunto de um ou mais procedimentos ou atividades relacionadas que são executadas de acordo com regras preestabelecidas, com o propósito de atingir o objetivo do negócio. O processo de negócio também envolve papéis funcionais bem definidos e relações de interação com os participantes do workflow. As atividades são tipicamente as menores unidades de trabalho ou passos lógicos que compõem o processo de workflow e podem ser automatizadas ou manuais. As atividades automatizadas não dependem da interferência do usuário e são coordenadas pelo gerenciador de workflow, já as atividades manuais são aquelas que não podem ser automatizadas porque necessitam de uma entrada de usuário ou de uma tomada de decisão para a sua execução. Essas atividades estão fora do escopo de trabalho dos sistemas gerenciadores de workflow, porém devem ser incluídas na definição do pracesso.

A definição do processo é a representação do negócio de uma forma passível de ser automaticamente manipulada por um sistema gerenciador de workflow. Pode ser representada por modelos, por exemplo, e é composta por atividades e seus relacionamentos, 
marcadores que indicam o início e o término do processo e informações sobre cada atividade, como usuários responsáveis ou aplicações externas requeridas para a sua execução.

Tanto processos quanto atividades podem possuir diferentes instâncias em um mesmo instante de tempo. Cada instância representa uma execução (chamada) particular de um processo ou atividade e, portanto, deve ser controlada independentemente e deve armazenar seu próprio estado. As instâncias de processos e de atividades são criadas e manipuladas pelo sistema gerenciador de workflow. Cada instância de processo é composta por uma ou mais instâncias de atividades que, por sua vez, são compostas por itens de trabalho e/ou por chamadas a aplicações externas, como mostrado na Figura 3.10.

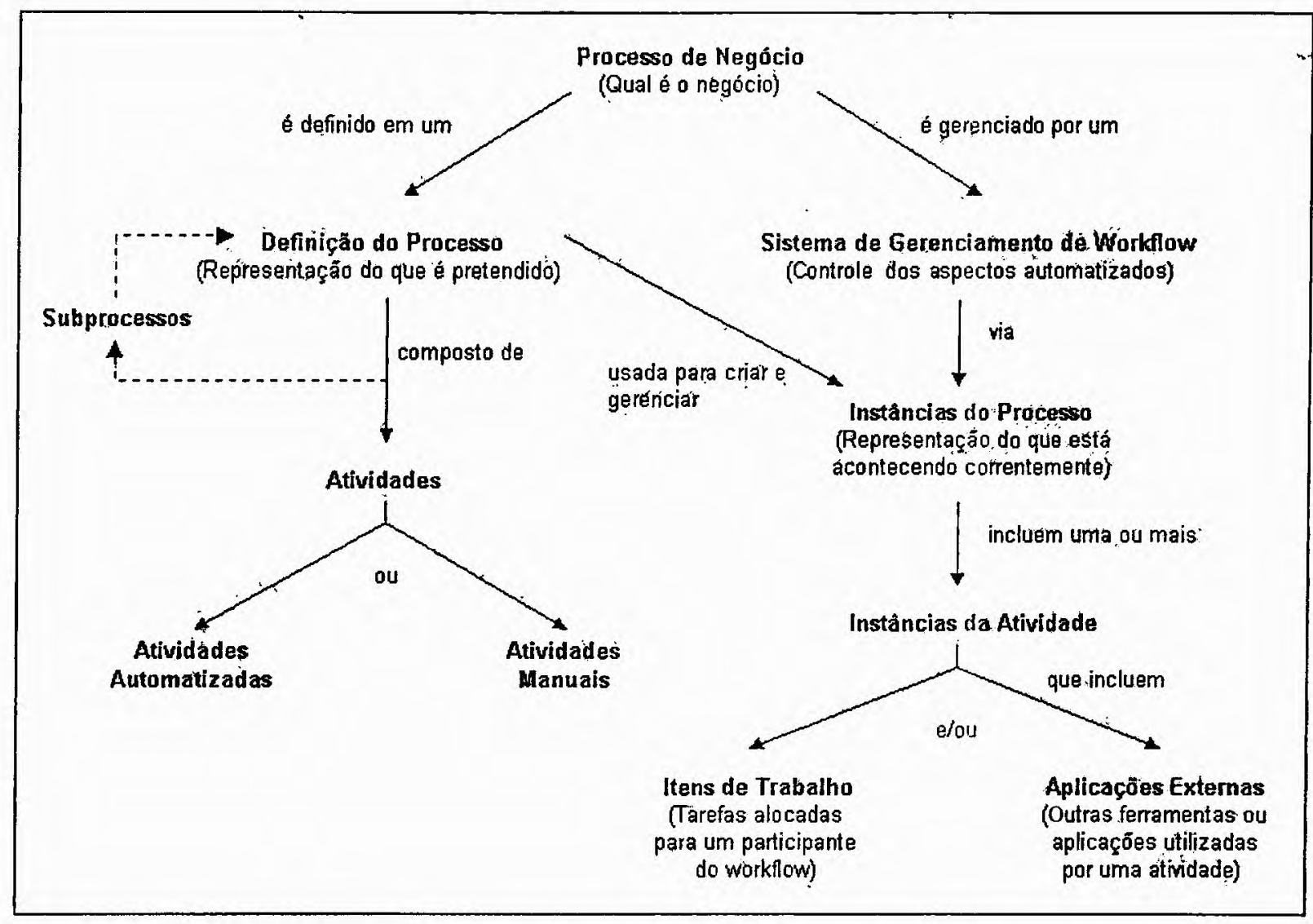

Figura 3.10: Relacionamentos entre os componentes da terminologia básica (WfMC, 1999b)

Um item de trabalho é a representação do trabalho a ser executado por um participante do workflow no contexto de uma atividade, em uma instância de processo. As atividades normalmente geram um ou mais itens de trabalho que, agrupados, constituem a meta de cada participante durante a execução do processo. Algumas atividades podem requerer chamadas a ferramentas ou aplicações externas, o que também é realizado pelo sistema gerenciador. 
Além de especificar uma terminologia básica para os processos de workflow, a WfMC desenvolveu um meta-modelo para a definição do processo, o qual identifica um conjunto básico de objetos apropriados, para um nível inicial, para a troca de definições de processos relativamente simples (WfMC, 1995). Os tipos de objetos do meta-modelo são apresentados na Figura 3.11.

Os conceitos de definição de processo, atividade e dado relevante para o workflow foram previamente definidos nesta seção. O objeto aplicação refere-se às ferramentas ou aplicações externas que eventualmente podem ser requeridas para a automatização parcial ou integral de uma atividade, ou para dar apoio a um participante do workflow na execução de um item de trabalho. Uma condição de transição é uma expressão lógica que pode ser avaliada por uma máquina de workflow para decidir a seqüência de execução de atividades de um processo. Os papéis definem o contexto do qual o usuário participa em um processo particular ou atividade. $O$ papel geralmente abrange conceitos organizacionais, tais como estrutura e relacionamentos, responsabilidade ou autoridade e habilidades (WfMC, 1999a).

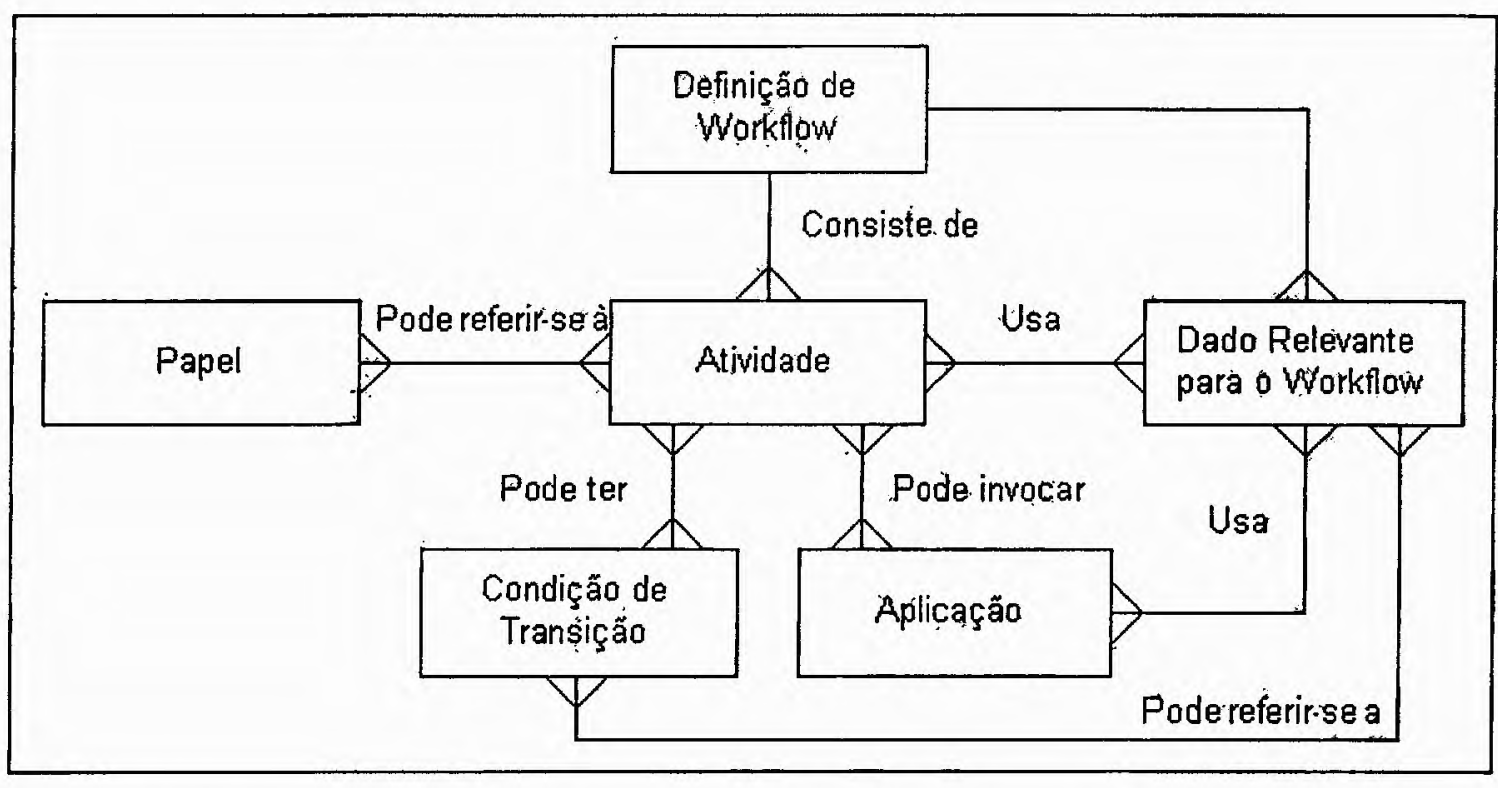

Figura 3.11: Meta-modelo para a definição de um processo básico (WfMC, 1995)

Com o objetivo de padronizar o produto final da fase de definição do processo, a WfMC especificou, no seu glossário, um conjunto de construtores gráficos para serem usados na modelagem do workflow. Durante essa fase, são identificadas todas as atividades manuais ou automatizadas e, então, é elaborada uma representação formal do processo de negócio, expressa em termos de conjuntos ou blocos de atividades associadas a um objetivo comum. As atividades podem ocorrer em paralelo ou seqüencialmente e são representadas por grafos direcionados que compõem os blocos. 
Os construtores gráficos são usados para ampliar o poder de expressão dos modelos, representando, de modo mais exato, a execução do workflow (Figura 3.12). Com eles pode-se representar:

- AND-Join: um ponto no workflow onde duas ou mais atividades executadas em paralelo convergem em um fluxo único de controle.

- AND-Split: um ponto no workflow onde um fluxo único de controle divide-se em duas ou mais atividades em paralelo.

- OR-Join: um ponto no workflow no qual, existindo dois ou mais ramos de atividades, apenas um deles terá prosseguimento e atuará como o próximo passo do processo.

- OR-Split: um ponto no workflow no qual, dado um fluxo único de controle, decide-se qual ramo seguir quando existirem múltiplos ramos alternativos.

- Iteração: um ciclo de atividades que envolve a execução repetitiva de uma ou mais atividades do workflow até que uma certa condição seja satisfeita.

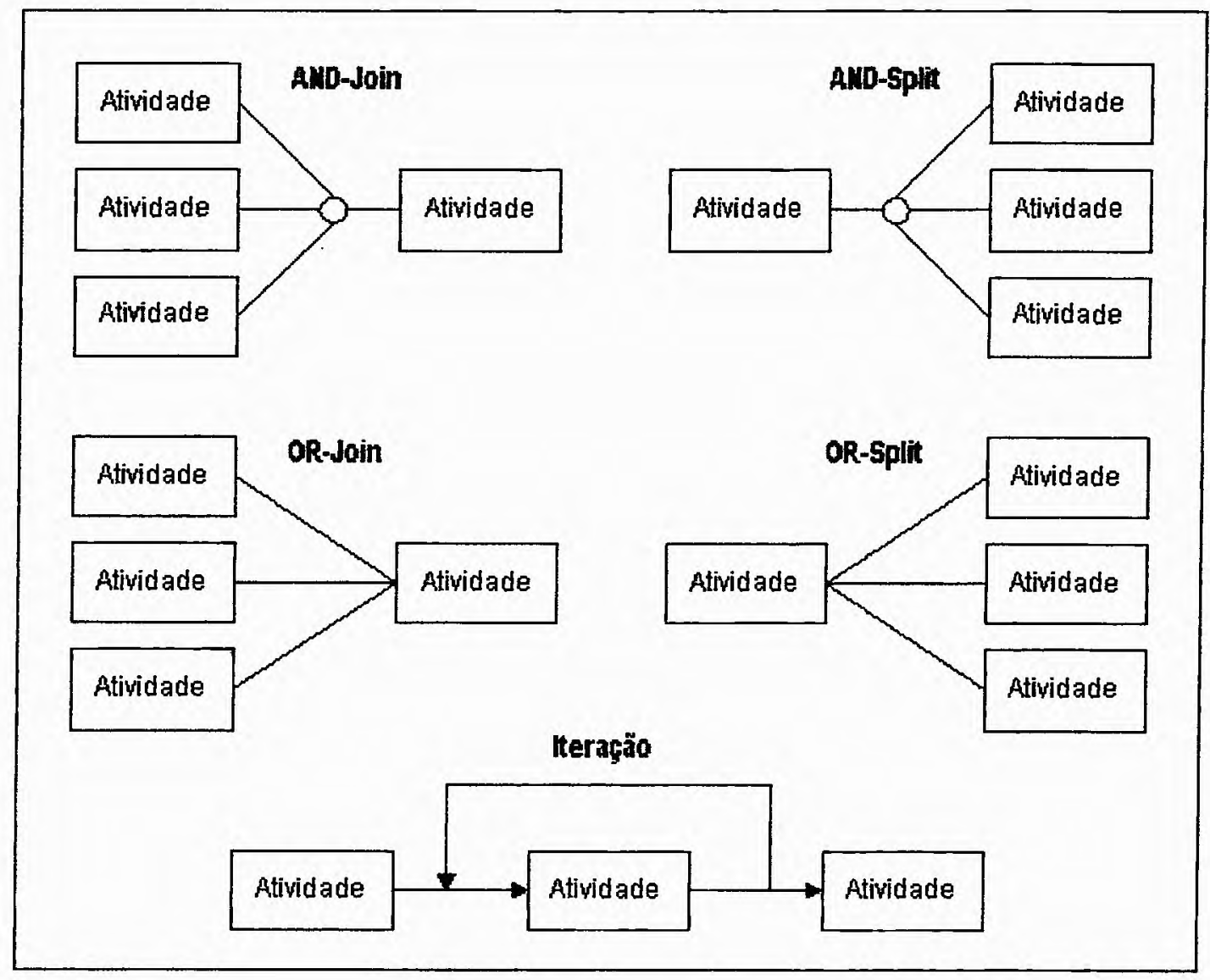

Figura 3.12: Construtores gráficos da WfMC (WfMC, 1999b) 
As atividades são executadas obedecendo às pré e pós-condições. Uma pré-condição é uma expressão lógica que deve ser avaliada para decidir se uma instância de um processo ou atividade pode ser inicializada. Uma pós-condição também é uma expressão que deve ser avaliada para decidir se uma instância de processo ou atividade está completa. Existem ainda condições de transição que também impõem restrições à execução do processo. Uma condição de transição é uma expressão lógica que deve ser avaliada para decidir a seqüência de execução das atividades, o que deve ocorrer no caso de um OR-Join, por exemplo. Durante a execução, diferentes estados podem ser assumidos pelas instâncias de processo ou de atividade. Um estado é a representação das condições internas que definem o status dessas instâncias em um momento particular. A maioria dos sistemas gerenciadores mantém essa informação de status como parte dos dados de controle do. workflow.

\subsubsection{Modelo de um Sistema de Workflow para Gestão de Docu- mentos}

Enquanto a WfMC propõe um modelo genérico para a especificação de processos de workflow, o trabalho de Mestrado de Bruzarosco (1998) propõe um modelo conceitual específico para a aplicação de workflow na gestão de documentos. No contexto dos sistemas gerenciadores de documentos, fazem parte do workflow a criação, o armazenamento, os serviços de apresentação e de distribuição de documentos e os serviços relacionados ao seu controle, tais como: controle de entrada e saída, do nível de proteção/segurança e da versão de documentos. Ainda nesse contexto, o fluxo de trabalho ou workflow é definido como a coordenação de tarefas, dados e pessoas com o intuito de tornar o processo mais eficiente, efetivo e adaptável a mudanças.

Embora a aplicação seja específica, a abordagem sugere a criação de um módulo de workflow genérico, isto é, que possa ser usado na modelagem de processos com diferentes enfoques, como por exemplo: processos de software, gerenciamento de configuração e processos de negócios. Para assegurar essa característica, o modelo conceitual do sistema é dividido em dois módulos: de workflow e de documentos. O módulo de workflow é fortemente baseado na padronização da WfMC e apresenta basicamente as mesmas características.

O modelo de dados do workflow é composto por três partes inter-relacionadas: o modelo de administração, que compreende as classes que armazenam os dados essenciais para que o sistema se torne operacional; o modelo de especificação de workflow, que compreende as classes que contêm informações geradas pelo editor de processos; e o modelo de instâncias de workflow, que é formado pelas classes que armazenam informações referentes 
à execução de processos.

O modelo de administração é composto pelas entidades participantes, papel e privilégio. Privilégios são atribuídos a papéis que são atribuídos a participantes, gerando, assim, os níveis de acesso e as autorizações para a manipulação do sistema. O modelo de especificação contém as entidades processo, atividade, ação e item de trabalho que representam os mesmos conceitos definidos pela WfMC. Nesse caso, o termo "ação" corresponde às atividades manuais ou automatizadas da WfMC. Existem ainda, nesse modelo, entidades relacionadas à edição de componentes gráficos e a entidade roteamento, que contérn regras de navegação de workflow, dentre as quais a que permite a execução em paralelo e a sincronização de atividades. O modelo de instâncias de workflow é composto pelas entidades história de atividade e história de processo, que mantêm, respectivamente, informações a respeito das atividades e dos workflows executados para fins estatísticos e de auditoria, e pelas entidades instância de processo, instância de atividade e instância de ação, que correspondem aos mesmos conceitos especificados pela WfMC.

Um outro requisito do sistema proposto é a facilidade para a especificação de workfiow, ou seja, o modelo deve oferecer simplicidade e clareza na definição de processos. Com o propósito de atender a esse requisito, foram desenvolvidas a Linguagem de Roteamento de Atividades (LiRA), em conformidade com o padrão estabelecido pela WfMC, e a Linguagem de Definição de Ações (LiDA).

A Linguagem de Definição de Ações define a gramática de uma linguagem para especificação de ações e expressões de pré-condições das atividades itens de trabalho e de expressões de transições das atividades de roteamento. Os comandos da linguagem seguem, sempre que possível, a estrutura dos comandos SQL (Bruzarosco \& Masiero, 1998a). A linguagem LiRA é descrita mais detalhadamente a seguir.

\subsubsection{Linguagem de Roteamento de Atividades (LiRA)}

A linguagem de roteamento de atividades (LiRA) (Bruzarosco \& Masiero, 1998b) especifica componentes gráficos para a representação de processos de workflow e de suas propriedades. Essa linguagem baseia-se nos símbolos e definições do glossário de terminologias da WfMC (WfMC, 1999b). No entanto, apresenta algumas diferenças devido a alterações realizadas com o objetivo de simplificar a modelagem do processo, tornar a simbologia mais intuitiva e possibilitar o tratamento de abstrações não definidas pela WfMC. Essas diferenças são descritas a seguir.

Foi adicionado ao conjunto de construtores gráficos da LiRA o círculo cheio para representar os roteamentos OR-join e OR-split, com o intuito de identificar melhor a existência de um roteamento do tipo OR, diferenciando-se do roteamento do tipo AND, que é representado pelo círculo vazio. A Figura 3.13 ilustra o símbolo adicional da linguagem. 


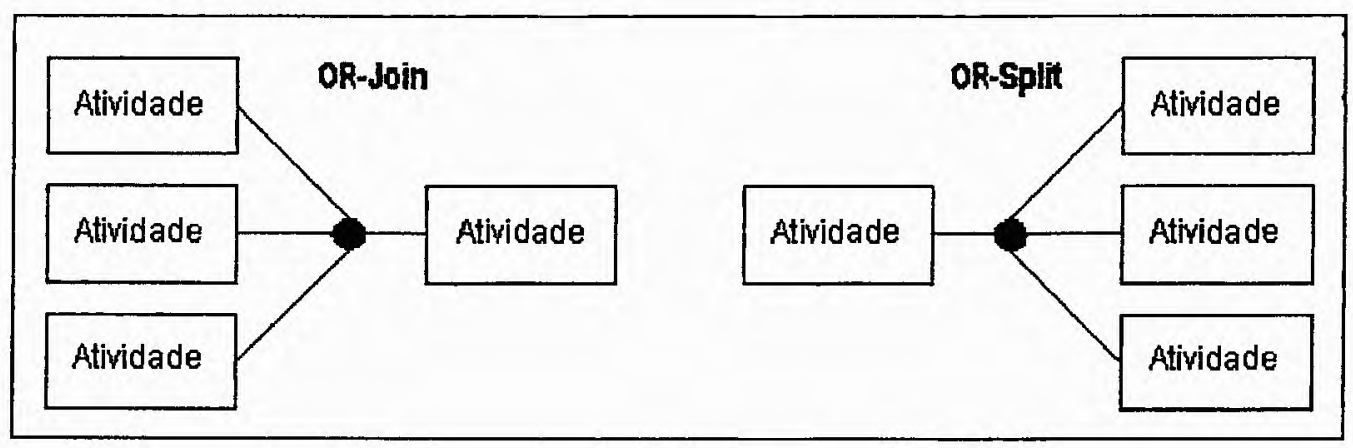

Figura 3.13: Representação dos roteamentos OR-Join e OR-Split (Bruzarosco \& Masiero, 1998b)

A LiRA também inclui o símbolo formado por duas barras paralelas para a representação de terminadores, o que não é tratado pela WfMC. Os terminadores indicam o ponto inicial ou final da execução do workflow e são exemplificados na Figura 3.14.

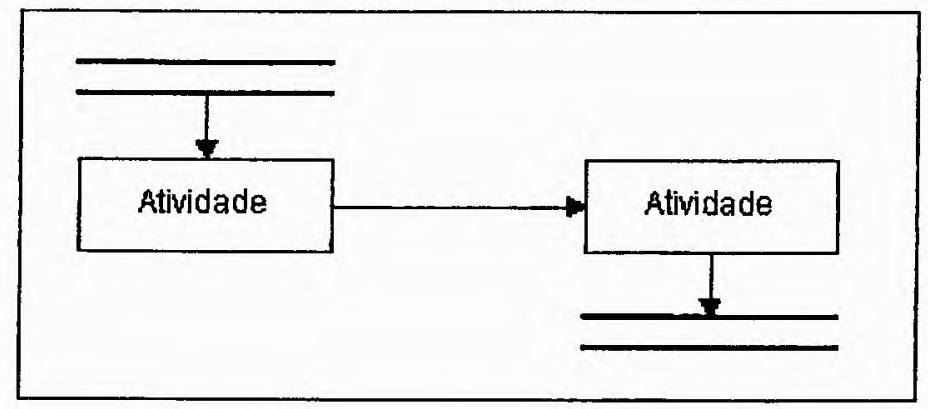

Figura 3.14: Representação dos terminadores (Bruzarosco \& Masiero, 1998b)

A representação gráfica da iteração também foi alterada por uma questão de simplificação da programação e a semântica foi restringida a uma única atividade, enquanto, pela definição da WfMC, uma iteração envolve a execução repetitiva de uma ou mais atividades. De acordo com a LiRA, a iteraçã̃o é controlada pela últịna ação da atividadè, que é do tipo automática e requer que uma certa condição seja satisfeita para finalizar as repetições de execução. Na Figura 3.15 são ilustradas as diferentes representações.

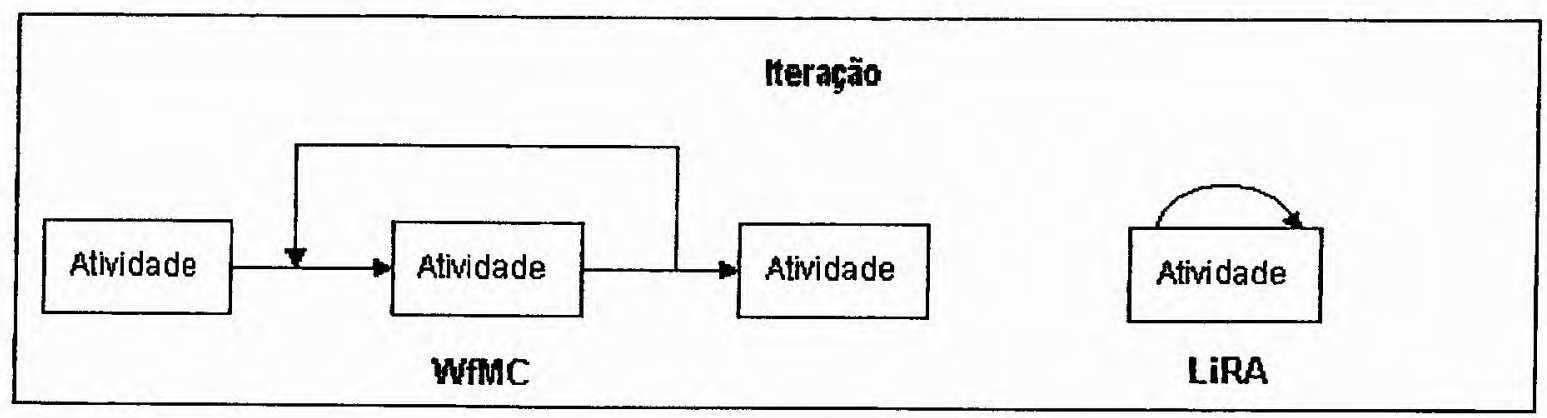

Figura 3.15: Representação de iteração da WFMC e da LiRA 
A linguagem LiRA inclui ainda um símbolo para a representação gráfica de uma atividade item de trabalho como um subprocesso, o que não é representado pela WfMC. Um subprocesso é composto por atividades que podem ser atômicas ou subprocessos, representando níveis de abstração do workflow.

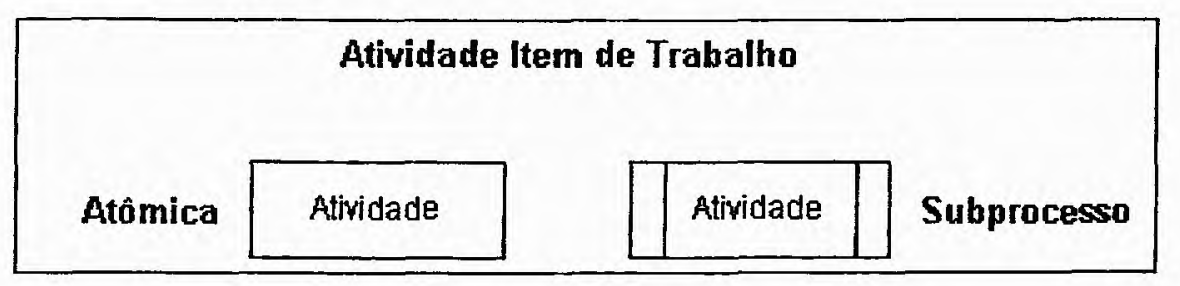

Figura 3.16: Representação gráfica de uma atividade atômica e de um subprocesso (Bruzarosco \& Masiero, 1998b)

A Figura 3.17 representa graficamente um exemplo simplificado de workflow para cálculo de imposto de renda.

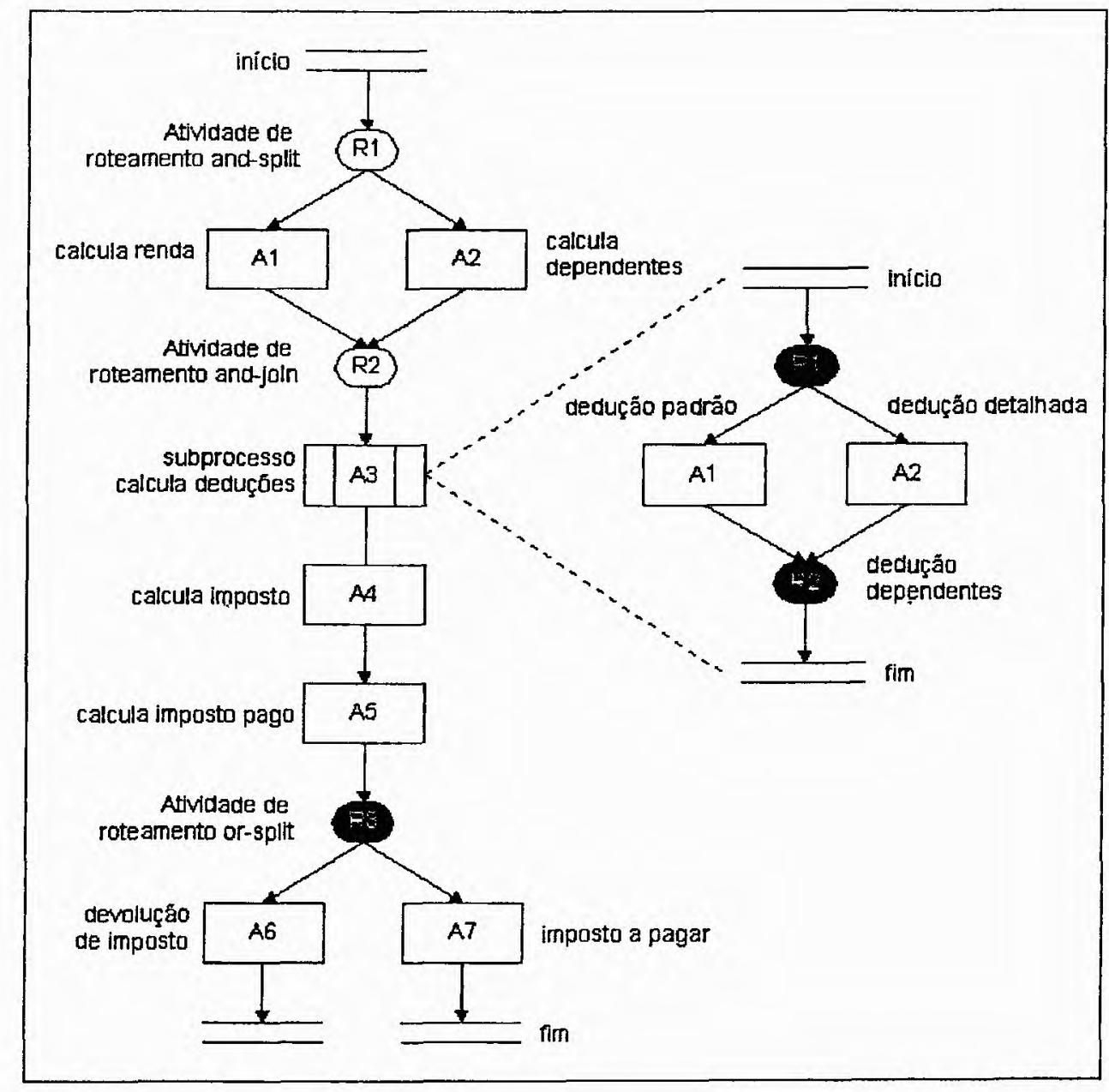

Figura 3.17: Exemplo simplificado de um workflow para cálculo de imposto de renda (Bruzarosco \& Masiero, 1998b) 


\subsection{Considerações Finais}

As propostas de padronização da terminologia e dos conceitos envolvidos pelos sistemas de gerenciamento de workflow são de grande importância e valia sobretudo no sentido de garantir a interoperabilidade entre diferentes sistemas de workflow e de definir uma sistemática para o desenvolvimento desse tipo de sistema. Entretanto, o método proposto por Jackson e Twaddle aparenta ser mais apropriado para o problema em questão pois engloba conceitos e define recursos que representam melhor os requisitos do sistema e, portanto, deve ser mais profundamente estudado. 


\section{Capítulo 4}

\section{Sistemas de Informação Baseados na Web}

\subsection{Considerações Iniciais}

A evolução das tecnologias relacionadas à Internet e à WWW ampliou os recursos e forneceu condições para o desenvolvimento de diferentes tipos de aplicações baseadas na Web, capazes de serem empregadas nas mais variadas áreas, tais como, o comércio, a educação, a publicidade e os negócios em geral. Muitas dessas aplicações envolvem a coleta, o processamento, o armazenamento e a transmissão de informações, ou seja, necessitam de um gerenciamento de dados e caracterizam-se, portanto, como sistemas de informação.

Neste capítulo, são abordados os aspectos que caracterizam os sistemas de informação baseados na Web, as categorias nas se quais subdividem e algumas de suas principais áreas de aplicação. São enfatizados os sistemas voltados para o ensino a distância, em especial os aspectos relacionados à administração de cursos oferecidos via Web. Nas Seções 4.3.1, 4.3.2 e 4.3.3, são apresentados, respectivamente, os ambientes AulaNet, WebCT e CALM com o intuito de exemplificar os sistemas voltados para o ensino a distância, bem como os principais recursos oferecidos por essa categoria de sistemas.

\subsection{Características dos Sistemas de Informação Ba- seados na Web}

Os sistemas de informação baseados na Web ou Web Information Systems (WISs) são, como qualquer sistema de informação, responsáveis pelo gerenciamento de informações, por meio de operações de registro, recuperação e controle de dados, visando à otimização 
desse processo. $\mathrm{O}$ que caracteriza particularmente os WISs é o fato de estarem apoiados na plataforma Web, o que lhes dá um potencial de integração muito maior, atingindo um público muito mais amplo, heterogêneo e geograficamente distribuído. $\mathrm{O}$ alcance proporcionado pela Web e suas conseqüentes vantagens, como maior facilidade de comunicação e cooperação entre usuários, têm feito os pesquisadores acreditarem que os WISs devem tornar-se mais difundidos do que os atuais sistemas cliente/servidor baseados em redes locais.

Os WISs podem ser classificados em quatro categorias: sistemas para intranets, responsáveis pelo processamento das informações internas às redes locais; sistemas Webpresence, cujo principal objetivo é atuar como uma estratégia de marketing e levar informações e serviços ao público externo; sistemas de comércio eletrônico, que apóiam interações com o consumidor, como shopping on-line; e sistemas para extranets, que são sistemas internos e externos que se comunicam de modo a dar apoio aos negócios das organizações (Isakowitz, Bieber \& Vitali, 1998a).

Existe uma clara diferença entre os WISs e os conjuntos de páginas Web. Os WISs não atuam somente como distribuidores de informações; suportam também o trabalho de armazená-las e processá-las e comumente são integrados a outros sistemas de informação, como bancos de dados e processadores de transações. Os WISs também diferem dos sistemas de informação tradicionais, visto que requerem novas abordagens de projeto e desenvolvimento, principalmente no que se refere à estruturação do conteúdo, e utilizam-se de diferentes tecnologias, além de serem voltados para um público mais amplo e diversificado.

Duas das principais áreas de aplicação dos WISs que se encontram em destaque são o comércio eletrônico e o ensino a distância. Com a invenção do comércio eletrônico, as empresas passaram a dispor de uma maneira eficaz para divulgar e vender seus produtos e serviços, com a vantagem de atingir um público extenso. Por outro lado, os clientes beneficiaram-se com a possibilidade de fazer compras de uma maneira mais rápida e fácil via Web. $O$ enfoque deste trabalho, no entanto, está no domínio de aplicação voltado para o ensino a distância, que será explorado na próxima seção.

Informações mais detalhadas sobre os WISs podem ser encontradas na seção especial da revista Communications of the $A C M$, de julho de 1998 (CACM, 1998), que trata exclusivamente desse tema, com vários artigos abordando o estado da arte em termos de estratégias de desenvolvimento, aplicações e recursos tecnológicos, bem como a sua relação com as pesquisas na área de hipermídia. 


\subsection{Sistemas Voltados para o Ensino via WWW}

Do ponto de vista tecnológico, o principal fator que tem motivado os pesquisadores a explorar o tema ensino e aprendizagem baseados na Web está ligado às grandes transformações que a tecnologia Web trouxe para o processo de desenvolvimento de software e para o próprio conceito de software.

As possibilidades de utilização das tecnologias Web na educação começaram a ser exploradas seriamente apenas no final de 1996, época em que o termo Web-based Education começou a popularizar-se. Desde então, diversos projetos de ambientes voltados para o ensino a distância começaram a ser desenvolvidos. Entretanto, os estudos ainda são muito recentes e não há, na comunidade acadêmica e tecnológica, quem possa intitular-se como um especialista no tema (Lucena \& Fucks, 1999).

Outro aspecto que desperta o interesse para o tema educação/treinamento baseado na Web está ligado ao potencial que esta área oferece à cooperação da universidade com o mercado de negócios e com a sociedade em geral. O surgimento da chamada "sociedade da informação", com características globais, vem aumentando a preocupação do mercado com a educação e o treinamento como forma de assegurar a competitividade. Acredita-se que as próprias tecnologias da informação (Internet, Intranets, WWW, etc.) que estão levando à construção da sociedade de informação sejam portadoras das soluções para 0 problema de oferecimento de educação e treinamento em grande escala e a custos mais acessíveis que os atuais.

Outro fator que tem motivado a criação de ambientes educacionais virtuais é a abordagem pedagógica construtivista. De acordo com o Construtivismo, o aluno deve possuir liberdade para escolher o assunto a ser estudado e deve poder manipular da maneira que preferir o material disponível. Sob essa visão, acredita-se que o conhecimento não deve simplesmente ser passado para o aluno e observado por ele; mas que o aluno deva interagir livremente com o objeto em estudo para que possa adaptar-se a ele, o que significa desenvolver e incorporar novos conceitos ao seu sujeito. O processo de adaptação é subdividido em duas fases: a assimilação e a acomodação. Por assimilação entendem-se as ações que o indivíduo realiza para poder internalizar o objeto, interpretando-o de forma a poder encaixá-lo nas suas estruturas cognitivas. A acomodação ocorre quando o indivíduo altera suas estruturas cognitivas para melhor compreender o objeto que não the é familiar.

Por meio dessas sucessivas e permanentes etapas de assimilação e acomodação, o indivíduo vai adaptando-se ao meio externo, ao longo de um interminável processo de desenvolvimento cognitivo. Essa teoria foi denominada Construtivismo por considerar que novos níveis de conhecimento são indefinidamente construídos por intermédio de interações entre o indivíduo e o meio. Os construtivistas sugerem ainda que a avaliação deve ser um 
meio para auxiliar o aprendizado do aluno, ou seja, a avaliação não deve ser taxativa; seu real propósito deve ser analisar a evolução do aluno durante o processo de aprendizagem, identificar suas deficiências e propor meios ou soluções para supri-las (Ferreira \& Carneiro, 1998).

Verifica-se, portanto, que tecnologias como a WWW e a Internet representam a possibilidade de dinamização das práticas pedagógicas por meio de ambientes de ensino e aprendizagem alternativos, onde a colaboração virtual vem apoiar o processo de desenvolvimento cognitivo e social dos sujeitos aprendizes, visando à construção coletiva de conhecimentos, pelo tratamento de informações compartilhadas, processadas e distribuídas em tempo real. Os cenários educacionais baseados na Web viabilizam a troca de idéias e de informações culturais independentemente das fronteiras espaciais ou temporais, representando possibilidades de experiências cooperativas e envolvendo aspectos importantes associados ao crescimento intelectual dos alunos.

\subsubsection{AulaNet}

O AulaNet é um ambiente de aprendizagem cooperativo desenvolvido no Laboratório de Engenharia de Software (LES) do Departamento de Informática da Pontifícia Universidade Católica do Rio de Janeiro (PUC-Rio), para a criação e manutenção de cursos baseados na Web, projetados para um público leigo em Informática. Os objetivos do AulaNet são a adoção da Web como um ambiente educacional; a criação de uma transição viável da sala de aula convencional para a sala de aula virtual, oferecendo as oportunidades de reutilizar o material educacional existente e de criar comunidades de conhecimento (LES, 1999; Lucena \& Fucks, 1999).

Comparando o AulaNet a outros ambientes de educação baseados na Web, pode-se fazer uma clara distinção. Enquanto a maioria desses sistemas enfatiza os aspectos de courseware - apresentação de material didático por computador - o AulaNet enfatiza os aspectos de learningware, que combinam as características do courseware com as várias formas de interação (interação entrę aprendizes e a interação aprendiz/instrutor). Sendo assim, as palavras-chave da abordagem adotada pelo AulaNet são: comunicação, coordenação e cooperação.

O AulaNet baseia-se nas premissas de que o autor do curso não precisa ser um especialista em Internet; os cursos criados devem buscar grande capacidade de interatividade, a fim de atrair maior participação do aluno no processo de aprendizado; e os recursos oferecidos para a criação de cursos devem corresponder aos de uma sala de aula convencional, acrescidos de outros normalmente disponíveis no ambiente Web, como correio eletrônico, chat e videoconferência. 
Considera-se que os seguintes atores estão envolvidos no processo de ensino/aprendizagem: o administrador, que lida com as questões predominantemente operacionais, integrando as entidades professor, curso e aluno; o aluno, que é o aprendiz e usuário final do curso; e o professor, que é o principal cliente do AulaNet. O professor é o criador do curso, isto é, aquele que participa desde a sua descrição inicial até a entrada de conteúdo. Ele pode ou não ser o responsável pela aplicação do curso; caso seja, ele também faz o papel de instrutor, que pode ou não ser auxiliado por um monitor. O monitor lida com os aspectos práticos do curso, além de ajudar a avaliar os alunos.

O AulaNet fornece um conjunto de mecanismos que se subdividem em mecanismos de comunicação, de coordenação e de cooperação. Os primeiros oferecem os meios para a comunicação entre o professor e os alunos e entre os próprios alunos, sendo os seguintes: contato com o professor, que permite a comunicação assíncrona entre os alunos e o professor; grupo de discussão, que é uma lista de discussão que inclui todos os participantes de um curso; grupo de interesse, que permite a discussão encadeada sobre um assunto específico, como é feito nas ferramentas de newsgroups; e debate, que permite a comunicação síncrona que pode ser puramente textual, utilizando-se uma ferramenta chat, ou multimídia, usando o software de videoconferência CU-SeeMe. Os mecanismos de coordenação são responsáveis pelo planejamento de tarefas e pela avaliação. Dentre

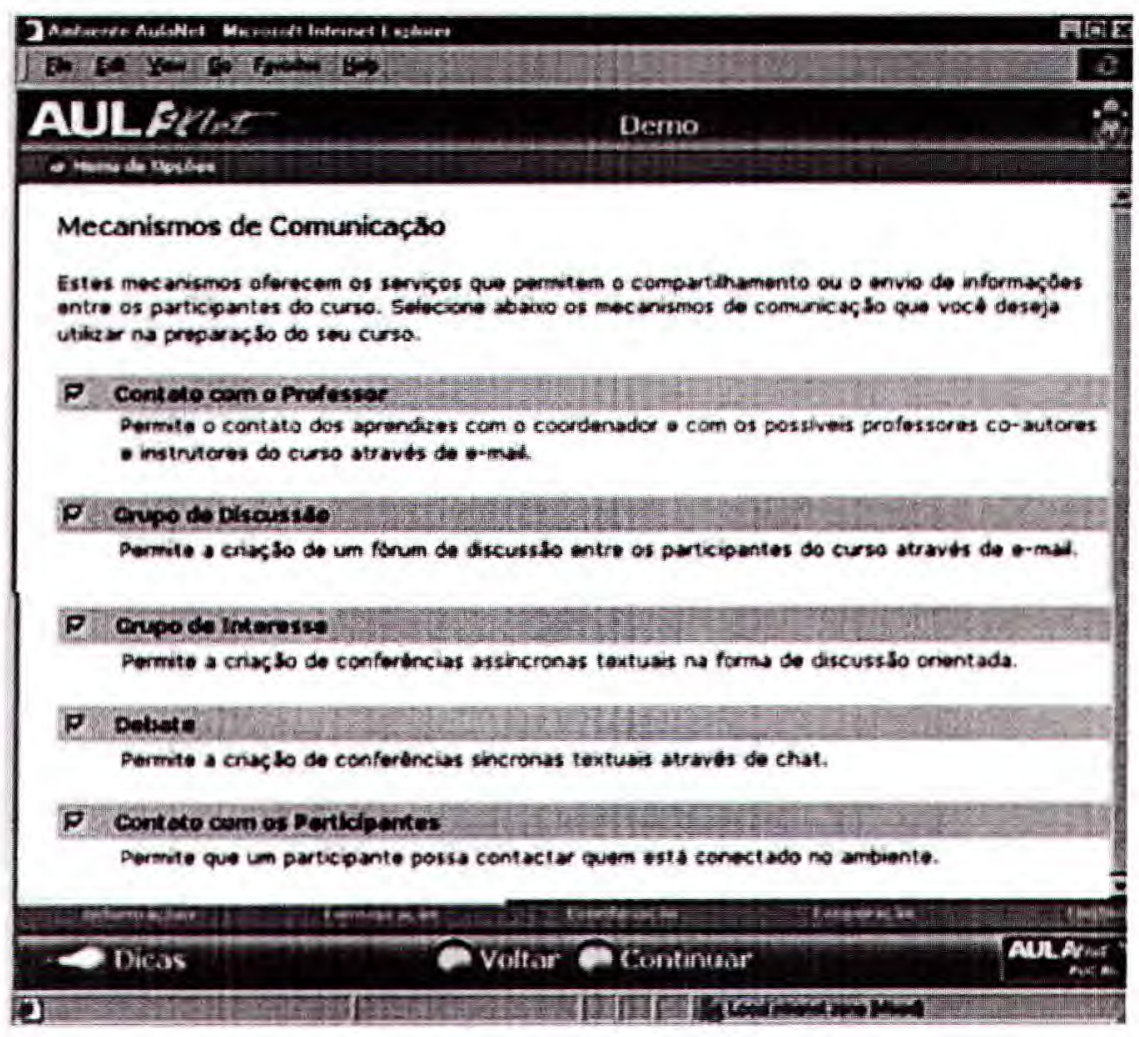

Figura 4.1: Tela para seleção dos mecanismos de comunicação 
eles, estão: agenda, que é um mecanismo para o planejamento de eventos, como chats e anúncios de prazos; notícias do curso, que funciona como um quadro de avisos; prova, trabalho e exercício, que são os métodos de avaliação dos alunos.

Finalmente, os mecanismos de cooperação fornecem os meios para a cooperação entre os alunos e o professor e entre os alunos. Cooperação, nesse caso, deve ser entendida sob o enfoque construtivista, isto é, outros professores e alunos possuem permissāo para preparar ou auxiliar a elaboração dos materiais que serão incorporados ao curso. $O$ AulaNet oferece os seguintes mecanismos de cooperação: transparência, que permite a utilizaçāo de arquivos PowerPoint para a apresentação do conteúdo do curso; apresentação gravada, que possibilita a utilização de arquivos RM como material do curso; texto de aula, que permite o uso de textos como arquivos PDF ou HTML; livro texto, que permite a leitura de livros texto em formato HTML no próprio ambiente; bibliografia, que permite o armazenamento de URLs ou referências; demonstração, que permite demonstrações com arquivos GIF, JPG, RM, AVI, MOV; co-autoria de professor, que permite que o professor convide outros professores para serem co-autores de seu curso; co-autoria de aluno, que permite que o professor escolha alunos para prepararem materiais para o curso.

Os mecanismos de comunicação, coordenação e cooperação são selecionados pelo professor em telas como a apresentada na Figura 4.1. Após selecionados, esses mecanismos tornam-se disponíveis para aquele curso específico. Na parte inferior da tela, existe uma barra que indica o progresso da elaboração do curso.

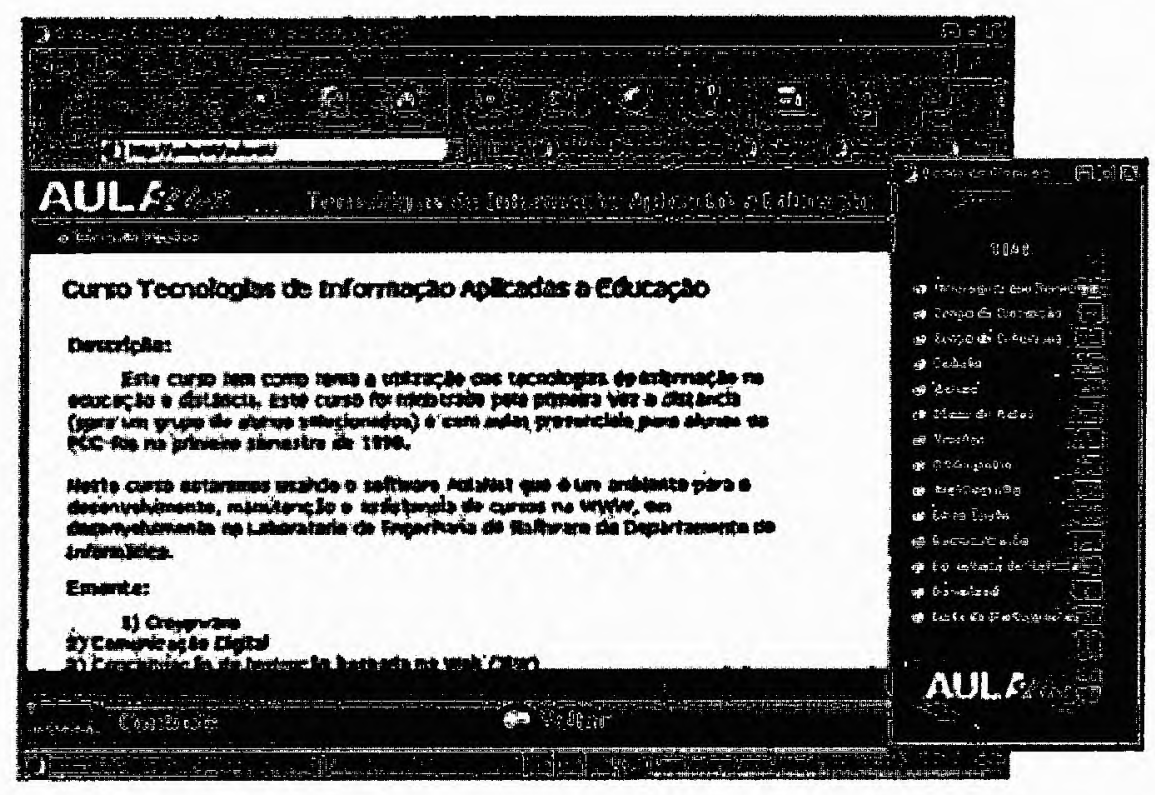

Figura 4.2: Controle remoto contendo o menu com os serviços específicos do curso

Como o AulaNet foi projetado para um público leigo, o ambiente possui a característica dè sẹparar o conteúdo da navegação, não exigindo que o professor tenha conhecimento 
sobre qualquer linguagem de programação para a Internet. Para a elaboração do material didático, o professor deve utilizar ferramentas de autoria que gerem arquivos nos formatos permitidos pelo ambiente (HTML, PDF, PPT e applets Java, entre outros). Esse material deve ser, em seguida, importado para o servidor AulaNet. Vale ressaltar que não existe nenhuma ferramenta de autoria no AulaNet, pois já existem muitas no mercado que podem ser utilizadas. A separação entre o conteúdo e a navegação também beneficia o aluno, que, ao invés de utilizar ligações de baixo nível, pode navegar por meio de um menu de serviços de alto nível e bastante intuitivo, o que ajuda a reduzir o problema de ficar perdido no hiperespaço. O menu de serviços é apresentado na forma de um controle remoto, como mostra a Figura 4.2. Além disso, os cursos oferecidos usando o ambiente são semelhantes estruturalmente, aumentando o sentido de orientação do aluno.

\subsubsection{Aspectos Administrativos do AulaNet}

O AulaNet realiza controle de acesso ao ambiente por meio da autenticação de seus usuários, ou seja, todos os participantes dos cursos devem estar cadastrados para que tenham acesso aos recursos e ao conteúdo disponível. O AulaNet permite que o próprio usuário cadastre-se no ambiente. Selecionando a opção "Registra-se", na tela exibida na Figura 4.3, é apresentado um formulário que deve ser preenchido pelo usuário para a requisição do cadastramento. Nesse formulário, o próprio usuário fornece um nome e uma senha que serão usados para a sua identificação no ambiente. A requisição é então apresentada ao administrador que analisa o pedido e, se este for aceito, é enviada uma notificação ao usuário interessado.

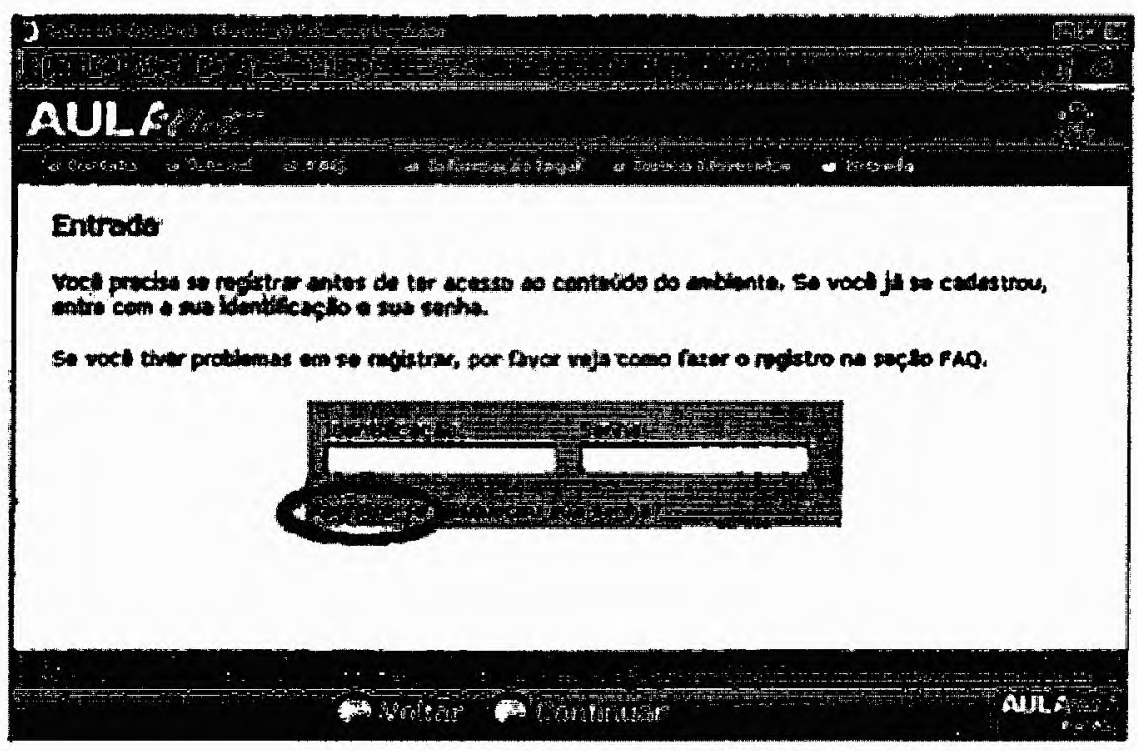

Figura 4.3: Tela inicial para identificação ou para solicitação de registro no ambiente 
Após o cadastramento, o usuário deve entrar no ambiente identificando-se corretamente. Seus dados são validados e uma lista de opções é exibida. Diferentes opções são apresentadas para diferentes níveis de usuários. Aos alunos é permitido solicitar matrícula em um curso e alterar seus dados cadastrais. Os pedidos de matrícula também são enviados ao administrador do AulaNet que os aceita ou não, enviando, em seguida, uma notificação para o aluno solicitante. Depois de matriculado em um curso, são acrescentadas à interface do aluno as opçōes: assistir curso e pedir trancamento de matrícula.

A interface do docente apresenta algumas opções adicionais, como mostra a Figura 4.4. Além das opções "alterar dados de registro", "pedir matrícula em um curso" e "assistir curso", que também estão presentes, pois o docente de um curso pode ser aluno de outro, existem as op̧̧ões "criar curso" e "fazer manutenção de curso". A criação de um curso é acompanhada por uma barra de progresso, na qual são disponibilizados os mecanismos que podem ser utilizados na montagem do curso e que serão convertidos em serviços e facilidades de navegação.

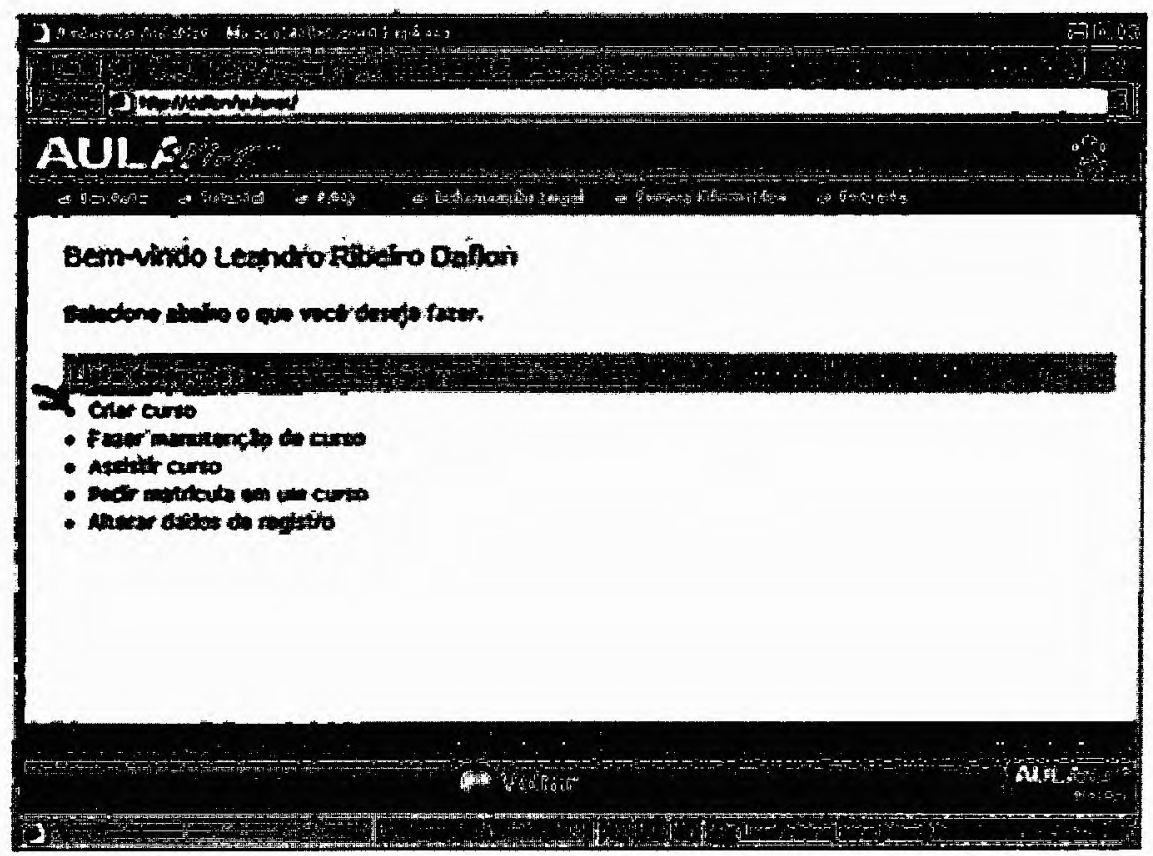

Figura 4.4: Interface inicial do docente

\subsubsection{WebCT}

O WebCT é uma ferramenta para a criação de ambientes educacionais virtuais baseados na Web, desenvolvida pelo Departamento de Ciência da Computação da Universidade da Columbia Britânica, Canadá. O WebCT permite a criação de cursos apresentados em páginas HTML e apresenta vários mecanismos que possibilitam a comunicação entre 
professores e alunos, por exemplo, listas de discussão ou fóruns subdivididos por assunto, chats para discussões on-line, correio eletrônico interno e agenda para comunicar avisos relativos ao curso e eventos. Tais mecanismos permitem maior integração entre os participantes de cada curso, bem como favorecem a construção do conhecimento de forma cooperativa (WebCT, 1999a).

Uma característica apresentada pelo WebCT é a preocupação com a avaliação do aluno ao longo do processo de aprendizagem. Para dar suporte a essa tarefa, o sistema possui recursos para publicação de gabaritos e comentários sobre provas anteriores, administração de notas de provas e trabalhos, gráficos estatísticos para acompanhamento da evolução dos alunos pelo professor e históricos que registram as páginas visitadas pelo aluno, entre outros, que também podem ser utilizados como apoio ao curso presencial.

Como meios de avaliação, são utilizados trabalhos, que podem ser publicados no próprio ambiente, e testes on-line, que podem ser de dois tipos: auto-teste e teste. $\mathrm{O}$ auto-teste permite a auto-avaliação do aluno. É elaborado e disponibilizado pelo docente e contém somente questões de múltipla escolha. $\mathrm{O}$ aluno responde as questões, obtendo um retorno imediato sobre seus erros e acertos. O teste já é um questionário mais elaborado que pode conter tanto questões de múltipla escolha e de associação como questões dissertativas. $\mathrm{O}$ aluno envia o teste e recebe um retorno imediato sobre seu desempenho nas questões que podem ser corrigidas automaticamente; no caso das questões dissertativas, o retorno não é imediato, pois o professor precisa corrigi-las primeiro.

Os atores considerados pelo WebCT são:

- Administrador: responsável pelo Servidor WebCT. O administrador é quem autoriza a criação de novos cursos e cria os usuários designers, que são as pessoas responsáveis pela elaboração de cada curso.

- Designer: na maioria dos casos é o professor, mas pode ser uma pessoa orientada pelo mesmo. O designer, na verdade, é o responsável pela elaboração e pelo registro das informações referentes ao curso. O designer cria as páginas e monta o curso, publica-o na Internet, enviando-o para o Servidor WebCT, cadastra os alunos e registra as notas das avaliações. O designer pode também criar um usuário especial chamado monitor.

- Monitor: pessoa que auxilia o designer a administrar registros dos alunos. Os monitores podem criar, alterar ou excluir alunos e editar as suas notas.

- Aluno: usuário final que irá acompanhar o curso criado (WebCT, 1999b).

Todos os cursos do WebCT possuem uma estrutura semelhante, embora algumas características possam ser configuradas como recursos específicos a serem utilizados em cada 
curso. Isso facilita tanto a criação do curso pelo professor quanto a adaptação do aluno ao ambiente. Existem ainda recursos no WebCT que auxiliam o usuário durante o processo de navegação e permitem a realização de pesquisas, tais como: mecanismos para criação de sumários, que organizam todas as páginas do curso dentro de um caminho, e glossários, que contêm definições de termos técnicos e palavras-chave ligados às suas ocorrências no conteúdo do curso. Outras opções também auxiliam o processo de navegação, como os botões "Contents", que levam ao índice de tópicos, e "Retrace" que retorna à última página visitada pelo aluno. Ambos aparecem em todas as páginas de conteúdo. A versão 2.0 do WebCT apresenta ainda recursos que têm como objetivo minimizar a desorientação do leitor, como o mapa do site, que mostra a organização do curso inteiro por meio de um mapa; e My WebCT, que é uma área reservada para cada usuário do WebCT, com ligações para todos os cursos em que ele está matriculado, com avisos relativos a cada um dos cursos, como novos trabalhos e testes enviados pelo professor e mensagens do administrador do sistema.

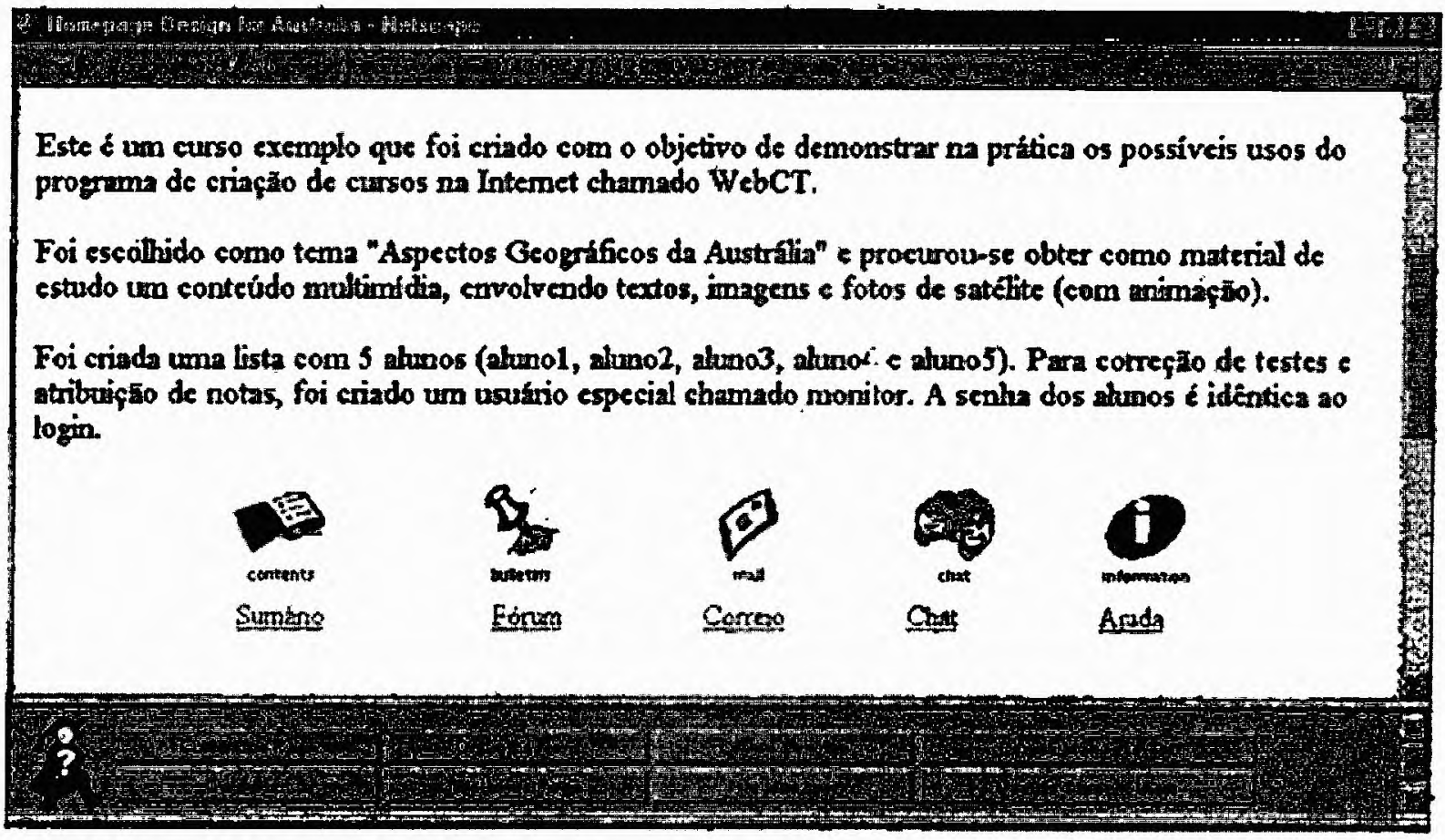

Figura 4.5: Tela de trabalho do designer

Além do My WebCT, existem outros recursos que auxiliam o aluno a organizar e a estruturar o seu material e a complementá-lo com informações que facilitem a sua compreensão, como é o caso das anotações, dos bookmarks e do mecanismo de revisão. As anotações correspondem a uma área de texto que pode ser utilizada para a criação de notas pelo aluno; essa área é privativa e está associada a páginas individuais de conteúdo. Os bookmarks permitem que o aluno marque algumas páginas do curso de maior interesse 
para consulta posterior. Finalmente, a revisão possibilita a montagem de uma nova página contendo somente tópicos específicos do curso, escolhidos pelo aluno.

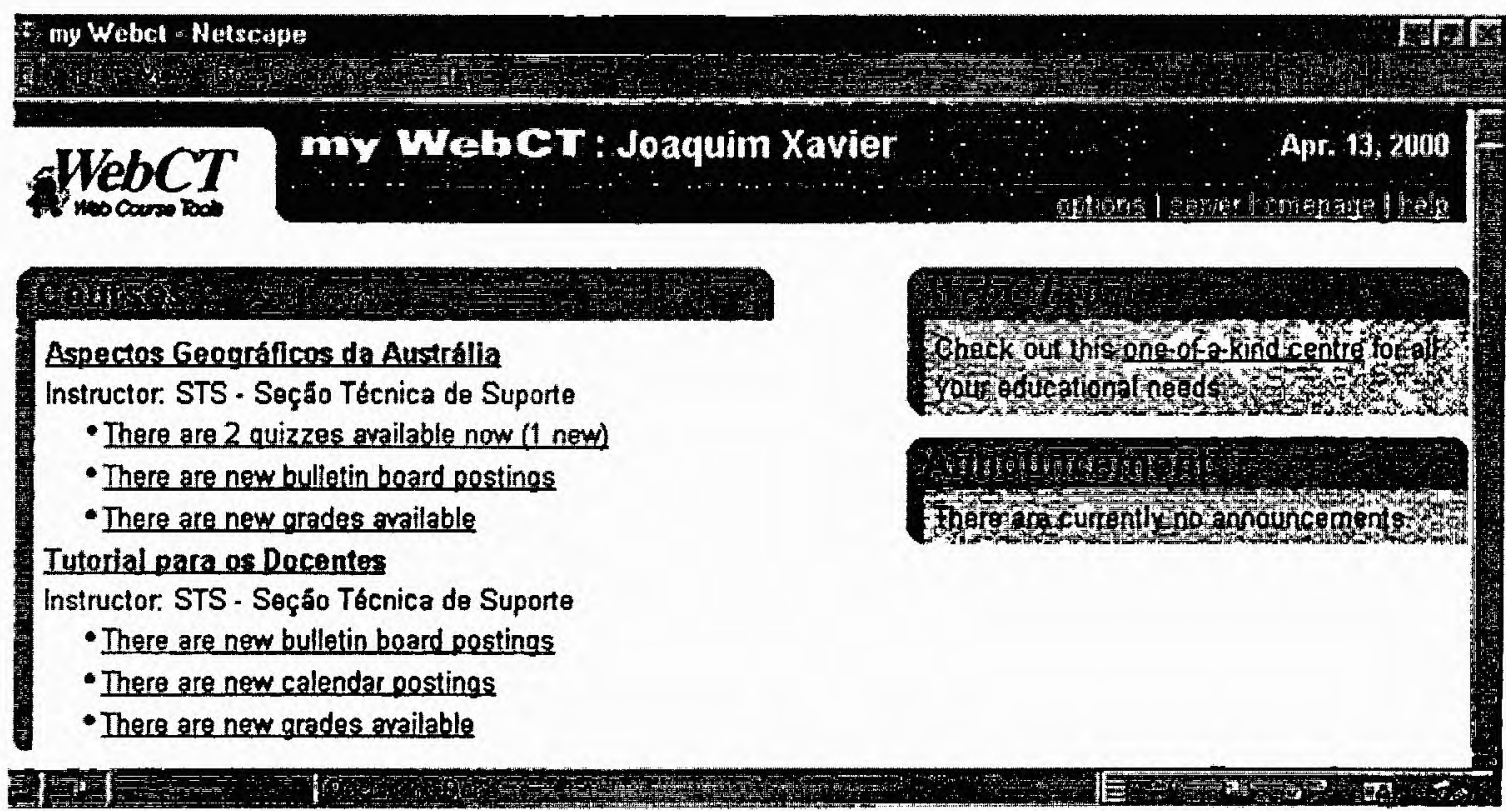

Figura 4.6: Interface do My WebCT

Por fim, o WebCT também oferece mecanismos que ajudam o professor a estruturar melhor o material didático, de modo a torná-lo mais claro e completo, dentre os quais estão os ícones objetivo, referências e informações. O primeiro ícone apresenta o objetivo que deveria ser atingido com a leitura daquele texto, ou seja, o que o aluno deveria ter aprendido após aquele estudo. O ícone de referências conduz a uma página preparada pelo docente, contendo uma listas de ligaçōes para páginas externas que complementam o assunto tratado no curso. $O$ ícone informações exibe um arquivo de ajuda disponibilizado pelo docente, que pode ser um site externo de ajuda do WebCT ou uma FAQ contendo respostas às perguntas mais freqüientes dos alunos do curso.

Quanto ao aspecto tecnológico, o WebCT é um ambiente disponivel na Web, o que faz com que alunos e professores possam utilizar o sistema sem precisar instalá-lo localmente; para usá-lo, tanto o docente quanto o aluno precisam somente de acesso à Internet, um navegador e uma conta no WebCT. Portanto, o WebCT oferece um ambiente baseado na Web para a criação e estruturação de cursos a distância, além de um conjunto de ferramentas que possam ser incorporadas aos mesmos.

\subsubsection{Aspectos Administrativos do WebCT}

Ao contrário do AulaNet, o WebCT não permite que os próprios usuários solicitem seu cadastramento no ambiente. No WebCT, o processo ocorre de uma maneira diferente. 
Inicialmente, o administrador cria uma conta para cada curso, que possui um identificador e uma senha. Essas informações são, então, passadas para o designer responsável pelo curso, que normalmente é o docente ou uma pessoa orientada por ele. $O$ fato de um usuário não poder requisitar seu cadastramento no ambiente sugere que o WebCT deva ser usado, principalmente, como uma ferramenta de apoio ao curso presencial e não somente como um ambiente de ensino a distância.

Cada designer pode elaborar vários cursos e, portanto, trabalhar com diversos identificadores e senhas diferentes. Entretanto, com o recurso My WebCT, introduzido na versão 2.0 do WebCT, cada usuário pode criar seu próprio identificador global (ID global) que é usado para acessar uma área de trabalho reservada, onde são agrupados todos os cursos dos quais o usuário é docente e nos quais está matriculado como aluno. Com esse recurso, elimìina-se a necessidade de utilização de múltiplos identificadores e senhas, pois todos os cursos tornam-se acessíveis pela utilizaçāo do ID global.

O designer também é o responsável pelos cadastramento dos alunos nos cursos e dos seus monitores, que possuem privilégios especiais de acesso, tais como incluir ou excluir alunos e editar notas. Para o acesso a cada curso, é atribuído ao aluno um identificador e uma senha. $\mathrm{O}$ aluno também pode usar o recurso My WebCT para ter acesso a todos os cursos em que está matriculado usando um único identificador.

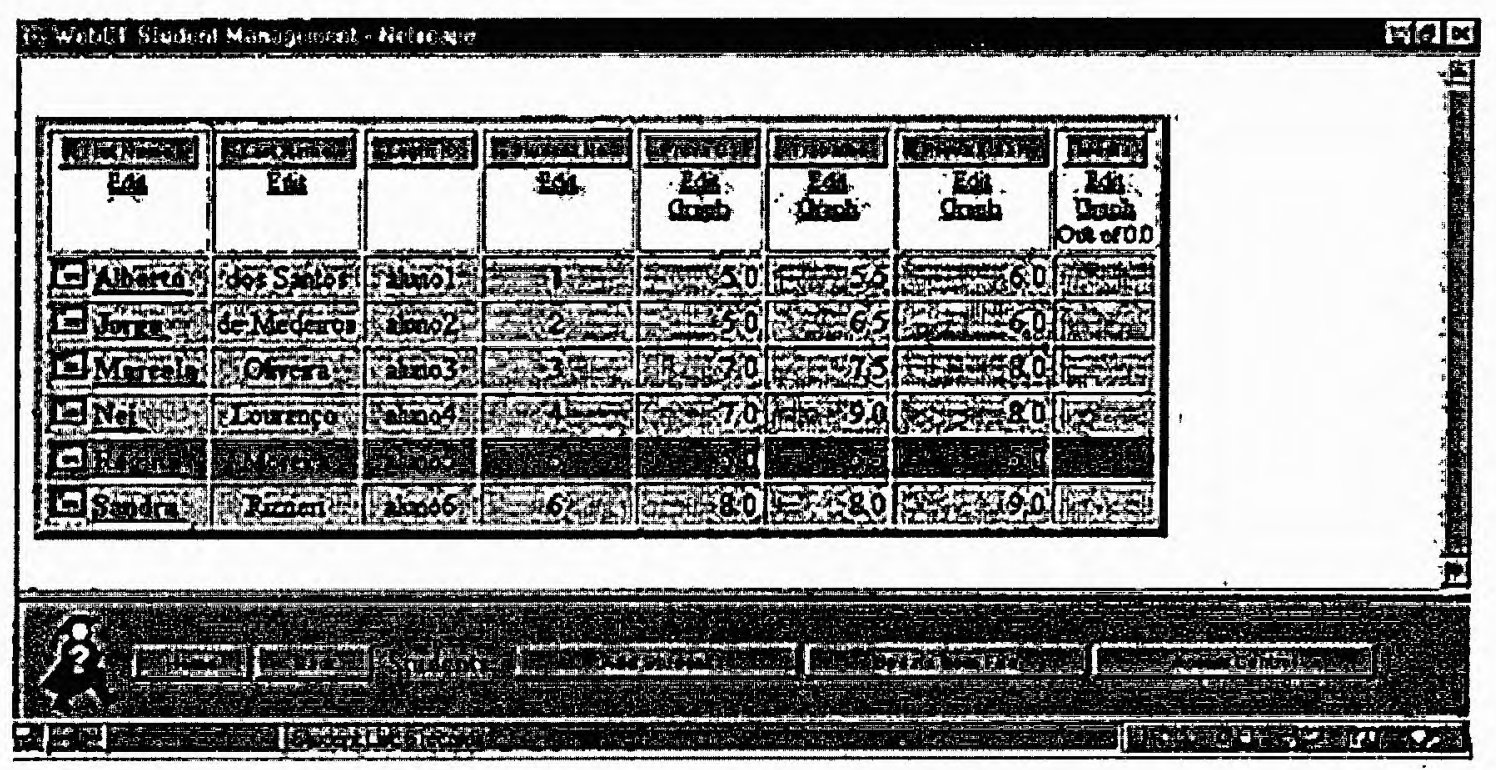

Figura 4.7: Planilha de notas dos alunos

Outros recursos oferecidos para o designer são o File Manager e o Course Management. Utilizando o File Manager, o designer é capaz de criar, excluir, editar, copiar, mover, renomear, compactar e descompactar, fazer downloads e uploads de arquivos, além de organizá-los em diretórios. Por meio do Course Management, o designer pode gerenciar aspectos relativos ao curso propriamente dito, como realização de backups do curso e 
acompanhamento das estatísticas das páginas de conteúdo visitadas; e também pode gerenciar as informações dos alunos pela opção Student Management. Uma das principais características do WebCT é a preocupação com a avaliação. Sendo assim, o ambiente oferece vários recursos para o acompanhamento do aluno, como históricos que indicam o seu progresso no curso e estatísticas das avaliações. O Student Management é o principal recurso oferecido ao designer para a organização dos dados do aluno. Esse recurso permite a criação e a edição de uma planilha, contendo o nome dos alunos, as notas recebidas em cada avaliação e a média final.

\subsubsection{CALM}

O CALM (Computer-Aided Learning Material) é um sistema desenvolvido com a finalidade de oferecer um curso de ensino a distância, integrando mecanismos para criação do material didático, apresentação teórica, avaliações, exercícios práticos e respostas a dúvidas. As funções que o sistema apresenta são: criação do material didático, seleção do material, interação entre alunos e instrutores e avaliação do aluno (Magalhães, 1998).

O propósito do CALM é disponibilizar materiais, apoiar o aprendizado extracurricular e oferecer um ambiente de aprendizagem colaborativo baseado em computador, que complemente o paradigma tradicional de ensino e integre a teoria à prática por intermédio de uma estratégia de ensino direcionada a objetivos.

No CALM, existem três atores: o aluno, o professor e o autor. O aluno é o aprendiz, ou seja, aquele que tem o propósito de adquirir conhecimentos ou habilidades pela utilização do sistema. O professor é o responsável por adaptar o material a um grupo de alunos, responder às dúvidas, organizar a FAQ (dúvidas mais freqüentes), corrigir os exercícios e adicionar sugestões às páginas de tópicos. O autor é o responsável por criar e atualizar as várias instâncias do material e pode também fazer sugestões. Geralmente o autor é o próprio professor. $\mathrm{Na}$ modelagem do sistema, existe ainda a entidade "pessoa" que é uma superclasse das entidades aluno, professor e autor, responsável pelas informações de acesso ao sistema e pelos dados gerais dos usuários. Todos os usuários do CALM devem ser previamente cadastrados na classe "pessoa" para que seu acesso ao sistema seja liberado (Adriano, Delgado, Junior, Bosnardo, Ricarte \& Magalhães, 1999).

O material de um curso é formado por uma seqüência de tópicos determinada pelo professor do curso para atingir seu objetivo de ensino. Esses tópicos podem conter subtópicos que formam uma estrutura hierárquica. A cada tópico são associados exercícios e testes que são utilizados como forma de avaliar o conhecimento adquirido pelo aluno, aprovando ou não a sua passagem para o tópico seguinte. Os tópicos, os materiais, os testes e os exercícios podem ser agrupados por assunto, que é um tema definido pelo professor para 
a identificação de uma área delimitada do conhecimento.

O CALM pode ser visto como um sistema "recomendador", no sentido de que, baseado em um conjunto de textos disponíveis, é capaz de selecionar, agrupar e recomendar tópicos associados a um assunto de interesse do usuário, baseado em algumas entradas por ele formecidas. No caso do CALM, em particular, as recomendações selecionadas baseiamse em metas de aprendizagem específicas, assuntos previamente estudados pelos alunos, materiais disponíveis e assuntos que ainda precisam ser explorados. Sendo assim, uma recomendação do CALM é uma composição dos assuntos que o aluno deseja estudar e que o professor supõe que deva ser aprendido de acordo com objetivos pré-definidos.

Nesse sentido, o progresso do aluno precisa ser acompanhado e seus objetivos conhecidos e, para isso, é armazenado o perfil de cada aluno. O perfil representa o conhecimento adquirido pelo aluno. A atualização desse conhecimento é dinâmica, isto é, conforme o aluno percorre o curso, o perfil é modificado. A existência do perfil é fundamental para que o tutor decida sobre a seqüência de tópicos que será oferecida ao aluno, pois a passagem de um tópico da seqüência formada para outro pode estar restrita e ser dependente do conhecimento acumulado pelo aluno (Delgado, Adriano, Vasconcelos, Junior \& Bosnardo, 1998). O tutor é um agente de software responsável pela composição da unidade de estudo que corresponde ao conjunto formado pela estrutura de tópicos a ser seguida e pelos testes e exercícios associados. Cada unidade de estudo é criada baseada no perfil do aluno, que inclui o conhecimento acumulado, no objetivo de aprendizagem e no material disponível. No CALM, um objetivo de aprendizagem é um conjunto de assuntos de interesse definidos pelo aluno.

Inicialmente, quando é criada uma instância do aluno, seu perfil está vazio. O tutor então gera uma unidade de estudo e atualiza o perfil armazenando o assunto e o peso total dos testes associados. No final de cada teste referente à unidade de estudo gerada, é recalculado e armazenado o atributo "nota", que indica o grau de conhecimento do aluno com relação àquele teste específico. A avaliação do aprendizado do aluno é importante para se decida se ele pode prosseguir com o curso ou se alguns tópicos precisam ser revisados.

Os testes possuem a finalidade de medir o desempenho do aluno em determinado assunto. No caso do CALM, os testes são usados para auto-avaliação e são compostos por questões objetivas. A correção dos"testes é realizada de forma automática e, para tanto, suas soluções são armazenadas na forma de um gabarito. Os exercícios visam à avaliação formativa e são apresentados ao aluno quando este conclui o estudo de um determinado assunto. Podem ser elaborados na forma de questões verdadeiro ou falso, múltipla escolha ou preenchimento de lacunas (Magalhães, 1999).

O CALM engloba ainda conceitos que auxiliam a aprendizagem, tais como: sugestão, 
que é uma anotação elaborada por um autor ou professor com o intuito de fornecer referências e explicações adicionais sobre o assunto abordado; anotação, que é um conteúdo que pode ser anexado a algum tópico e que contém alguma observação para o seu melhor entendimento; e tópico recomendado, que é um tópico que contém algum conhecimento requerido para a compreensão de um outro tópico. Vale ressaltar que muitos dos conceitos usados pelo CALM baseiam-se nos conceitos definidos pelo Learning Technology Standard Committee (LTSC), cuja finalidade é especificar padrões para as tecnologias associadas à educação.

\subsubsection{Outros Exemplos de Ambientes para o Ensino a Distância}

Existem ainda vários outros ambientes voltados para o ensino ou treinamento a distância via WWW, que ainda estão em desenvolvimento, em fase de teste ou que já estão sendo utilizados. A seguir, é apresentada uma visão geral de alguns desses ambientes (Magalhães, 1998) e uma tabela com a comparação dos principais recursos oferecidos pelos mesmos, incluindo o WebCT e o AulaNet, descritos anteriormente.

Virtual-U é um software para projeto, oferecimento e manutenção de cursos e treinamento via WWW. Esse é um projeto desenvolvido pela Universidade Simon Fraser, Burnaby, BC, Canadá. O sistema está estruturado em cinco componentes. O componente Vgroups Conferecing System oferece aos instrutores a possibilidade de definir grupos colaborativos, tarefas e objetivos. A ferramenta Course Structuring Tool é usada para preparação dos cursos, sem supor conhecimento de programação pelo usuário. O componente Gradebook gerencia o desempenho do aluno. O conjunto de ferramentas System Administration Tools gerencia o sistema em geral (contas, privilégios, etc.). Finalmente, o componente Upload Features permite o envio de informações multimídia dos clientes ao servidor.

Learning Space é um produto da Lotus com o objetivo de oferecer soluções para aprendizagem via WWW. Apresenta cinco componentes principiais: Schedule database permite que participantes naveguem pelo material de um curso; MediaCenter database contém o material didático (artigos, resumos, etc.); Virtual CourseRoom permite discussões entre os participantes e o instrutor, além de apoiar atividades de equipe; Profiles database contém informações sobre os participantes; e Assessment Manager database apóia a avaliação dos alunos pelo instrutor.

First Class é um software que apóia a comunicação e colaboração entre professores e alunos como forma de disseminação de conhecimento. Possibilita a comunicação assíncrona, por meio de fóruns de discussão, e síncrona, por meio de chats. Fornece facilidades de uso por leigos e para a administração do sistema. Possui ferramentas para 
criação de conteúdo.

Top-Class é um sistema da WBT Systems desenvolvido para educação via Web. O sistema oferece ferramentas para criação e edição de cursos, administração de cursos e para guiar a aprendizagem multimídia. Não suporta a comunicação síncrona por chats, mas permite o envio e o recebimento de mensagens e a comunicação por listas de discussão.

\begin{tabular}{|c|c|c|c|c|c|c|}
\hline 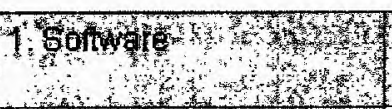 & vituato & Spatarg & Whitas & 7mos & Andret & Webt \\
\hline $2 \mathrm{Esbjedw}$, & $\begin{array}{c}\text { Virtual } \\
\text { Learning } \\
\text { Environments }\end{array}$ & Lotus & SotAarc & $\begin{array}{l}\text { WaT } \\
\text { Systems }\end{array}$ & $\begin{array}{l}\text { LES } \\
\text { PUC-Rio }\end{array}$ & $\begin{array}{l}\text { University } \\
\text { British } \\
\text { Columbia }\end{array}$ \\
\hline 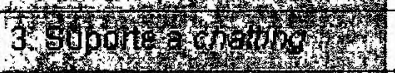 & กล̃o & $\operatorname{sim}$ & sim & กลึo & $\operatorname{sim}$ & $\operatorname{sim}$ \\
\hline 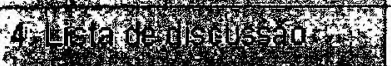 & $\operatorname{sim}$ & sim & sim & $\operatorname{sim}$ & sim & $\sin$ \\
\hline 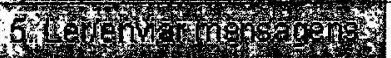 & $\operatorname{sim}$ & $\operatorname{sim}$ & $\operatorname{sim}$ & $\sin$ & $\operatorname{sim}$ & $\operatorname{sim}$ \\
\hline 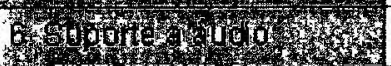 & กลื่ & กล̃o & กล๊o & $\operatorname{sim}$ & $\operatorname{sim}$ & $\operatorname{sim}$ \\
\hline brong & กล๊o & กล̃o & กล๊o & $\sin$ & $\operatorname{sim}$ & $\operatorname{sim}$ \\
\hline 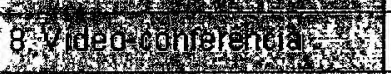 & กล๊o & não & กล̃o & $\operatorname{sim}$ & $\operatorname{sim}$ & กล๊o \\
\hline $4 \log ^{2}$ & $\operatorname{sim}$ & $\operatorname{sim}$ & $\operatorname{sim}$ & sim & $\operatorname{sim}$ & $\operatorname{sim}$ \\
\hline solow & $\operatorname{sim}$ & sim & $\operatorname{sim}$ & sim & $\operatorname{sim}$ & $\operatorname{sim}$ \\
\hline 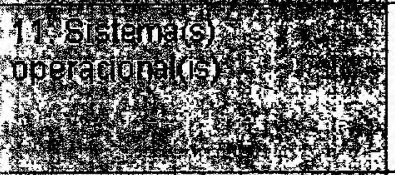 & $\begin{array}{c}\text { UNIX } \\
\text { Em teste para } \\
\text { o Windows } \\
\text { NT }\end{array}$ & $\begin{array}{l}\text { Mac OS, } \\
\text { Windows, } \\
\text { DOS e } \\
\text { UNX }\end{array}$ & $\begin{array}{l}\text { Mac OS, } \\
\text { Windows, } \\
\text { DOS e } \\
\text { UNIX }\end{array}$ & $\begin{array}{l}\text { Windows } \\
\text { 95NT, } \\
\text { Solarls, Mac } \\
\text { OS, Linux } \\
\end{array}$ & $\begin{array}{l}\text { Windows } \\
\text { 95/NT }\end{array}$ & $\begin{array}{l}\text { UNIXe } \\
\text { Windows } \\
\text { NT }\end{array}$ \\
\hline 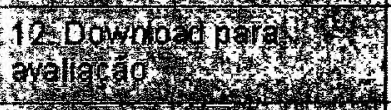 & กล๊o & sim & $\operatorname{sim}$ & $\operatorname{sim}$ & $\operatorname{sim}$ & $\operatorname{sim}$ \\
\hline 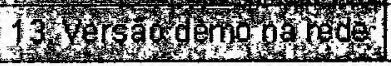 & sim & กลิ์ & กล๊o & $\sin$ & $\operatorname{sim}$ & sim \\
\hline
\end{tabular}

Figura 4.8: Comparação de ferramentas de ensino a distância

\subsection{Considerações Finais}

Com relação aos aspectos administrativos, que é o enfoque deste trabalho, verifica-se que o WebCT e sobretudo o AulaNet não oferecem um processo de administração muito complexo com relação à aprovação de cursos e ao registro do perfil de cada usuário, por exemplo. $\mathrm{O}$ gerenciamento nesses casos restringe-se basicamente a cursos, a alunos, a docentes ou autores dos cursos e a usuários do sistema, cujo registro armazena informações para controle de acesso e permite a atribuição de privilégios especiais. O WebCT ainda engloba um processo mais elaborado de acompanhamento e avaliação do alụno, o que não ocorre no AulaNet. 
No caso do CALM, os cadastros são os mesmos, entretanto há uma preocupação maior com o acompanhamento do progresso e dos objetivos do aluno, o que exige que o sistema armazene e gerencie uma quantidade maior de informações semânticas e que o conteúdo dos cursos não seja apresentado de forma aleatória, mas de acordo com os interesses e objetivos definidos pelo aluno. Uma possível aplicação que envolve um processo administrativo mais elaborado é o tema deste trabalho e é apresentada no próximo capítulo. 


\section{Capítulo 5}

\section{Um Método para Análise e Projeto de Sistemas de}

\section{Administrativo com Interface para a Web}

\subsection{Considerações Iniciais}

Neste capítulo é apresentado o Método para Análise e Projeto de Sistemas de Workflow Administrativo com Interface para a Web, que consiste no principal objetivo deste trabalho. Na Seção 5.2 são descritas as características e os principais requisitos do Sistema Atena - aplicação desenvolvida e utilizada como estudo de caso para a exploração das metas propostas neste projeto. Na Seção 5.3 é apresentada uma visão geral do processo de desenvolvimento. Na Seção 5.4 são descritos, para cada fase que compõe o ciclo de desenvolvimento, os aspectos relacionados ao processo, a notação utilizada e o exemplo de aplicação do método ao Sistema Atena, incluindo os modelos e documentos de especificação gerados em cada etapa.

\subsection{Estudo de Caso: Sistema Atena - Administração de Cursos de Extensão na Web}

O sistema escolhido para dar suporte à elaboração e exemplificar a aplicação do método implementa um processo de administração de cursos de extensão. Essa escolha justificase pela possibilidade que o sistema oferece de integrar a aplicação de um sistema de informação para Web à aplicação de um sistema que implementa um fluxo de trabalho 
administrativo bem definido. Em outras palavras, o sistema escolhido tanto é apropriado para ser implementado e utilizado na Web, quanto se caracteriza como um sistema de workflow e, portanto, permite a exploração dessas duas tecnologias de forma integrada, o que é o principal objetivo deste trabalho. Por tratar-se de uma aplicação para a Web, esse sistema também permite verificar a adequação dos modelos e métodos para especificação de aplicações hipermídia revisados no Capítulo 2, quanto à modelagem de sistemas para a Web.

Além do gerenciamento de cursos, departamentos, unidades, docentes, alunos, funcionários, etc., esse tipo de sistema também engloba a elaboração das propostas de cursos, o processo de aprovação dos cursos, as inscrições e aprovações dos candidatos aos cursos e o acompanhamento da freqüência e dos resultados das avaliações dos alunos para posterior certificação.

As primeiras atividades que devem ser apoiadas pelo sistema proposto são a elaboração da proposta do curso, a criação de um processo referente a essa proposta e a sua aprovação. A proposta do curso deve ser elaborada pelo docente responsável por sua realização, que deve preencher um formulário, disponível no próprio sistema, informando os dados gerais do curso e quem irá ministrá-lo. Essa proposta é encaminhada ao Assistente Acadêmico, que abre um processo para registrar a sua existência e para dar início ao processo de aprovação. A nova proposta é, então, submetida à aprovação do Conselho Departamental e da Comissão de Cultura e Extensão Universitária (CCEx) da Unidade. Caso a proposta tenha sido aprovada nas duas instâncias, o curso é divulgado e são abertas as inscrições na Web para os interessados em cursá-lo. É importante ressaltar que a sequiência de atividades aqui descrita baseia-se no processo de administração de cursos de extensão aplicado na USP e pode variar de acordo com a Instituição.

Pessoas interessadas em participar do curso podem acessar o formulário de inscrição, preenchê-lo e encaminhá-lo para que seus pedidos de inscrição sejam aprovados. O docente responsável pelo curso recebe esses pedidos, avalia as informações fornecidas e verifica se o candidato interessado atende aos pré-requisitos exigidos pelo curso, caso existam, e então aprova ou não a sua solicitação. Quando a inscrição de uma pessoa é aprovada, ela deixa de assumir o papel de candidato e passa a assumir o papel de aluno e usuário do sistema. Para isso, recebe uma identificação e uma senha de acesso que são atribuídas pelo docente. Se o curso não possuir nenhum pré-requisito ou se o docente não aprovar os candidatos até uma data-limite, os pedidos de inscrição são aceitos de acordo com a ordem de chegada até que todas as vagas tenham sido preenchidas. Ao término dessa atividade, é divulgada, no próprio ambiente do sistema, a lista de candidatos aprovados.

O curso é ministrado caso exista um número mínimo de alunos exigido e pode ser oferecido tanto na Web quanto em sala de aula. Em ambos os casos, a freqüência ou 
participação do aluno deve ser controlada pelo docente e armazenada pelo sistema. Os resultados obtidos pelos alunos, nos cursos de extensão nos quais são realizadas avaliações, também devem ser registrados para que, concluído o curso, possam ser emitidos os certificados daqueles que cumpriram as exigências requeridas.

Ao término do curso, o docente deve solicitar o cálculo das médias e das freqüências finais dos seus alunos e enviar essas informações para a Diretoria da Unidade. Em seguida, o Diretor encaminha à Pró-Reitoria de Cultura e Extensão Universitária o demonstrativo do aproveitamento obtido pelos alunos do curso em referência e solicita a autorização para a emissão dos certificados. O Pró-Reitor recebe e avalia essa solicitação e encaminha o processo à Assistência Acadêmica com a autorização para a emissão dos certificados. Esses são, então, emitidos pelo próprio sistema e entregues aos alunos aprovados. Após a emissão de certificados, o Assistente Acadêmico encaminha o processo novamente à PróReitoria para conhecimento do Conselho de Cultura e Extensão Universitária (CoCEx). Estando ciente, o CoCEx devolve o processo ao Assistente Acadêmico que irá arquivá-lo.

Observa-se, portanto, a existência dos seguintes atores: o docente, que é o responsável pela elaboração da proposta, por ministrar cursos, por aprovar inscrições e por controlar a freqüência e as notas dos alunos; os candidatos, que são as pessoas interessadas em participar dos cursos e que realizam o pedido de inscrição; os alunos, que são aqueles que tiveram suas inscrição aceitas e que realmente participam do curso; o Assistente Acadêmico, que atua como um administrador e é responsável pela correta tramitação do processo e pela criação de usuários, de processos, de departamentos e de unidades; - Diretor, que encaminha a proposta de curso à Pró-Reitoria de Cultura e Extensão e solicita a autorização para a emissão dos certificados; o Pró-Reitor, que toma ciência da proposta, autoriza a emissão de certificados e a encaminha para arquivo; e aqueles que assinam as aprovações, que são o Chefe do Departamento e o Presidente da CCEx.

O fator que motiva a automatização desse sistema é a necessidade de otimização do processo de aprovação dos cursos de extensão, isto é, de reduzir o tempo gasto nessa atividade, tornando-a mais ágil. Para que isso ocorra, dois aspectos importantes precisam ser tratados. O primeiro deles é a implementação do maior número possível de tarefas automatizadas. Quanto mais as atividades forem executadas de forma automática, mais fluente torna-se o processo e minimiza-se a necessidade de interferência humana ou de atividades manuais que, normalmente, duram mais tempo. O segundo deles está fortemente associado à disponibilidade do sistema na Web. Com isso, o sistema pode ser acessado e as aprovações e as inscrições podem ser realizadas a partir de qualquer lugar e em qualquer instante de tempo, o que certamente otimiza o processo. Além disso, um sistema como o proposto pode ser integrado e servir de apoio a servidores de cursos na Web que requerem um processo administrativo mais completo. 


\subsection{O Processo de Desenvolvimento}

Nesta seção é apresentada uma breve descrição das fases que compõem o processo de desenvolvimento de sistemas de workflow com interface para a Web, das interdependências entre elas e dos resultados obtidos com a sua execução. A forma como essas fases estão organizadas e interagem entre si é ilustrada na Figura 5.1. Cada etapa produz um modelo, isto é, um conjunto de um ou mais diagramas, que descreve formalmente os aspectos da aplicação focalizados naquela etapa e documenta as atividades realizadas.

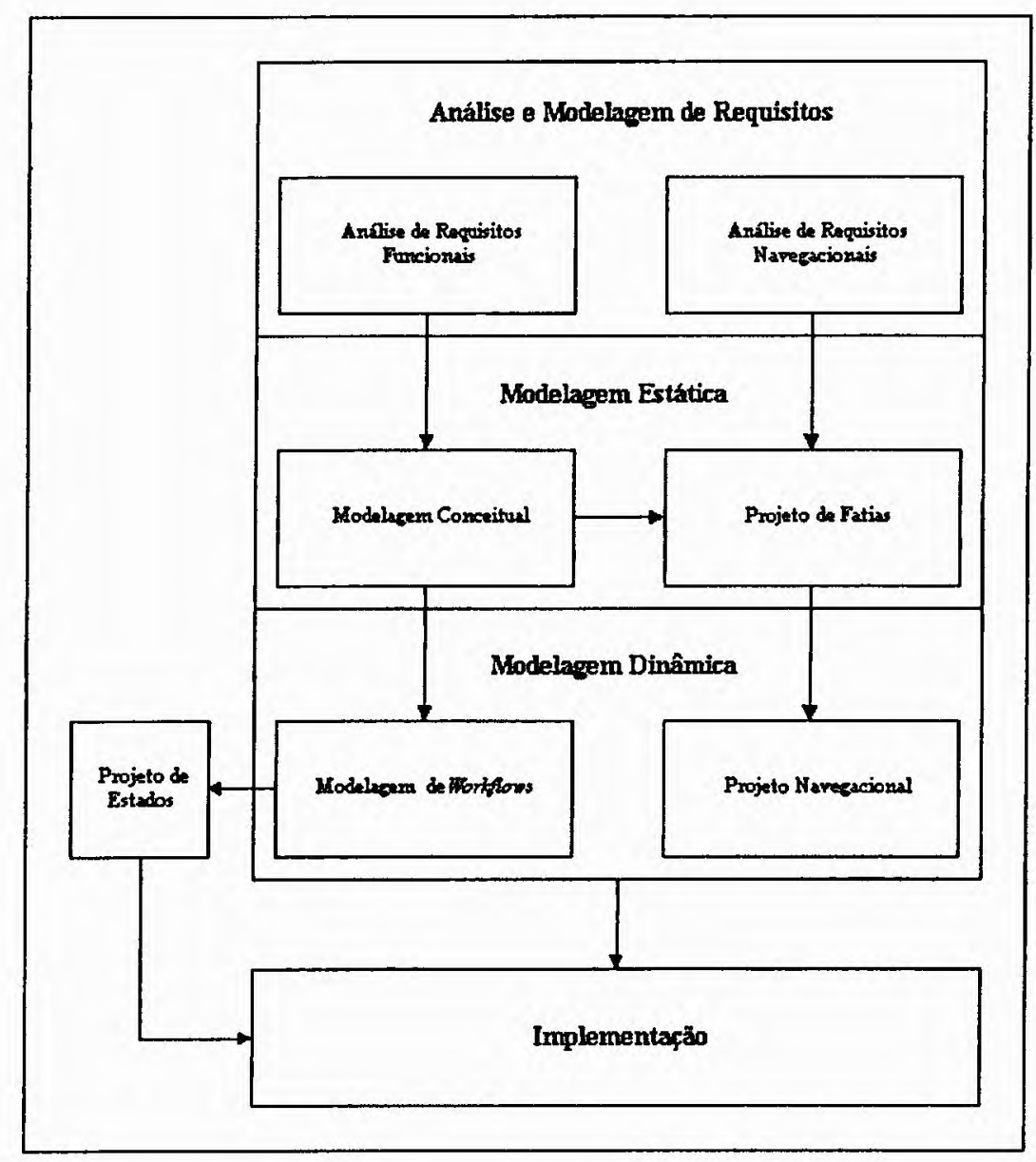

Figura 5.1: Fases do processo de desenvolvimento

Análise e Modelagem de Requisitos: Durante esta primeira etapa do processo de desenvolvimento, é realizada a análise e a modelagem dos requisitos que definem as funcionalidades e metas do sistema. No caso de sistemas com interface para a Web, a análise de requisitos deve ser estendida para especificar também os requisitos navegacionais e de visibilidade. Sendo assim, esta fase consiste na definição de atores ou papéis, na análise de requisitos funcionais e na análise de requisitos navegacionais da aplicação. Para a sua representação e documentação, são utilizados os diagramas de casos de uso 
da UML (Fowler, 1998; Rumbaugh et al., 1999), o padrão para descrição de casos de uso sugerido por Larman (1997) e a extensão proposta por Baresi et al. (2001).

Modelagem Conceitual: A modelagem conceitual é representada por um modelo de classes e define a estrutura estática das informações ou conceitos envolvidos pelo sistema, em termos de classes de objetos e dos relacionamentos ou associações existentes entre elas. Esse modelo também define as operações e os atributos que caracterizam cada objeto. A notação do modelo de classes da UML será utilizada para a sua representação.

Projeto de Fatias: O projeto de fatias determina como as informações devem ser apresentadas aos usuários. Para isso, os atributos de diferentes entidades são agrupados em fatias significativas de informação que são organizadas na forma de um hipertexto. Esse é o primeiro passo para a especificação da interface dos sistemas para a Web. O agrupamento de atributos pertencentes a diferentes entidades será feito utilizando-se o conceito de $m$-slice do RMM estendido (Isakowitz et al., 1998b).

Modelagem de Workflows: Esta fase tem como base os requisitos funcionais especificados na fase de análise e modelagem de requisitos. Durante esta etapa, é definido o comportamento do sistema em termos das seqüências nas quais as atividades devem ser realizadas e das pré e pós-condições para a execução de cada tarefa, ou seja, é nesta etapa que são especificados os workflows abrangidos pelo sistema. Os diagramas de atividades e o conceito de linha divisória (swimlane) da UML serão utilizados para esta especificação e a classificação sugerida no método BPI (Jackson \& Twaddle, 1997) será utilizada para o detalhamento das tarefas.

Projeto Navegacional: O propósito do projeto navegacional é definir como os usuários podem navegar pela informação e quais estruturas serão utilizadas para o acesso às páginas que compõem o sistema. No caso do RMM (Isakowitz et al., 1995), que será aplicado nesta etapa, as estruturas de acesso são as ligações uni e bidirecionais, os agrupamentos, os índices, os roteiros guiados e os roteiros guiados indexados. Nesta etapa, também serão utilizados conceitos provenientes do modelo HDM (Garzotto et al., 1993a; Garzotto et al., 1994), tais como as coleções e alguns dos estereótipos da UML estendida (Conallen, 1999a). O projeto navegacional é fundamental pois a sua definição auxilia a organização do conteúdo de forma a evitar que, durante a navegação, o usuário se perca no hiperespaço. Ainda nesta fase, são especificadas as diferentes visões do sistema. O conceito de visão é um dos aspectos-chave tanto dos sistemas workflow quanto dos sistemas de informação para a Web, pois nesses sistemas é muito comum que diferentes grupos de usuários tenham diferentes perspectivas da aplicação, das informações contidas no sistema e das operações disponíveis. Nesse sentido, as visões permitem especificar quais funcionalidades, estruturas de acesso e contextos de navegação estarão disponíveis para cada usuário do sistema. 
Projeto de Estados: O projeto de estados complementa a fase de modelagem de workflows, pois especifica os diferentes estados assumidos por objetos do sistema no decorrer da execução dos fluxos de trabalho. Os estados assumidos são particularmente importantes nos sistemas de workflow, pois determinam a evolução do fluxo de trabalho e a criação de diferentes contextos funcionais para cada grupo de usuários. Essa atividade não é obrigatória para todos os elementos do sistema, mas deve ser realizada para aqueles objetos cuja mudança de estado gera conseqüências significativas para a evolução da aplicação. Para a documentação desta etapa, serão utilizados os diagramas de estados da UML.

Implementação: A implementação é a fase na qual é realizada a conversão dos modelos ou representações, elaborados durante todas as etapas do processo de desenvolvimento apresentadas para os programas codificados em uma linguagem de programação e legível por computadores. Durante esta etapa, também devem ser tomadas decisões acerca da estrutura da base de dados e das mídias apropriadas para a apresentação do conteúdo do sistema e deve ser realizada a documentação do código-fonte, o que facilita o entendimento da implementação para a posterior manutenção.

\subsection{Fases do Processo de Desenvolvimento}

\subsubsection{Análise e Modelagem de Requisitos}

O ciclo de desenvolvimento de todo e qualquer sistema deve ter início com a captura ou elicitação dos requisitos que definem suas funcionalidades e suas principais características. O resultado da atividade de elicitação é um documento de requisitos que descreve o sistema e que pode tanto ser escrito de maneira informal e em linguagem natural (como na Seção 5.2) quanto pode ser utilizada alguma técnica específica de especificação de requisitos. Com base nesse documento deve ser realizada a análise e a modelagem dos requisitos, atividades nas quais ocorre a descrição e o detalhamento dos requisitos identificados. $O$ propósito desta fase é compreender as metas e o domínio da aplicação. É fundamental que a fase de análise e modelagem de requisitos seja completa, coesa e sem ambigüidades, pois os documentos gerados durante essa etapa formam as diretrizes ou a base para todo $o$ restante do processo. Como resultado dessa etapa, deve-se obter uma abstração funcional do sistema expressa em termos de casos de uso (use cases).

No caso dos sistemas de workflow para a Web, a análise de requisitos deve ser estendida para abordar também os requisitos navegacionais e de visibilidade do sistema. Sendo assim e seguindo o procedimento adotado pelos autores do framework W2000 (Baresi et al., 2001), esta primeira etapa do método divide-se em: definição de atores ou papéis, análise 
de requisitos funcionais e análise de requisitos navegacionais. Para a sua representação, são utilizados os diagramas de casos de uso da UML (Fowler, 1998; Rumbaugh et al., 1999) e o padrão para descrição de casos de uso sugerido por Larman (1997).

Um caso de uso é uma seqüência de ações ou interações que compõem uma porção funcional do sistema e fornece ao usuário um resultado significativo. Os casos de uso foram originalmente criados para a descrição dos requisitos funcionais, porém, como sugerido nesta seção, também podem ser utilizados para a definição de outros requisitos do sistema, por exemplo, os navegacionais.

A UML descreve o conceito e os diagrams de casos de uso, porém não especifica um formato rígido para a sua descrição, que deve ser realizada para o melhor entendimento do sistema e dos processos por ele envolvidos. Dessa forma, o formato padrão proposto por Larman (1997) foi adotado para a descrição formal,dos casos de uso.

A primeira parte da definição deve conter uma descrição sumária do caso de uso, como apresentado na Tabela 5.1.

\begin{tabular}{|ll|}
\hline \multicolumn{1}{|c|}{ Descrição do Caso de Uso: } \\
\hline Caso de uso: & Nome do caso de uso. \\
Atores: & Lista de atores (agentes externos) que iniciam o caso de uso. \\
Objetivo: & Função ou propósito do caso de uso. \\
Descrição: & Síntese das atividades envolvidas pelo caso de uso. \\
\hline
\end{tabular}

Tabela 5.1: Descrição do caso de uso

A segunda parte, representada na Tabela 5.2, descreve o progresso típico dos eventos na forma de uma sequiência de interações entre os atores e o sistema. Entende-se por progresso típico a seqüência mais comum na qual os eventos ocorrem ou a ordem correta a ser seguida para a execução com sucesso do caso de uso. Isso significa que situações alternativas ou casos de erro não devem ser incluídos nesse ponto.

\begin{tabular}{|c|c|}
\hline \multicolumn{2}{|c|}{ Progresso Típico de Eventos: } \\
\hline $\begin{array}{c}\text { Ações dos Atores: } \\
\text { Lista numerada das acões dos atores. }\end{array}$ & $\begin{array}{c}\text { Ações do Sistema: } \\
\text { Lista numerada das respostas do sis }\end{array}$ \\
\hline
\end{tabular}

Tabela 5.2: Progresso típico de eventos

A terceira e última parte define as exceções ou eventos alternativos que podem ocorrer durante a execução de um caso de uso, em circuntâncias especiais previsíveis.

Progressos Alternativos:

Descrição dos eventos alternativos com indicação do número do evento alterado.

Tabela 5.3: Progressos alternativos 
Há várias razões que justificam a utilização de casos de uso. Primeiramente, a modelagem de casos de uso é uma das técnicas utilizadas para descrever os requisitos de forma mais clara e objetiva e de modo a reduzir as incorreções e as inconsistências existentes nos documentos informais de especificação de requisitos. Além disso, a definição de casos de uso representa uma maneira sistemática e intuitiva de identificar os requisitos. Por fim, os casos de uso conduzem o processo de desenvolvimento tendo em vista que a execução da maioria das atividades, tais como, a análise, o projeto e os testes, pode ser planejada em termos da sua definição (Jacobson, Booch \& Rumbaugh, 1999).

A aplicação de casos de uso também é vantajosa pelo fato de que estes não definem apenas o que o sistema deve fazer, mas também o que deve ser feito para cada usuário em particular. A descrição dos casos de uso na forma sugerida também facilita a posterior definição dos workflows. Existe ainda uma preocupação com o valor agregado ao usuário após a execução de uma determinada ação. Isso significa que os casos de uso descrevem as funcionalidades que devem existir no sistema para que este satisfaça às reais necessidades do usuário. Tais características são fundamentais, sobretudo, na especificação de sistemas de workflow, nos quais o principal objetivo é atingir as metas predefinidas, otimizando o processo e agregando valor à organização.

\subsubsection{Definição de Atores ou de Papéis}

Para facilitar a identificação completa dos requisitos, sugere-se iniciar a análise pela definição das diferentes categorias de atores. Os atores são entidades externas que tanto podem representar pessoas físicas que atuam como usuários do sistema, quanto podem representar outros sistemas computacionais ou dispositivos que interagem com ele. Tipicamente, os atores ativam operações do sistema fornecendo dados de entrada ou esperando receber dados de saída, ou seja, os atores iniciam e são beneficiados pelos casos de uso. Os atores ou papéis ajudam a determinar e a organizar os caminhos navegacionais e as operações pertencentes ao sistema.

No caso do Sistema Atena, os atores são: o Assistente Acadêmico, os Docentes, o Chefe do Departamento, o Presidente da CCEx, o Diretor da Unidade, o Pró-Reitor de Cultura e Extensão, os Candidatos aos cursos, os Alunos e os Usuários genéricos.

Deve-se notar que um determinado usuário pode assumir diferentes papéis nesse sistema. Um docente, por exemplo, pode também atuar, inclusive simultaneamente, como um Chefe Departamental ou como um aluno de um curso que ele não esteja ministrando. Isso significa que uma pessoa física não precisa estar estaticamente associada a um único papel. Sendo assim, a definição de atores ou de papéis garante essa flexibilidade e é a melhor maneira de explicitar diferentes perfis e de evitar a redundância na definição de funcionalidades e de contextos navegacionais (Baresi et al., 2001). 


\subsubsection{Análise de Requisitos Funcionais}

$A$ análise de requisitos funcionais identifica as atividades ou operações executadas pelos diferentes atores. Identifica também o comportamento do sistema e as transformações ocorridas em resposta às ações dos usuários. Por isso, esta etapa do desenvolvimento é centrada no usuário e definida de acordo com a sua perspectiva do sistema.

No caso dos sistemas de workflow, a definição dos requisitos funcionais costuma ser facilitada pelo fato de que esses sistemas normalmente automatizam processos administrativos que seguem regras e seqüências de atividades bem definidas.

O propósito desta etapa, portanto, é sintetizar as funções que ultrapassam os limites do sistema e atribuir essas funções aos atores responsáveis por sua ativação. Um exemplo de descrição de um caso de uso funcional é apresentado nas Tabelas 5.4, 5.5 e 5.6.

\begin{tabular}{|ll|}
\hline \multicolumn{1}{c|}{ Descrição do Caso de Uso: } \\
\hline Caso de uso: & Aprova Candidatos. \\
Ator: & Docente. \\
Objetivo: & Aprovar as inscrições de candidatos interessados em um curso. \\
Descrição: & O Docente acessa as informações sobre um candidato ao curso, \\
& analisa-as e aprova ou não o seu pedido de inscrição. No caso de \\
& aprovação, o Docente atribui uma senha ao candidato, que recebe, em \\
& seguida, um e-mail informando a sua aprovação. \\
\hline
\end{tabular}

Tabela 5.4: Exemplo de descrição de um caso de uso funcional

\begin{tabular}{|ll|}
\hline \multicolumn{2}{c|}{ Progresso Típico de Eventos: } \\
\hline Ações do Ator: & Ações do Sistema: \\
1. Solicita a listagem dos candidatos & 2. Lista os candidatos a serem aprovados. \\
a serem aprovados. & 4. Exibe os dados do candidato selecionado. \\
3. Seleciona um candidato. & 7. Verifica a unicidade do candidato no curso. \\
5. Aprova o candidato. & 8. Se os dados forem consistentes, salva-os e \\
6. Atribui uma senha ao candidato, & atualiza o status do candidato para aluno. \\
caso não exista. & 9. Exibe mensagem informando o sucesso na \\
& aprovação do candidato. \\
& 10. Envia um e-mail para o candidato, informan- \\
& do a sua aprovação no curso. \\
\hline
\end{tabular}

Tabela 5.5: Exemplo do progresso típico de eventos de um caso de uso funcional

Progressos Alternativos:

8. Se o candidato já estiver inscrito no curso, não salva os seus dados e exibe mensagem de erro. Os eventos 9 e 10 não ocorrem.

Tabela 5.6: Exemplo dos progressos alternativos de eventos de um caso de uso funcional 
Na Figura 5.2 é apresentada a modelagem dos casos de uso funcionais do Sistema Atena. Note que nesse modelo o aluno e o usuário genérico não são incluídos. Isso ocorre porque essas classes de usuários não executam nenhuma operação do sistema, apenas acessam informações particulares ou públicas por meio de consultas, o que não deve ser representado nesse modelo e sim no modelo navegacional.

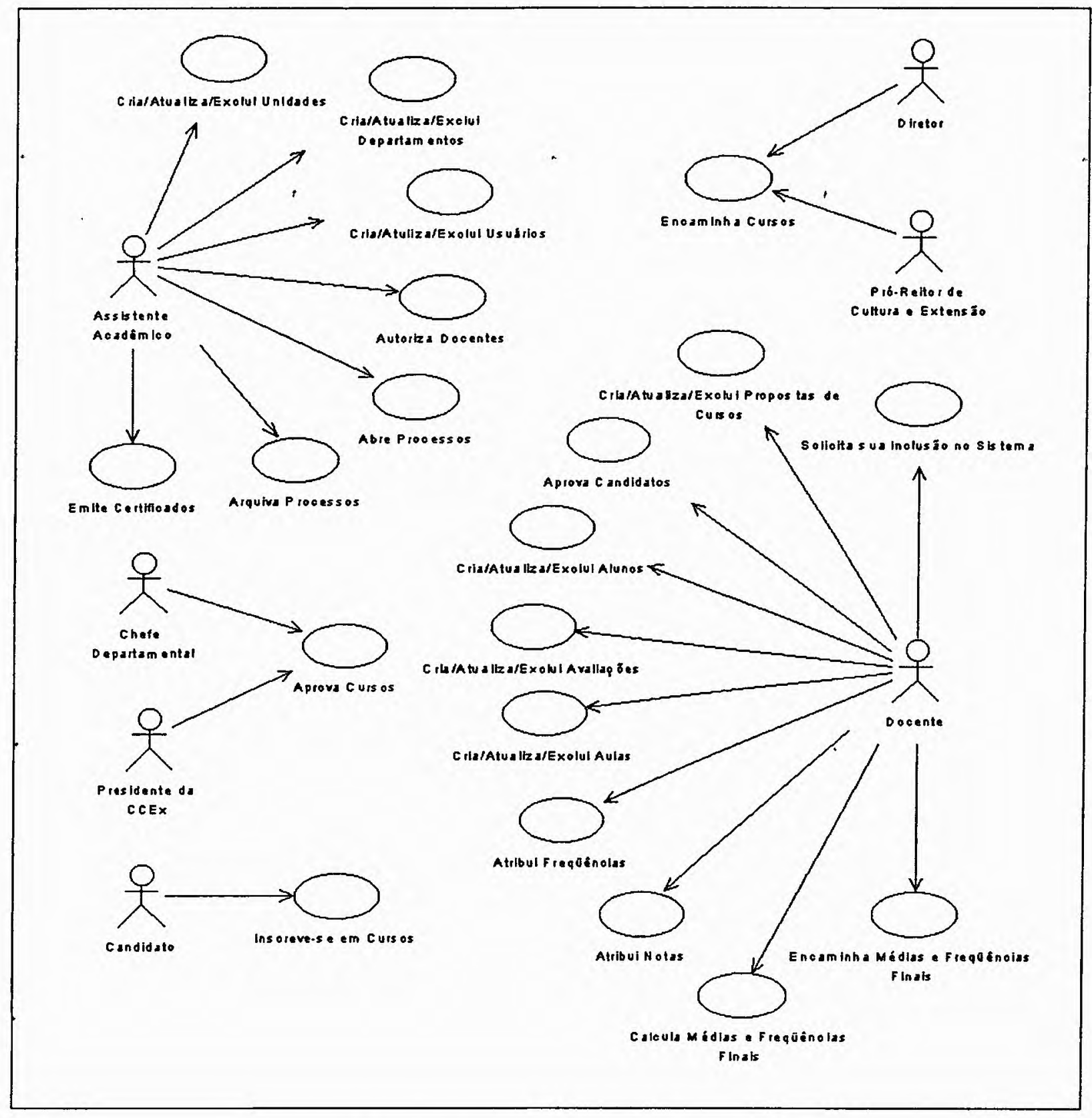

Figura 5.2: Modelo de casos de uso funcionais 


\subsubsection{Análise de Requisitos Navegacionais}

Os requisitos navegacionais definem os conteúdos específicos de interesse para cada tipo de usuário em particular e as estruturas de navegação necessárias para acessar e percorrer tal informação. Nos sistemas de informação para a Web, é muito comum o uso do conceito de visões ou perspectivas. A modelagem de visões agrupa informações, estruturas navegacionais e funcionalidades, gerando diferentes contextos navegacionais com diferentes níveis de visibilidade.

A modelagem de casos de uso navegacionais é capaz de expressar todas as capacidades navegacionais associadas a cada tipo de ator. As estruturas de navegação, porém, somente são definidas no projeto de fatias e no projeto navegacional. Na Figura 5.3 é ilustrado o modelo de casos de uso navegacionais para o Sistema Atena. Nesse modelo, o usuário genérico, que representa inclusive pessoas externas ao sistema, já está presente. Ele é capaz de acessar e navegar sobre todas as informações públicas do sistema, assim como todos os demais atores do mesmo. Nesse ponto, o aluno também é incluído e tem acesso às informações sobre notas e freqüências particulares e aos calendários de aulas e de avaliações dos cursos dos quais participa.

Um exemplo de descrição de um caso de uso navegacional é apresentado nas Tabelas 5.7 e 5.8 .

\begin{tabular}{|ll|}
\hline & \multicolumn{1}{c|}{ Descrição do Caso de Uso: } \\
\hline Caso de uso: & Acessa Informações sobre Candidato. \\
Ator: & Docente. \\
Objetivo: & Obter informações sobre um candidato a um determinado curso. \\
Descrição: & O Docente seleciona um curso entre os quais é responsável, \\
& para ter acesso a informações sobre um candidato. \\
\hline
\end{tabular}

Tabela 5.7: Exemplo de descrição de um caso de uso navegacional

\begin{tabular}{|ll|}
\hline \multicolumn{2}{|c|}{ Progresso Típico de Eventos: } \\
\hline Ações do Ator: & Ações do Sistema: \\
1. Solicita a listagem dos seus cursos. & 2. Lista todos os cursos propostos pelo \\
& Docente. \\
3. Seleciona o curso de interesse. & $\begin{array}{l}\text { 4. Lista todos os candidatos ao curso } \\
\text { selecionado. }\end{array}$ \\
5. Seleciona o candidato & $\begin{array}{l}\text { 6. Exibe as informações referentes ao } \\
\text { candidato selecionado. }\end{array}$ \\
\hline
\end{tabular}

Tabela 5.8: Exemplo do progresso típico de eventos de um caso de uso navegacional

Esse é apenas o primeiro passo para a definição das visões ou contextos navegacionais. $\mathrm{O}$ aperfeiçoamento dessa atividade ocorre durante o projeto navegacional. As visões são 

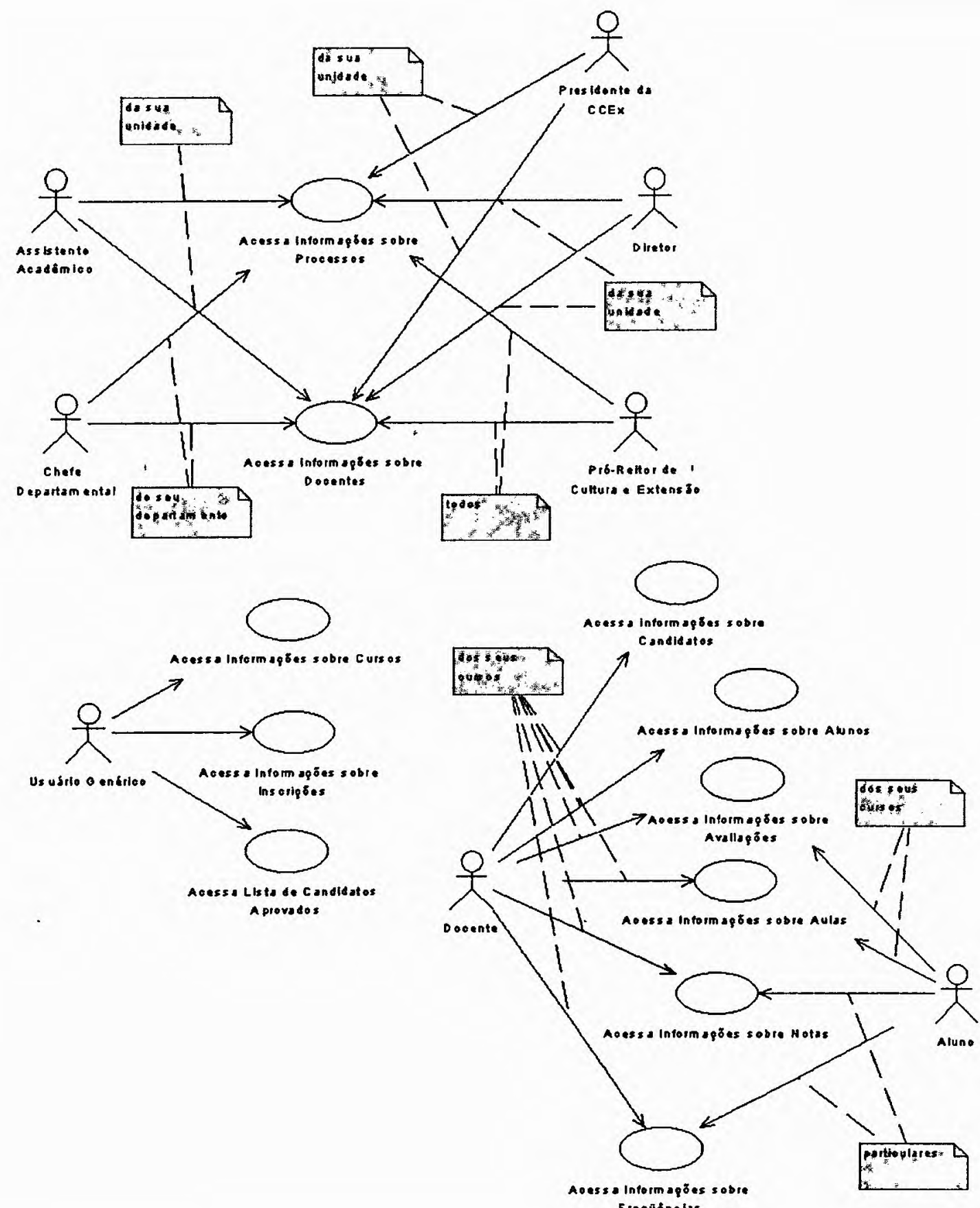

Frequitnoles

Figura 5.3: Modelo de casos de uso navegacionais

importantes não só para os sistemas para a Web mas também para os sistemas de workflow, pois personalizam o sistema de acordo com as necessidades e com o perfil dos diferentes grupos de usuários e restringem o acesso e a execução de serviços específicos aos atores competentes em conformidade com as exigências do domínio da aplicação. 


\subsubsection{Modelagem Estática}

A modelagem estática define os aspectos do sistema que não se alteram com o decorrer da sua execução. Nos sistemas em geral, durante esta etapa, são definidos os conceitos, as classes de objetos ou as entidades envolvidas pela aplicação. No caso dos sistemas para a Web, a modelagem estática também organiza o conteúdo da aplicação, agrupando dados relacionados e construindo estruturas de informação que não se modificam com o passar do tempo e com a utilização do sistema.

Para a especificação desses dois aspectos, a modelagem estática divide-se em:

- Modelagem Conceitual

- Projeto de Fatias

\subsubsection{Modelagem Conceitual}

A modelagem conceitual representa a estrutura estática do sistema, mostrando os objetos ou as classes de objetos que o compõem, os relacionamentos existentes entre essaś classes e os atributos e as operações que as caracterizam. Essa modelagem está presente tanto nos ciclos de desenvolvimento clássicos dos sistemas tradicionais como nos métodos para especificação de aplicações hipermídia, entre os quais o RMM, o HDM e o OOHDM, seja na forma de modelos de entidades e relacionamentos (ME-R), seja na forma de modelos de classes ou modelos de objetos. No método proposto por este trabalho, sugere-se o uso da modelagem orientada a objetos.

A modelagem orientada a objetos é vantajosa porque é capaz de expressar importantes características do domínio da aplicação, por exemplo, a abstração, o encapsulamento e o compartilhamento de operações e atributos por meio da herança. Tais características permitem especificar os componentes do sistema de maneira abstrata, ocultando detalhes de implementação. Além disso, a elaboração de ứ projeto com base nessas características facilita a geração de componentes reutilizáveis e permite que os conceitos definidos sejam aplicados durante todo o ciclo de desenvolvimento do sistema (Rumbaugh, 1994).

A modelagem de sistemas com ênfase nos objetos vem sendo amplamente utilizada, em substituição à modelagem funcional, baseada em procedimentos, devido à sua maior estabilidade. À medida que o processo de desenvolvimento evolui, as características de um objeto são muito menos alteradas do que o modo como esse objeto é utilizado, isto é, do que as funções que envolvem o objeto. Além disso, os modelos de objetos correspondem mais aproximadamente ao mundo real e facilitam a documentação da estrutura do sistema.

Sob o ponto de vista das aplicações para Web ou aplicações hipermídia em geral, a modelagem conceitual também é utilizada para a organização e estruturação da hiperbase, ou seja, do conteúdo apresentado para os diferentes tipos de usuários. Nesse caso, 
as classes ou entidades correspondem a porções significativas de informação perceptíveis pelos usuários e podem ser expressas na forma de páginas Web. Analogamente, as associações semânticas entre essas classes podem ser expressas por ligações (links), no sistema implementado.

Para a representação desta etapa, é utilizado o modelo de classes da UML. Esse modelo incorpora, além de classes, atributos e operações, alguns outros conceitos importantes, tais como: associação, generalização/especialização, agregação e dependência, que definem diferentes tipos de relacionamentos entre as classes.

As associações representam relações semânticas entre classes, específicas para o domínio da aplicação e que são úteis sob o ponto de vista do usuário. Uma associação pode conectar classes, subclasses, componentes de uma agregação e outras associações (Rumbaugh et al., 1999). As generalizações ou especializações permitem a representação das classes de forma hierárquica e exprimem a relação de herança entre as super e as subclasses.

A agregação expressa a relação "todo-parte", isto é, a relação existente entre uma classe e seus componentes. Os componentes são objetos ou subunidades de informação que não são independentes, mas que possuem um papel bem definido no contexto de uma classe. No framework W2000, sugere-se a utilização dos estereótipos "tipo classe" e "tipo componente" para diferenciar os elementos que compõem as relações de agregação (Baresi et al., 2001). Isso, porém, não é obrigatório, pois a notação já possibilita essa diferenciação.

A semântica da relação de dependência é bastante ampla, mas normalmente expressa uma relação na qual, quando ocorre alguma modificação em uma classe, a classe dependente é também modificada. No caso mais comum, a relação de dependência indica que se uma classe for excluída, a classe dependente também o será. Maiores detalhes sobre a notação utilizada pela UML para a representação do modelo de classes podem ser encontrados em diversos livros (Rumbaugh et al., 1999; Fowler, 1998; Furlan, 1998).

A identificação dos componentes do modelo de classes deve ser realizada a partir da definição dos casos de uso. As classes de objetos podem representar, por exemplo, conceitos, porções de informações ou atores envolvidos pelo sistema. Desse modo, as descrições dos casos de uso devem ser analisadas com o intuito de identificar elementos como esses e determinar quais são os objetos que compõem o domínio da aplicação. No Processo Unificado de Desenvolvimento de Software, elaborado por Jacobson et al. (1999), sugere-se uma análise incremental na qual conjuntos de casos de uso semanticamente relacionados são agrupados e avaliados progressivamente.

Por exemplo, os casos de uso funcionais "Inscreve-se em Curso" (Tabelas 5.9 e 5.10) e "Aprova Candidatos" (Tabelas 5.4, 5.5 e 5.6) relacionam-se semanticamente e, portanto, podem ser avaliados em conjunto. Pela análise da descrição do primeiro caso de uso, 
observa-se a existência do ator "Candidato", do objeto "Curso" e de uma associação entre eles que ocorre quando a inscrição é realizada. Esses são os elementos que são candidatos à composição de classes; no entanto, uma análise de mais baixo nível deve ser realizada para que isso se concretize. Deve-se verificar quais são as propriedades ou informações que definem esses elementos. Se essas informações pertencerem ao escopo do sistema e puderem ser traduzidas em atributos que determinam com exatidão um conceito, com características próprias e bem definidas, então, esses elementos são, de fato, objetos do sistema e podem ser representados por classes no modelo conceitual. Como existem dados que as caracterizam e que são mantidos pelo sistema, as classes "Candidato", "Curso" e a relação entre eles, representada pela classe associativa "Inscreve-se", são incorporadas ao modelo da Figura 5.5.

\begin{tabular}{|ll|}
\hline \multicolumn{1}{c|}{ Descrição do Caso de Uso: } \\
\hline Caso de uso: & Inscreve-se em Curso. \\
Ator: & Candidato. \\
Objetivo: & Realizar a sua inscrição em um curso de interesse. \\
Descrição: & O Candidato acessa o formulário on-line de inscrições no curso do \\
& qual deseja participar, informa os seus dados e submete o pedido \\
& de inscrição à aprovação do docente responsável. \\
\hline
\end{tabular}

Tabela 5.9: Descrição do caso de uso "Inscreve-se em Curso"

\begin{tabular}{|ll|}
\hline \multicolumn{2}{|c|}{ Progresso Típico de Eventos: } \\
\hline Ações do Ator: & Açōes do Sistema: \\
1. Acessa o formulário de inscrição & 3. Verifica se os dados obrigatórios foram \\
do curso de interesse. & fornecidos. \\
2. Entra com seus dados, sugerindo & 4. Verifica a unicidade da identificação \\
um nome para a sua identificação & sugerida no sistema. \\
no sistemá. & 5. Se os dados fórem consistentes, salva-os. \\
& 6. Exibe mensagem informando o sucesso na \\
& realização da inscrição. \\
& 7. Envia um e-mail para o candidato, informan- \\
& do os dados referentes à inscrição realizada. \\
\hline
\end{tabular}

Tabela 5.10: Progresso típico de eventos do caso de uso "Inscreve-se em Curso"

Analisando o segundo caso de uso, sob a mesma perspectiva, identificam-se as classes de objetos "Curso", "Candidato", "Docente" e "Aluno". As duas primeiras classes também foram identificadas pela análise de "Increve-se em Curso". É devido à existência dessas interseções, que se sugere a avaliação de conjuntos de casos de uso relacionados. Pela descrição do caso de uso "Aprova Candidatos", observa-se que uma mesma pessoa que, em um primeiro momento, caracteriza-se como um candidato, sob o ponto de vista 
do sistema, em um momento posterior, torna-se um aluno. Como se trata de uma mesma instância de objeto, os atributos que caracterizam essa pessoa permanecem os mesmos. A única diferença é que um objeto "Aluno" possui uma senha como atributo adicional. Desse modo, identifica-se a possibilidade de criação de uma superclasse, denominada "Interessado", que contém todos os atributos comuns às suas subclasses "Candidato" e "Aluno", como representado na Figura 5.4. Para dar continuidade ao processo, poderiam ser avaliados os conjuntos de casos de uso associados à classe "Curso" e, em seguida, aqueles associados à classe "Aluno", por exemplo, e assim sucessivamente até que todo o domínio tenha sido definido.

Na Figura 5.5 é ilustrado o modelo de classes para o Sistema Atena. Observa-se nesse modelo a existência de uma relação de dependência entre as classes que representam os processos administrativos e os cursos. Isso ocorre porque um processo administrativo só existe enquanto e se existir o curso associado. Há também um exemplo de agregação que ilustra o fato de uma unidade ser composta por um ou mais departamentos. Nesse modelo, existem ainda exemplos de generalizações/especialiações entre a superclasse "Interessado" e as subclasses "Candidato" e "Aluno" e entre a superclasse "Usuário" e as suas subclasses, cada qual representando uma categoria específica de atores do sistema.

Nota-se também que, no modelo apresentado, as operações e os métodos referentes às classes não foram incluídos. Isso porque, na fase de modelagem conceitual, a visão que se tem do sistema ainda é bastante abstrata e os aspectos de mais baixo nível não podem ser precisamente definidos. A definição e a inclusão no modelo de todas as operações e métodos só é possível após a modelagem dinâmica ou, mais especificamente, após a modelagem de workflows, etapa na qual todas as atividades e tarefas, automatizadas ou manuais, são especificadas. Algumas operações, porém, podem ser inferidas a partir dos casos de uso. Nesses casos, elas podem ser incluídas no modelo de classes já na fase de modelagem conceitual, conforme o exemplo da Figura 5.4 .

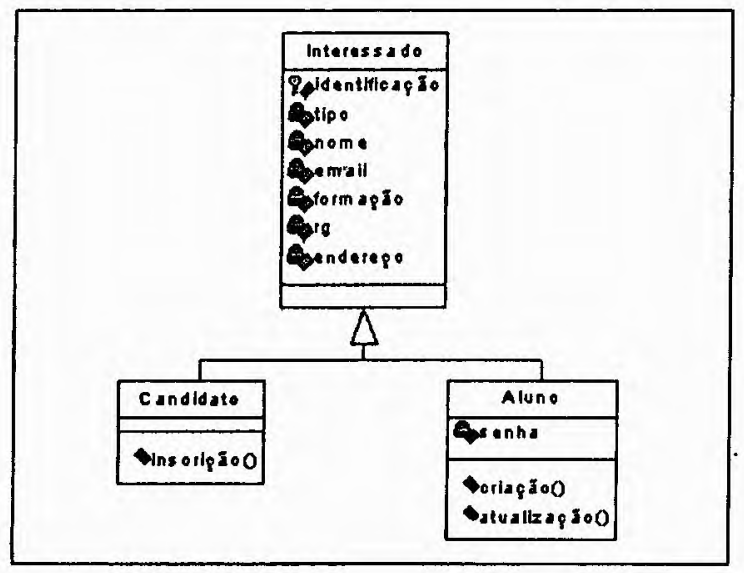

Figura 5.4: Exemplo de classes com operações 


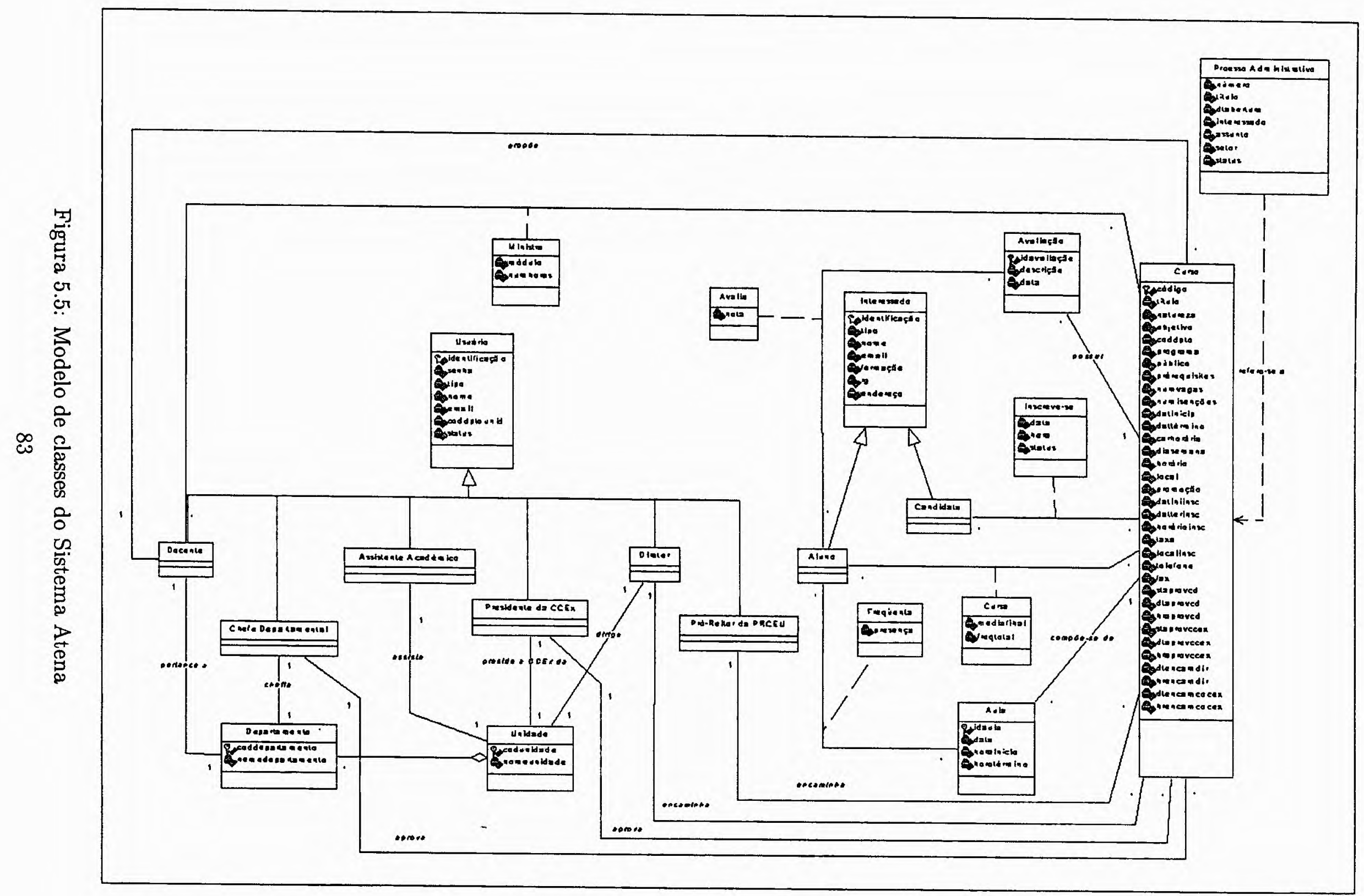




\subsubsection{Projeto de Fatias}

O propósito do projeto de fatias é estruturar o conteúdo do sistema. Sendo assim, durante essa atividade, especifica-se como as informações devem ser apresentadas aos usuários e como podem ser acessadas. Para isso, os atributos de diferentes classes são agrupados em fatias ou porções significativas de informação, organizadas na forma de um hipertexto.

$O$ projeto de fatias, que existe apenas nos ciclos de desenvolvimento de aplicações hipermídia, é o primeiro passo para o projeto de interfaces dos sistemas para a Web. Nessa etapa, é realizada a modelagem da parte estática da interface, isto é, daquilo que permanece inalterado, independentemente do estado do sistema. No projeto de fatias, as informações referentes às diversas classes armazenadas na base de dados são organizadas e agrupadas de acordo com o contexto do conteúdo apresentado. Informações contextualizadas são melhor compreendidas e, portanto, reduzem a desorientação do usuário durante a navegação no sistema. Desse modo, observa-se que a estruturação do conteúdo para a apresentação, de um modo geral, distingue-se da estrutura utilizada para o armazenamento das informações.

Para o projeto de fatias, são utilizados os diagramas de $m$-slices definidos no RMM estendido (Isakowitz et al., 1997; Isakowitz et al., 1998b). Um $m$-slice define uma fatia de informação que agrupa atributos, possivelmente pertencentes a diferentes classes, e que estão associados a um mesmo contexto. Para cada $m$-slice são definidos precisamente os atributos que o compõem, a origem de cada um desses atributos e os meios de acesso aos mesmos.

Nesse ponto do processo de desenvolvimento, pode ser elaborado um protótipo do sistema, com o intuito de identificar quais são as interfaces necessárias para a implementação dos casos de uso definidos na fase de análise e modelagem de requisitos (Figuras 5.2 e 5.3). Ainda que esse protótipo não seja elaborado, cada caso de uso deve ser analisado em termos dos elementos eśtáticos que uma interface deve conter para que ele possa ser implementado. Nessa etapa do projeto de interface, no entanto, não devem ser definidos os caminhos ou contextos de navegação de todo o sistema; somente devem ser definidas, para cada interface identificada, as estruturas de navegação utilizadas para acessar as interfaces imediamente posteriores à interface modelada. Os elementos estáticos de qualquer interface podem ser modelados por um $m$-slice, apesar do seu uso ser mais significativo nos casos em que agrupa atributos de diferentes classes.

A notação gráfica utilizada para o projeto de fatias do RMM estendido incorpora algumas das primitivas do RMM original (Isakowitz et al., 1995) e algumas primitivas novas. Todo $m$-slice está associado a uma classe proprietária ou principal que é representada por um retângulo com bordas arredondadas. Sobrepondo parcialmente esse retângulo, existe uma fatia na qual são explicitados os atributos que constituem o $m$-slice. Na parte 
superior da fatia, que sobrepõe o retângulo, são colocados os atributos ou demais fatias pertencentes à classe proprietária e na parte inferior são colocadas as fatias com os atributos pertencentes a outras classes. Existe ainda a possibilidade de haver atributos fora das bordas da fatia. Tais atributos representam elementos do ambiente imediatamente externo ao $m$-slice, como objetos de destino de um link pertencente ao $m$-slice.

Sempre que um $m$-slice aninhar fatias pertencentes a outras classes, o relacionamento existente entre essas classes e a classe proprietária deve ser explicitado. Isso é representado por uma linha contínua, caso seja um relacionamento real, ou por uma linha pontilhada, caso seja um relacionamento deduzido a partir de uma associação semântica entre as classes que não é definida no modelo conceitual.

Os m-slices também podem incluir estruturas de acesso tais como links e índices, que normalmente estão associados a relacionamentos. Os índices possuem um símbolo específico para a sua representação, ilustrado na Figura 5.7. Seu conteúdo pode ser atributos ou $m$-slices e isso deve ser explicitado. Os links são representados por setas que unem os elementos de origem e de destino. Um atributo pertencente a um $m$-slice pode ser uma âncora (ponto de origem) de um link para um elemento pertencente ao mesmo domínio, isto é, ao domínio de informação incorporado pelo sistema, ou a outro domínio, pertencente a um sistema ou ambiente externo.

\section{Controle de Frequiência}

Curso: Introdução à Ciência da Computação

\begin{tabular}{|c|c|c|c|c|c|c|}
\hline & Nome & $02 / 04$ & $03 / 04$ & $04 / 04$ & $05 / 04$ & 06104 \\
\hline 1 & Ana Paula Ladeira & ᄃ & $\Gamma$ & $\Sigma$ & ⿷ & $\square$ \\
\hline & Andromeda Menezes & $\Gamma$ & $\Gamma$ & $\Gamma$ & $\bar{D}$ & $\square$ \\
\hline & Helena Monjardim & \ulcorner & $\Gamma$ & $\Sigma$ & $\Gamma$ & $\square$ \\
\hline 4 & Leonardo Antonio de Andrade & $\Sigma$ & $\Gamma$ & $\Gamma$ & $\square$ & ㅁ \\
\hline & Lillian Oliveira de Moraes & $\Gamma$ & $\Gamma$ & $\Gamma$ & ᄃ & $\square$ \\
\hline & Rachel Carlos Pereira & $\Gamma$ & $\Gamma$ & $\bar{L}$ & $\Gamma$ & E \\
\hline & Weverton Araújo Martins & $\Gamma$ & $\Gamma$ & $\Gamma$ & $\Gamma$ & $\Gamma$ \\
\hline
\end{tabular}

Figura 5.6: Exemplo de interface que agrupa atributos de diferentes classes

Na Figura 5.6, é apresentado um exemplo de interface do Sistema Atena, associado ao 
caso de uso funcional "Atribui Freqüência" (Figura 5.2), que agrupa atributos provenientes da classe "curso", que é a classe proprietária, da classe associativa "freqüenta" e das classes "aluno" e "aula". Esse agrupamento de atributos forma uma porção significativa de informação utilizada para realizar o controle de frequiência dos alunos, que é denominada "pauta". Os nomes dos alunos são utilizados como âncoras para links que possibilitam o acesso às informações específicas sobre cada aluno. Todo o conjunto de links forma, na realidade, um índice. Essa interface é modelada pelo $m$-slice rotulado por "curso.pauta", ilustrado na Figura 5.7.

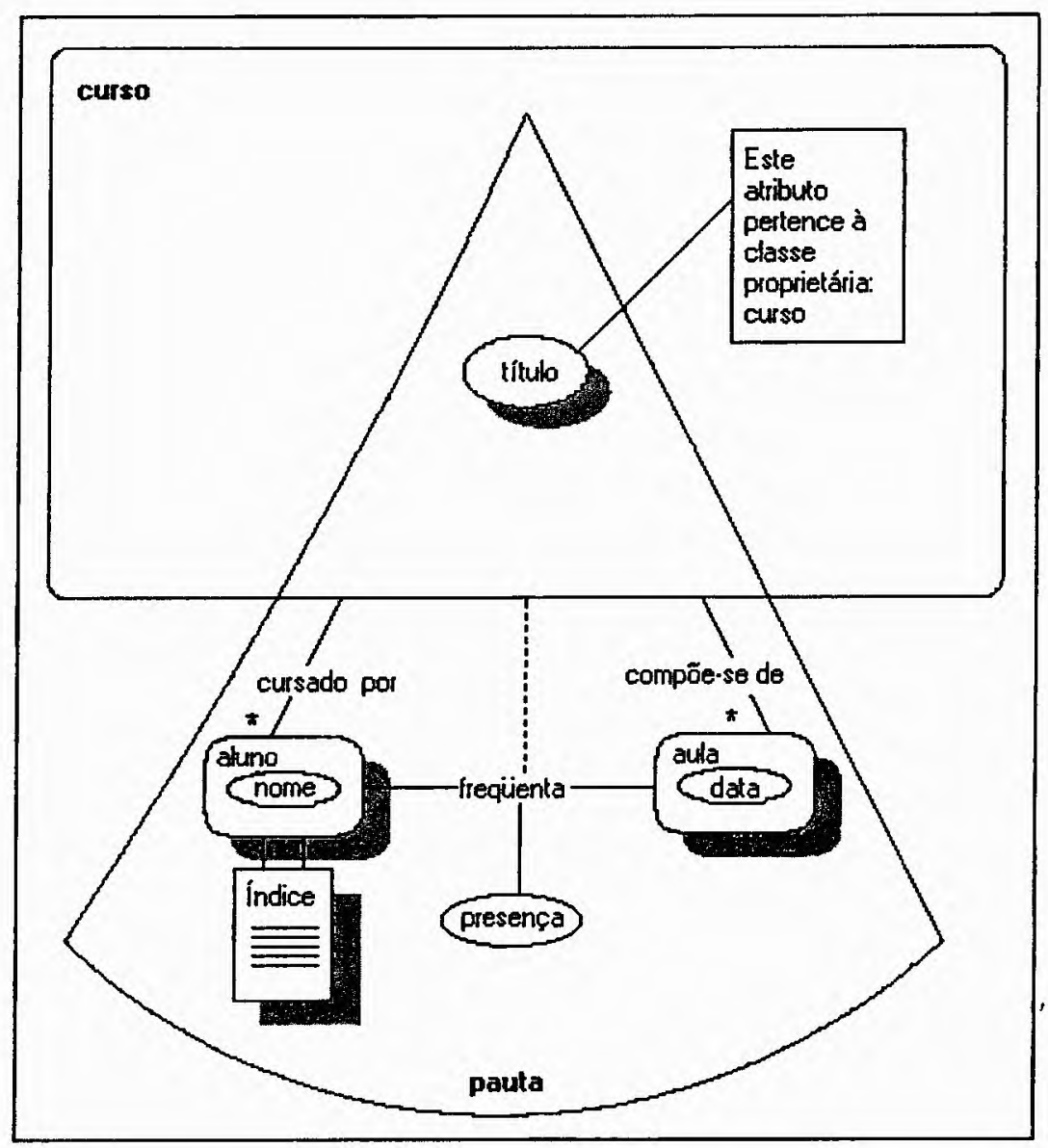

Figura 5.7: Exemplo de um m-slice do Sistema Atena

\subsubsection{Modelagem Dinâmica}

O propósito da modelagem dinâmica é representar o comportamento do sistema. No caso dos sistemas de workflow para a Web, existem dois aspectos dinâmicos distintos que precisam ser modelados: o comportamento funcional e o comportamento navegacional.

Para o entendimento do comportamento funcional, um sistema deve ser descrito em termos das atividades que deve executar, das regras que conduzem essas atividades e das 
suas reações às interações com os usuários, ou seja, em termos de fluxos de trabalho ou workflows.

O comportamento navegacional, por sua vez, deve ser descrito sob a perspectiva de como o usuário vê, interage e acessa os serviços e as informações disponíveis no sistema. Deve-se observar que a modelagem navegacional também prevê as reações do sistema às interações com os usuários, porém isso é descrito em termos de estruturas de acesso e caminhos navegacionais incorporados ao sistema e não em termos de funções.

Desse modo, a modelagem dinâmica divide-se em:

- Modelagem de Workflows

- Projeto Navegacional

O Projeto de Estados também está relacionado à modelagem dinâmica, porém não é uma atividade obrigatória. Essa atividade só deve ser realizada se os diferentes estados assumidos pelo sistema exercerem uma influência significativa sobre a sua execução e o seu funcionamento.

\subsubsection{Modelagem de Workflows}

A modelagem de workflows concentra-se na especificação dos processos ou fluxos de trabalho automatizados pelo sistema. Um workflow é definido como um conjunto coordenado de atividades que devem ser executadas em uma ordem específica e obedecendo a condições e regras predefinidas, com o propósito de atingir um determinado objetivo (Amberg, 1997). Como o método apresentado neste trabalho visa à análise e ao projeto dos sistemas de workflow, esta etapa pode ser considerada como a parte central ou o núcleo do processo de desenvolvimento.

Existem alguns aspectos principais que caracterizam uma aplicação como um sistema de workflow. Primeiramente, pode-se afirmar que a meta primordial de um sistema de workflow é gerenciar e dar suporte a processos administrativos ou de negócios (business processes). Isso significa que esses sistemas devem coordenar e automatizar, completa ou parcialmente, rotinas de trabalho definidas em termos de atividades e procedimentos regulamentados por normas rígidas próprias do negócio. Uma outra característica dos sistemas de workflow é a existência de atores que possuem habilidades ou papéis bem definidos e que, portanto, são responsáveis pela execução de tarefas específicas (Stark, 1997; WfMC, 1999a).

Os conceitos básicos que compõem um workflow e que são necessários para a sua modelagem são: 
Atividades: As atividades correspondem a agrupamentos de tarefas que possuem um propósito comum. Representam, portanto, as funcionalidades do sistema e são os elementos mais significativos do workflow.

Tarefas: As tarefas são as unidades fundamentais de trabalho e, portanto, correspondem às operações ou aos métodos do sistema. Podem ser automatizadas ou manuais, ou seja, ativadas por atores específicos. São classificadas de acordo com: o modo como são iniciadas, o modo como são executadas e o seu conteúdo, como sugerido por Jackson \& Twaddle (1997):

Atores ou papéis: Os atores, como descrito na fase de análise de requisitos, são os elementos que interagem com o sistema e iniciam a execução de uma atividade ou tarefa. No caso das tarefas executadas automaticamente, o próprio sistema é considerado um ator. Nos sistemas de workflow, a definição de atores, de acordo com papéis ou competências, é essencial para a alocação e coordenação de tarefas.

Fluxo de trabalho: O fluxo de trabalho determina as transições e o fluxo de controle e de dados entre as tarefas, isto é, ordena a execução das atividades conforme as exigências das regras de negócio. Na maior parte dos casos, o fluxo de trabalho deve ser independente das atividades individuais, ou seja, caminhos alternativos podem ser seguidos sem que ocorra necessariamente uma mudança no conjunto de atividades.

Pré-condições: As pré-condições definem restrições para o início de atividades ou tarefas. São expressões lógicas que podem fazer referência a dados do sistema ou testar variáveis, como data e tempo, e estabelecem critérios de entrada para uma tarefa em particular.

Pós-condições: As pós-condições são expressões lógicas que devem ser avaliadas para que se decida se uma atividade ou tarefa está completa. Tais condições podem estar presentes em iterações, nas quais uma ou mais tarefas são executadas repetidamente até que uma pós-condição seja satisfeita. Assim como as pré-condições, podem fazer referência a dados, variáveis ou outros eventos do sistema.

Condições de transição: As condições de transição são expressões lógicas que devem ser avaliadas para que a correta seqüência de atividades seja executada. Elas impõem restrições e facilitam o controle das tomadas de decisões e do processamento paralelo.

A etapa de modelagem de workflows, portanto, inclui as seguintes atividades:

- Definição das atividades que compõem o workflow.

- Definição e classificação das tarefas que compõem cada atividade.

- Especificação do fluxo de trabalho (seqüência de execução, fluxo de dados e de controle) e das condições de transição entre as atividades e entre as tarefas. 
- Identificação de possíveis processamentos paralelos, tomadas de decisão, pontos de interrupção do processo e pontos de sincronização das atividades e das tarefas.

- Especificação das pré e pós condições para a execução de cada atividade ou tarefa.

- Determinação das entradas necessárias e das saídas esperadas com a execução de cada atividade ou tarefa.

- Atribuição aos seus respectivos atores ou papéis das atividades ou tarefas sob sua responsabilidade.

- Definição dos pontos de interação dos atores com o sistema.

- Identificação das interações ou troca de mensagens entre os diferentes atores ou entre objetos do sistema.

Para a modelagem dos itens citados, são utilizados o diagrama de atividades e o conceito de linhas divisórias (swimlanes) da UML. A escolha e o uso combinado dessas técnicas justifica-se pelos fatores explicitados a seguir.

Os diagramas de atividades são particularmente úteis para a modelagem de workflows e para a descrição de sistemas concorrentes, por serem capazes de representar processamentos paralelos. Além disso, os diagramas de atividades facilitam a compreensão do comportamento do sistema, por representarem com precisão o progresso dos workflows e as interações existentes entre os casos de uso.

No uso de diagramas de atividades, a desvantagem está na ausência de recursos para representar a relação entre atividades e objetos ou atores do sistema. Por essa razão, sugere-se o uso de linhas divisórias. Esse recurso, aplicado aos diagramas de atividades, é utilizado para definir qual classe de objetos ou qual ator é responsável pela execução de cada atividade (Fowler, 1998; Kobryn, 1999).

$\mathrm{O}$ uso de diagramas de atividades aninhados também é interessante para a modelagem dos workflows em diversos niveis. Isso significa que esse mesmo recurso pode ser utilizado tanto para a definição de atividades, o que corresponde a uma modelagem em um nível mais abstrato, quanto para a definição das tarefas que compõem cada atividade, o que equivale a uma especificação de mais baixo nível.

Com base nessas considerações, recomenda-se que os diagramas de atividades devem ser utilizados para dar início ao processo de modelagem dos workflows, momento no qual os casos de uso explicitados na primeira fase do ciclo de desenvolvimento devem ser analisados e compreendidos. Nesse estágio, o mais importante é identificar as atividades do sistema e suas restrições de execução. De modo geral, cada atividade do diagrama corresponde a um caso de uso, isto é, a uma macro função do sistema. 
O próximo passo baseia-se no detalhamento de cada caso de uso. Nesse momento, identificam-se as tarefas que compõem cada atividade (caso de uso). Tais tarefas correspondem a operações ou métodos do sistema e, portanto, devem estar associadas a objetos específicos. As interações ou troca de mensagens entre os objetos e o sistema e alguns detalhes de implementação já passam a ser relevantes. Para a modelagem desses aspectos, sugere-se o uso de diagramas de atividades aninhados.

\section{- Definição de Atividades}

A primeira etapa da modelagem de workflows é a representação das atividades. Para isso, são descritas neste item a notação utilizada e as diretrizes para a construção e para a identificação dos componentes do diagrama de atividades.

As atividades, que são os elementos principais do diagrama, são interconectadas por fluxos de trabalho e ordenadas de acordo com a seqüência em que devem ser executadas. A cada fluxo de trabalho podem estar associadas pré e pós-condições para a execução das atividades. A partir de uma atividade, podem existir vários caminhos alternativos a serem seguidos. Isso representa a possibilidade de processamento paralelo de diferentes fluxos de trabalho e também significa que a ordem de execução entre as atividades pertencentes aos diferentes fluxos é irrelevante. Nesses casos, podem existir ainda condições de transição que devem ser avaliadas para que se decida qual é o fluxo correto que deve ser percorrido, de acordo com o estado atual do sistema. Em situações como essas, normalmente, são incluídos no diagrama losangos que simbolizam tomadas de decisão. Esses podem ser aninhados, formando decisões compostas.

Geralmente, fluxos de trabalho paralelos acabam atingindo um ponto em comum, o que normalmente ocorre devido a exigências das regras de negócio, isto é, uma determinada atividade só pode ser executada se um outro conjunto de outras atividades, possivelmente paralelas, tiver sido concluído. Para que isso seja representado de forma explícita, são utilizadas barras de sincronização. Tais barras também podem ser controladas por condições que devem ser satisfeitas para que as atividades subseqüentes sejam executadas. Esse recurso faz com que os diagramas de atividades também sejam úteis para a modelagem de programas concorrentes.

Um outro recurso existente nos diagramas de atividades da UML é a multiplicidade. Esse recurso indica que a atividade associada pode ou deve ser executada repetidas vezes antes que o workflow tenha continuidade. Nesse caso, a ordem de execução das diferentes chamadas de uma atividade não é relevante e elas podem, inclusive, ocorrer em paralelo. Comumente, existe uma condição que determina o número de vezes que a atividade deve ser executada. 
$\mathrm{Na}$ UML existem ainda dois símbolos especiais que indicam os pontos de início (start points) e de término (end points) dos workflows. Um único diagrama de atividades pode incluir e modelar as interações existentes entre vários casos de uso, sendo cada um deles representado por um fluxo de trabalho distinto. Dessa forma, os diagramas de atividades são capazes de expressar como as ações de um caso de uso podem afetar as ações de outro. Considerando-se que todo caso de uso é iniciado por um ator do sistema, pode-se afirmar que os pontos de início dos workflows também indicam pontos nos quais ocorrem interações do sistema com o ambiente externo, portanto, é possível a existência de diversos pontos de início em um mesmo diagrama. Do mesmo modo, podem existir vários pontos de término indicando a finalização normal de fluxos independentes ou a interrupção de um fluxo devido a alguma situação adversa. A Figura 5.8 ilustra o diagrama de atividades contendo os workflows automatizados pelo Sistema Atena.

Realizando uma comparação com as notações revisadas, verifica-se que a barra de sincronização da UML corresponde tanto ao construtor gráfico AND-Join quanto ao construtor AND-Split da WfMC. Analogamente, o losango de tomada de decisão da UML corresponde ao construtor OR-Split da WfMC. Similarmente à WfMC e à linguagem LiRA, a notação da UML também permite a modelagem de iterações. Os símbolos da UML que indicam os pontos de início e de término do workflow no diagrama de atividades equivalem aos terminadores da LiRA.

\section{- Definição e Classificação de Tarefas}

A segunda parte da modelagem de workflows consiste na definição de tarefas. Como citado, normalmente, uma atividade corresponde a um caso de uso. Cada caso de uso, por sua vez, é formado por uma seqüência de eventos, que podem ser trocas de mensagens, operações ou métodos do sistema. Esses eventos são as tarefas, que representam as menores unidades de trabalho de um sistema. Assim como os casos de uso, toda tarefa está associada a um ator ou a um objeto que é diretamente responsável pela sua execução. A meta desta etapa da modelagem, portanto, é identificar e ordenar agrupamentos de tarefas com um propósito comum, que compõem as atividades ou casos de uso.

O conceito de tarefa utilizado neste trabalho tem origem no método Business Process Implementation proposto por Jackson \& Twaddle (1997). De acordo com esses autores, a execução de uma seqüência de tarefas determina o progresso do ciclo de vida de um objeto, o que também ocorre no método aqui proposto, porém, no contexto de casos de uso. O resultado de uma tarefa pode afetar ou até mesmo interromper tanto o ciclo de vida do objeto responsável por sua execução quanto os ciclos de vida de outros objetos relacionados. 


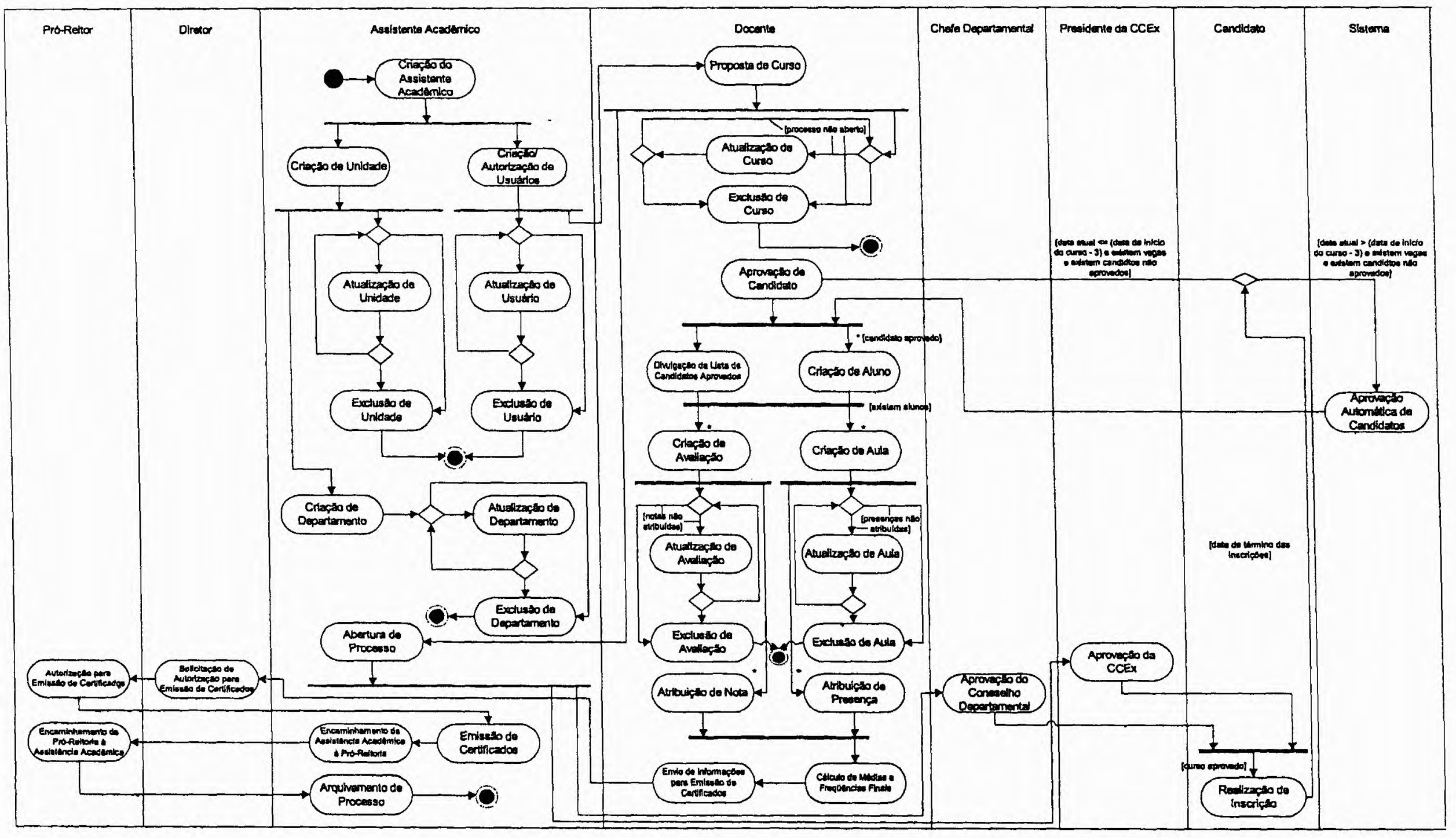

Figura 5.8: Diagrama de atividades do Sistema Atena 
Para a representação das tarefas que compõem uma atividade, também são utilizados os diagramas de atividades da UML. Nesse ponto, porém, os diagramas devem descrever, para um caso de uso particular, os eventos gerados por atores externos, sua ordem e as reações do sistema a esses eventos. Desse modo, a identificação e ordenação das tarefas exibidas no diagrama deve basear-se nas descrições dos casos de uso realizadas na primeira etapa do processo de desenvolvimento. Para a completa modelagem do sistema, pelo menos um diagrama de atividades, representando o progresso típico de eventos, deve ser elaborado para cada caso de uso. No entanto, outros diagramas podem ser desenvolvidos para um mesmo caso de uso, descrevendo os progressos alternativos mais relevantes. $\mathrm{Na}$ Figura 5.9, é ilustrado o uso de um diagrama de atividades para a representação de tarefas. Esse exemplo ilustra simultaneamente o progresso típico e os progressos alternativos do caso de uso "Aprova Candidatos", descrito nas Tabelas 5.4, 5.5 e 5.6, da Seção 5.4.1.

Após a construção dos diagramas de atividades aninhados, as tarefas identificadas são detalhadas para a sua maior compreensão e para a geração de um documento que servirá de base para a fase de implementação.

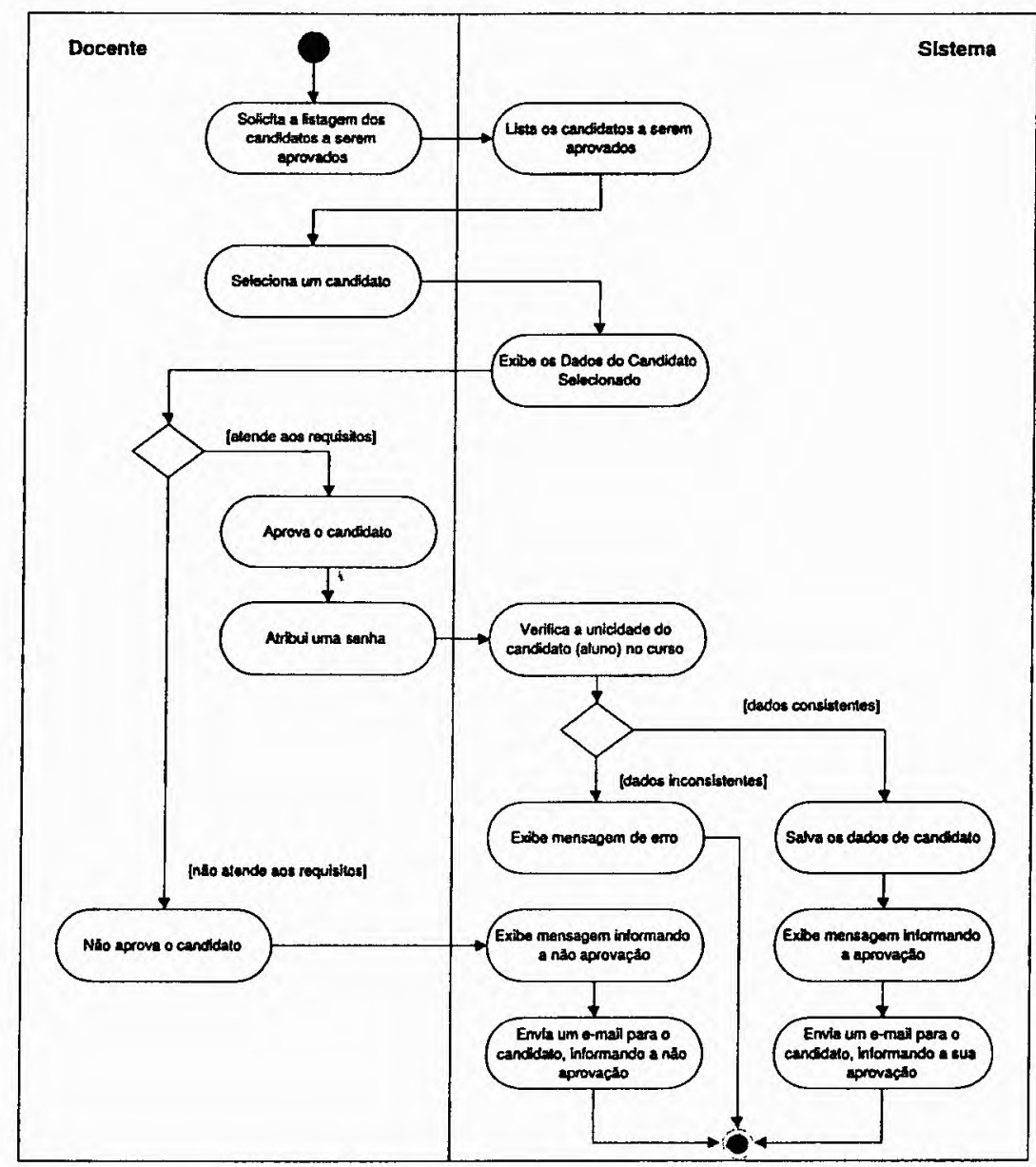

Figura 5.9: Diagrama de atividades representando tarefas 
As tarefas são classificadas de acordo com:

- O modo como são iniciadas, como:

- tarefas X: iniciadas externamente;

- tarefas T: iniciadas pela ocorrência de um tempo predeterminado;

- tarefas P: iniciadas imediatamente após a ocorrência de uma tarefa precedente;

- tarefas I: iniciadas internamente.

- O modo como são executadas, como:

- tarefas A: executadas automaticamente;

- tarefas M: executadas manualmente.

- O seu conteúdo, como:

- tarefas E: de entradas de dados;

- tarefas C: de checagem da consistência ou completitude de dados;

- tarefas U: de atualização de dados;

- tarefas D: de tomadas de decisão;

- tarefas S: que produzem dados de saída.

$\mathrm{Na}$ Tabela 5.11 é apresentado um exemplo de classificação de tarefas do Sistema Atena.

\section{Aprovação de Candidatos:}

1. Solicita a listagem dos candidatos a serem aprovados.

2. Lista os candidatos a serem aprovados.

Docente IME

3. Seleciona um candidato.

Sistema PAS

4. Exibe os dados sobre o candidato selecionado.

Docente IME

5. Aprova o candidato.

Sistema PAS

Docente IMD

6. Atribui uma identificação e uma senha, caso não existam. Docente IME

7. Verifica a unicidade da identificação do candidato no sistema. Sistema PAC

8. Verifica a unicidade do candidato (aluno) no curso.

Sistema PAC

9. Se os dados forem consistentes, salva-os e atualiza o status Sistema PAU do candidato para aluno.

10. Exibe mensagem informando o sucesso na aprovação do Sistema PAS candidato.

11. Envia um e-mail para o candidato, informando a sua

Sistema PAS aprovação no curso.

Tabela 5.11: Exemplo de classificação de tarefas 
As tarefas listadas fazem parte da atividade de aprovação manual de candidatos que é realizada pelo Docente. Para a simplificação do exemplo, está sendo considerada apenas a situação na qual o candidato é aprovado, tornando-se um novo aluno de um curso específico, e os dados de entrada são corretos e consistentes, portanto, a aprovação e a atualização da base de dados ocorrem com sucesso. Maiores detalhes sobre a classificação adotada podem ser obtidos na Seção 3.3.1 deste trabalho e no livro de Jackson \& Twaddle (1997).

\subsubsection{Projeto Navegacional}

O projeto navegacional complementa o projeto de fatias quanto à definição da interface do sistema, acrescentando à especificação os aspectos dinâmicos. A meta, portanto, dessa etapa é definir os caminhos navegacionais que possibilitam o acesso às estruturas de informação definidas anteriormente. Assim como o projeto de fatias, o projeto navegacional também é centrado no usuário, uma vez que seu objetivo é modelar a informação e a navegação da maneira na qual esses elementos são percebidos pelo usuário.

Durante essa etapa do desenvolvimento, são definidos os nodos que compõem a hiperbase e as estruturas de navegação ou de acesso a esses nodos. Os nodos formam as unidades de navegação, podem ser compostos por uma ou mais fatias de informação e são os elementos utilizados para a apresentação do conteúdo do sistema e para a interação entre o usuário e a aplicação. As estruturas ou primitivas de acesso incorporadas ao método aqui proposto são as mesmas utilizadas pelo RMM estendido, isto é: as ligações uni e bidirecionais, os agrupamentos, os índices, os roteiros guiados e os roteiros guiados indexados (Isakowitz et al., 1997; Isakowitz et al., 1998b).

As ligações uni e bidirecionais são utilizadas para interligar dois objetos. Esses objetos podem ser nodos; fatias de diferentes classes ou fatias de uma mesma classe. Os índices atuam como uma tabela de conteúdo que lista as instâncias de uma classe e que permitem acesso direto a cada um dos itens listados. Um roteiro gujado implementa um caminho linear entre um conjunto de nodos que permite ao usuário acessar os nodos anterior e posterior ao nodo corrente em cada passo da navegação. Os roteiros guiados indexados combinam as características dos índices e dos roteiros guiados, formando uma estrutura de acesso completa. Finalmente, os agrupamentos são estruturas semelhantes a menus que permitem o acesso a partes diversificadas da hiperbase. Os agrupamentos são tipicamente utilizados nas telas principais (de entrada) de várias aplicações, para dar acesso a diferentes ambientes ou a conjuntos independentes de serviços ou informações. Um índice é um tipo particular de agrupamento restrito à exibição dos itens de uma única classe (Isakowitz et al., 1995). 
As ligações (links) são definidas por um ponto de origem, também chamado de âncora, e por um ponto de destino. As âncoras podem ser tanto um atributo quanto uma fatia e são representadas no hipertexto por áreas clicáveis que ativam o acesso ao destino. Já os pontos de destino correspondem sempre a um nodo ou a uma fatia (porção de informação dentro de um nodo).

O RMDM e a notação gráfica utilizada no RMM original e estendido, acrescidos de alguns conceitos, tais como, as coleções propostas por Garzotto et al. (1994), os centros propostos por Baresi et al. (2001) e os estereótipos das extensões à UML propostos por Conallen (1999a), constituem a base para a construção do modelo navegacional.

O primeiro passo para a realização do projeto navegacional deve ser a definição dos nodos de informação e de navegação. Os nodos são os elementos estruturais da hiperbase e são derivados dos elementos conceituais, isto é, classes, subclasses e relacionamentos. Comumente, os nodos são representados por páginas Web ou por blocos logicamente identificáveis de informação existentes em uma página. A disposição dos elementos no modelo navegacional é hierárquica. A raiz dessa hierarquia é sinalizada pelo símbolo "@", que indica que o nodo raiz é o nodo default, ou seja, é a partir desse nodo que todos os usuários acessam o sistema e iniciam a navegação.

No método proposto neste trabalho, os nodos de informação ou de conteúdo são representados por classes de interface, cada qual associada aos $m$-slices que a compõem e a uma classe do modelo conceitual cujos atributos formam a base para aquela interface específica. As classes conceituais associadas às interfaces são semelhantes às classes proprietárias dos $m$-slices. Não existe, porém, obrigatoriamente, uma relação de equivalência entre as classes de interface e as classes conceituais, uma vez que um nodo de interface pode agrupar um ou mais $m$-slices que, por sua vez, podem agrupar atributos provenientes de diferentes classes, com o propósito de organizar e apresentar a informação de uma maneira mais compréensível para o usuário. Para melhor especificação dos nodos de informação, um estereótipo é atribuído a cada classe de interface, diferenciando-as entre: páginas do cliente, páginas do servidor e formulários, entre outros, de acordo com as extensões específicas para as aplicações Web feitas à UML, propostas por Conallen (1999b).

Os demais nodos, embora também contenham informação, são considerados nodos de navegação pois representam sobretudo estruturas de acesso. Esses nodos são modelados por símbolos do RMM que representam os agrupamentos, os índices, os roteiros guiados e os roteiros guiados indexados. Os links, ou ligações uni e bidirecionais, formam um caminho que interliga dois nodos. Normalmente, as ligações bidirecionais não são ilustradas para não prejudicar a clareza do modelo navegacional, apesar de serem implementadas. Os links podem representar tanto ligações estruturais, deduzidas a partir de relações de 
"todo-parte" entre uma classe e suas subclasses, quanto ligações semânticas, inferidas a partir de relações semânticas entre as classes associadas aos nodos conectados (Baresi et al., 2001).

Aos índices e às demais estruturas de acesso podem estar associadas coleções, que são indicadas no modelo pelo estereótipo "coleção". Embora o conceito original de coleção, apresentado por Garzotto et al. (1994), seja mais amplo, considera-se neste trabalho uma definição mais restrita. Desse modo, uma coleção é um agrupamento de instâncias de uma mesma classe que satisfazem a um determinado critério de seleção. As coleções podem especificar não somente critérios de seleção, mas também critérios de ordenação e/ou agrupamento das informações recuperadas a partir da base de dados por meio de consultas. Os diferentes estados assumidos pelos objetos são critérios de seleção comumente utilizådos pelas coleções. Sob esse aspecto, as coleções são bastante úteis, sobretudo nos sistemas de workflow, para expressar quais objetos encontram-se em quais estados e, conseqüentemente, qual é o estado (status) atual do sistema. Essas informações são fundamentais para que os usuários tenham conhecimento e controle sobre o progresso do workflow. Nos sistemas de workflow, também é comum a existência de operações que só podem ser executadas para objetos específicos, que satisfazem a determinadas condições. Nesses casos as coleções são utilizadas para filtrar esses objetos. As coleções são também importantes pois asseguram a dinamicidade da interface. Quando a coleção é vazia, a estrutura de acesso não é gerada ou fica desativada.

A definição de uma coleção deve incluir a classe à qual ela está relacionada, os seus critérios de seleção, ordenação e/ou agrupamento e. os atributos utilizados por esses critérios. Os atributos utilizados pelas coleções, no entanto, normalmente não são os atributos que identificam os objetos selecionados (chaves primárias ou secundárias). Desse modo, para a identificação dos objetos que compõem a coleção, são utilizados centros (Baresi et al., 2001). A Figura 5.10 ilustra a notação utilizada para representar as coleções e os centros.

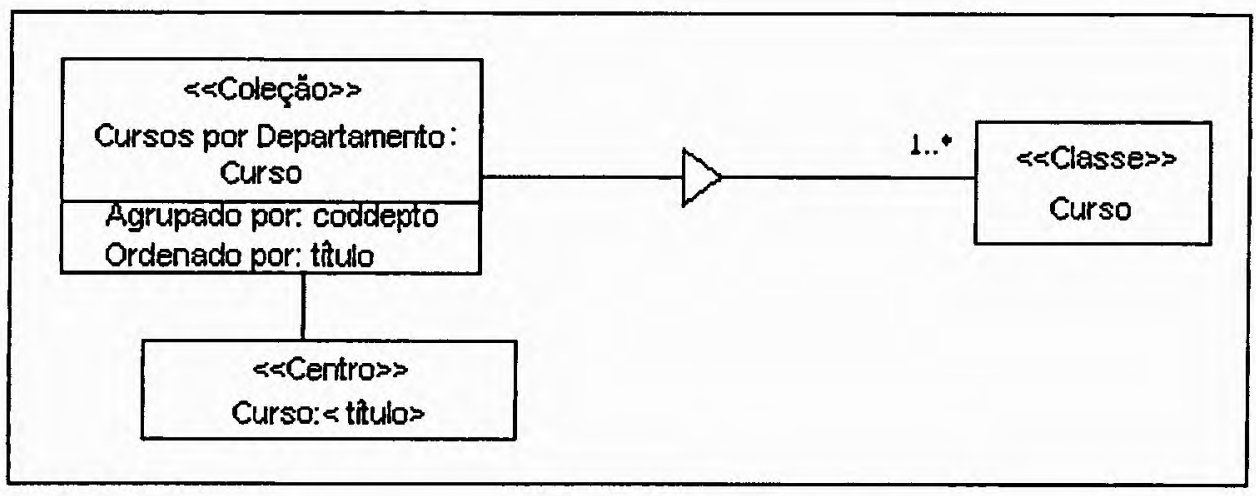

Figura 5.10: Exemplo de uma coleção e de um centro 
Os centros auxiliam o usuário a compreender o propósito da coleção, quais são os seus elementos e ainda definem pontos de início para a navegação. . São estruturas de informação relacionadas a associações semânticas entre duas classes e, por essa razão, são utilizados para complementar a especificação das ligações e das demais estruturas de navegação. Um centro define os atributos que são utilizados pelos usuários para navegar sobre uma associação. Esses atributos podem ser provenientes das classes interligadas, podem pertencer à própria classe associativa ou podem ser atributos adicionais usados, por exemplo, para organizar as informações. Os atributos que compõem um centro identificam quais são os objetos conectados por uma estrutura de navegação, o que permite ao usuário selecionar o objeto de seu interesse antes de realizar propriamente a navegação. $\mathrm{Na}$ maioria das aplicações para a Web, esses atributos indicam áreas clicáveis utilizadas como âncoras para os links.

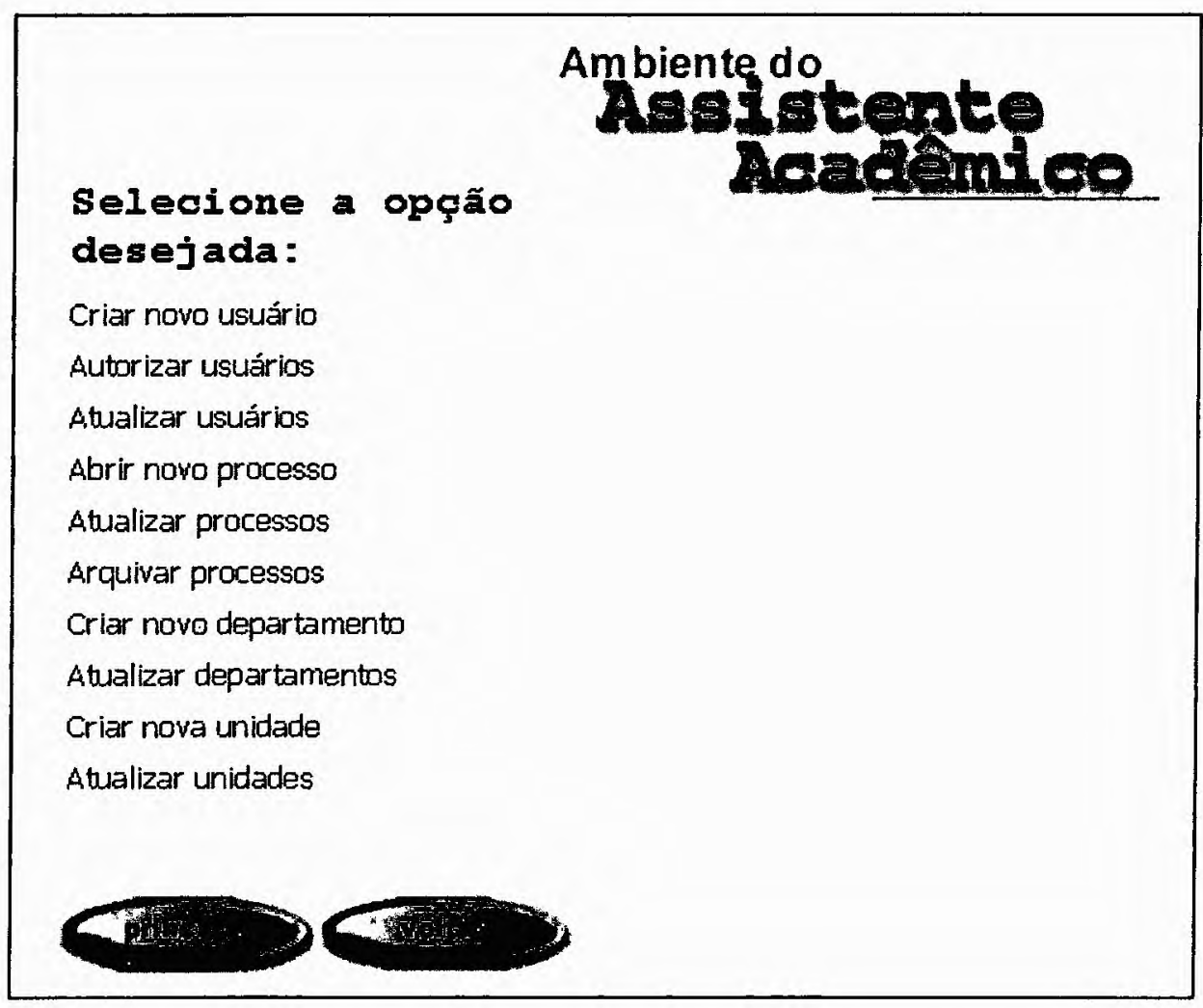

Figura 5.11: Exemplo de uma interface representada por um agrupamento

Parte da modelagem navegacional do Sistema Atena; a começar pelo nodo raiz ou tela principal da aplicação, é apresentada na Figura 5.12. Os agrupamentos que são atingidos a partir da tela de entrada no sistema correspondem aos diferentes ambientes que contêm os menus de serviços específicos para cada perfil de usuário. Um exemplo de ambiente representado no modelo por um agrupamento é exibido na Figura 5.11. Observa-se 
claramente por essa representação a existência de diferentes níveis de visibilibade e de diferentes contextos de navegação. A expansão desses agrupamentos é, de fato, a definição das visões introduzidas na Seção 5.4 .1 deste trabalho. Na Figura 5.13 é ilustrada a expansão do Ambiente do Assistente Acadêmico (Figura 5.11), agrupamento utilizado como exemplo.

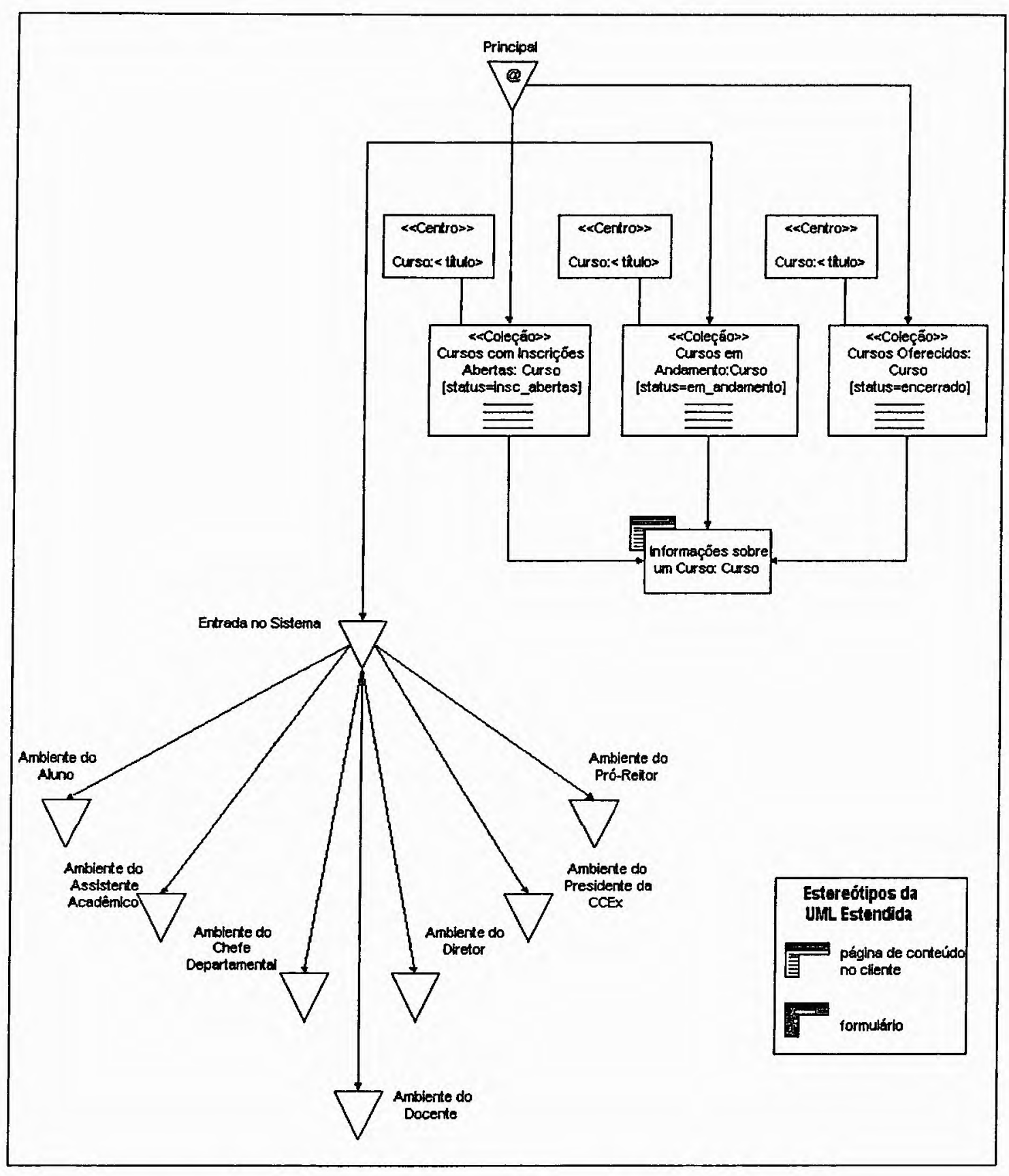

Figura 5.12: Modelo navegacional parcial do Sistema Atena 


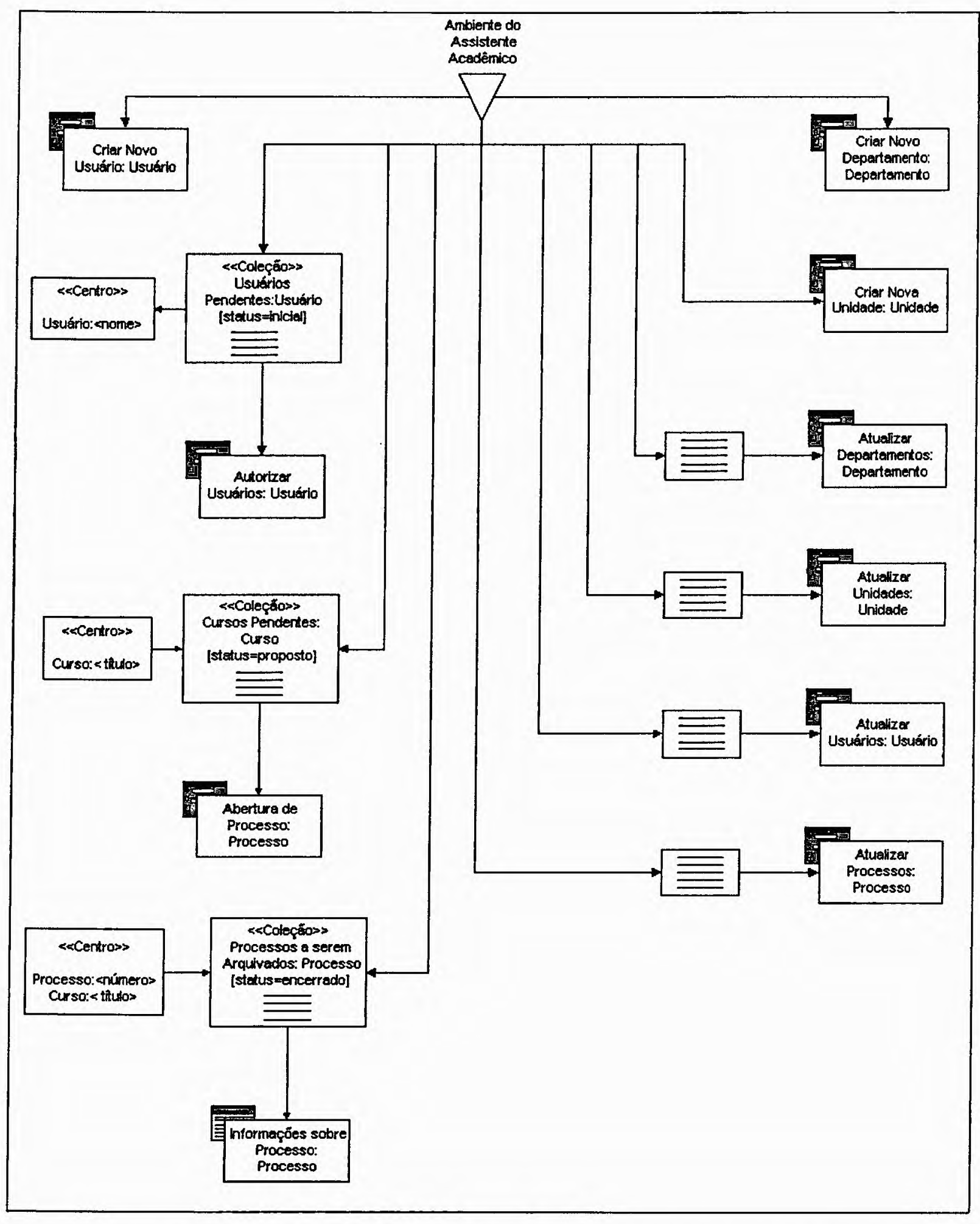

Figura 5.13: Expansão do agrupamento "Ambiente do Assistente Acadêmico" 


\subsubsection{Projeto de Estados}

Uma característica peculiar dos sistemas de informação para a Web é o dinamismo do conteúdo, dos serviços, das estruturas de acesso e dos caminhos navegacionais que são disponibilizados ao usuário. O dinamismo dessas aplicações não apenas baseia-se, mas justifica-se pelas variações de estado dos sistemas. A possibilidade de criação de interfaces dinâmicas, baseadas no estado corrente do sistema, viabiliza a geração de diferentes contextos de navegação e torna mais consistente a própria hiperbase (Baresi et al., 2001).

Potencialmente, todos os elementos de uma aplicação para a Web estão sujeitos à evolução e podem assumir diferentes estados. A execução dos workflows tanto gera quanto é influenciada por essa mudança de estado. Desse modo, observa-se a importância de modelar essa evolução, já que a mudança de estados influencia o comportamento do sistema.

O projeto de estados, portanto, complementa a fase de análise de requisitos e de modelagem de workflows, pois define como os objetos que compõem a aplicação evoluem, quais são os possíveis estados assumidos por esses objetos e quais são os eventos que provocam as mudanças de estado.

Essa modelagem não é obrigatória para todos os objetos do sistema, mas deve ser realizada para aqueles objetos cuja mudança de estado exerce uma influência direta sobre o progresso dos workflows e o comportamento do sistema.

Para a representação dessa atividade, são utilizados os diagramas de estados da UML. $\mathrm{Na}$ maioria das técnicas orientadas a objetos, tais diagramas são usados para representar as variações de estados de um único objeto no decorrer do seu ciclo de vida (Fowler, 1997). Existem várias formas de diagramas de estados, cada qual com suas pequenas diferenças semânticas, porém a mais comumente usada em métodos orientados a objetos baseia-se nos stạtecharts propostos por Harel (1987). Essa forma, incorporada atualmente à UML, foi primeiramente usada em métodos OO por Rumbaugh (1994) no OMT, sendo depois adotada por Booch (1994) na segunda edição do seu método.

A notação utilizada para a construção dos diagramas de estado incorpora símbolos que representam os pontos de início e de término do ciclo de vida do objeto modelado. Os estados são representados por retângulos com bordas arredondadas e as transições são representadas por setas que ligam um estado a outro e que indicam a ordem na qual as mudanças de estado ocorrem. As transições são rotuladas por uma expressão, que possui três partes opcionais, cuja sintaxe é: evento[condição]/ação. Essa expressão especifica as condições necessárias e os efeitos de uma transição de estado.

Cada estado pode ser associado a uma atividade expressa pelo rótulo: faça/atividade. Observe que é utilizado o termo ação para as transições e $o$ termo atividade para os estados. Embora pareçam ter o mesmo significado, esses termos denotam coisas distintas. 
As ações são sempre associadas a transições e são atômicas, instantâneas e não podem ser interrompidas. Já as atividades, associadas aos estados, podem prolongar-se por um intervalo maior de tempo e podem ser interrompidas por algum evento. Quando o rótulo de uma transição não especifica um evento, isso significa que a transição ocorre assim que a atividade associada ao estado é finalizada. Quando um estado associado a uma atividade é atingido, normalmente, essa atividade é executada até que alguma condição seja satisfeita. Porém, quando não existe uma atividade associada, o objeto permanece no mesmo estado até que ocorra algum evento.

Várias transições podem ter origem em um mesmo estado, mas apenas uma delas pode ocorrer. Dessa forma, as condições que controlam essas transições são mutuamente exclusivas para qualquer evento. Do mesmo modo, várias transições podem ter o mesmo estado como destino. É possível até que todos os estados que compõem um diagrama sejam capazes de mudar para um estado específico. Isso acontece, por exemplo, nos casos em que o ciclo pode ser interrompido a qualquer momento devido a um evento de cancelamento. Nesse caso, todos os estados podem passar para o estado "cancelado". Para tornar mais clara essa representação, ao invés de adicionar para cada estado uma nova transição, recomenda-se a utilização de um superestado e a inclusão de uma única transição. Assim, todos os sub-estados herdam as transições do superestado.

Existem ainda os diagramas de estado concorrentes. Nesses diagramas existem seções formadas pelo agrupamento de dois ou mais diagramas de estados que representam transições que podem ocorrer em paralelo. Isso significa que essas seções reproduzem períodos do ciclo de vida nos quais o objeto pode assumir mais de um estado. Os diagramas de estado concorrentes são úteis para descrever a evolução de objetos caracterizados por conjuntos de comportamentos independentes. A Figura 5.14 apresenta um exemplo de utilização de diagramas de estados concorrentes, em que são ilustrados os possíveis estados assumidos pelo objeto "curso" do Sistema Atena. Note que as tramitações da proposta de curso pelo Conselho Departamental e pela CCEx são independentes e as aprovações podem ocorrer em paralelo.

Considerando mais uma vez o uso combinado de diferentes técnicas visando ao melhor entendimento e à completa modelagem do sistema, verifica-se que os diagramas de estados complementam as técnicas anteriores uma vez que descrevem o comportamento de um objeto particular durante a execução de diversos casos de uso, enquanto os diagramas de seqüência descrevem o comportamento de vários objetos no contexto de um único caso de uso e os diagramas de atividades descrevem as seqüências de ações executadas por diversos objetos ao longo de muitos casos de uso. 


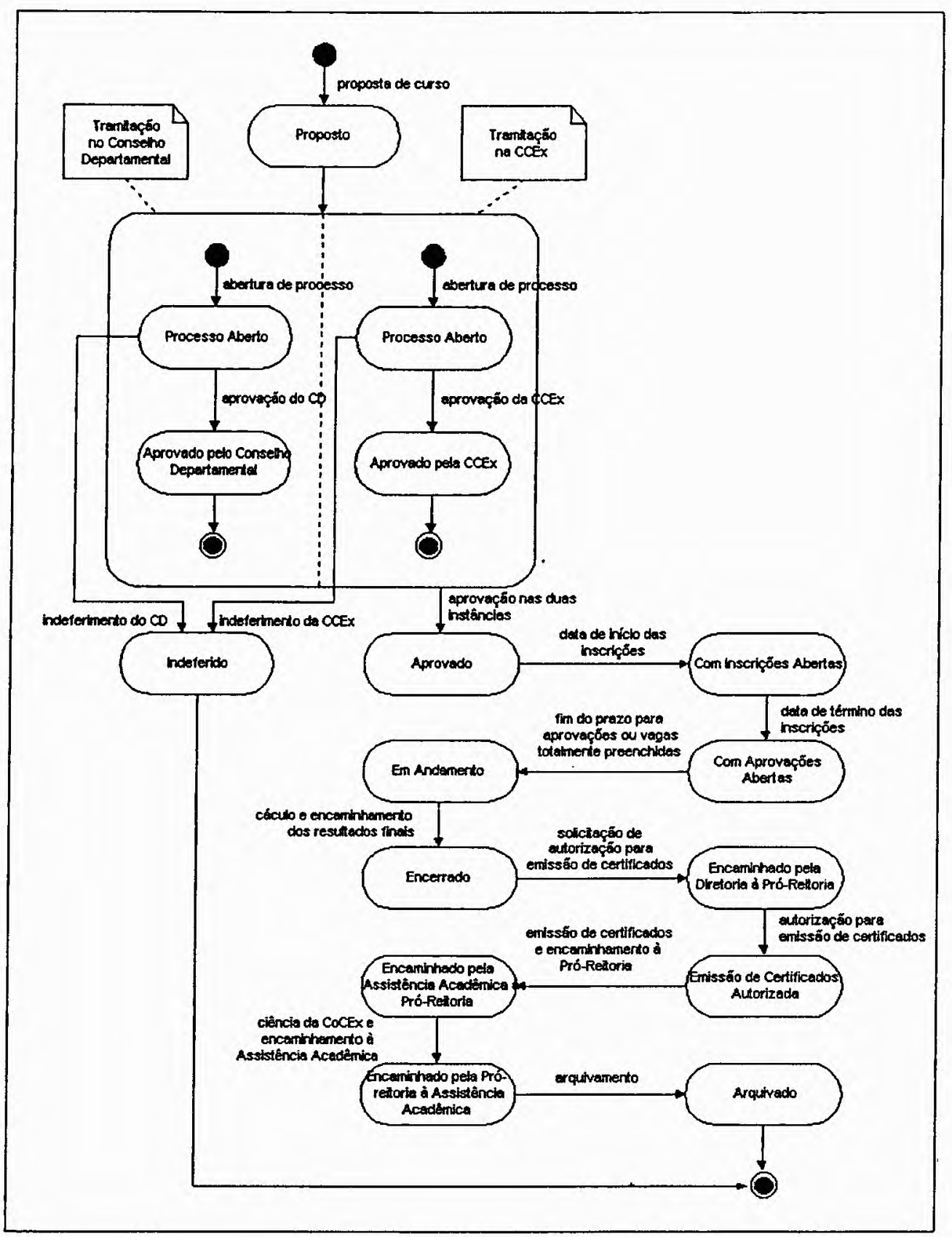

Figura 5.14: Diagrama de estados para o objeto curso do Sistema Atena

\subsubsection{Implementação}

Todas as etapas do processo de desenvolvimento apresentadas até este ponto são direcionadas a um objetivo final: traduzir as representações do sistema para uma forma que possa ser "entendida" pelo computador. Segundo Pressman (1995), a implementação ou codificação é a conversão do projeto numa forma legível por máquina, isto é, numa linguagem de programação. Se o projeto for completo, consistente e for realizado detalhadamente, a implementação é executada de uma maneira direta e mecânica. 
Desse modo, o projeto do banco de dados baseia-se na modelagem conceitual; a implementação das operações executadas pelos usuários e dos métodos automatizados pelo sistema baseia-se na definição dos casos de uso, realizada na fase de análise e modelagem de requisitos, e na definição das atividades e das tarefas, realizada na fase de modelagem dos workflows. Essa última fase também determina a ordem das operações e dos métodos e as regras que regem a implementação dos workflows. As diferentes visões do sistema, comuns nos sistemas de workflow e que são definidas durante o projeto navegacional podem dar origem a subsistemas na fase de implementação. Por fim, o projeto de fatias e o projeto navegacional juntos formam a base para a elaboração da interface.

O método de desenvolvimento proposto neste trabalho é independente de implementação e sobretudo de plataforma, característica exigida pelos sistemas de informação para a Web. O método também é flexível quanto à estrutura do banco de dados que pode ser relacional, orientado a objetos ou objeto-relacional, apesar da abordagem mais voltada para a orientação a objetos. Tal abordagem permite que as aplicações desenvolvidas com base nesse método sejam implementadas em Java, linguagem de programação orientada a objetos, consagrada pelos desenvolvedores por oferecer recursos para a construção de sistemas complexos para a Web. No entanto, a programação orientada a objetos não é uma exigência e outras linguagens, como PHP, ASP e JavaScript, podem ser utilizadas.

Os sistemas implementados tanto podem ser estáticos quanto dinâmicos. O método é capaz de expressar o dinamismo presente na maioria das aplicações para a Web. As coleções, que eventualmente podem ser nulas, são exemplos disso. O projeto de estados contribui para a implementação nesse sentido, já que a dinâmica dos serviços oferecidos, das informações apresentadas e da própria interface está fortemente baseada nos diferentes estados assumidos pelo sistema. É importante salientar que a representação do dinamismo é fundamental quando se trata de sistemas de workflow.

O método também não impõe restrições quanto à implementação da interface, uma vez que por meio dele são modelados conceitos, porções contextualizadas de informação, estruturas abstratas de acesso e de navegação e não especificamente os elementos perceptíveis pelos usuários. Isso possibilita a utilização de diversas mídias para a apresentação dos elementos modelados, o que também é uma característica dos sistemas para a Web.

Durante esta última fase do ciclo de desenvolvimento, portanto, devem ser realizadas, além da codificação, a escolha das mídias apropriadas para a apresentação do conteúdo do sistema e a documentação do código-fonte, o que facilita o entendimento da implementação e as posteriores manutenções adaptativas ou corretivas. 


\subsubsection{Arquitetura}

A arquitetura mais comumente usada para a execução de aplicações para a Web é a arquitetura de três camadas (3-tier), na qual existe um browser na máquina cliente, que corresponde à camada de apresentação, um servidor de Web ou servidor HTTP, que corresponde à camada de aplicação, e um servidor de banco de dados, que corresponde à camada persistente. Esse tipo de arquitetura é ilustrado na Figura 5.15.

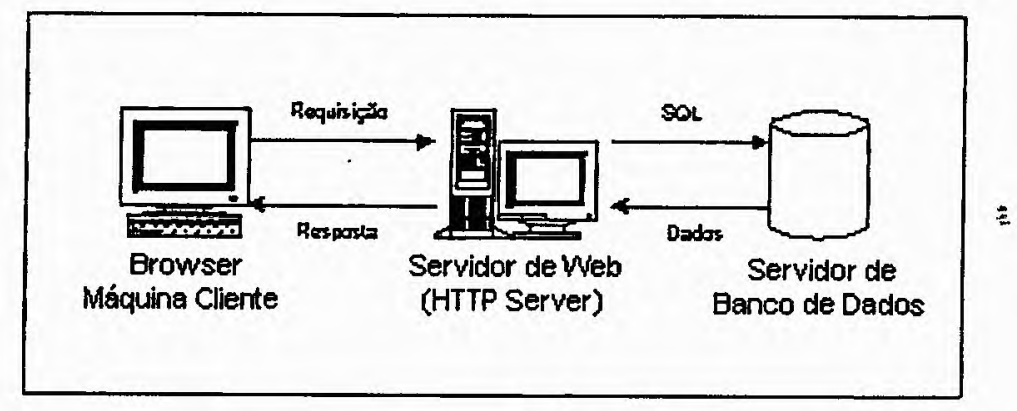

Figura 5.15: Arquitetura de três camadas

As camadas de apresentação, de aplicação e persistente são, na realidade, camadas lógicas. A camada de apresentação contém todas as classes de interface e é a única camada visível aos usuários e, portanto, é a que mais sofre alterações. Essa camada exibe o estado atual do sistema ao usuário, permite a entrada de dados, a navegação, a propagação de eventos gerados pelo mesmo e a requisição de páginas ou ativação de tarefas que devem ser processadas na camada de aplicação.

A camada de aplicação detém a lógica de negócio, o que inclui algoritmos e regras procedimentais, e define o comportamento do sistema, ou seja, nessa camada intermediária as requisições são interpretadas e processadas e, em seguida, as respostas são enviadas para a máquina cliente. Caso seja necessário, o acesso, a inserção, a exclusão ou a modificação de algum objeto armazenado na base de dados, uma operação, normalmente definida por comandos escritos em SQL, é enviada à camada persistente para a recuperação desse objeto ou para a execução da ação solicitada.

A camada persistente corresponde à lógica de manipulação de dados e de conexão com o SGDB e é responsável pelo armazenamento físico dos objetos do domínio em uma base permanente. Essa camada possui forte potencial para ser reutilizada como estrutura (framework), mas o seu potencial de reutilização torna-se praticamente nulo quando instanciada para uma aplicação particular.

Dependendo da linguagem de programação utilizada para o desenvolvimento do sistema, partes da camada de aplicação podem ser distribuídas entre as camadas físicas. Quando a maior parte ou todo o processamento ocorre no cliente e os servidores atuam 
somente como repositórios de páginas e/ou de dados, a arquitetura é denominada "fat client" (Sun, 1997). Nos casos em que a lógica da aplicação e o seu processamento estão concentrados no servidor, a arquitetura recebe a denominação de "thin client" ou "anorexic client" e nos casos em que a lógica da aplicação encontra-se distribuída, de forma balanceada, entre o cliente e o servidor, a arquitetura é denominada "big-boned client". As tradicionais aplicações cliente/servidor, normalmente utilizam-se da arquitetura "fatclient", já as aplicações para a Web que implementam processos de negócios requerem a arquitetura "thin-client", para não sobrecarregar a máquina cliente, para permitir que não seja necessário mais do que um simples browser para a sua execução e para não exigir que os browsers possuam recursos específicos, como plug-ins, para a utilização da aplicação.

\subsection{Considerações Finais}

O propósito deste capítulo foi apresentar o Método para Análise e Projeto de Sistemas de Workflow Administrativo com Interface para Web, descrevendo as fases que compõem o processo de desenvolvimento proposto, as notações utilizadas e alguns exemplos dos resultados obtidos com a aplicação do método ao Sistema Atena - estudo de caso utilizado para dar suporte a este trabalho.

$\mathrm{O}$ método baseia-se em modelos, métodos e técnicas preexistentes, tais como o HDM, o RMM original e estendido e o BPI, sendo o principal recurso utilizado a UML que é a linguagem ou notação padrão para a modelagem de sistemas orientados a ọjetos, amplamente aceita pela comunidade de Engenharia de Software. A UML também permite a especificação de sistemas com processamentos paralelos, característica comum entre os sistemas de workflow, e com processamentos concorrentes, por meio dos seus diagramas de atividades. Possibilita ainda a modelagem das interações entre os objetos e/ou usuários entre si e com o sistema, por meio dos diagramas de interação ou colaboração.

O método BPI (Business Process Implementation) contribui para o detalhamento e a classificação das tarefas. Esse método, por ser específico para o projeto de sistemas que implementam fluxos de trabalho, foi utilizado como ponto de partida para a modelagem dos workflows. No decorrer do projeto, porém, observou-se que a modelagem realizada utilizando-se o BPI pôde ser traduzida para uma modelagem em UML com a mesma propriedade e, portanto, optou-se pelo uso da notação aceita como padrão, para especificar a maior parte das atividades elaboradas na fase de definição de workflows. As contribuições do BPI para a definição das tarefas, no entanto, foram mantidas, já que a UML não trata o assunto com o mesmo nível de detalhes.

A UML, no entanto, ainda não é apropriada para a modelagem de sistemas de in- 
formação para a Web. Devido a essa limitação, diversos autores, entre os quais citam-se Conallen (1999), Baumeister, Koch \& Mandel (1999) e Baresi, Garzotto \& Paolini (2001), têm desenvolvido e apresentado propostas de extensões à linguagem com o objetivo de torná-la apta para a especificação de projetos para a Web. Neste trabalho, foram consideradas as extensões propostas por Conallen (1999a), que definem novos estereótipos para a caracterização dos elementos que fazem parte das aplicações Web. Também foram abordadas as extensões sugeridas por Baresi et al. (2001), para a modelagem dos requisitos navegacionais e para o projeto navegacional, que propõe o uso integrado de elementos gráficos e conceitos do HDM com a notação da UML.

Dentre os modelos e métodos de aplicações hipermídia revisados, foram selecionados e utilizados o HDM, o RMM original e o RMM estendido para a elaboração do projeto de fatias e do projeto navegacional, ou seja, para a representação dos elementos específicos das aplicações Web que não podem ser modelados utilizando a UML.

Algumas adaptações realizadas e as justificativas para a escolha dos métodos e técnicas utilizadas como base para este trabalho são apresentadas com maiores detalhes no Capítulo 7. 


\section{Capítulo 6}

\section{Implementação e Uso do Sistema Atena}

\subsection{Considerações Iniciais}

Neste capítulo são apresentados alguns detalhes referentes à implementação, à aplicação do método proposto no Capítulo 5 e ao uso do Sistema Atena. Na Seção 6.2 são descritas algumas decisões de implementação, como a linguagem de programação e a plataforma utilizada. Na Seção 6.3 são apresentados exemplos da aplicação de praticamente todos os conceitos incorporados ao projeto de fatias e ao projeto de navegação. Nesses exemplos são ilustrados elementos de interface que auxiliam a implementação do workflow e que traduzem alguns de seus componentes. Na Seção 6.4 é apresentada uma seqüência de interfaces que exemplifica parte do uso do Sistema Atena e de como progride o workflow. Por fim, na Seção 6.5 é realizada uma breve avaliação da adequação do método a outros domínios a partir dos resultados obtidos com a sua aplicação ao Sistema Atena.

\subsection{Decisões de Implementação}

O Sistema Atena foi desenvolvido na linguagem PHP, sobre a plataforma Linux e, em conformidade com a arquitetura apresentada no Capítulo 5, utiliza o Apache como servidor de Web (http server), o MySQL como servidor de banco de dados e a linguagem JavaScript para a verificação da consistência de alguns dados de entrada, capturados por meio de um browser nas máquinas clientes.

O PHP é uma linguagem de script, cuja sintaxe é baseada nas linguagens C, Perl e Java e em primitivas próprias, que permite a criação de aplicações Web dinâmicas e que possibilita a interação dos usuários por meio de formulários, parâmetros de URL e links. 
A linguagem PHP foi criada com o propósito de suprir algumas limitações das linguagens tradicionalmente usadas para o desenvolvimento de aplicações e de sites dinâmicos para a Web. A primeira vantagem do PHP é ser independente de plataforma, superando assim a linguagem ASP, cujos scripts só podem ser processados pelos servidores da Microsoft (PWS e IIS) na plataforma Windows.

O PHP também apresenta vantagens sobre os scripts CGI escritos em C ou Perl pelo fato do seu código ser embutido no próprio código HTML, enquanto, no outro caso, é necessário que o script CGI gere todo o código HTML ou leia-o a partir de um outro arquivo. O que diferencia o PHP de linguagens como o JavaScript é o fato do código ser executado pelo servidor (server-side) e não pelo browser (client-side). Desse modo, o código proçessado gera páginas contendo apenas HTML que são, então, enviadas para o cliente. Com isso os usuários somente têm acesso aos resultados da execução do script PHP e não ao seu código fonte. Isso garante, em parte, a segurança da aplicação. Uma outra vantagem é a otimização do tempo de resposta ao cliente nos casos em que a base de dados encontra-se na mesma máquina que o servidor de Web, pois todo o processamento ocorre em um mesmo local, eliminando a necessidade de requisições a máquinas remotas.

Uma outra característica importante do PHP é a sua simplicidade para a geração de consultas e o seu suporte a vários bancos de dados, tais como MySQL, InterBase, PostgreSQL, Sybase, Informix e Oracle. O código PHP é consideravelmente menos complexo que os códigos em Java ou JSP (Java Server Pages) mas não se beneficia das vantagens das linguagens orientadas a objetos. A documentação completa sobre o PHP pode ser encontrada no seu site oficial (http://www.php.net).

O MySQL é um gerenciador e um servidor de banco de dados relacional, implementado em C e C++, que utiliza o SQL (Structured Query Language) padrão para o acesso e a manipulação dos dados armazenados. Esse SGBD possui as vantagens de ser multiplataforma, podendo ser executado sobre sistemas operacionais como Unix, Linux e Windows NT/9x, e de possuir o código aberto, podendo ser modificado e adaptado pelos desenvolvedores, de acordo com as necessidades específicas das suas aplicações. Além disso, a distribuição do MySQL é livre, se utilizado nas plataformas Linux ou Unix. No entanto, permissões de uso ou licenças são exigidas, caso seja utilizado no Windows ou para dar suporte a transações comerciais.

Uma característica do MySQL bastante útil para a implementação de sistemas de workflow é a possibilidade de criação de usuários com diferentes níveis ou privilégios de acesso aos dados e de execução das funcionalidades oferecidas pelo servidòr. Isso garante, em parte, que as informações armazenadas somente serão modificadas por pessoas autorizadas. Por fim, o MySQL é bastante flexível e robusto; permite um acesso rápido a grandes bases de dados; seus dados são transferidos criptografados pela rede, além 
de permitir o gerenciamento de usuários, aos quais são atribuídos senhas para o controle de acesso. Maiores informações sobre o MySQL podem ser encontradas no site: http://www.mysql.com.

O Apache é um servidor de Web baseado no protocolo HTTP, que pode ser executado em máquinas com os sistemas operacionais Windows NT/9x, Netware 5.x, OS/2 e com a maioria das versões do Unix. Sua distribuição é totalmente livre e seu código também é aberto. Arquivos específicos são configurados para que o Apache interprete scripts PHP ou CGI. O pacote original do Apache não inclui suporte a Java, JSP, EJB (Enterprise Java Beans) ou servlets Java. Essa característica, porém, pode ser incorporada por meio de pacotes adicionais (add-ons) desenvolvidos pelo Apache/Java Project (http://jakarta.apache.org).

Como a maior parte do processamento da aplicação concentra-se no servidor e uma parte mínima, direcionada para a consistência local de dados, ocorre no cliente, a arquitetura na qual está baseado o Sistema Atena (Figura 6.1) caracteriza-se como "thin client", de acordo com as denominações apresentadas na Seção 5.4.4, referente à fase de implementação do processo de desenvolvimento proposto. No caso dos sistemas implementados usando apenas a linguagem JavaScript, a arquitetura possui apenas duas camadas (2tier) e se caracteriza como "fat client", pois todo o processamento é realizado no cliente e somente são feitas requisições de páginas, por meio de parâmetros URL, ao servidor de Web. Por questões de segurança e pelo fato de ser executada exclusivamente no cliente, a linguagem JavaScript não realiza acessos a bases de dados e, desse modo, não existe a camada permanente.

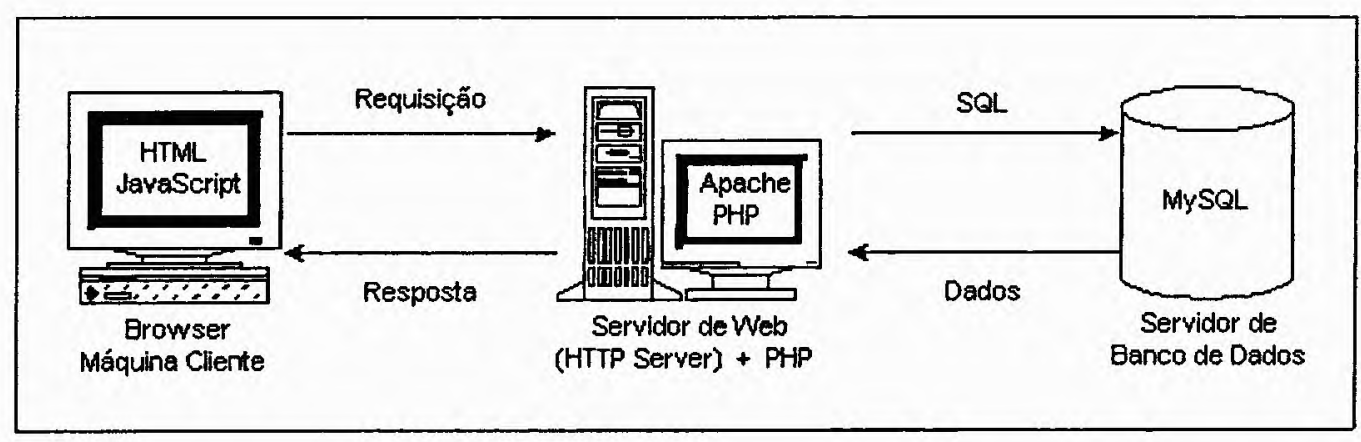

Figura 6.r: Arquitetura utilizada para a execução do Sistema Atena

Por ter sido implementado em PHP e JavaScript, o Sistema Atena pode ser utilizado a partir de qualquer browser, já que todos os navegadores atuais possuem plug-ins que interpretam a linguagem JavaScript e o código PHP é processado no servidor e, portanto, não exige que nenhum recurso adicional seja instalado nos clientes. 


\subsection{Interface do Sistema}

A tela principal do Sistema Atena, ilustrada na Figura 6.2, possui ligações que possibilitam - acesso à tela de entrada, usada para a identificação dos usuários do sistema, e a páginas públicas, que podem ser acessadas por usuários genéricos. Essa interface corresponde ao nodo raiz ou nodo default da aplicação e é representada, no modelo navegacional (Figura 5.12), por um agrupamento denominado "Principal". O conjunto de ligações do nodo raiz forma um menu que permite a navegação por contextos diversificados de serviços e de informação e, por essa razão, é representado por um agrupamento e não por um índice ou outra estrutura de navegação.

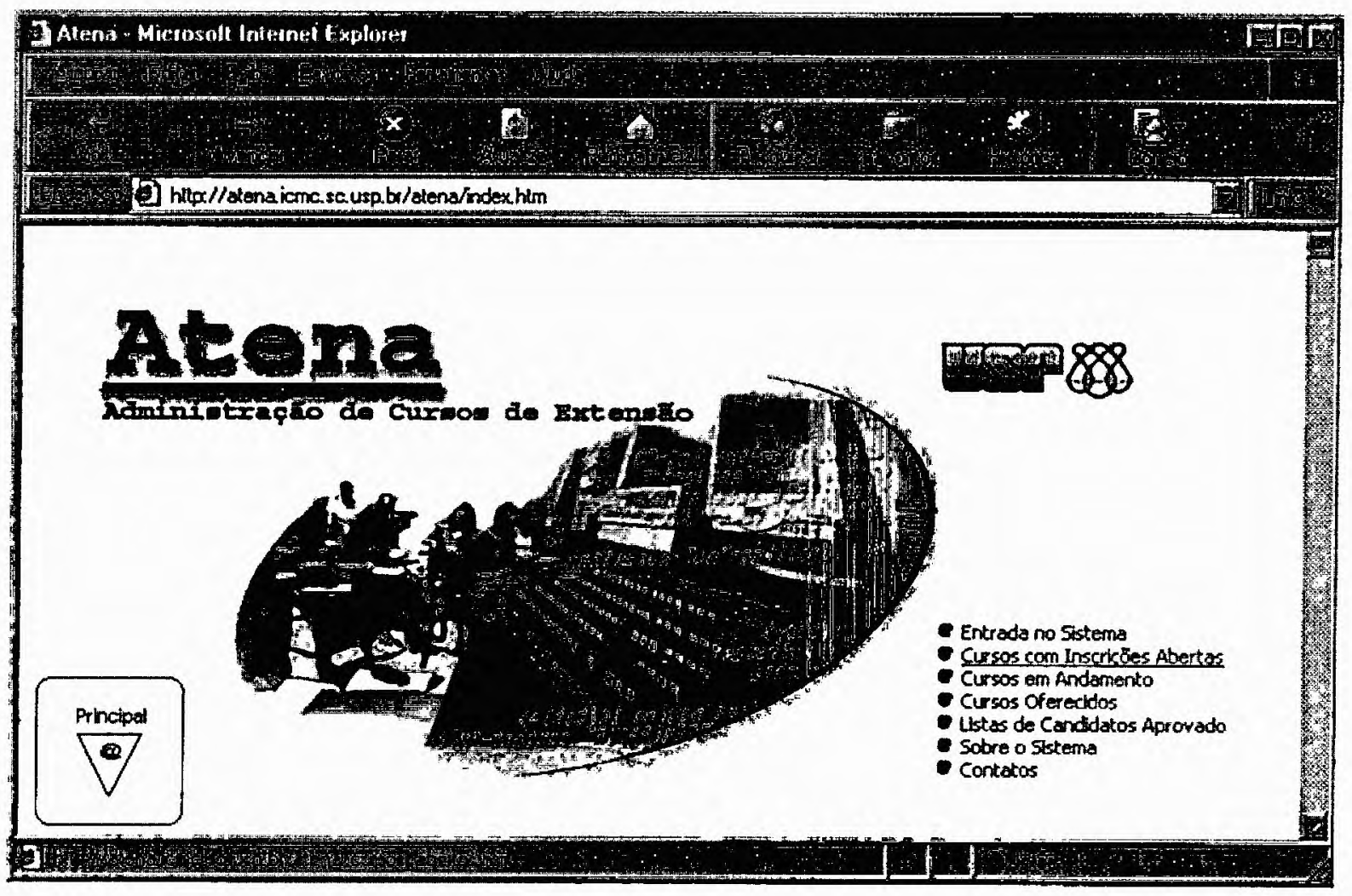

Figura 6.2: Tela principal do Sistema Atena - exemplo de agrupamento

Um grupo de ligações constitui um índice, um roteiro guiado ou um roteiro guiado indexado quando esses permitem o acesso a instâncias de uma única classe. No caso específico da interface apresentada na Figura 6.3, os ligações compõem um índice, pois permitem acesso direto a cada uma das instâncias e não existem ligações ou um caminho navegacional entre os cursos. Nesse exemplo, o atributo "título" identifica as diferentes instâncias e é usado como âncora para o acesso às informações sobre um curso. Tal atributo, portanto, define um centro associado à classe que representa a interface ilustrada.

A interface da Figura 6.3 é pública e é acessada pelo ligação "Cursos com Inscrições 


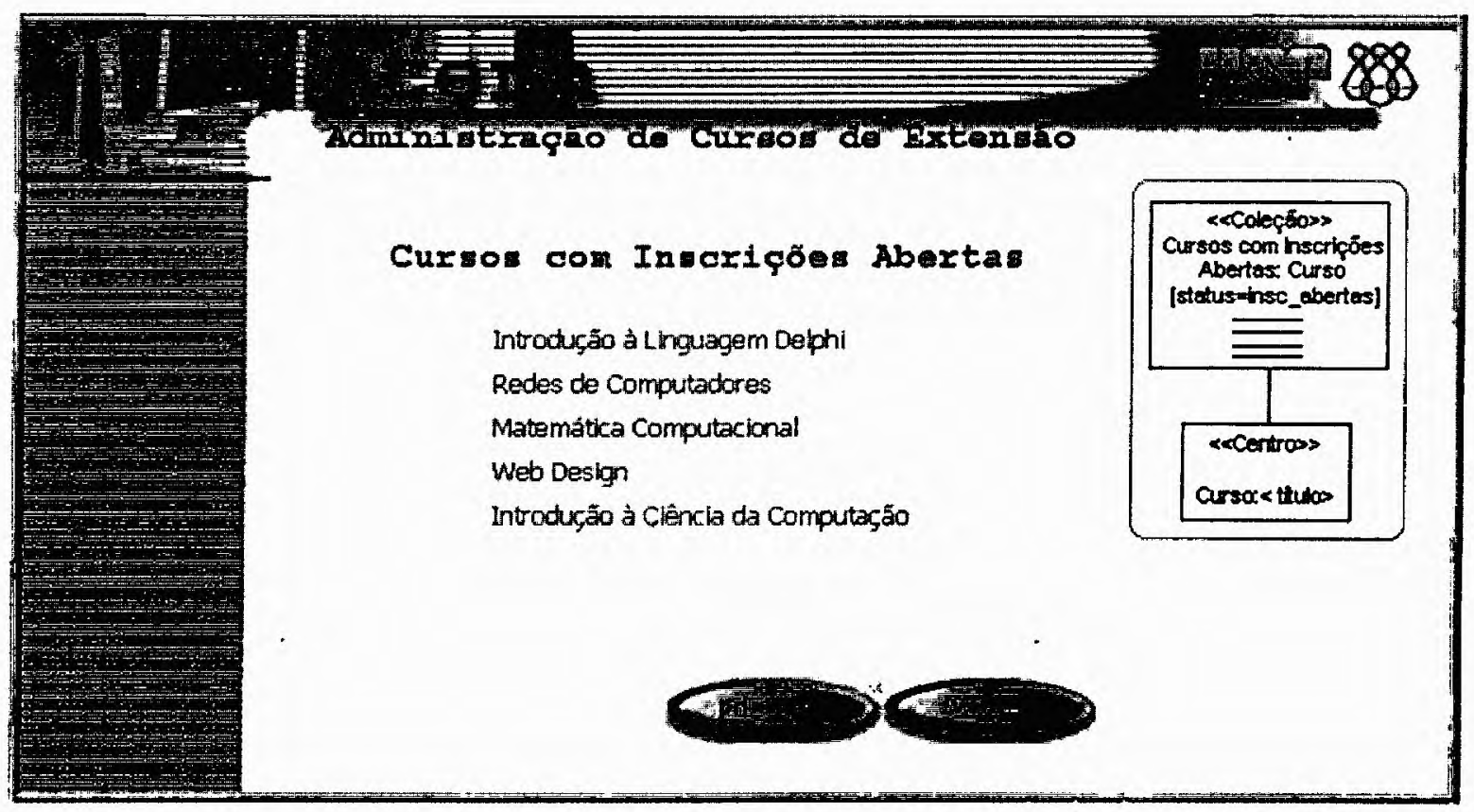

Figura 6.3: Exemplo de um índice

Abertas" da tela principal, que, assim como os ligações "Cursos em Andamento" e "Cursos Oferecidos", permite o acesso a uma classe de interface que corresponde a um índice e à qual está associada uma coleção. Desse modo, os elementos que compõem o índice satisfazem ao critério de seleção especificado na coleção. Nos três casos, o critério de seleção baseia-se no estado do objeto "curso". No primeiro deles, são filtrados os cursos que já foram aprovados pelo Conselho Departamental e pela CCEx e que encontram-se no período de inscrição. No segundo caso, são selecionados os cúrsos cujas aprovações de candidatos estão finalizadas e que, portanto, encontram-se em andamento. Um curso permanece nesse estado até que o docente responsável calcule as médias e as freqüências finais dos alunos e encaminhe-as ao Diretor da unidade para que seja solicitada a autorização da Pró-Reitoria de Cultura e Extensão Universitária para a emissão dos certificados. Quando ocorre o encaminhamento dos resultados obtidos pelos alunos, o curso assume o estado "encerrado" e passa a ser um componente da coleção "Cursos Oferecidos".

Quando não existem cursos no estado referenciado pela coleção, o resultado da seleção é um conjunto vazio, logo, não ocorre a geração do índice. Nesses casos, o ligação que ativa a coleção é previamente desativado, pois não há sentido em compor um índice sem elementos. A desativação de estruturas de navegação associadas à coleções é um dos principais recursos utilizados para o controle das atividades do workflow, pois as coleções restringem os dados acessados e oferecem mecanismos para que as pré-condições sejam avaliadas quando uma tarefa é executada.

Cada elemento do índice ou cada ligação da coleção "Cursos com Inscrições Abertas" 
ativa uma página contendo informações sobre um curso específico, como a apresentada na Figura 6.4. As classes de interface que correspondem a essa categoria de páginas são identificadas, no modelo navegacional (Figura 5.13), pelo estereótipo "página de conteúdo no cliente", cujo ícone também é ilustrado na Figura 6.4.

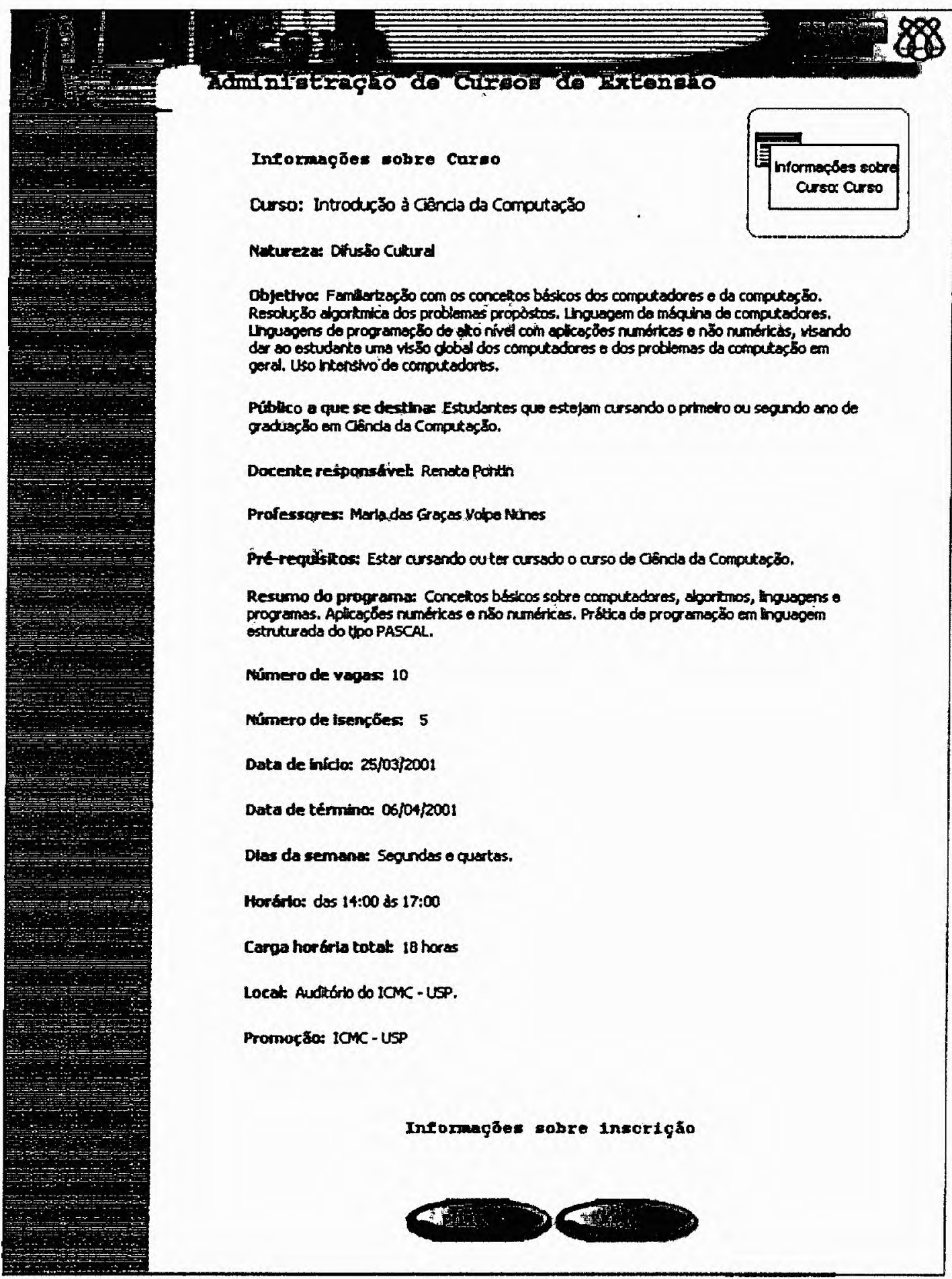

Figura 6.4: Exemplo de uma página de conteúdo 
O conteúdo da página da Figura 6.4 pode ser estruturado pelo $m$-slice apresentado na Figura 6.5. Esse é um exemplo bastante simples que representa a seleção de alguns atributos da classe proprietária "curso".

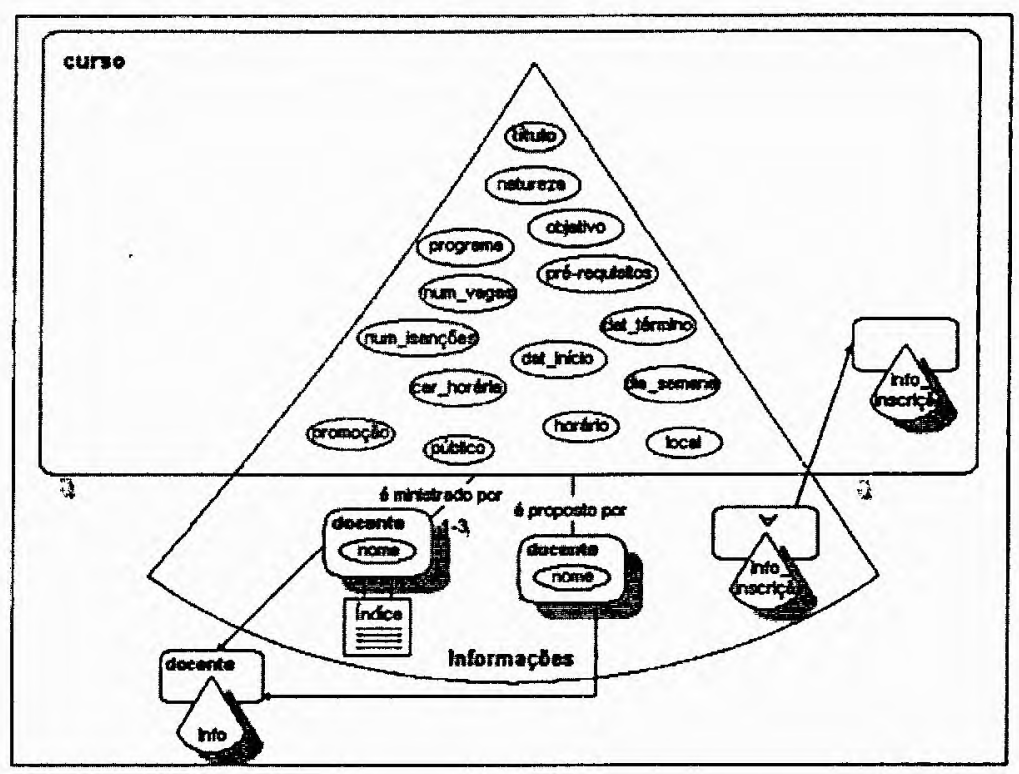

Figura 6.5: Exemplo de um m-slice

Como mencionado anteriormente, a partir da tela principal acessa-se a tela de entrada no sistema, ilustrada na Figura 6.6. Apesar de conter campos de um formulário, essa tela é representada por um agrupamento, pois a partir dela é possível o acesso aos diferentes ambientes, que representam as visões do sistema, definidas sob a perspectiva de cada ator do workflow. O ambiente do Assistente Acadêmico, por exemplo, é apresentado na Figura 6.7 .

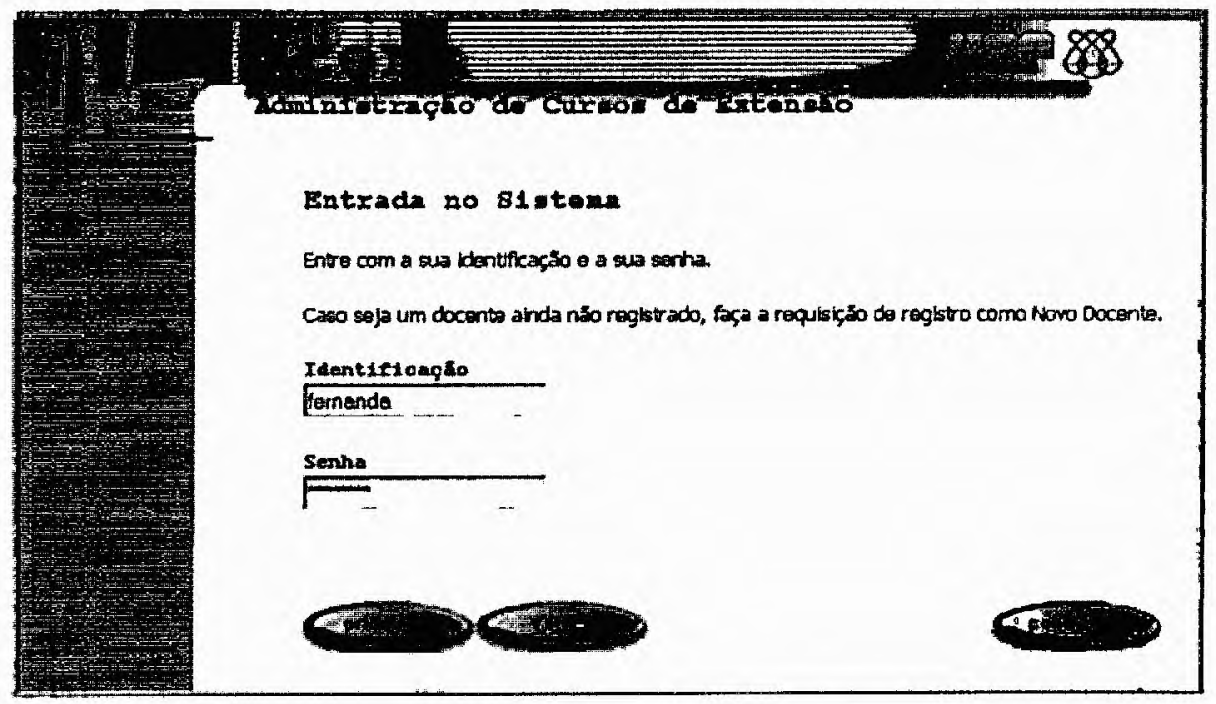

Figura 6.6: Tela de Entrada no Sistema 
Assim como no AulaNet e no WebCT, os dados fornecidos na tela de entrada (identificação e senha) são utilizados para identificar o usuário, o seu perfil e o seu nível de acesso ao sistema. No Sistema Atena, quando o perfil do usuário é reconhecido, o ambiente relativo a esse perfil é ativado.

Cada ambiente agrupa um conjunto de serviços que são de responsabilidade de uma classe específica de ator do workflow, conforme as regras do processo de negócio. Os serviços equivalem a uma ou mais atividades do fluxo de trabalho. Essa forma de apresentação ou organização é uma maneira de agrupar atividades fortemente relacionadas. Os ambientes correspondem a visões ou subsistemas e também são modelados como agrupamentos, por serem formados por menus de serviços.

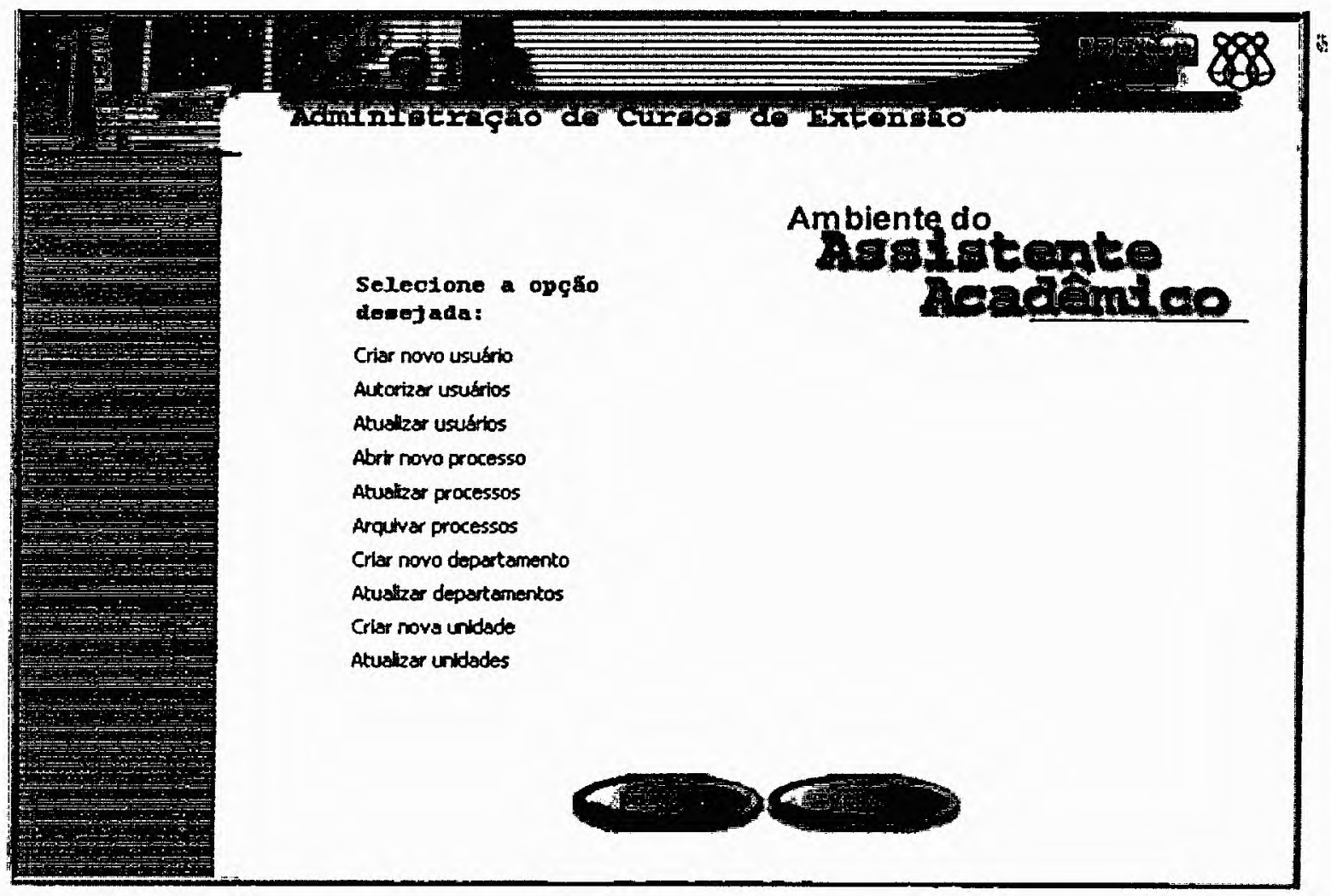

Figura 6.7: Ambiente do Assistente Acadêmico - exemplo de visão

O primeiro item do menu e uma das principais atividades executadas pelo Assistente Acadêmico é a criação dos usuários do sistema, com exceção dos alunos, que são de responsabilidade do docente. Essa atividade é realizada por meio de uma interface que contém um formulário, como a apresentada na Figura 6.8. A interface ilustrada exemplifica a desigualdade entre as classes de interface e as classes conceituais. Nessa classe de interface, por exemplo, o departamento, a unidade ou a Pró-Reitoria à qual o usuário é vinculado é identificada pelo seu nome e não pelo seu código, como ocorre na classe conceitual (ver modelo de classes do Capítulo 5). 


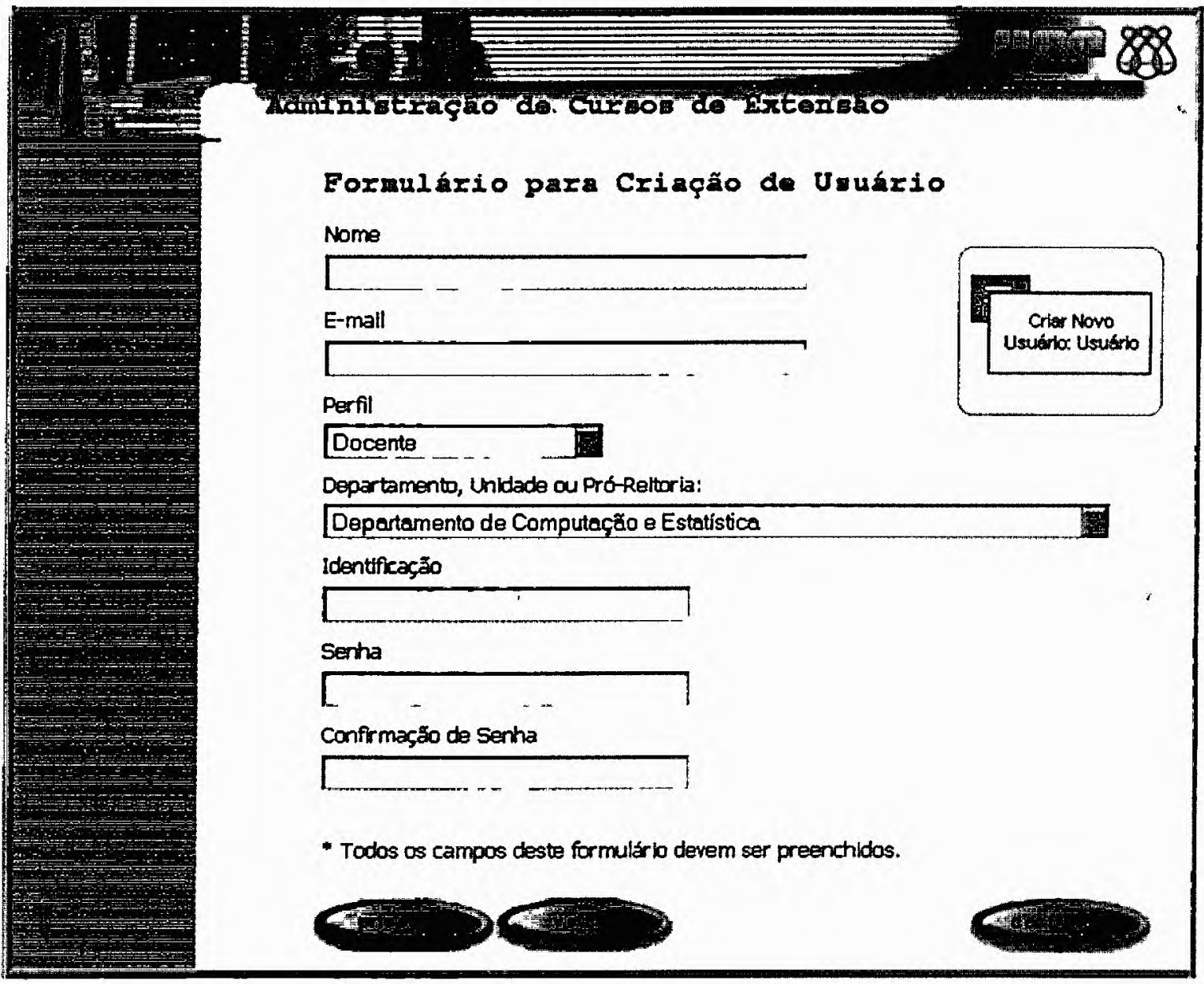

Figura 6.8: Interface para a criação de usuários - exemplo de formulário

\subsection{Exemplo de Uso}

A primeira ação a ser tomada antes que o sistema possa ser utilizado é a criação do Assistente Acadêmico, tarefa realizada diretamente no banco de dados. Isso porque o Assistente Acadêmico é o usuário que atua como administrador do sistema e, portanto, é responsável pelo início de todo o processo.

Após sua criação, a primeira atividade realizada pelo Assistente Acadêmico é o registro das unidades, dos departamentos e dos usuários pertencentes ao escopo do sistema. Esses registros devem ser realizados nessa ordem, pois os departamentos devem ser associados, na base de dados, às suas respectivas unidades e os usuários devem ser associados aos departamentos ou unidades aos quais estão vinculados, de acordo com o seu perfil ou nível hierárquico. Essas três atividades são realizadas por meio de formulários, que permitem a inserção de registros no banco de dados. O formulário para a criação de usuário foi apresentado na Figua 6.8 da seção anterior.

Criadas as unidades, os departamentos e os usuários, inicia-se o principal workfiow 
que é referente à oferta e à aprovação dos cursos de extensão. Esse processo inicia-se com a criação de uma proposta de curso, que é realizada pelo docente responsável por sua oferta. Esse docente não é necessariamente o docente que ministra o curso; nesse caso, o professor do curso também deve estar registrado no sistema. Para a criação de uma proposta de curso é utilizado um formulário, semelhante ao apresentado na Figura 6.8, contendo, no entanto, todos os campos referentes aos atributos apresentados na Figura 6.4 e mais alguns outros relativos às informações sobre a inscrição. Quando um curso é criado, ele assume o estado "proposto" e passa a compor a lista de cursos cuja abertura de processos encontra-se pendente que é gerenciada pelo Assistente Acadêmico (Figura $6.9)$.

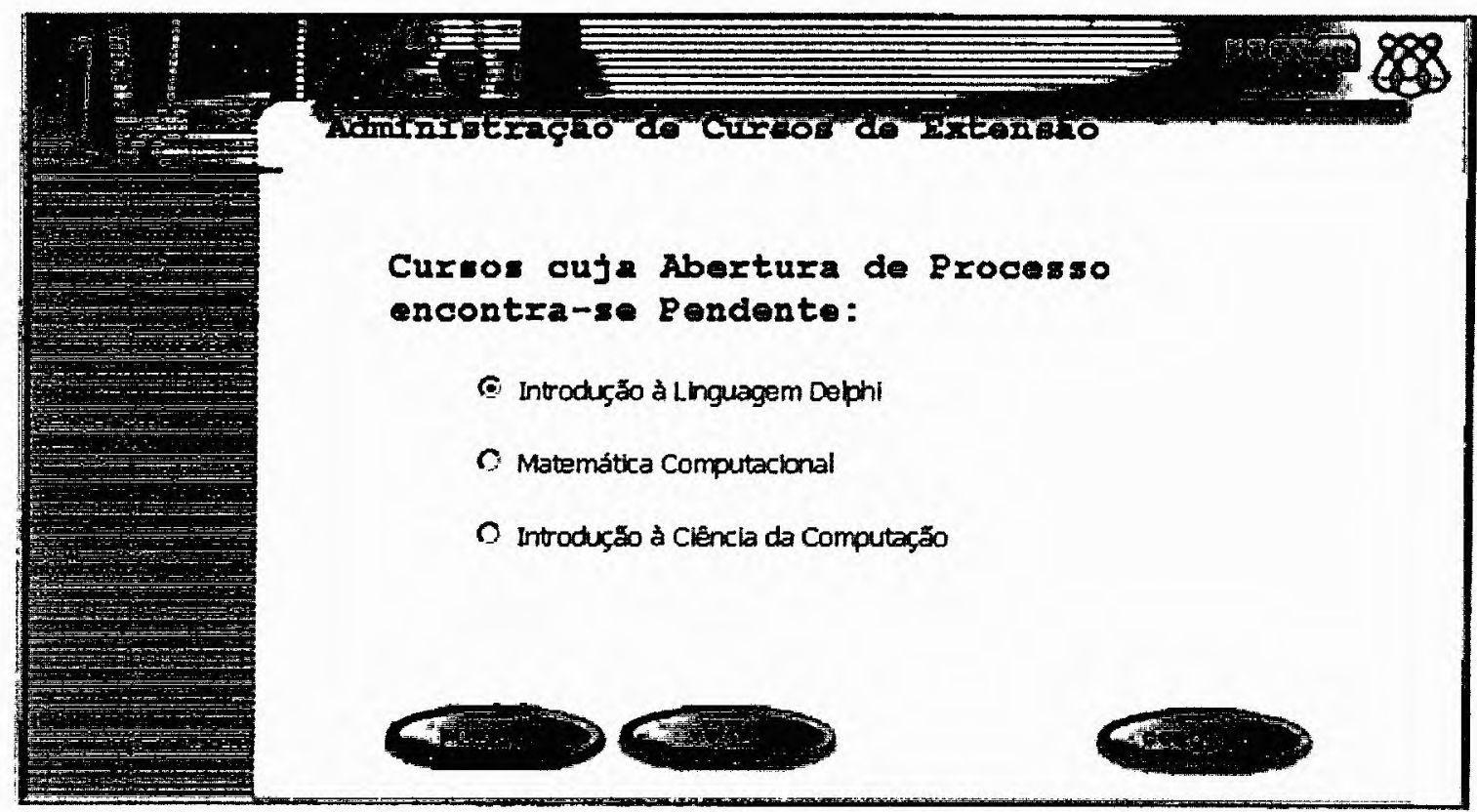

Figura 6.9: Lista de cursos cuja abertura de processo encontra-se pendente

O próximo passo, portanto, é a abertura de um processo referente ao curso proposto. Essa é uma exigência do domínio da aplicação, isto é, para que a proposta de um curso seja encaminhada e aprovada pelos órgãos competentes ela deve estar incorporada a um processo administrativo que a regulamenta. A tela para a abertura de processo é ilustrada na Figura 6.10.

Como representado no modelo de classes, a classe "processo administrativo" é totalmente dependente da classe "curso", o que significa que não existe um processo caso não exista um curso que o origina. Do mesmo modo, se a proposta de curso for excluída do sistema, o processo associado também o será. 


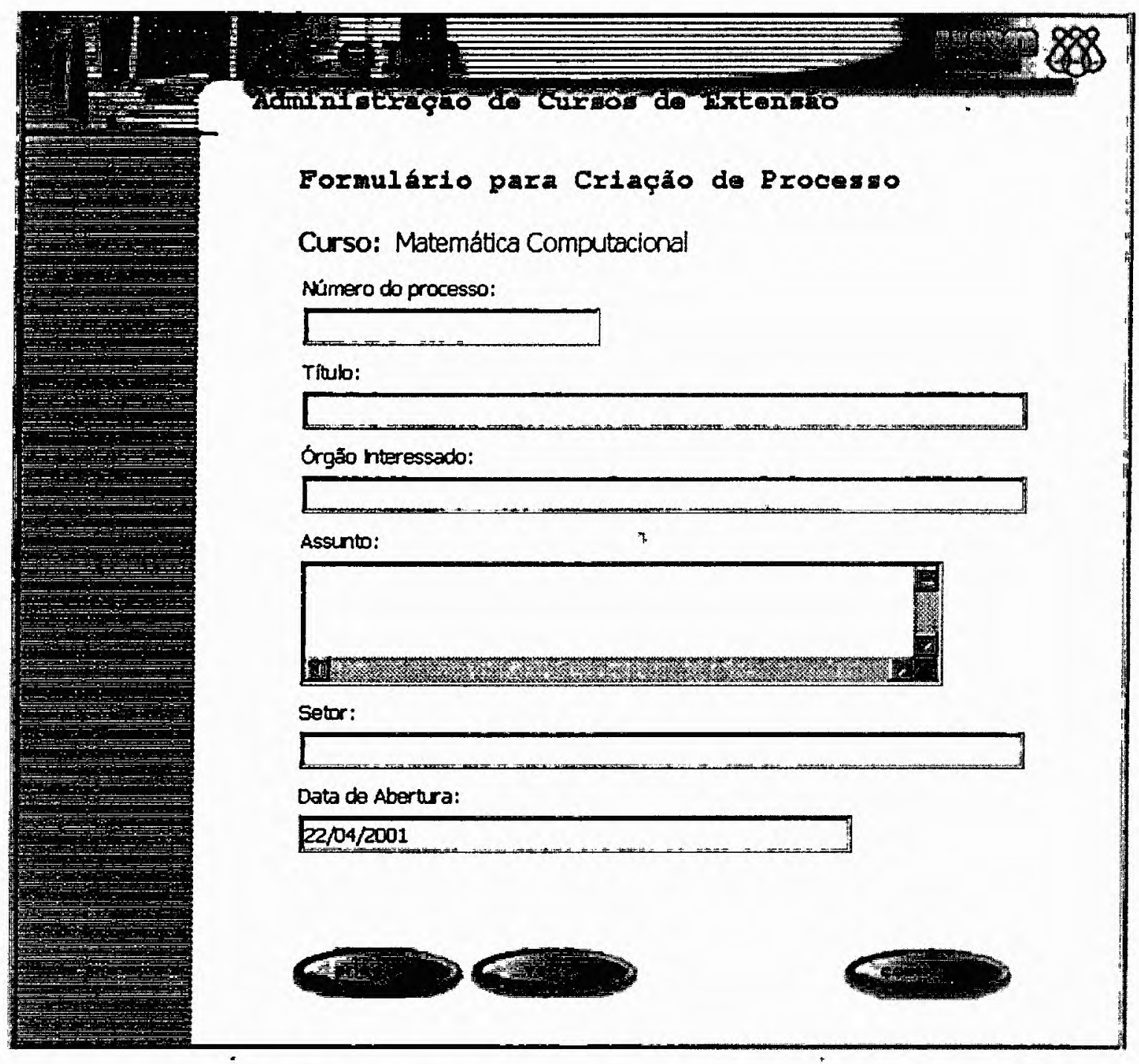

Figura 6.10: Formulário para abertura de processo

Aberto o processo, a proposta de curso é submetida às aprovações do Conselho do Departamento e da Comissão de Cultura e Extensão (CCEx) da Unidade à qual o curso está relacionado. Não existe nenhuma regra que restringe a ordem de aprovação por esses dois órgãos, portanto, ambos podem aprovar ou não aprovar o curso em paralelo. Os ambientes do Chefe Departamental e do Presidente da CCEx, que são os atores que "assinam" as aprovações, são apresentados nas Figuras 6.11 e 6.12.

Observe que a CCEx está vinculada a uma Unidade, logo, o Presidente é responsável pela aprovação dos cursos referentes a todos os Departamentos que compõem a sua Unidade. No exemplo da Figura 6.12, o curso "Programação Matemática" está associado ao Departamento de Matemática, enquanto os outros dois cursos estão associados ao Departamento de Computação, ambos pertencentes à Unidade ICMC. 


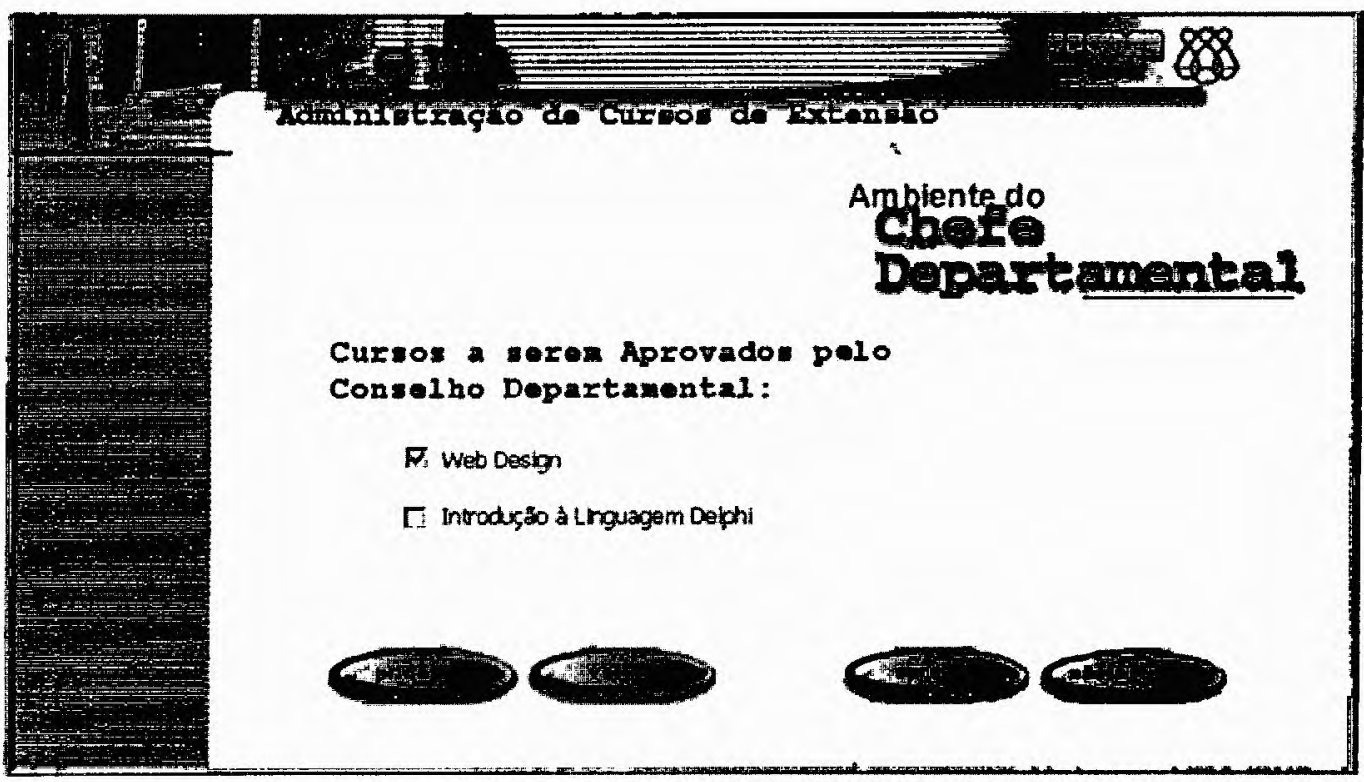

Figura 6.11: Aprovação da proposta de curso pelo Conselho Departamental

Um outro detalhe que pode ser observado nesses exemplos é a independência da ordem de aprovação. O curso "Web Design", por exemplo, aparece simultaneamente nas listagens dos dois ambientes, o que significa que ele ainda não foi aprovado em nenhuma das instâncias. Já o curso "Introdução à Ciência da Computação" foi aprovado pelo Conselho do Departamento de Computação, mas ainda não foi aprovado pela CCEx. O caso contrário acontece com o curso "Introdução à Linguagem Delphi".

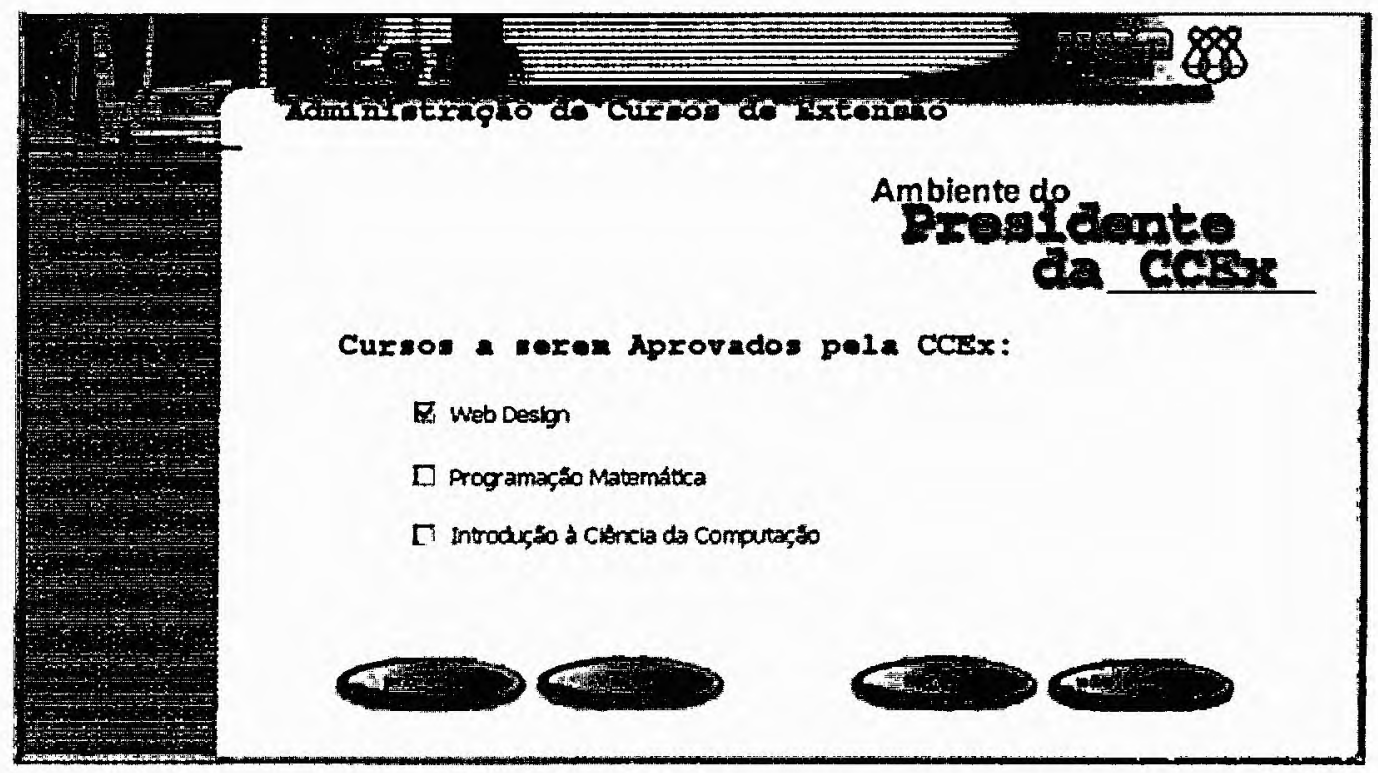

Figura 6.12: Aprovação da proposta de curso pela CCEx

Se o curso não for aprovado em pelo menos uma das instâncias ele assume o estado "indeferido" e o workflow é interrompido. Caso seja aprovado nas duas instâncias, ele 
assume o estado "aprovado" e o workflow prossegue normalmente. Na data de início das inscrições ele é incluído na listagem da Figura 6.3 e assume o estado "com inscrições abertas". Os interessados, então, podem acessar as informações sobre o curso e realizarem suas inscriçōes, assumindo o papel de candidatos. O formulário de inscrições é apresentado na Figura 6.13. Nesse formulário, o candidato ao curso sugere um nome que será utilizado para a sua posterior identificação no sistema, caso sua inscrição seja aprovada e ele se torne um aluno.

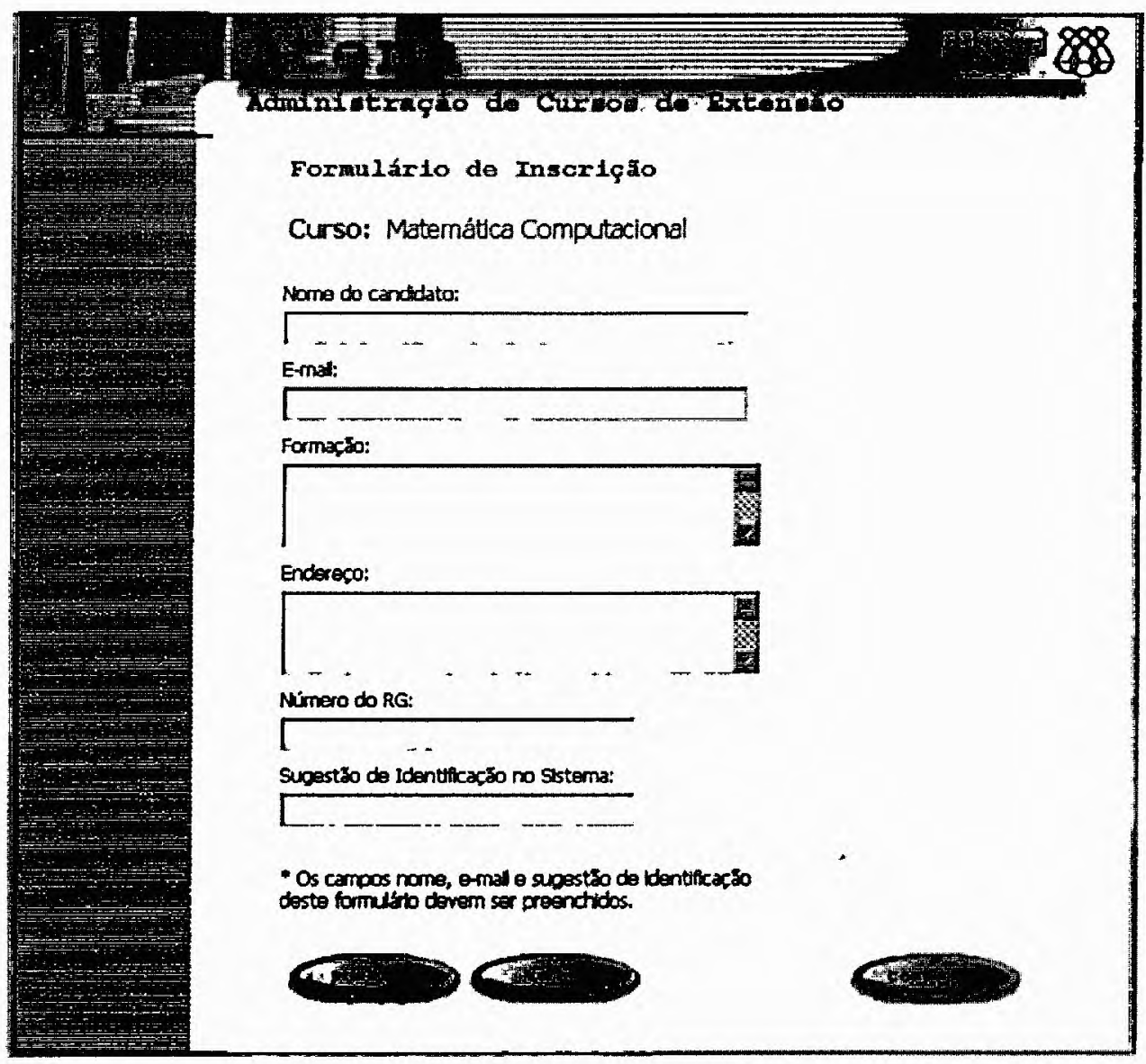

Figura 6.13: Fomulário de inscrição

Na data de término das inscrições, o curso é excluído da lista de cursos com inscrições abertas e passa para o estado "com aprovações abertas". A partir desse momento, o docente responsável deve aprovar manualmente as inscrições até que todas as vagas do curso tenham sido preenchidas ou até três dias antes do seu início. Se três dias antes da data de início do curso ainda existirem vagas remanescentes e inscriçōes não aprovadas, o sistema aprova os candidatos automaticamente, preenchendo as vagas de acordo com a ordem de inscrição, e a lista de candidatos aprovados é divulgada. A interface da Figura 6.14, exibe ao docente todas as informações necessárias para a aprovação dos candidatos a um curso. 


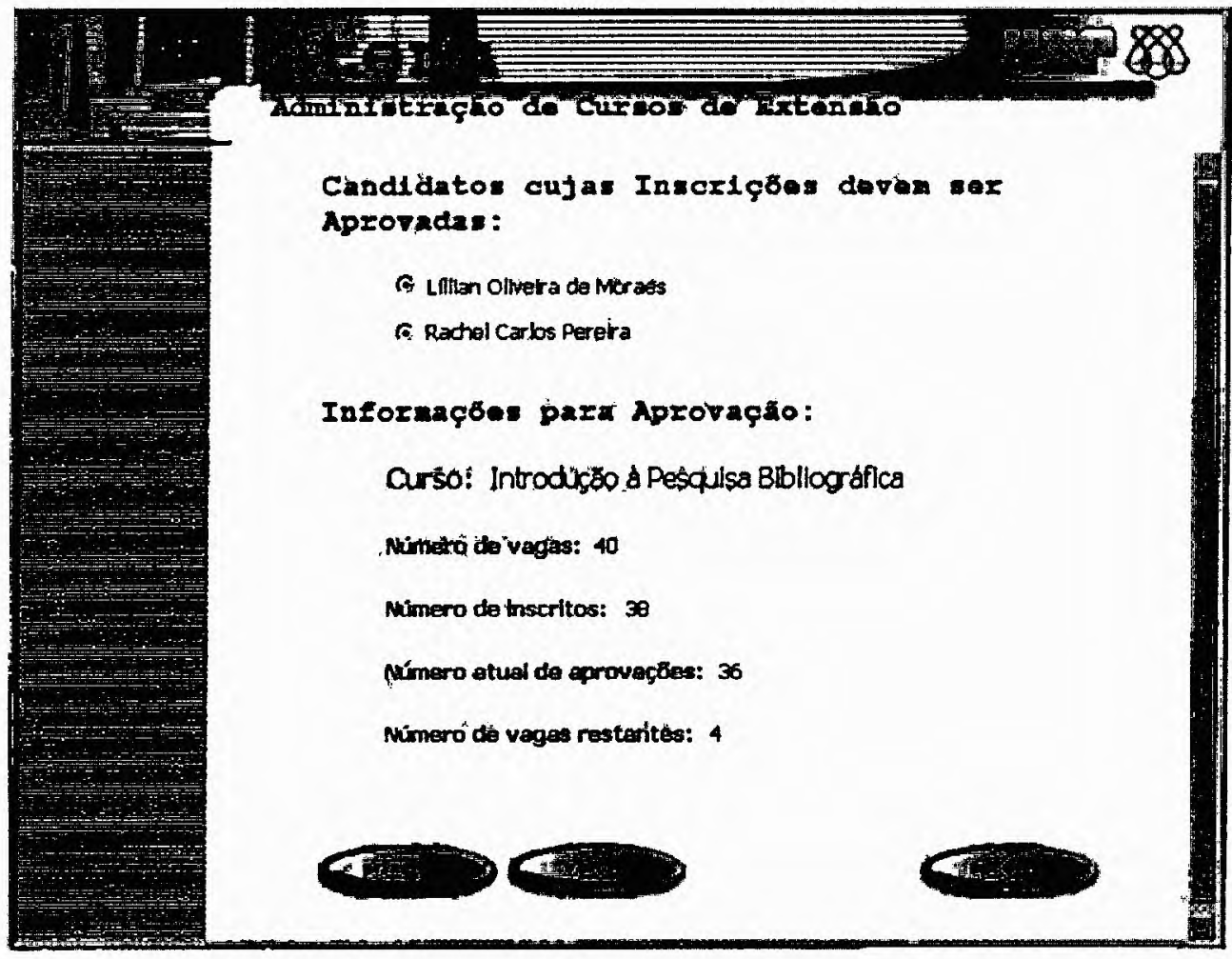

Figura 6.14: Informações para aprovação de candidatos

Finalizadas as aprovações, o curso assume o estado "em andamento". A partir de agora, o docente pode criar os calendários de aulas e de avaliaçōes, como ilustrado na Figura 6.15 .

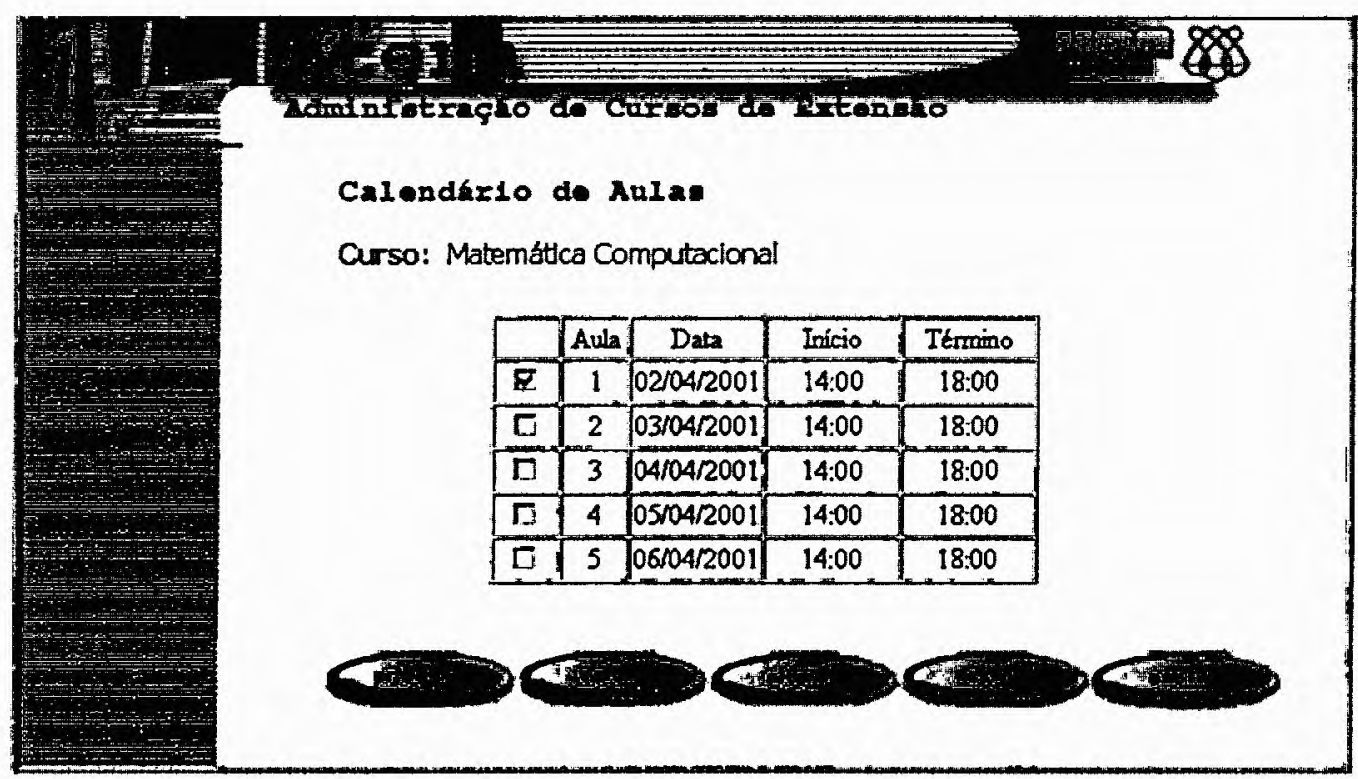

Figura 6.15: Interface para a edição do calendário de aulas

Definidos os calendários, no decorrer do curso o docente atribui freqüências e notas 
aos alunos. Essas informaçōes são utilizadas para a posterior certificação. Nas Figuras 6.16 e 6.17 , são apresentadas as interfaces utilizadas, respectivamente, para o controle de freqüências e para o controle notas.

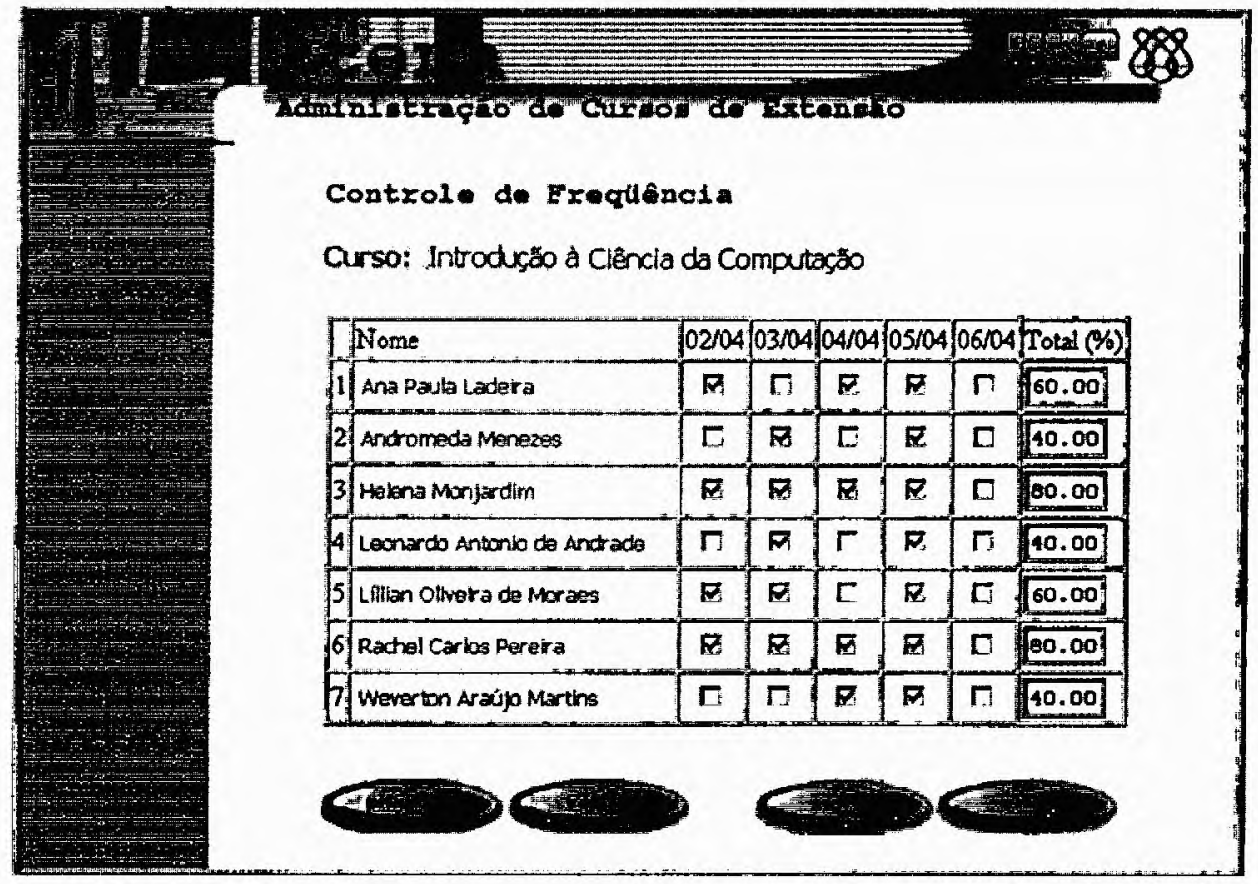

Figura 6.16: Interface para o controle de freqüência

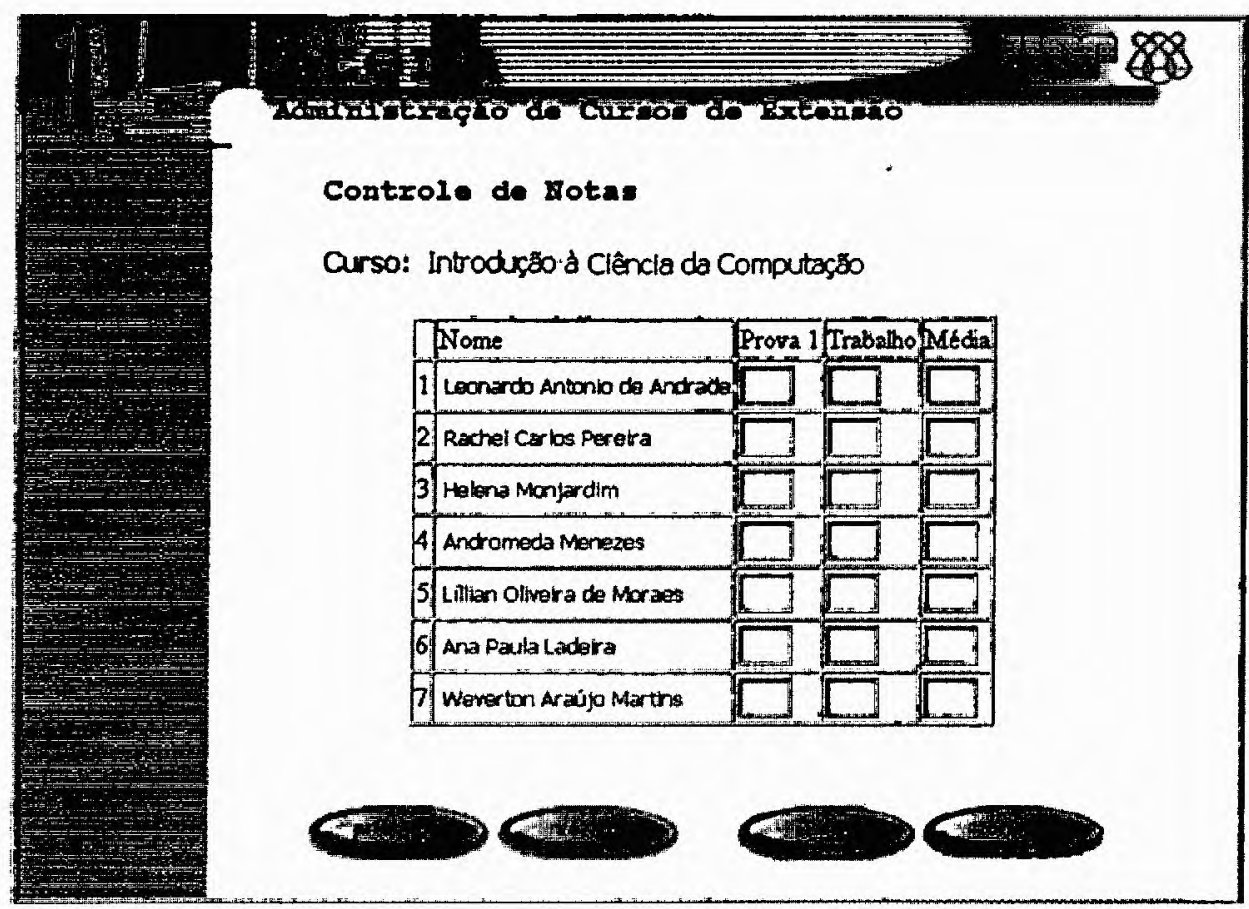

Figura 6.17: Interface para o controle de notas

No final do curso, o docente calcula as médias e as freqüências finais dos alunos e envia 
esses resultados para a Diretoria da Unidade. O Diretor, em seguida, encaminha o demonstrativo do aproveitamento obtido pelos alunos à Pró-Reitoria de Cultura e Extensão Universitária, para que seja autorizada a emissão dos certificados dos aprovados (Figura $6.18)$.

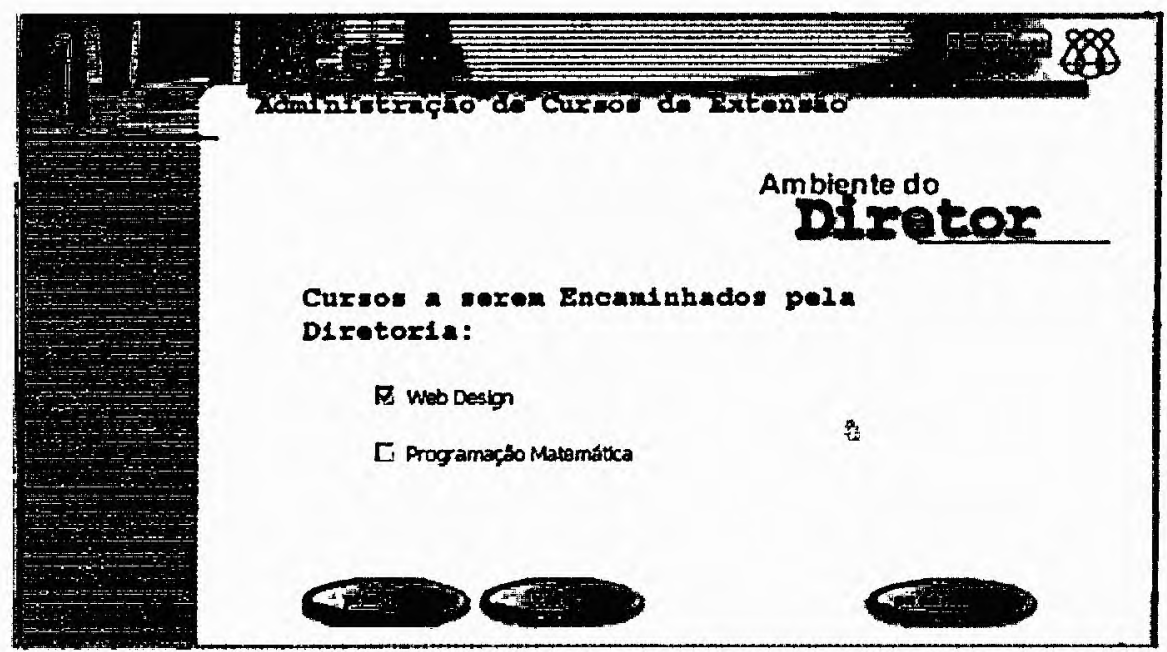

Figura 6.18: Encaminhamento da Diretoria à Pró-Reitoria

O Pró-Reitor recebe esse demonstrativo, analisa-o e autoriza a emissão dos certificados, como demonstrado na Figura 6.19. Tendo sido informado sobre a autorização da PróReitoria, o Assistente Acadêmico emite os certificados e encaminha novamente o processo à Pró-Reitoria para o conhecimento da Comissão de Cultura e Extensão Universitária (CoCEx). Estando a CoCEx ciente de todas as informações referentes ao curso realizado, o processo retorna ao Assistente Acadêmico, pelo encaminhamento do Pró-Reitor, por quem ele é finalmente arquivado (Figura 6.20).

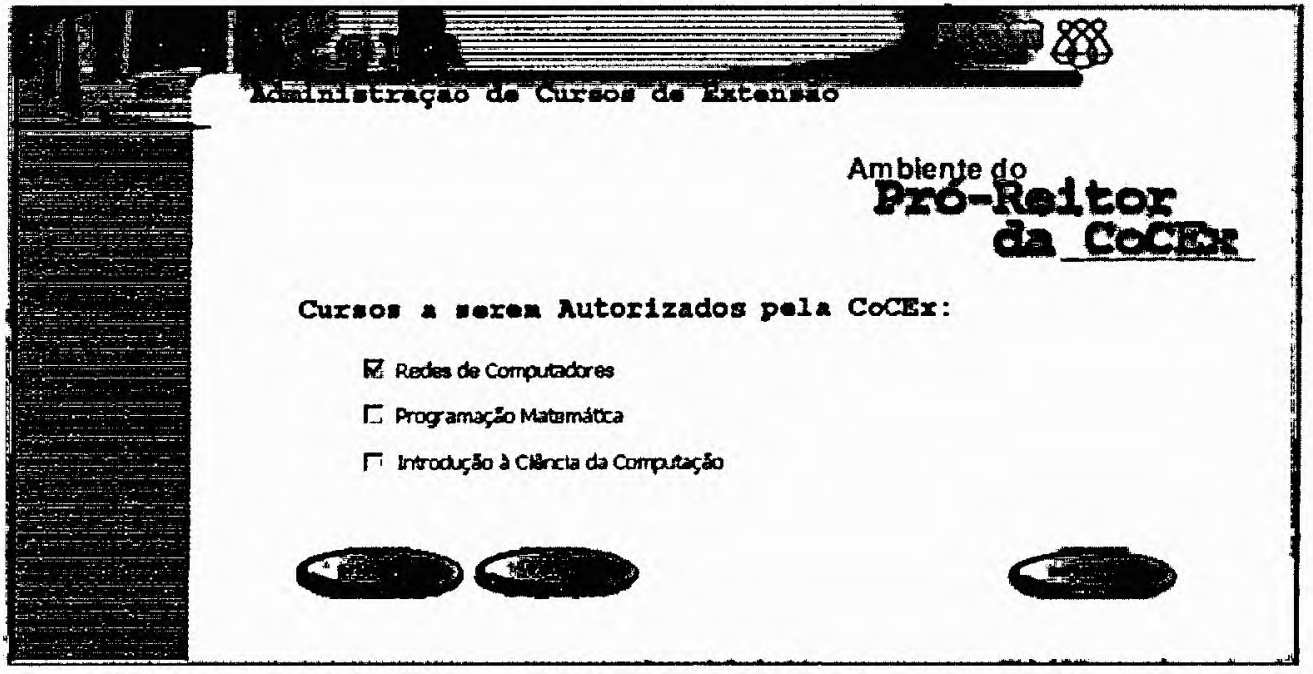

Figura 6.19: Autorização para emissão de certificados 


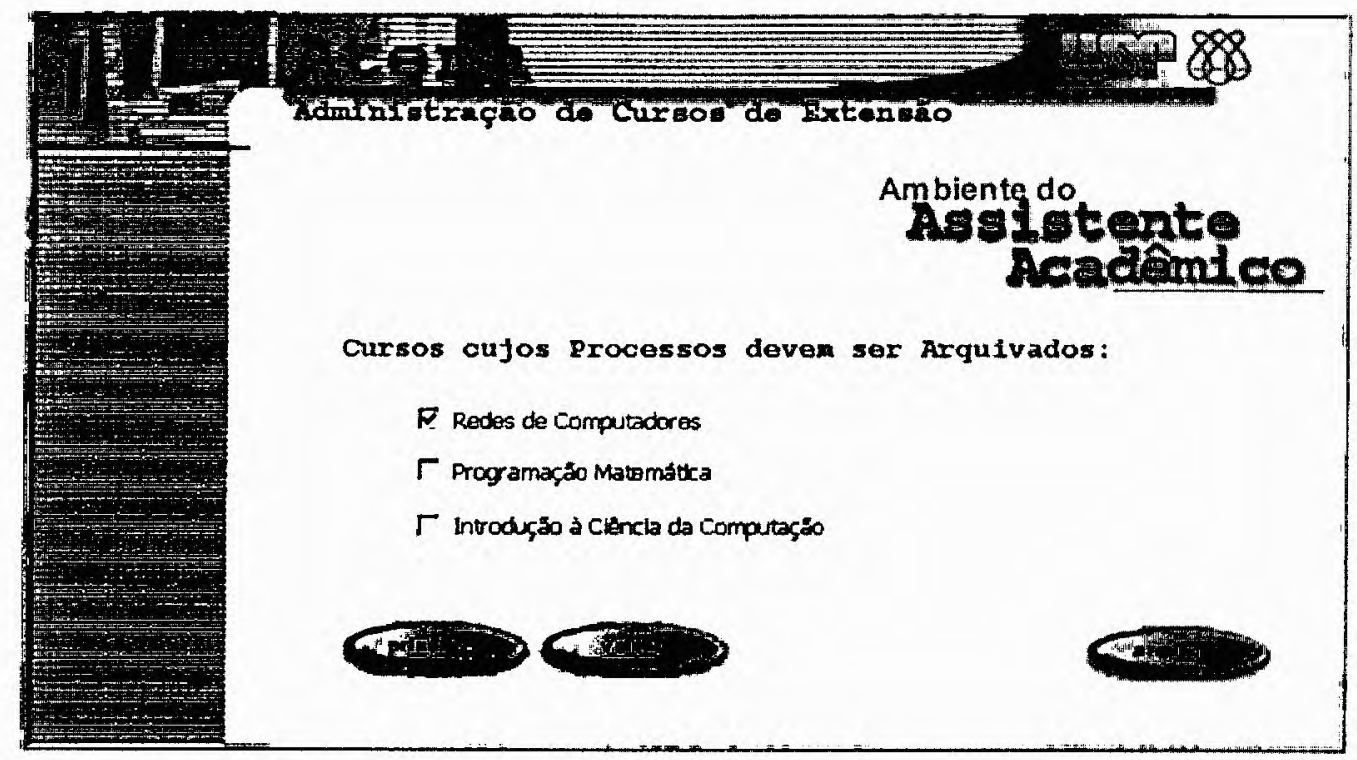

Figura 6.20: Arquivamento de processos

\subsection{Avaliação de Resultados}

As atividades de implementação do Sistema Atena e de elaboração do método ocorreram de forma intercalada e iterativa. Desse modo, parte da aplicação foi implementada antes, parte durante e parte depois da proposição do método. Com isso, o Sistema Atena foi utilizado tanto como base para a construção do método, quanto para testá-lo e validálo. Analisando os resultados atingidos, não foram encontradas dificuldades ou limitações para a modelagem do sistema aplicando o processo de desenvolvimento, as técnicas e as notações propostas.

O método desenvolvido tanto serviu para modelar as partes do sistema que já estavam implementadas, quanto serviu para projetar, com um bom nivel de detalhes, as porções a serem elaboradas. Isso significa que o método, da maneira como foi proposto, não impôs restrições ou limitações à implementação e, ao mesmo tempo, foi apropriado e flexível - suficiente para representar uma aplicação preexistente. Essa característica deve ser evidenciada pois existem métodos que limitam o projeto e a implementação dos sistemas por eles suportados, como é o caso do RMM original. Isso faz com que a aplicação tenha que se adaptar ao método de projeto e não o contrário.

Realizando uma breve avaliação dos resultados obtidos com o desenvolvimento do Sistema Atena, sob o ponto de vista de outros domínios de aplicação, verifica-se que o método proposto também pode ser utilizado para a análise e o projeto de outras classes de sistemas, bastante comuns na WWW, como, por exemplo, sistemas de comércio eletrônico, sites de busca na Internet ou sistemas para a divulgação de oportunidades de emprego e de currículos na Web. 
A flexibilidade do método é garantida, sobretudo, pela possibilidade de criação de diferentes visões e pelas coleções. Nos sistemas de comércio eletrônico e nos bancos de ofertas de emprego e currículos, por exemplo, as visões são utilizadas para a personalização do sistema de acordo com o perfil ou com possíveis configurações do cliente ou do usuário, atendendo, dessa forma, às necessidades e aos objetivos de cada categoria de ator. $\mathrm{O}$ principal tema abordado pela edição de agosto de 2000, da Communications of the ACM (CACM , 2000) é exatamente esse - a personalização de interfaces e de sistemas.

As coleções também são recursos bastante flexíveis, uma vez que podem ser definidas por diversos tipos de consultas às bases de dados, atribuindo, assim, um dinamismo bastante significativo à aplicação (Barroso \& Schwabe; 1998). As condições que definem uma coleção podem ser definidas previamente durante a implementação ou, de maneira interativa, pelo usuário em tempo de execução. Um exemplo de uma coleção gerada interativamente são as buscas na Internet, cujos critérios são definidos pelo próprio usuário. Nesse caso, tanto os valores quanto a estrutura da consulta são definidos durante a execução. Uma busca como essa pode ser encontrada no site da ACM (http://www.acm.org/dl/ search.html).

Um outro exemplo, no qual os elementos que compõem uma coleção são definidos mediante a escolha do usuário, são as tradicionais "cestas de compras" das lojas e catálogos virtuais encontrados na Web. Em aplicações como essas, o usuário navega pelas "prateleiras virtuais" e seleciona os produtos -que deseja comprar, formando a sua coleção personalizada de produtos, que posteriormente será usada para o cálculo do valor total a ser pago, para a emissão da nota de compra e para o envio dos produtos. Um exemplo bastante conhecido de livraria virtual é a Amazon (http://www.Amazon.com) e de loja virtual é o Submarino (http://www.submarino.com.br).

As visões e as coleções também são úteis para controlar restrições de acesso a contextos de navegação, pois determinam quais são os grupos de usuários que têm permissão para navegar por um determinado contexto e executar as operações nele disponíveis. Uma importante aplicação desses recursos, sob esse ponto de vista, são os sistemas de home banking. Essa é uma categoria de sistemas que é baseada em processos e regras muito bem definidas e que exige um controle rígido e seguro de acesso a informações e serviços e de execução de tarefas. Pelo fato do método proposto neste trabalho ser voltado para a especificação de workflows e, por isso, ser apropriado para a modelagem de condições e restrições exigidas pelo domínio da aplicação, ele também pode ser aplicado para o projeto de sistemas bancários utilizados via Web. 


\subsection{Considerações Finais}

Devido a problemas de prazo e ao fato de não ser esse o principal objetivo deste projeto, o Sistema Atena não foi completamente implementado e são necessários alguns refinamentos e a codificação de algumas funções para que ele possa ser, de fato, utilizado para a administração da oferta e da aprovação dos cursos de extensão da USP ou para que seja possível estabelecer uma interface com algum servidor de ensino a distância.

Esse trabalho, porém, deve ser realizado como parte do projeto de Doutorado, que vem sendo desenvolvido no ICMC e cujo propósito principal é permitir e gerenciar o acesso remoto $\mathrm{e} o$ uso de materiais referentes aos cursos disponíveis em um ambiente de ensino a distância, para que o Sistema Atena possa ser integrado e possa atuar como um módulo administrativo para controlar, sobretudo, os cursos, os docentes e os alunos quie fazem parte desse ambiente. 


\section{Capítulo 7}

\section{Conclusões}

\subsection{Considerações Gerais}

A concepção deste trabalho teve origem em algumas questões, tais como: $O$ que há em comum ou quais são as relações existentes entre os sistemas de informação para a Web e os sistemas de workflow? Em que sentido a implementação na plataforma Web otimiza a execução dos fluxos de trabalho? Quais são as particularidades das aplicações Web que contribuem para a implementação dos aspectos que caracterizam ou que são exigidos pelos sistemas de workflow?

Algumas definições podem ser usadas como premissas para a solução dessas questões. De acordo com o manual de referência da WfMC, principal órgão que atua em projetos para a padronização dos conceitos relacionados a workflow, um sistema de workflow é definido como uma solução computacional que automatiza completa ou parcialmente procedimentos nos quais documentos, informações ou tarefas são passados entre os participantes de acordo com um conjunto bem definido de regras, com a finalidade de atingir ou contribuir para metas específicas de um negócio (WfMC, 1999b).

Os sistemas de workflow oferecem, portanto, suporte para o controle e a coordenação da execução das tarefas que compõem um processo de negócio e das habilidades de indivíduos requeridas para a realização de cada uma dessas tarefas. As regras que regulamentam o workflow determinam não só as atividades que devem ser executadas, mas sobretudo a seqüência na qual a execução deve ocorrer e quais são as pré e pós-condições que devem ser satisfeitas para o sucesso de cada atividade. Sendo assim, as regras impõem restrições ao fluxo de trabalho e delegam responsabilidades.

O conjunto de condições internas dos objetos que fazem parte do sistema define o status do workflow e essa informação é utilizada para o controle do fluxo de dados e da seqüência de execução e para a habilitação de opções na interface. Os fatores que alteram o estado dos objetos e, conseqüentemente, o estado de toda a aplicação são as interações 
dos usuários que ativam tarefas manuais ou tarefas automatizadas, que são executadas pelo sistema em resposta a essas interações.

A partir da definição de sistemas de workflow, pode ser realizada uma comparação com algumas das definições e com alguns dos principais aspectos que caracterizam os Sistemas de Informação para a Web ou Web Information Systems (WISs). Segundo Conallen (1999a), um sistema para a Web é um tipo particular de aplicação hipermídia no qual as ações dos usuários, por meio de navegação ou por entrada de dados, afetam o estado do negócio ou da própria aplicação. Por essa afirmação já é possível identificar algumas similaridades dos WISs com os sistemas de workflow, pois, em ambos as interações dos usuários, produzem alterações de estado e mudanças que afetam a visibilidade e a execução da aplicação.

Outra similaridade existente entre os WISs e os sistemas de workflow *é a personalização da interface. $\mathrm{Na}$ Web é comum a existência de ambientes personalizados de acordo com o perfil de cada usuário. Esses ambientes correspondem a diferentes visões ou perspectivas da aplicação. A implementação de diferentes visões do sistema também é uma exigência dos processos de workflow, pọis esse é o recurso utilizado para a restrição do acesso a informações e serviços específicos e para a atribuição de tarefas somente a pessoas autorizadas e competentes, conforme as normas estabelecidas pelo negócio. Portanto, as visões são um dos meios utilizados para o controle, para a segurança e para a coordenação automatizada do workflow.

Com relação especificamente aos sistemas que implementam fluxos de trabalho administrativos, categoria enfatizada neste projeto, pode-se afirmar que a implementação na Web apresenta diversos benefícios. Em primeiro lugar, deve-se chamar a atenção para o potencial de integração oferecido pela WWW, que interconecta sistemas de informação remotos, grandes repositórios de dados e pessoas geograficamente distribuídas, por meio da rede mundial de computadores - a Internet. Tal capacidade de integração facilita a comunicação e a troca de documentos e informações em geral entre os participantes do workflow, o que evita atrasos no cronograma e interrupções na sua execução. Esses fatores também fazem com que a WWW seja a plataforma ideal para a construção de ambientes de trabalho colaborativos que incentivam e sobretudo fornecem diversos recursos necessários para a cooperação entre os agentes do processo administrativo. A integração proporcionada pela Web também facilita a coordenação de tarefas realizadas por grupos independentes de trabalho ou por setores autônomos da organização, espacialmente isolados ou não, o que também consiste em um dos propósitos dos sistemas de workflow.

Pelo fato de implementarem processos burocráticos, os sistemas administrativos normalmente manipulam um conjunto muito amplo de documentos. Sob esse aspecto, a plataforma Web também é vantajosa pois possibilita o gerenciamento desses documentos, 
uma vez que eles podem ser organizados na forma de hipertexto. Desse modo, todas as informações relacionadas são interconectadas por links, o que minimiza o tempo de busca e acesso, facilitando o trabalho dos atores e otimizando o workflow. A WWW permite ainda a integração e o acesso a documentos digitais armazenados em bancos de dados distribuídos.

Uma das principais características das aplicações Web que contribuem para a implementação de sistemas de workflow é a dinamicidade. As interfaces criadas dinamicamente refletem com exatidão o estado corrente do sistema, dos seus componentes e do fluxo de trabalho no momento em que são ativadas. Isso faz com que os atores tenham sempre uma visão atualizada do sistema e saibam com precisão em que estágio encontra-se o workflow. A dinamicidade da interface permite que serviços sejam desativados ou excluídos do menu de tarefas de um determinado ator, caso as condições internas para a sua execução não sejam satisfeitas ou caso não seja o momento correto para a sua realização. Esse recurso agregado à implementação de visões ajuda a gerenciar o progresso do workflow, controlando principalmente a seqüência de execução de atividades.

Como a integração, o gerenciamento de documentos, o controle de acesso, a possibilidade de implementação de diferentes visões, a facilidade de comunicação e de cooperação entre os atores e o dinamismo são fatores essenciais para a execução dos processos de negócio, constata-se que a plataforma Web é de fato vantajosa e apropriada para a implementação de sistemas de workflow.

Um segundo objetivo deste trabalho foi a análise da adequação de modelos e métodos para especificação de aplicações hipermídia quanto à modelagem dos sistemas baseados na Web e, em especial, aqueles que implementam workflows. Com base na experiência obtida com a especificação do Sistema Atena, conclui-se que os modelos e métodos revisados apresentam alguns problemas ou limitações quanto à completa especificação de sistemas para a Web.

Como o propósito original desses modelos e métodos é a especificação de aplicações hipermídia genéricas, a ênfase dessas técnicas está na modelagem das estruturas de informação e de navegação que definem a hiperbase, das mídias utilizadas e dos objetos perceptíveis pelos usuários e não propriamente dos conceitos relacionados à aplicação. Essa característica faz com que a modelagem seja, em parte, dependente de elementos da interface e, conseqüentemente, dependente de implementação, o que limita o poder de abstração das representações elaboradas. A dependência de interface está explícita em algumas das definições apresentadas por esses modelos e métodos e, principalmente, em exemplos utilizados para a modelagem de classes ou entidades e relacionamentos, nos quais é comum a existência de classes de interface ao invés de classes conceituais. Obviamente, os modelos para a especificação de sistemas para a Web e de aplicações hipermídia 
em geral são mais do que modelos conceituais, como sugerem Rossi, Schwabe \& Lyardet (1999d), no entanto as características específicas da interface e da estruturação da hiperbase devem ser tratadas nas fases de projeto e não nos níveis mais abstratos, como o da modelagem conceitual.

Além disso, o modelo HDM e os métodos RMM e OOHDM originais não foram projetados visando à especificação de sistemas, sendo, assim, mais adequados para a modelagem de aspectos estáticos e menos apropriados para a modelagem de fluxos de dados e de controle, o que é indispensável para a especificação de qualquer sistema de informação.

Analisando as técnicas revisadas, sob o ponto de vista da especificação de sistemas de workflow com interface para a Web, verifica-se que, por serem demasiadamente voltadas para a perspecțiva do usuário, essas técnicas não tratam ọs detalhes internos de 'processamento, as tarefas automatizadas, as mudanças de estado do sistema e de seus componentes e a sequiência de execução de atividades, além de vários outros aspectos, sendo, portanto, inviável a sua aplicação para a modelagem de sistemas de workflow. Isso se aplica a todas as técnicas apresentadas, excetuando-se a UML. O framework W2000 satisfaz a apenas alguns desses requisitos. Apesar de incluir um projeto funcional e um projeto de evolução de estados, o framework apresenta limitações decorrentes do fato de tratar somente as operações, isto é, tarefas ativadas externamente, e não os métodos, que são executados internamente ao sistema.

Com relação à UML, verifica-se que a linguagem é apropriada para a modelagem de sistemas de workflow, mas ainda não é adequada para a especificação de sistemas com interface para a Web. A UML não inclui principalmente elementos gráficos para a modelagem das estruturas de acesso e de navegação, como agrupamentos e índices. A linguagem também não oferece uma notação específica para a definição de estruturas de informação, por exemplo, os $m$-slices do RMM, no entanto a informação pode ser estruturada nas fases de projeto, por meio de classes de interface agregadas ou associadas.

As extensões realizadas, principalmente a criação dos novos estereótipos que representam elementos específicos dos sistemas para a Web, são úteis mas, da maneira como são propostas por Conallen, apresentam o mesmo problema dos métodos para especificação de aplicações hipermídia, uma vez que a modelagem conceitual é definida em termos de elementos da interface.

Com base nas considerações anteriores, constata-se que o método ou processo de desenvolvimento ideal para a análise e o projeto de sistemas de workflow com interface para a Web deve ser uma solução híbrida, que agrega as técnicas utilizadas para a especificação de processos e fluxos de trabalho aos recursos utilizados para a modelagem das características e dos elementos específicos das aplicações Web como as estruturas de navegação. Desse modo, o método proposto neste trabalho de Mestrado sugere o uso da 
UML para a modelagem dos requisitos funcionais e navegacionais, representados pelos diagramas de casos de uso; para a modelagem de classes e associações conceituais, representadas pelo modelo de classes; para a modelagem de workflows, representados pelos diagramas de atividades; e para a modelagem de estados, representados pelo diagrama de estados.

Como citado no Capítulo 5, o método BPI (Business Process Implementation) também é utilizado para complementar a modelagem de workflows, contribuindo para o detalhamento e a classificação das tarefas. Esse método, por ser específico para o projeto de sistemas que implementam processos de negócios, foi utilizado como base para a modelagem dos workflows. Observou-se, no entanto, que os recursos oferecidos pela UML eram adequados para a representação de praticamente todos os aspectos modelados utilizandose o BPI, tais como, as interrupções de processo, as interações entre os objetos e o fluxo de atividades e, portanto, optou-se pelo uso da notação aceita como padrão, para especificar a maior parte das atividades desenvolvidas durante a fase de modelagem de workflows. Os diagramas de atividades da UML não definem claramente os ciclos de vida dos objetos, o que ocorre no BPI, entretanto, expressam melhor o processo pois enfatizam as atividades e não os objetos.

A notação do RMM foi a técnica escolhida para a modelagem das características específicas dos sistemas para a Web, pois é a mais próxima da linguagem UML e, portanto, seus elementos gráficos são os que mais facilmente podem ser integrados e poderão vir a ser incorporados à notação considerada como padrão. Além disso, os autores do RMM foram os primeiros a propor extensões a um método para especificação de aplicações hipermídia com o objetivo de torná-lo adequado às aplicações para a Web (Isakowitz et al., 1997; Isakowitz et al., 1998b). Desse modo, o RMM estendido é utilizado para o projeto de fatias e para o projeto navegacional.

Apesar das notações utilizadas pelo HDM e pelo RMM serem semelhantes, até porque o segundo é baseado no primeiro, a notação do RMM é mais rica e mais expressiva, exatamente por suprir algumas limitações do seu antecessor. No entanto, alguns recursos do HDM, como as coleções, foram mantidos e utilizados no projeto navegacional do método apresentado neste trabalho, por serem úteis para modelar o dinamismo da aplicação e por não serem considerados no RMM. A integração dos mecanismos e conceitos do método RMM e do modelo HDM ocorre com facilidade, pois ambos possuem diversos pontos em comum, uma vez que um sucede outro. Por ser apenas um modelo, no HDM não são estabelecidas fases para um processo de desenvolvimento, o que ocorre no RMM e no OOHDM.

As etapas do processo de desenvolvimento e a parte conceitual do OOHDM foram, parcialmente, consideradas neste trabalho, mas a notação utilizada por esse método não 
foi utilizada por estar mais distante da UML. Desde 1998 os autores do OOHDM também estão desenvolvendo extensões para a adequação do método à plataforma Web (Schwabe \& Rossi, 1998a). Essas extensões, porém, enfatizam e incorporam ao método trabalhos voltados para a definição de padrões de projeto (design patterns), que incluem padrões arquiteturais, navegacionais e de interface, próprios para as aplicações Web (Rossi, Schwabe \& Lyardet, 1999b; Rossi, Schwabe \& Lyardet, 1999c; Lyardet, Rossi \& Schwabe, 1998; Garrido, Rossi \& Schwabe, 1997; Rossi, Schwabe \& Garrido, 1996b; Rossi, Garrido \& Carvalho, 1996a). No entanto, não foram encontradas, na literatura pesquisada, referências sobre $o$ OOHDM que abordassem os aspectos associados à modelagem de workflows.

\subsection{Contribuições deste Trabalho}

A principal contribuição deste trabalho é a proposta de um método para a análise e o projeto de sistemas de informação baseados na Web que automatizam fluxos de trabalho administrativos ou processos de negócio. O método proposto é uma solução híbrida que enfatiza a orientação a objetos e que agrega técnicas para a especificação de workflows a recursos para a modelagem dos aspectos que caracterizam os sistemas para a Web. Devido à atualidade do tema abordado por este projeto, ainda existem poucas contribuições direcionadas para o mesmo objetivo. Dentre as soluções pesquisadas, o framework W2000 é a que mais se aproxima da solução aqui apresentada, no entanto, algumas limitações foram identificadas, quanto à modelagem de workflows.

Os recursos utilizados e integrados para a composição do método foram o diagrama de casos de uso, o modelo de classes, o diagrama de atividades e o diagrama de estados da UML, o padrão para a descrição de casos de uso proposto por Larman (1997), a classificação de tarefas do BPI, os $m$-slices e as primitivas de acesso ou de navegação do RMM, as coleções do HDM, os centros e as extensões à UML propostos por Baresi et al. (2001) e os novos estereótipos da UML propostos por Conallen (1999a).

Uma outra contribuição deste projeto é o próprio Sistema Atena, que tanto pode ser utilizado para a administração de cursos de extensão, que é o seu objetivo original, quanto pode ser integrado, como um módulo administrativo, a um sistema de ensino a distância. O desenvolvimento do sistema possibilitou o teste e a validação do método proposto $\mathrm{e}$ serviu como base para uma avaliação preliminar da adequação deste a outros domínio de aplicação. 


\subsection{Trabalhọs Futuros}

Com relação à continuidade deste projeto de pesquisa, uma possível linha seria a avaliação do grau de generalidade do método proposto, ou seja, qual é a abrangência ou o conjunto de sistemas que podem ser projetados e modelados utilizando-se as técnicas e o processo de desenvolvimento sugerido. Uma outra possibilidade de pesquisa, seguindo a mesma linha de raciocínio, seria o teste ou o uso do método em outros estudos de casos, abordando diferentes domínios de aplicação, com o objetivo de verificar a sua adequação à modelagem desses domínios e de propor melhorias ou extensões ao método a partir de limitações detectadas.

Caso as extensões que têm sido realizadas à UML, com o objetivo de torná-la apropriada para a representação dos elementos e dos aspectos específicos dos sistemas para a Web, sejam padronizadas e, de fato, incorporadas à linguagem, seria interessante adaptar o método proposto neste trabalho para que essas extensões fossem utilizadas, sobretudo no projeto de fatias, ou fase similar, e no projeto navegacional. Desse modo, a notação padrão da UML estaria sendo utilizada em todas as etapas do processo.

Como o Sistema Atena não foi totalmente implementado, a realização de melhorias, principalmente quanto à consistência de dados, e a conclusão do sistema seriam sugestões de um trabalho futuro, para que ele pudesse realmente ser utilizado para o controle da aprovação e da oferta dos cursos de extensão da USP. Algumas adaptações também são necessárias para que o Sistema Atena possa ser integrado ao servidor de cursos a distância que está sendo desenvolvido como um trabalho de Doutorado, no ICMC. 


\section{Referências Bibliográficas}

Adriano, C. M., Delgado, A. L. N., Junior, L. G. S., Bosnardo, R. C., Ricarte, I. L. M. \& Magalhães, L. P. (1999). Inquiring the Course Paradigm with CALM, Anais da International Conference on Engineering and Computer Education, ICECE'g9, Rio de Janeiro, RJ, pp. 17-24. Disponível em: http://www.dca.fee.unicamp.br/projects/sapiens/.

Amberg, M. (1997). Understanding Workflow. Workflow Handbook 1997 - Wiley.

Barbieri, C. (1997). A Unificação dos Métodos de Orientação a Objetos, Developers' Magazine: Axcel.

Baresi, L., Garzotto, F. \& Paolini, P. (2001). Extending UML for Modeling Web Applications, Proceedings of the 34th Hawaii International Conference on System Sciences, Maui, USA.

Barros, P. (1998). UML - Linguagem de Modelagem Unificada, Relatório técnico, Departamento de Ciências Formais e Tecnológicas, Universidade Tiradentes. Disponível em: http://cc.usu.edu/ slqz9/uml.

Barroso, N. G. \& Schwabe, D. (1998). Projeto de Navegação em Aplicativos Hipermídia Orientado ao Usuário, Relatório Técnico 10, Departamento de Informática - PUCRio, Rio de Janeiro.

Baumeister, H., Koch, N. \& Mandel, L. (1999). Towards a UML Extension for Hypermedia Design, Proceedings of UML'gg The Unified Modeling Language - Beyond the Standard, Fort Collins, USA.

Booch, G. (1994). Object-Oriented Analysis and Desing with Applications, AddisonWesley, Menlo Park, California.

Bruzarosco, D. C. (1998). Um Sistema de Gerenciamento de Workflow para Gestão de Documentos, Dissertação (Mestrado), ICMC - USP, São Carlos. 
Bruzarosco, D. C. \& Masiero, P. C. (1998a). Linguagem de Definição de Ações (LiDA), Relatório Técnico 4, ICMC - USP, São Carlos.

Bruzarosco, D. C. \& Masiero, P. C. (1998b). Linguagem de Roteamento de Atividades (LiRA), Relatório Técnico 3, ICMC - USP, São Carlos.

CACM (1998). Communications of the ACM. Special Issue on Web Information Systems, v.41, n.7.

CACM (2000). Communications of the ACM. Special Issue on Personalization, v.43, n.8.

Conallen, J. (1999a). Building Web Applications with UML, Addison-Wesley.

Conallen, J. (1999b). Modeling Web Application Architectures with UML, Communications of the Association of Computer Machinêry 42(10): 63-70.

Conallen, J. (1999c). Modeling Web Applications with UML. Disponível em: http://www.conallen.com/whitepapers/webapps/ModelingWebApplications.htm. Acessado em: 29/03/2001.

Delgado, A. L. N., Adriano, C. M., Vasconcelos, J. R., Junior, L. G. S. \& Bosnardo, R. C. (1998). CALM - Computer Aided Learning Material, Relatório de Atividades - Disciplinas: Tópicos de Engenharia de Computação V e Projetos de Objetos Educacionais, FEEC, UNICAMP, Campinas.

Ferreira, L. F. \& Carneiro, M. L. F. (1998). A Evolução dos Ambientes de Aprendizagem Construtivistas, Relatório técnico, Laboratório de Teleducação, Universidade do Rio Grande do Sul. Disponível em: http://penta.ufrgs.br/ luis/Ativ1/AmbApC.html.

Fowler, M. (1997). Analysis Patterns: Reusable Object Models, Addison-Wesley, Reading, Massachusetts.

Fowler, M. (1998). UML Distilled: Applying the Standard Object Modeling Language, Addison-Wesley, Reading, Massachusetts.

Furlan, J. D. (1998). Modelagem de Objetos através da ỦML: Análise e Desenho Orientados a Objeto, Makron Books, São Paulo, SP.

Garrido, A., Rossi, G. \& Schwabe, D. (1997). Patterns Systems for Hypermedia, Proceedings of PLoP97, Allerton, USA.

Garzotto, F., Mainetti, L. \& Paolini, P. (1994). Adding Multimedia Collections to the Dexter Model, Proceedings of the European Conference on Hypermedia Technologies, $A C M$ ECHT'94, Edinburgh, UK, pp. 70-80. 
Garzotto, F., Mainetti, L. \& Paolini, P. (1995). Hypermedia Design, Analysis and Evaluation Issues, Communications of the Association of Computer Machinery 38(8): 7486.

Garzotto, F., Paolini, P. \& Schwabe, D. (1991). HDM - A Model for the Design of Hypertext Applications, Proceedings of Hypertext'91, pp. 313-328.

Garzotto, F., Paolini, P. \& Schwabe, D. (1993a). HDM - A Model-based Approach to Hypertext Application Design, ACM Transactions on Information Systems 11(1): 126. Disponível em: http://www.inf.udec.cl/ yfarran/HDM.htm.

Garzotto, F., Paolini, P. \& Schwabe, D. (1993b). HDM2 - Extending de E-R Approach to Hypermedia Application Design, Proceedings of the ER'93, pp. 178-189.

Georgakopoulos, D., Hornick, M. \& Sheth, A. (1995). An Overview of Workflow Management: From Process Modeling to Workflow Automation Infrastructure, Distributed and Parallel Databases 3: 119-153.

Harel, D. (1987). Statecharts: A Visual Formalism for Complex Systems, Science of Computer Programming.

Isakowitz, T., Bieber, M. \& Vitali, F. (1998a). Web Information Systems, Communications of the Association of Computer Machinery 41(7): 78-80.

Isakowitz, T., Kamis, A. \& Koufaris, M. (1997). Extending the Capabilities of RMM: Russian Dolls and Hypertext, Proceedings of the 30th Annual Hawaii Internacioal Conference on System Sciences.

Isakowitz, T., Kamis, A. \& Koufaris, M. (1998b). The Extended RMM Methodology for Web Publishing, Working Paper IS-98-18, Center for Research on Information Systems.

Isakowitz, T., Stohr, E. \& Balasubramanian, P. (1995). RMM: A Methodology for Structured Hypermedia Design, Communications of the Association of Computer Machinery 38(8): 34-44.

Jackson, M. \& Twaddle, G. (1997). Business Process Implementation - Building Workflow Systems, ACM Press.

Jacobson, I., Booch, G. \& Rumbaugh, J. (1999). The Unified Software Development Process, Addison-Wesley, Reading, Massachusetts. 
Kobryn, C. (1999). UML 2001: A Standardization Odyssey, Communications of the Association of Computer Machinery 42(10): 29-37.

Larman, C. (1997). Applying UML and Patterns: An Introduction to Object-Oriented Analysis and Design, Prentice Hall.

LES (1999). Projeto AulaNet: Ajudando Professores a Fazer seu Dever de Casa, Laboratório de Engenharia de Software, Departamento de Informática da PUC-Rio. Disponível em: http://ead.les.inf.puc-rio.br/aulanet.

Lucena, C. J. P. \& Fucks, H. (1999). AulaNet: Um Ambiente para Desenvolvimento e - Manutenção de Cursos na WWW, Relatsório técnico, Laboratório de Engenharia de Software, Departamento de Informática, PUC, Rio de Janeiro.

Lyardet, F., Rossi, G. \& Schwabe, D. (1998). Patterns for Dynamic Websites, Proceedings of PLoP98, Allerton, USA.

Magalhães, L. P. (1998). SAPIENS: Ambiente Colaborativo para Apoio à Aprendizagem, Projeto de pesquisa FAPESP, UNICAMP e USP. Disponível em: http://www.dca.fee.unicamp.br/projects/sapiens/.

Magalhães, L. P. (1999). Projeto SAPIENS, Relatório técnico, UNICAMP e USP.

OMG (2000). OMG Unified Modeling Language Specification, Object Management Group.

Pressman, R. S. (1995). Engenharia de Software, Makron Books, São Paulo, SP.

Rossi, G. (1996). Um Método Orientado a Objetos para o Projeto de Aplicação Hipermídia, Tese (Doutorado), Departamento de Informática - PUC, Rio de Janeiro.

Rossi, G., Garrido, A. \& Carvalho, S. (1996a). Design Patterns for Object-Oriented Hypermedia Applications, Pattern Languages of Programs 2, Vlissides, Coplien and Kerth eds.

Rossi, G., Schwabe, D. \& Garrido, A. (1996b). Towards a Pattern Language for Hypermedia Applications, Proceedings of the 3rd. Annual Conference on Pattern Languages of Programs, Monticello, Illinois.

Rossi, G., Schwabe, D. \& Garrido, A. (1997). Design Reuse in Hypermedia Application Development, Proceedings of Hypertext'97, Southampton, UK. 
Rossi, G., Schwabe, D. \& Lyardet, F. (1999a). Improving Web Information Systems with Navigational Patterns, Proceedings of the 8th International World Wide Web Conference.

Rossi, G., Schwabe, D. \& Lyardet, F. (1999b). Improving Web Information Systems with Navigational Patterns, International Journal of Computer Networks and Applications - WWW8 31(11-16): 1667-1678.

Rossi, G., Schwabe, D. \& Lyardet, F. (1999c). Patterns for Designing Navigable Information Spaces: Pattern Languages of Program Design 4, Addison-Wesley, Reading, Massachusetts.

Rossi, G., Schwabe, D. \& Lyardet, F. (1999d). Web Application Models are more than Conceptual Models, Proceedings of the World Wide Web and Conceptual Modeling'gg Workshop, ER'gg Conference, Springer, Paris.

Rumbaugh, J. (1994). Modelagem e Projetos Baseados em Objetos, Campus, Rio de Janeiro, RJ.

Rumbaugh, J., Jacobson, I. \& Booch, G. (1999). The Unified Modeling Language Reference Manual, Addison-Wesley, Reading, Massachusetts.

Schwabe, D. \& Rossi, G. (1995). The Object-Oriented Hypermedia Design Model, ${ }^{\circ}$ Communications of the Association of Computer Machinery 38(8): 45-46.

Schwabe, D. \& Rossi, G. (1998a). An Object Oriented Approach to Web-Based Applications Design, Theory and Practice of Object Systems 4(4): 207-225.

Schwabe, D. \& Rossi, G. (1998b). Developing Hypermedia Applications using OOHDM, Proceedings of Workshop on Hypermedia Development Processes, Methods and Models, Hypertext'g8, Pittsburgh, USA.

Sette, B. (1998). A Unified Modeling Language: Modelagem Visual e Arquitetura, Developers' Magazine: Axcel.

Stark, H. (1997). The Benefits of Business Process Modeling for Workflow Systems. Workflow Handbook 1997 - Wiley.

Sun (1997). The Java TM Enterprise Server Platform: A Java Adoption White Paper for Developers, Sun Microsystems.

Turine, M. A. S. (1998). HMBS: Um Modelo Baseado em Statecharts para a Especificação Formal de Hiperdocumentos, Tese (Doutorado), IFSC - USP, São Carlos. 
WebCT (1999a). Getting Started Tutorial: for WebCT Version 2.0. Disponível em: http://about.webct.com/v2/tutorial/tutorial.html e http://about.webct.com/get/ tutorial.html.

WebCT (1999b). Tutorial do WebCT para Docentes, Centro de Informática de São Carlos, USP. Disponível em: http://webct.cisc.sc.usp.br:8900/public/exemplo2/index.html.

WfMC (1995). The Workflow Reference Model, Workflow Management Coalition. Disponível em: http://www.aiim.org/wfmc/mainframe.htm.

WfMC (1999a). Interface1: Process Definition Interchange - Process Model, Workflow Management Coalition. Disponível em: http://www.aiim.org/wfmc/mainframe.htm.

WfMC (1999b). Terminology \& Glossary, Workflow Management Coalition. Disponível em: http://www.aiim.org/wfmc/mainframe.htm. 